\title{
WestVirginiaUniversity
}

THE RESEARCH REPOSITORY @ WVU

Graduate Theses, Dissertations, and Problem Reports

2019

\section{Material Disease: Agency and Illness in Early American Literature}

Mariah Crilley

West Virginia University, mcrilley@mix.wvu.edu

Follow this and additional works at: https://researchrepository.wvu.edu/etd

Part of the Literature in English, North America Commons

\section{Recommended Citation}

Crilley, Mariah, "Material Disease: Agency and Illness in Early American Literature" (2019). Graduate Theses, Dissertations, and Problem Reports. 3936.

https://researchrepository.wvu.edu/etd/3936

This Dissertation is protected by copyright and/or related rights. It has been brought to you by the The Research Repository @ WVU with permission from the rights-holder(s). You are free to use this Dissertation in any way that is permitted by the copyright and related rights legislation that applies to your use. For other uses you must obtain permission from the rights-holder(s) directly, unless additional rights are indicated by a Creative Commons license in the record and/ or on the work itself. This Dissertation has been accepted for inclusion in WVU Graduate Theses, Dissertations, and Problem Reports collection by an authorized administrator of The Research Repository @ WVU.

For more information, please contact researchrepository@mail.wvu.edu. 
Material Disease: Agency and Illness in Early American Literature

\author{
Mariah Crilley \\ Dissertation submitted \\ to the Eberly College of Arts and Sciences \\ at West Virginia University \\ in partial fulfillment of the requirements for the degree of \\ Doctor of Philosophy in \\ English Literature
}

Timothy Sweet, Ph.D., Chair

Sari Altschuler, Ph.D.

Cari Carpenter, Ph.D.

Lowell Duckert, Ph.D.

Catherine Gouge, Ph.D.

Department of English

Morgantown, West Virginia

2019

Keywords: Early American Literature, Disease, Medical Humanities, New Materialism, Ecocriticism Copyright 2019 Mariah Crilley 


\section{Abstract \\ Material Disease: Agency and Illness in Early American Literature \\ Mariah Crilley}

Material Disease: Agency and Illness in Early American Literature argues that diseases shaped bodies of literature. Drawing on new materialism, disability studies, and the medical humanities, this dissertation argues that diseases were material and literary agents that transformed not only individual bodies and lives but also cultures, history, and even literature. In each chapter, I explore how one disease impacted a particular genre or paradigm: syphilis and the natural history, smallpox and the body politic, yellow fever and the novel, dysentery and sensibility, and malaria and narratives of Western expansion. By emphasizing disease's material and literary agency, by conjoining the study of illness and disability with the study of the environment, this dissertation demonstrates how disease challenges fundamental beliefs about humanity, including sovereignty, autonomy, rationality, and intentionality. Yet this challenge is not entirely negative. Instead, it opens up a critical space for reimagining how humans relate to other humans and nonhumans, to how we experience, treat, and write about one of our most fundamental interactions with the nonhuman world-illness. In the age of the Anthropocene, and the global reckoning of human supremacy, it is absolutely vital that we reimagine and remap the relationship between humans and between humans and nonhumans like disease. 


\section{Table of Contents}

$\begin{array}{ll}\text { Introduction } & 1\end{array}$

Chapter $1 \quad 30$

Syphilis "Itself" and the Natural History: The Ethical Limits of Human Certainty and Mastery

Chapter 2

An Inoculated Body Politic: Inoculation as Metaphor and Agent

Chapter 3

The Pandemic Roots of the Early American Novel: Yellow Fever and the Haitian Revolution

\section{Chapter 4}

A Rotting Sensibility: Dysentery's Putrefaction and the Limits of Human-Centered Ethics

\section{Chapter 5}

How the West was Undone: Malarial Seasoning in Narratives of Western Imperialism

Conclusion

John Tanner's Seasonal Paradigm

Works Cited 


\section{Introduction}

"Your Foul Disease is too filthy and odious to have the nasty Symptoms of it mentioned," Cotton Mather condemns in The Angel of Bethesda. "As for any Remedies," he continues, "You are so Offensive to me, I'll do nothing for you" (120). Mather may never use this disease's modern name, but his references to the French Pox, Lues Venerea, "Whoremongers and Adulterers," decaying noses, and seeping ulcers, all suggest that he was describing that allegedly American scourge - syphilis. In a medical compendium otherwise devoted to cataloging early American illnesses and cures_-not to mention illustrating his own medical prowess after the notoriously bitter inoculation controversy - the prolific minister's reticence is striking. Syphilis deserves no mention and certainly no mention of cure. Those suffering had only themselves and their sins to blame. To even describe "the symptoms that attend it, would be such a Nasty Discourse, that Civility to the Readers will Supercede it; and the Sheets of this Treatise now before him, Shall not be stained with so much Conspurcation [pollution]" (116). The simple act of description could stain the text and its reader. To keep his work and certainly himself pure, Mather abjures the subject completely.

Yet this "Nasty Discourse" not only persists for another seventeen paragraphs but eventually divulges all of the information so sanctimoniously forsworn: Mather delivers syphilis' symptoms and even reveals three remedies $(285) .{ }^{2}$ Fueled as he was by ministering to his flock

\footnotetext{
${ }^{1}$ Mather, The Angel of Bethesda, 118, hereafter cited parenthetically.

${ }^{2}$ In this chapter, Mather describes the symptoms of yaws and gonorrhea, which were not yet differentiated from syphilis. Unlike many European colonials, he cites Royal Society member William Becket who claimed that syphilis was not a new disease: "in the English Nation more than Six Hundred years ago, it went under the Name of Brenning, or Burning, which signified what is now called A Clap" (117). It is for "the Running of the Reins," or this "brenning," that Mather provides three cures, albeit in a different "catch-all" chapter on "Lesser Inconveniences" (279).
} 
and proving his erudition, Mather must have been torn: was syphilis evidence of justly-punished sin or pastoral need? Should he let the disease run its righteous course or perform his Christian duty by helping those in need? How could he write about such a polluting disease without polluting himself? Yet how could he not write about the disease in his comprehensive work on "the Common Maladies of Mankind" (1)? Mather's oscillation between reticence and censure, censure and succor, reveals that his fear of "Conspurcation" had been realized. Yet syphilis did not simply stain or corrupt The Angel of Bethesda. Syphilis wrote it.

Material Disease: Agency and Illness in Early American Literature argues that diseases like syphilis wrote early American bodies and bodies of literature. As syphilis, smallpox, and malaria produced particular, identifiable, but also idiosyncratic symptoms in and across human bodies, they similarly produced particular, identifiable, and idiosyncratic symptoms in and across the early American paradigms and genres that described them, including the natural history, the body politic, and the novel. By emphasizing disease's intertwined physiology and textuality, Material Disease proposes materiality as a central factor in early American life and literature and our study of them. "Materiality" clarifies the layered experiences of illness, accounting for the range of human and nonhuman agents that create both disease and texts. As such, this dissertation offers materiality as a more responsive and responsible foundation for ethical relations between humans, between humans and nonhumans, and between scholars and our early American materials. After all, the limiting and limited paradigm of humanity failed to prevent chattel slavery and colonization as much as it still fails to prevent racism and ableism. In our current moment of ecological and epidemiological crisis, it could not be more vital to outline alternative ways of relating to each other and the nonhuman world. 


\section{Early American Matter(s)}

Early America was a world of matter and of matter that mattered. The Atlantic world collected and collided an unprecedentedly diverse group of bodies and agencies: indigenous Americans, enslaved and free Africans, Europeans, creoles, agricultural products and commodities like wheat, apples, corn, and tobacco, imports and exports, including pigs, guns,

furs, and timber that eventually supported modern capitalism, plants and specimens that provided the material foundation for modern science, and, of course, lists, reports, drawings, accounts, narratives, and medical compendiums like Mather's that described and organized this material miscellany.

What united these diverse bodies was their shared place. Mary Louise Pratt famously calls such colonial places "the contact zone," a "social space" where cultures "meet, clash, and grapple with each other." ${ }^{3}$ Colonial texts are not "discrete, coherently structured, monolingual edifices," nor are they "anomalous or chaotic" (36). Rather, they are "heterogeneous," collating their diverse social milieu into a single text. Kathleen Donegan, however, christens the very same space "the chaos zone," arguing that colonial experiences "just as often inhibit crosscultural interaction as occasion it." 4 The chaos zone, therefore, is a space of "eruptive, endemic, and usually unresolved" disarray (35). Hurricanes, starvation, heat, and humidity meant that humans and their texts were rarely secure, certain, and ordered. Whereas the contact zone emphasizes how the heterogeneous forms a single text — and how the scholar can explain such heterogeneity — the chaos zone centers those moments that resist explanation and order. Moreover, the chaos zone implicitly emphasizes the nonhuman world. While Donegan does not

\footnotetext{
${ }^{3}$ Pratt, "Arts of the Contact Zone," 34, hereafter cited parenthetically.

${ }^{4}$ Donegan, Seasons of Misery, 35, hereafter cited parenthetically.
} 
focus on this distinction, her model recognizes that humans were not the only ones meeting, clashing, and grappling in the Americas. Nonhumans disordered lives, cultures, and texts at least as much as humans. ${ }^{5}$

One of the most important members of the chaos zone was disease. As Alfred W. Crosby, Jr. argued over half a century ago in The Columbian Exchange, American colonization facilitated an unprecedented exchange of microbes: the bacteria that spread syphilis, the smallpox virus, Aedes aegypti and Anopheles mosquitoes that transmitted the yellow fever virus and malarial parasites, and the bacteria and amoebas that produced dysentery. Even if indigenous Americans and Europeans did not "swap" syphilis and smallpox as neatly as Crosby argues, and even if his focus on biological history threatens to naturalize colonization—a serious danger taken up below—his core argument remains true. As Mather's account of syphilis attests, diseases intimately shaped early American lives, cultures, and histories. They helped create the "eruptive, endemic, and usually unresolved disorder" that characterized the chaos zone, ending individual lives as well as entire communities, revising personal identities as well as cultures. ${ }^{6}$

Their most dramatic, most tragic, and certainly most theorized impact, however, was on indigenous Americans. From the Arawak in Hispaniola to the Wampanoag in New England, indigenous people suffered and died at devastating rates from smallpox, measles, influenza, and other European and African diseases. As Thomas Morton famously described, they were "not able to bury the dead," and "their bones and skulls... seemed to mee a new found Golgatha."7

\footnotetext{
${ }^{5}$ In Plants and Empire, Londa Schiebinger revises Pratt's model to include botanical exchanges, dubbing the colonial Atlantic a "biocontact zone." Although Schiebinger's model acknowledges nonhumans, Donegan's emphasis on disorder offers a more useful paradigm and methodology for probing disease - a nonbotanical nonhuman.

${ }^{6}$ Donegan, Seasons of Misery, 35.

${ }^{7}$ Morton, New English Canaan, 23, hereafter cited parenthetically.
} 
Early colonists probably exaggerated indigenous deaths - especially those fiscally invested in a land expunged of native peoples. Morton, for example, claims that this "mortality...fortuned some few years before the English came" (22, emphasis mine). We should not take such selfserving accounts at face value, but we also should not simplify or erase the very real effects of colonization, which included both concerted military and cultural efforts to eradicate native peoples and disease.

Yet focusing on disease does not require rehearsing colonialist paradigms like the virgin soil thesis and the germ theory of history. Since at least the mid-twentieth century, scholars have used the "virgin soil" model to explain why so many indigenous Americans suffered and died from "old world" diseases while the colonists seemed to flourish. This model argues that indigenous people had no prior immunological experience with many endemic European diseases - because they had crossed the Bering Strait so long ago, because many diseases could not have survived that long and frigid route, because they did not domesticate animals, because some groups did not grow large enough or travelled too much to host viable epidemic disease. Whatever the reason, the virgin soil thesis asserts that indigenous Americans had neither experiential nor genetic protections against European and African illnesses. Reappraising the dated model, some have added that diseases may have grown more virulent through new animal reservoirs, antigenic shift, and genetic homogeneity. ${ }^{8}$ Indigenous people were not disease-free

\footnotetext{
${ }^{8}$ Of the historians who focus on this topic, Alfred Crosby developed the virgin soil model in The Columbian Exchange, while William H. McNeill extended this paradigm in Plagues and Peoples. More recently, Gerald N. Grob has theorized on genetic homogeneity and antigenic shift in The Deadly Truth, 15-17.
} 
before colonization, but the "virgin soil" model attempts to explain how and why they died in such unthinkable numbers after their encounters with Europeans. ${ }^{9}$

Still, many scholars reject the virgin soil model. Cristobal Silva argues that it misrepresents the creole immunological experience. After a generation away from Europe, settlers' children were also increasingly susceptible to diseases like smallpox-hence, Boston's infamous 1721 epidemic, returned to in chapter two. ${ }^{10}$ Likewise, William Cronon maintains that while genetics may have played a part, immunological realities were enabled and compounded by "social and economic disorganization" (86). Malnutrition, starvation, opportunistic infections, and despair all exacerbated the impact of "old world" disease, genetics, and immunity.

For many scholars, however, the critical danger of the virgin soil model is that it absolves Europeans of their role in indigenous disease burden and death. ${ }^{11}$ What Heather Schell calls "the germ theory of history"- exemplified by Crosby's The Columbian Exchange and William H. McNeill's Plagues and Peoples — transforms social, cultural, political, and, ultimately, human explanations of human history into naturalized biological mechanism. ${ }^{12}$ Paul Kelton argues that this paradigm relies on "historical accident": "The colonizers exercised little agency in this catastrophe yet were its unwitting beneficiaries." 13 They let Europeans off the hook. It may not have been "crafted as an apology for the colonizers," and may even retain some "utility," but, Kelton maintains, the virgin soil model "hid[es] colonialism's violence under a cloak of

\footnotetext{
${ }^{9}$ Grob argues that dysentery and respiratory infections were especially rampant among preColumbian indigenous people. The Deadly Truth, 17-22.

10 Silva, Miraculous Plagues, chaps. 1 and 3.

${ }^{11}$ See, especially, Beyond Germs: Native Depopulation in North America, edited by Catherine M. Cameron, Paul Kelton, and Alan C. Swedlun, which argues that even the critical emphasis on disease is exaggerated and serves colonialist ends.

${ }^{12}$ See Schell, "The Sexist Gene."

${ }^{13}$ Kelton, Cherokee Medicine, 7, hereafter cited parenthetically.
} 
biological determinism" (9). This critique seems absolutely necessary when McNeill asserts that "mutual support between micro- and macroparasitism"- disease and war-“is, assuredly, a normal ecological phenomenon." ${ }^{14}$ According to these critics, the germ theory of history, including the virgin soil model, unintentionally but nonetheless effectively naturalizes colonization and indigenous depopulation by overemphasizing disease's agency and thereby dehumanizing indigenous people. A study of early American disease—and especially of disease's agency — must reckon with the ways in which those in power wield the attribution of agency as part of that power, assigning the vaulted category to humans, nonhumans, and even themselves unevenly and inconsistently. Early America represents a critical space to parse this problem not only because microbes and other agencies proliferated, but also because systems of power revolved around restrictive and mutable definitions of the human, of which humans mattered.

\section{Matters of Agency}

If my problem isn't clear, I'll put it as plainly as possible: how can I argue for disease's agency without recapitulating the "germ theory of history"? Although they offer no straightforward solutions, new materialism, including agential realism and object-oriented ontology, provide insight into human and nonhuman agency and its intersection with bodies and cultures. As the chaos zone recognizes, nonhumans intimately affected early Americans' daily lives, including their record of those daily lives. And, as anyone who lives with an illness knows, diseases intimately affect our lives, including our narration of them. By recognizing and theorizing disease's impact on human life and culture—its agency—we need not recommit the

${ }^{14}$ McNeill, Plagues and Peoples, 45. 
sins of our cultural and academic forefathers. Instead, we can more fully address lived experiences of illness and theorize an alternative ethics of relation and care.

Agency is not intentional, causal, rational, or effective, nor is it unique to humanity. Agency is not something one has or doesn't have. Rather, as Janet Bennett argues, agency is the simple but diffuse capacity to affect— - to impact, inform, and transform other bodies. To Bennett, all matter is inherently affective, whether "animate" or not. Although humans may represent "a particularly rich and complex collection" of such vibrant, agential matter, our rational intentions are "always in competition and confederation with many other strivings." ${ }^{15}$ As we've all experienced, intentions rarely net their desired results. This theory of vibrant matter and vital materialism is expressly political: if "the image of dead or thoroughly instrumentalized matter feeds human hubris and our earth-destroying fantasies of conquest and consumption" (ix), then reinvesting matter with agency might enable a more responsible demos. A true democracy, one with the power to combat climate change, would need to make space at the table for nonhuman agents.

While Bennet does not solve the germ theory of history, she highlights the urgent necessity of redefining agency, of recognizing and theorizing how nonhumans shape our shared world. As early Americans fleeing yellow fever or suffering a bout of the ague knew, effective agency wasn't limited to rational intentional beings. Diseases ended lives, challenged identities, decimated entire cultures, and changed history. They acted and continue to act. This doesn't mean we can boil history or literature down to disease, but we should not and cannot erase disease either.

${ }^{15}$ Bennett, Vibrant Matter, 11, 32, hereafter cited parenthetically. 
If diseases act, then they act through the intersection of two distinct materialist theories: Karen Barad's “intra-action” and Stacey Alaimo's “trans-corporeality.” Using quantum physics, Barad argues, "individually determinate entities do not exist, measurements do not entail an interaction between separate entities; rather, determinate entities emerge from their intraaction." 16 Whereas interaction describes the coordination of two distinct bodies, "intra"-action emphasizes the "fundamental inseparability" of all bodies and the necessity of an artificial "cut" to parse the many agencies at work in any given "thing." Intra-action asserts that ontology cannot be reduced to "independent objects with discrete boundaries and properties": no thing is inseparable from any other thing, even though we must separate them for ontological and epistemological clarity (139). Like Bennett, Barad envisions ethical implications: If "the very boundaries and constitution of the 'human' are continually being reconfigured," then "[r]esponsibility—-the ability to respond to the other—cannot be restricted to human-human encounters" (392). "We" must confront an expanded we.

Like "intra-action," Stacey Alaimo's theory of "trans-corporeality" argues that "the human is always intermeshed with the more-than-human world" and, thus, "ultimately inseparable from "the environment." "17 Yet while the prefix "trans" rejects corporeal borders as Barad's intra-action does, it also emphasizes "movement across different sites," recognizing "the often unpredictable and unwanted actions of human bodies, nonhuman creatures, ecological systems, chemical agents, and other actors" (2). "Trans" recognizes not just a difference between microbe and human but also the ethical responsibility of acknowledging such a distinction, particularly in the context of negative consequences like illness. Although Barad does not

${ }^{16}$ Barad, Meeting the Universe Halfway, 128, hereafter cited parenthetically.

${ }^{17}$ Alaimo, Bodily Natures, 2, hereafter cited parenthetically. 
employ disease, it exemplifies her central argument: human bodies, agency, and especially knowledge are never truly separate or different from nonhuman agencies - though we must divorce them for clarity. Alaimo and trans-corporeality, however, reminds us that the relationship between self and environment is never purely theoretical. Trans-corporeality cautions intra-action to remember that an "expanded we" is not necessarily a good thing.

Disease, therefore, is both intra-active and trans-corporeal. It is not that treponema pallidum does not exist without me, nor that I don't exist without it, but that "syphilis" does not exist but for the intra-action of microbe and human. "Microbe" and "human" take shape as discrete categories through intra-actions called syphilis or yellow fever or dysentery.

Differentiation, however, is not given; it must be enacted through a microscope, blood tests, cultural constructs, and history. Thus, syphilis or any other disease names both an intra-action and its differentiation, the conjunction of human and microbe as well as the cut between "me" and "not me" necessary for medical treatment and coherent subjectivity (not to mention ethical scholarship). If Bennett demonstrates disease's agency by reframing it as a verb-disassociating it from purportedly unique human qualities - then Barad and Alaimo show how neither disease's nor humanity's agency is self-evident. They intra-act, intersect, co-produce, even co-create-for better or for worse.

While neither Barad nor Alaimo solve the problem of the virgin soil model or the germ theory of history, an intra-active trans-corporeality posits a nuanced relationship between humans and nonhumans. Both the virgin soil thesis and germ history minimize the colonizer's agency in disease and death, but an intra-active trans-corporeality and agential realism more broadly suggest that nonhuman and human agency are inextricable. By acknowledging and parsing this inseparability, we can address both how colonials wielded disease and its effects, 
and how nonhumans and those believed to be non- or subhuman challenged and changed bodies, history, and literature.

Disease's agency, therefore, need not absolve the colonizer, nor does it necessarily dehumanize and objectify those believed to have had limited agency in the early modern period — women, people with disabilities, indigenous people, and Africans. Rather, as Mel Y. Chen argues, dehumanization and objectification, especially in the context of racism, rely on "a fragile humanity." 18 They rely on a limited and limiting concept of "the human"-as distinct from animals, plants, and inanimate objects — which has only ever been applied to select humans anyway. Closely analyzing the way racism mobilizes beliefs about the differences between humans and animals as well as things, Chen argues that both racists and progressives alike, invoking the "theoretical discourse" of dehumanization and objectification, "continue to disavow, if not simply ignore, the possibility of significant horizontal relations between humans, other animals, and other objects" (50). Instead, they maintain, we might build a more just and ethical world for both humans and nonhumans by acknowledging these "significant horizontal relations" (50). Though Chen does not examine early America, their argument seems vital at the moment when humans were colonized, enslaved, and subjugated at an unprecedented scale, when humans and nonhumans intra-acted to form race. Chen reminds us that the restrictive category of the human continues to animate racism, ableism, colonialism, and xenophobia. Thus, Chen and agential realism revise the categories of agency and humanity, arguing for an expanded definition of who and what shapes the world.

Yet agential realism is not without its critics. In particular, object-oriented ontology (OOO) critiques new materialism's emphasis on relations, connections, and assemblages. After

${ }^{18}$ Chen, Animacies, 40, emphasis in original, hereafter cited parenthetically. 
all, Barad makes "intra-action" the fundamental unit of the universe, while Bennet focuses on democracy and agential assemblages. Similarly, Bruno Latour's theories - central to many new materialist arguments — concentrate on networks and relations. ${ }^{19}$ Graham Harman defines OOO’s central critique of agential realism as "relationism": "a thing's existence consists solely in its relation with other things." 20 The sensual or perceptual qualities of an object are collapsed into the real and inaccessible object itself. Although we think we understand an object based on its relation to ourselves, Harman contends that the real object is "withdrawn." Objects are not fundamentally inseparable, as Barad argues, but fundamentally inaccessible.

Like agential realism, however, OOO also envisions its theory as ethical. In the age of the Anthropocene, of "hyperobjects" like global warming, and the end of the world, Timothy Morton argues that nonhumans are "out of control, withdrawn from total human access." ${ }^{21}$ Humans "have not lost the sense of inner space" that used to define us. Rather, we've begun to realize that nonhumans have that "inner space" as well (172). Harman writes, "The only way to do justice to objects is to consider that their reality is free of all relations," that things are uniquely and wondrously themselves. ${ }^{22}$ Ian Bogost explains further, "an object enters an ethical relation when it attempts to reconcile the sensual qualities of another object vis-à-vis the former's withdrawn reality"- that is, when I attempt to grasp the object's reality beyond its use-value to me, even though I know I can never really, fully, completely understand. ${ }^{23} \mathrm{OOO}$, therefore, asks us to be ethical by recognizing the radical individuation and inaccessibility of all objects and by still working to understand and account for them anyway. Although agential realism and OOO are

\footnotetext{
${ }^{19}$ See, for example, Bruno Latour, Reassembling the Social.

${ }^{20}$ Harman, The Quadruple Object, 12.

${ }^{21}$ Morton, Hyperobjects, 172, hereafter cited parenthetically.

${ }^{22}$ Harman, The Quadruple Object, 47.

${ }^{23}$ Bogost, Alien Phenomenology, 77-78.
} 
frequently opposed, both — coming of age at the end of the world—are dedicated to caring for a world that is profoundly intimate and alien.

It is probably impossible to reconcile agential realism and OOO, but I'm going to take my ethical cue from OOO and try anyway. Disease illustrates the vital importance of attempting to unite the two- of attempting to account for relations and individuation, intimacy as well as alienation. ${ }^{24}$ Agential realism, especially intra-active trans-corporeality, helps to explain how disease is produced: syphilis is not a discrete, pre-existing entity that we can isolate in a lab, but the intra-action or co-production of many bodies and agencies, including microbes, humans, vectors, environments, hygiene, culture, history, etc. In turn, OOO remembers that "syphilis" names the sensual qualities of a withdrawn treponema pallidum — what we humans perceive of the microbe — not the real microbe nor the microbe's reality. Both of these perspectives are critical for fathoming lived, early American experiences of disease, as I detail in the next section. Agential realism offers a critical paradigm for parsing the foundational relations between nonhumans and humans — biologically, culturally, and, as I argue, textually—while OOO reminds us that the disease above, below, or beyond our symptoms is withdrawn and inaccessible, eliding our understanding and narration.

Reconciling disease's relationality with its irreducibility is critical in the age of the Anthropocene, when global warming, globalization, medicalization, and suburbanization have allowed new diseases to emerge, old diseases to resurge, and epidemics to spread more rapidly

\footnotetext{
${ }^{24}$ While none of these theorists fully address diseases, Morton touches on "miasma," one of the ancient and early modern explanations for disease and epidemics, in Dark Ecology. He writes, miasma was "the first hyperobject we noticed": "You can observe miasmic phenomena haunting the edges of your temporal tunnel vision. You see them as accidental, and you try to get rid of them" (50). Miasma represents an attempt to explain the inexplicable. Still, Morton's use of miasma is to explain how the hyperobject works not disease.
} 
and efficiently than ever before. As Latour argues, conventional critique—deconstructing, unveiling, and debunking — has "run out of steam," having been mobilized against the most urgent concern of our time, climate change. Instead, the critic's job should be composition, "searching for universality without believing that this universality is already there." 25 (474). Disease represents one of our most profound and intimate compositions with nonhumans, with our intra-active trans-corporeality and the extent to which we are "always already part of an active, often unpredictable material world." ${ }^{26}$ We don't desire smallpox or malaria or syphilisespecially Mather. Intra-action and transcorporeality provide a space for "epistemological reflection and precautionary principles" rather than "affirmation" (Alaimo 144). We must build "a common world," Latour argues, but we must also recognize "that this common world has to be built from utterly heterogeneous parts that will never make a whole, but at best a fragile, revisable, and diverse composite material," including microbe and human, agential realism and OOO, and new materialism and the study of illness and disability (474). By taking disease as one of the human's most important environmental experiences, I aim to show both how disease represents a distinct agency that shaped human lives, history, and writing, and how attending to this agency could reframe both our present environmental crisis and lived experience of illness and disability.

\section{Illness and Disability Matters}

Disease may be lively, but it is also deadly—painful, disruptive, terrifying, and lingering. Yet emphasizing disease's lively agency does not necessarily contradict its deadliness, the lived

${ }^{25}$ Latour, "An Attempt at a Compositionist Manifesto," 474, hereafter cited parenthetically. See also "Why Has Critique Run out of Steam?"

${ }^{26}$ Alaimo, Bodily Natures, 17, hereafter cited parenthetically. 
human experiences of illness. In fact, new materialism's emphasis on relations and irreducibility provide a more nuanced paradigm for understanding illness as intimacy and alienation, self and other, and, thus, for the medical humanities and disability studies (DS). They provide a framework of the human who both is and is not their illness, who is radically related to and formed by other agencies, including microbes, physicians, family, those who share the same disease or a similar experience of pain or even pleasure, while also radically separate and singular. As much as we cannot know treponema pallidum, we also cannot fully understand another's experience of syphilis. By bringing materialist theory to the medical humanities and DS, I do not mean to resurrect the medical model of disease or disability. Rather, I am arguing that such theories offer a more nuanced way to talk about materiality and embodiment, typically anathema to DS especially. Joining these fields together helps us to trace early American illness - always connected to the environment—and probe how paradigms of "normal" or "natural" humanity limit ethical treatment and care.

Although DS and the medical humanities are distinct fields, both revolve around the medical model. In this model, both disease and disability require treatment and cure by trained medical professionals. The medical humanities are largely invested in improving medical treatment, highlighting, for example, the individual's right to narrate their experience of illness and providing doctors with what Rita Charon calls the "narrative competence" to read these stories critically and empathetically. ${ }^{27} \mathrm{DS}$, however, rejects the medical model entirely. The

\footnotetext{
${ }^{27}$ Some of the most notable references here are The Wounded Storyteller Arthur W. Frank, who argues that the physician's narrative of disease subsumes and overpowers the individual's experience of illness, their very life story. In turn, Rita Charon in Narrative Medicine argues that doctors can resist dominating patients by developing "singularity, humility, accountability, empathy...through intensive narrative training" (viii). Recently, Sari Altschuler has critiqued the medical humanities for its emphasis on "a well-meaning but vaguely conceived sense of
} 
medical model of disability conflates the diversity of human bodies and minds with being illwith needing treatment, cure, and frequently eradication. While the medical humanities typically attempt to teach doctors empathy or help ill people reclaim their narrative power, disability studies develops a minority identity and politics based on the shared experience of discrimination. ${ }^{28}$

Rejecting medicalization, activists and theorists developed the social model of disability. In its simplest iteration, the social model claims that environments rather than impairments are disabling. Many scholars have critiqued and expanded a simplistic social model. Tobin Siebers argues for a more nuanced "theory of complex embodiment" that "views the economy between social representations and the body not as unidirectional as in the social model, or nonexistent as in the medical model, but as reciprocal," while Alison Kafer offers a "political/relational model" that acknowledges that medical treatment and even cure can be part of a radical, social politics. ${ }^{29}$ Likewise, Michael Schillmeier argues for embracing empirical philosophy in DS: "the relations between and within biomedical practices, physiological relations, etc. - say between bodies, senses, and things - (re-)assemble and (re-)enact the socialness of disability." 30 That is, the conventional social model of disability needlessly and dangerously severs the physical or biological from the social, when both are vital to understanding disabling practices and

empathy," instead arguing that the humanities offer a rigorous epistemological toolkit. The Medical Imagination, 20.

${ }^{28}$ Susan Wendell complicates this division in "Unhealthy Disabled," calling for "solidarity" between the two, typically divided groups, through "acknowledging" both "the existence of suffering that justice cannot eliminate" and "that illness is not only suffering" (31). While I agree with Wendell's analysis, in the context of this argument, it is important to maintain the significant differences between disease and disability and the medical humanities and disability studies.

${ }^{29}$ Siebers, Disability Theory, 25; Kafer, Feminist, Queer, Crip.

${ }^{30}$ Schillmeier, Rethinking Disability, 103, hereafter cited parenthetically. 
experiences. While the "split" between disability and impairment "was meant as a strong political tool and conceptual remedy against oppression, exclusion and discrimination," many disability scholars now emphasize the interaction, or intra-action, between real spaces, real cultures, and real bodies (Schillmeier 4).

To be clear, I am not emphasizing DS here to argue that the diseases I discuss were or are disabilities. Though some like syphilis produced chronic illness, social stigma, and even subjective recalibration - all definitions important to modern disability — it is important to maintain these distinct categories, to resist medicalizing impairments in a way that would misrepresent both early American and modern lived experiences. Nor am I arguing that diseases and illnesses are only socially constructed, though cultures undeniably shaped lived experiences, as I emphasize in the final chapter on the seasoning ague. Instead, I engage DS in the realm of disease as a reading practice that recognizes that human physical, cognitive, and emotional diversity transforms narratives.

Literary disability studies has focused on representations of disability, including how these representations overwhelmingly stigmatize real people with disabilities. Yet, in The Life of Stories, Michael Bérubé offers an alternative, outlining how cognitive disability transforms narratives and the very act of reading. He asserts, "There must be something about the reading of disability as reading that changes the way we read." ${ }^{31}$ Bérubé argues that intellectual disability, whether identifiable in the DSM or not, challenges the fundamental values of narrative and humanity like temporality and self-awareness.

In their special issue on early American literature and disability studies, Sari Altschuler and Cristobal Silva employ Bérubé's argument, defining critical DS as a methodology rather

${ }^{31}$ Bérubé, The Life of Stories, 52, hereafter cited parenthetically. 
than a diagnosis. Disability "pushes us to learn from the inchoate and the elusive," to search "for the textual traces of imprecision, confusion, volatile consciousness, and disordered epistemology" that expose "the aesthetic impulse to rely on familiar approaches to telling history as a means of resolving textual disorders." 32 DS as reading practice rather than retrospective diagnosis examines those textual moments that fail to conform, that resist normalizing and naturalizing formal conventions. The "inchoate and elusive" produce valuable insights into systems of relation, knowledge, being, and especially narrative itself.

While I am not arguing that syphilis or smallpox or malaria are or should be considered disabilities, I am arguing that this methodology can and should be applied to disease. Silva and Altschuler warn against "importing the concept of disability into familiar medical topics like yellow fever, smallpox, and tuberculosis," and instead "ask how disability studies orients us differently toward illness and disease in early America" (13). Among the many directions such an orientation could take, they suggest examining "how early American communities narratively encoded certain corporeal or cognitive conditions" (13). Like modern disability, diseases both took shape through narrative and shaped narrative. Though DS should never be severed from its social context and exigency, its methodology orients us to lived experiences of physical difference and human embodiment and offers a methodology for reading their narrative forms. As Bérubé contends that intellectual disability "can be a textual matter...even when there are no characters with intellectual disabilities to be found" (38), I argue that we can employ a DS methodology and attend to the concerns of DS, including temporary able-bodiedness, in the presence of disease - to consider not just how early Americans "encoded" the "corporeal" and "cognitive" experience of illness, but also how those diseases "narratively encoded" themselves.

\footnotetext{
32 Altschuler and Silva, "Early American Disability Studies," 9, hereafter cited parenthetically.
} 
As the intra-action of human and nonhuman, disease unites these social and material theories. On the one hand, DS and the medical humanities may seem antithetical to new materialism. The "human" remains a vital category for social and political justice, especially to people who have been dehumanized, objectified, and euthanized for centuries, while new materialism claim the restrictive and vaulted category of the human has led to our current environmental crisis. Yet, on the other hand, both navigate a similar problem: what is at stake when a limited definition of humanity guides ethics and politics? And what can be done to change it? DS could achieve its radical reformation by more closely attending to new materialism's claims: the human is not a useful category when so many people fail to meet its expectations, when so many humans and nonhumans simply don't count. In turn, new materialism should take seriously DS' and the medical humanities' insights: the lived experiences of intra-active trans-corporeality remain stigmatized, and the "human" may only be available to reject for those who already meet its high performance criterion. Still, new materialism provides a complex language to talk about materiality and embodiment that denies normative definitions of the human body and subject — one of DS' most important goals. There are no easy answers here, and this isn't an easy relationship, but probing the intersections of these two fields is vital for our study of early American disease and for our present moment of ecological and epidemiological disaster.

\section{Textual Matters}

The treponema pallidum and human intra-act physiologically to generate syphilis, while syphilis and human cultures intra-act, generating stigma, shame, or even religious power, described in chapter one. Yet this intra-action extends even further: syphilis, human authors, and 
human cultures intra-act to write. Cotton Mather and syphilis may not have met at the biological level, but we nonetheless glimpse syphilis' presence-its writing - in those contradictory and hypocritical moments when Mather reveals the symptoms and cure he had so smugly repudiated. New formalism and ecocriticism offer a way to read textual disorder and discrepancy as moments when diseases impinge upon, shape, and write early American texts.

In "History before Fact," Jehlen argues that the "lapses and incoherencies...redundancies and paradoxes" that pervade American colonial literature witness history in the making. They represent debate in the historical record_-"moments when alternatives coexist, when...futures are underdetermined and therefore genuinely undetermined ${ }^{33}$ " Jehlen might read The Angel of Bethesda as part of the contested production of transatlantic science. Colonials were supposed to generate the raw materials to be refined by professionals at home, but Mather routinely resisted this division. ${ }^{34}$ Thus, his confused chapter on syphilis might evidence this contentious debate. Like Jehlen, Donegan similarly contends that "disorder" is "endemic" to American settlement literature, yet she argues that it is "volatile consciousness textually preserved" (36). Whereas Jehlen emphasizes historical debate, Donegan emphasizes personal chaos. She emphasizes early settlement and does not include later figures like Mather, but her argument might imply that Mather's inconsistency and hypocrisy reflect the psychologically harrowing experience of the Americas, including its new diseases.

In turn, Ed White and Kelly Wisecup contend that such formal discrepancies witness not only European debates or psychology but indigenous and African perspectives as well. White

33 Jehlen, "History before Fact," 692, hereafter cited parenthetically.

${ }^{34}$ In theory, Europeans theorized, while creoles collected and mailed. In practice, however, knowledge and knowledge making were diffuse and polycentric, as Susan Scott Parrish agues in American Curiosity. 
argues that those moments that "escape systematicity" point toward "conflicting systemic interpretations," or "counterethnographies" that include indigenous American ideas and perspectives. ${ }^{35}$ Like White, Kelly Wisecup argues that early texts' “texture”__“" any syntactic anomaly, semantic contradiction or logical inconsistency, as well as physical properties of the document"' — evidence the confluence of European, African, and indigenous paradigms of medical meaning. ${ }^{36}$ These and many other early American scholars suggest that formal hiccups and inconsistencies not only pervade colonial texts but actually define them. They are symptomatic of the colonial situation, the contact zone.

Yet the contact zone was truly a chaos zone that also included nonhumans. When Jehlen claims that though "many forces, intentions, and effects combine, interact, parallel, or counter one another" in a narrative "they do not yet add up...to cause the reality that ultimately ensues," she certainly means the varied human "intentions" of the colonial situation (692). She clarifies, "For what these underdetermined and therefore incoherent moments inscribe is not historical direction but human agency" (692). Though Jehlen undoubtedly is resisting history as teleology, and possibly even the "germ theory of history," she also preempts the possibility of nonhuman "forces, intentions, and effects." If these inconsistent moments are less about "outcome" than "interaction," then this interaction, or intra-action, consists not only of diverse colonial peoples but also of diverse colonial nonhumans (692).

In his meditation on the verb "represent," Julian Yates argues that the act of representation is not limited to humans; nonhumans represent as well. The orange, for example, is a "thoroughly rhetorical entity," "a representation of what the plant assumes that we sighted,

\footnotetext{
35 White, "Invisible Tagkanysough," 765.

${ }^{36}$ Wisecup, Medical Encounters, qtd. in 11.
} 
smelling, tasting animals might desire." ${ }^{37}$ When a microbe like treponema pallidum infects a human, this intra-action rewrites the body, and some part of the microbe asserts and represents itself. Yet Yates extends his argument further: the literary inscription of an orange-ostensibly written by a human—can also "exist[] not as a moment of capture so much as a ceding of our writing systems to others" (127). He implies that only "certain writers and artists" can "cede" authorial power, but the experience of disease and infection suggests that such representation and writing may not be purposeful or directed (127). In this study, an author need not be infected with treponema pallidum or a plasmodium parasite for their work to be infected and written; rather, the nonhuman could overwhelm the human and the human's writing, as Mather's religious stigma suggests.

Monique Allewaert and Michael Ziser have already begun the work of establishing a materialist study of early American literature. Whereas Allewaert uses the tropics and especially tropical slavery to posit an alternative genealogy of personhood, one unbeholden to Enlightenment ideals like autonomy and wholeness, Ziser argues for "a more-than-human literary-critical method." 38 He writes that, conventionally, "the nonhuman physical aspects of the American continent are assumed to appear in cultural productions only as occasions, backgrounds, or limits for the development of immaterial aesthetic, spiritual, or ideological discourses" (4). Thus, "art and literature may well imitate the natural world or be about it, but they are never of it in the strong, positive sense of emerging through its agency" (4). Instead, he argues, we should focus on the practices like agriculture that embedded a writer in the nonhuman world and "through which it is possible to hear more than just our own species'

\footnotetext{
37 Yates, "Represent," 132, 131, hereafter cited parenthetically.

38 Ziser, Environmental Practice, 4, hereafter cited parenthetically.
} 
interests" (16). While Ziser focuses on environmental practices, and Allewaert on bodily disaggregation more broadly, both outline the importance of nonhuman materialities to early America and especially early American texts. ${ }^{39}$

Building on the work of these assorted scholars, I argue that disease, health, and medical knowledge and practices united not only the disparate groups of humans in the Americas, as Wisecup has shown, but the nonhumans as well. We witness this intra-action of human and nonhuman disease and disease's agency in textual discrepancies and disorder, especially in texts written by people with firsthand experience of disease or with close proximity to illness and suffering. As OOO reminds us, we cannot access the "real" illness—neither the microbe's experience nor the person's - but in these moments we hear an echo of something outside or beyond the text, the author, and the human. Although I would not presume to argue that it is only disease that represents and writes — other nonhumans intra-act as well, as Ziser demonstrates-I focus on texts that focus on disease, because, of all the intra-actions of humans and nonhumans in the Americas, disease was perhaps the most recorded, the most obviously constitutive of life, art, and culture. In order to study early America more inclusively, and to attend to our present crisis, we must develop a methodology for listening to these echoes and for responding to their partial knowledge ethically.

In addition to probing for disorder, then, I also search for consistency, for similar disruptions across a range of texts. To revise Jane Tompkins, it is not that I "look[] for continuities rather than ruptures," but that I look for continuities in ruptures..$^{40}$ In particular, I draw on modern and early modern etiologies to argue that specific diseases wrote specific genres

\footnotetext{
${ }^{39}$ See Allewaert, Ariel's Ecology. I return to Allewaert more fully in chapter 3.

${ }^{40}$ Tompkins, Sensational Designs, xv.
} 
specifically. For example, malaria's material symptoms—cyclical fits, relapses, chimerical immunity — disrupted the teleological pull of the paradigm of seasoning and the genre most invested in this paradigm — narratives of Western expansion. Likewise, inoculated smallpox revised images of the body politic by revising the contours of individual bodies, paradoxically divorcing the human from its environment while inviting that very same environment within the person. By emphasizing continuity in disorder, I do not aim to demonstrate a single text's bizarre representation of disease but to chart how nonhumans asserted themselves or elements of themselves across a range of texts and, thereby, shaped seminal early American literature, history, and life.

Yet the danger of this argument, especially in its emphasis on material symptoms, is "retrospective diagnosis." It is fruitless to attempt strict diagnosis of disease; it's impossible to know for certain which disease an early modern text describes, especially when "diseases" did not exist as such. Moreover, as Silva and Altschuler warn, albeit on disability, "diagnosis forecloses as much as it opens texts to criticism" (12). It threatens to reimpose the reign of the medical model, to cement professional medical knowledge as the only appropriate system for understanding disease. My use of modern and early modern etiology is not mean to reaffirm this paradigm, nor am I trying to describe "normative" symptoms - though I admit both are a sincere risk. Rather, I emphasize materiality and medical/scientific knowledge tentatively, recognizing as $\mathrm{OOO}$ reminds us that no system can fully explain disease and illness - even the symptoms of disease do not grant us access to either the microbe or the person living it.

Although it might seem counterintuitive, my materialist argument and formalist methodology don't require diagnosing specific texts with specific diseases. Instead, I argue in a more qualified way that diseases' ontologies shaped our ways of knowing them, especially in the 
texts that carefully describe them. When Mather claims syphilis will "stain" his text, he fears a disease that may corrupt, even write. Jehlen argues that formal inconsistencies represent a kind of textual recalcitrance, a moment when a narrative is "unable to fully transform its materials": "The materials remain undigested or semidigested; they retain a quasi-independent and possibly rebellious life" (689). Though Jehlen's “materials" are decidedly historical, her description echoes OOO, which emphasizes the withdrawn and inaccessible lives of things. Though all matter and all materials are independent and rebellious, diseases simultaneously rely upon and destroy human bodies and history, acting and subsisting for themselves. If the treponema pallidum intra-acts with human bodies to create syphilis, then it can also intra-act with textual bodies to write syphilis. Neither flawed execution nor rhetorical bravado, the eccentricities and downright inconsistencies of Mather's chapter on syphilis evidence an "undigested" and "rebellious" agent refusing the silence and prejudice that Mather and his larger culture mandate.

Neither medical theories nor personal narratives ever exhaust disease. To consider this agency, to acknowledge its presence in physical and textual bodies, is to work toward a more nuanced understanding of the event(s) of disease, to reference early American literature and history more materially and thus more complexly and to posit alternative means of relating to those unruly nonhumans, intra-acting agents, and withdrawn hyperobjects that have become unavoidable in our environmental and epidemiological crisis.

\section{Chapter Outlines}

This argument, therefore, is organized by disease and genre: syphilis and natural history, smallpox and the body politic, yellow fever and the novel, dysentery and sensibility, and malaria and narratives of Western expansion. Each of these chapters includes a range of texts, spanning 
place and time. Though they may seem disconnected or only arbitrarily related, this disconnection is actually vital to my argument. Spanning the Caribbean, mainland America, the Pacific, and even centuries worth of time, I emphasize patterns in textual disorder to show that diseases represent themselves in particular ways. This distance and breadth are necessary to demonstrate a pattern of disorder that goes beyond a single author like Mather, a single epidemic site, or a single culture. At times, this dissertation seems chronological: the earliest texts appear in the first chapter on syphilis, while the latest are in the final chapter on malaria. Yet my argument is not chronological, detailing how representations of disease changed over time. Rather, what unites these disparate texts, is their disease, genre or paradigm, and the particulars of their formal discrepancies.

The first chapter analyzes syphilis' impact on the natural history—-the new world's paradigmatic disease and the new world's paradigmatic genre. Reading Hans Sloane's $A$ Voyage to the Islands of Madeira, Barbados, Nieves, S. Christopher and Jamaica, John Lawson's A New Voyage to Carolina, and James Cook's Journals, this chapter traverses the seventeenth and eighteenth centuries as well as the Caribbean and the Pacific to argue that syphilis' incomprehensibility — its lifelong yet disconnected symptoms, uncertain origin, and quixotic cure - undermined the genre most devoted to comprehending the Americas. Under the thumb of the Royal Society, natural histories increasingly ascribed to special rules for style and content. Yet syphilis itself ruptures the natural historical rules, disclosing both syphilis' intra-active agency and the limits of natural historical control: our narratives can never fully account for syphilis, neither a microbe's motivations and desires, nor a human's lived experiences. Ultimately, syphilis reminds us that this impossibility is imminently ethical. Whereas the natural history and certainly modern medicine assumes a knowable and controllable experience of 
syphilis, the disease itself posits the unknown and the uncontrollable as a more ethical orientation to the layered, intra-active, and multivalent experiences of disease.

The next chapter shifts to the other best-known colonial disease-smallpox-expanding on how disease itself writes. While the first emphasized disease's impact on a particular genre, this chapter addresses how smallpox and, especially, inoculated smallpox revised one of the predominant models of early modern political theory, the body politic. In particular, inoculated smallpox simultaneously enabled and resisted a paradigm of a bounded and bordered body politic. The first section of this chapter develops how inoculation transformed real human bodies and metaphors about human bodies through Cotton Mather's animalcular theory, which paradoxically imagined the body as an impregnable fortress walled off from its environment by soliciting intra-action between human and nonhuman infectious matter. The second section of this chapter, then, tests how this inoculated smallpox transformed the body politic by closely examining another early American site, Charlestown, South Carolina, 1758-1761, and the letters and diaries of prominent Carolinians, including Dr. Alexander Garden and Eliza Lucas Pinckney. Here, white South Carolinians attempted to use inoculation as a metaphor to excise and ostracize Africans and indigenous peoples from their body politic, but the epidemic's material circumstances actively subverted a racialized division of interior and exterior. If we are to revise those metaphors that frame how we live bodily difference, as well as how bodily difference structures the body politic, then we must extend our physical, historical, and literary borders to include the intra-active, trans-corporeal agency of disease.

The following chapter argues that the concurrence of pandemic yellow fever, the Haitian Revolution, and the rise of the American novel at the end of the eighteenth century was not coincidental but coevolutionary. In particular, defiant agents like yellow fever and black rebels 
ruptured the gothic and didactic conventions of Charles Brockden Brown's yellow fever novels, Arthur Mervyn and Ormond, as well as Leonora Sansay's primary canon, Secret History and Laura. As nonhuman and purportedly non- or subhuman agents, they challenged the relationship between white humanity and agency and, even more precisely, between intentionality and efficacy. They exposed the myth of clear causes and calculable effects, undermining the very premise of plot, character, and gothic and didactic denouements. Though the modern novel is conventionally associated with white, bourgeois, colonial, human subjectivity, these early novels reveal the experience of illness to be the experience of the nonhuman —of disease itself and, as disability studies reminds us, of being culturally constructed as non- or subhuman. By focusing on disease in the form most closely aligned with modern humanity, we can begin to unravel how humanity maligns both human and nonhuman variation.

The fourth chapter argues that dysentery rotted the paradigm and literature of sensibility. Early American writers, including Abigail Adams, West Indian poet and physician James Grainger, and Virginian plantation owner, Landon Carter, deployed sensibility to mitigate their personal suffering and reaffirm their own sensitivity and virtue. Yet dysentery consistently disturbed these goals and exposed their hypocrisy. It putrefied human embodiment and, thus, relations based on a particularly limited definition of human embodiment and feeling. Instead, the disease emphasized nonhuman relations and affinities, positing an ethics of shared materiality rather than shared humanity. After all, shared humanity did not and does not ensure the just treatment of enslaved, disabled, and aging or otherwise "rotting" people. Instead, dysentery posits ethical relations based on shared, mutating materiality, a radical alternative both to eighteenth-century sensibility and to the modern discourse of humanity that animates disability studies and the medical humanities. 
Finally, the last chapter examines how malaria undermined the paradigm of seasoning and, thus, narratives of Western imperialism. By the nineteenth century, the seasoning represented a rite of passage, a routine stage in the exorable march of western expansion and colonial progress. As surely as settlers would survive illness, they would colonize the land. Yet no one was every fully seasoned by malaria. Fevers and chills could cycle for months at the slightest provocation, relapses could recur for years, and complete immunity was biologically impossible. Malaria's antiteleological symptoms, therefore, resisted the teleological pull of seasoning and imperialism in Elizabeth House Trist's Travel Diary, Timothy Flint's Recollections of the Last Ten Years, and Caroline Kirkland's Western oeuvre, including A New Home-Who'll Follow?, Forest Life, and Western Sketches. Ultimately, malaria rejected the certainty that all disease could and would be conquered and, thus, that the West itself could and would be conquered.

Each of these chapters ultimately argues that disease transformed bodies and bodies of literature. By emphasizing disease's material and literary agency, by conjoining the study of illness and disability with the study of the environment, this dissertation demonstrates how disease challenges fundamental beliefs about humanity, including sovereignty, autonomy, rationality, and intentionality. And, in so doing, disease also reimagines how humans relate to other humans and nonhumans, to how we experience, treat, and write about one of our most fundamental intra-actions-illness. In the age of the Anthropocene, it is absolutely vital that we reimagine and remap our relationship with nonhumans, especially disease. 


\section{Chapter One: Syphilis "Itself” and the Natural History: The Ethical Limits of Human Certainty and Mastery}

Nearly four centuries after syphilis first ravaged Europe at the siege of Naples, and nearly three centuries after Girolamo Fracastoro coined the very word "syphilis," a physician named Jonathan Hutchinson described the infamous venereal disease as an "imitator." It mimicked psoriasis, smallpox, measles, epilepsy, and blindness, but lacked any identifiably unique symptoms of its own. It was "mixed up," and its "development" was "seldom quite regular" and frequently "rapid." Although few symptoms are particular to one disease only, an accurate diagnosis requires a clear progression of identifiable symptoms over time, what Kathryn Montgomery Hunter calls "narrative emplotment."2 Even four centuries after its European debut, therefore, syphilis remained a diagnostic quagmire. Hutchinson concedes, "Whenever the evolution of a disease is irregular, and the use of definite nomenclature thus rendered difficult, we may suspect that the malady is syphilitic" (541). In short, if it wasn't anything else, it might be syphilis. That the disease remained so unknowable and uncontrollable so long after its initial description suggests that something about the disease itself was unknowable and uncontrollable. In the absence of clear and chronological symptoms, syphilis lacked both content and narrative. Or, rather, it resisted both content and narrative. Syphilis resisted early modern attempts to name, explain, codify, and cure it and the genre most devoted to such pursuits - the natural history.

Before the nineteenth century, before medicine and science were professionalized, natural historians labored to reveal the hidden workings of the nonhuman world, carefully observing and transcribing plants, places, animals, and diseases into Linnaean taxonomies, topographical maps,

\footnotetext{
${ }^{1}$ Hutchinson, “An Address on Syphilis as an Imitator," 541, hereafter cited parenthetically.

2 Hunter, Doctor's Stories, 45.
} 
precise images, and dedicated tomes. Both a genre and an epistemology, the natural history evolved in the late seventeenth and early eighteenth centuries in tandem with American colonization. New world matter provided the material fodder for emerging fields like science and medicine as well as global imperialism and modern capitalism. Essentially, the genre and its practitioner believed that the nonhuman world could be fully understood with close observation, acumen, and patience - that, as Michel Foucault claimed, humans could "reduce the distance between" things and language "so as to bring language as close as possible to the observing gaze, and the things observed as close as possible to words." ${ }^{3}$ Through careful rhetorical choices, the natural history could eschew mere representation and replicate the thing itself.

Syphilis itself, however, was "mixed up." Physicians, historians, and lay people alike debated its name, origin, and nosology. Called the great pox, French pox, Spanish pox, lues venerea, and other epithets like Cotton Mather's "foul disease," syphilis sometimes served to name an enemy and at other times proved too dangerous to even name at all. ${ }^{4}$ In part, these variations derive from a greater unknown—origin. While many early writers located syphilis' genesis in the New World, imported to Europe by Christopher Columbus and his crew, others refused to believe that any disease could be completely "new," citing references to the same or a similar disease the Old Testament and Hippocratic texts. ${ }^{5}$ Ultimately, these debates signaled the

\footnotetext{
${ }^{3}$ Foucault, The Order of Things, 132.

${ }^{4}$ For example, Marie E. McAllister argues in "Stories of the Origins of Syphilis in EighteenthCentury England" that tales of syphilis' origins reflected cultural prejudices, ranging from national stigma to racism, misogyny, and anti-Semitism. Nationalist origin tales were especially popular before the eighteenth century but were supplanted by racist ones by the end of the eighteenth century. In "The New and the Old: The Spread of Syphilis (1494-1530)," Anna Foa similarly argues that though early origin stories demonized other Europeans, many eventually shifted the blame to non-Christians, including natives in the West Indies and Jews in Europe. ${ }^{5}$ Some writers argued that nothing like syphilis had existed in Europe before contact with the New World. They believed that American natives transmitted it to Columbus and his crew, who infected other Spaniards, who, in turn, transmitted the disease to Europeans at Charles VIII's
} 
difficulty of defining syphilis itself, of identifying precisely what "it" was. Syphilis seemed like a variation on a familiar venereal disease, gonorrhea, but it also acted like another purportedly American ailment, yaws. It could have been a combination, dictated and exacerbated by the local climate, or it could have been something new entirely. ${ }^{6}$ In the early era of American colonization, syphilis was not simply "mixed up" and "irregular," but without name, history, and definition - the central components of the natural history.

Syphilis "itself" remains mysterious. The bacterium Treponema pallidum is sexually transmitted, beginning with a chancre, an ulcer in the genitals, fever, swollen glands, rashes, and other ulcers in the mouth and genitals. These symptoms usually resolve in a few weeks, but the bacterium remains in the body for decades if untreated, producing internal ulcers and eventually

Siege of Naples (1494-1495). See, for example, Gonzalo Fernandez de Oviedo's Natural History of the West Indies and Girolamo Fracastoro's Syphilis. For the historiographical debate on the Columbian origin hypothesis, a narrative that remains contested, see Alfred Crosby's "The Early History of Syphilis: A Reappraisal" and Richard Holcomb's Who Gave the World Syphilis? as representative examples of the two extremes of this debate- that syphilis was a New World disease and that syphilis existed in the Old World before American contact, respectively. For a thorough overview of the particulars of this debate, see Brenda Baker and George Aremlagos' "The Origin and Antiquity of Syphilis." Yet, a 2016 study claims to have found a pre-Columbian skeleton with evidence of a thoracic aortic aneurysm, which links the man's death to syphilis and, thus, syphilis to the Americas. See. Mario M. Castro, et al., "Thoracic Aneurysm in a PreColumbian (210 BC) Inhabitant of Northern Chile: Implications for the Origins of Syphilis." ${ }^{6}$ The climate was an important factor for health in early modern Europe and grew even more important as Europeans encountered the extreme climates of the Americas. Georges-Louis Leclerc, Comte du Buffon, famously argued in his Natural History that the American environment produced small, impotent, and degenerated animals. Although Leclerc would walk back this claim, Cornelius de Pauw would expand the discourse of climactic degeneration by extending its effects to humans in Las Recherces Philosophiques sur les Américains. See Antonello Gerbi's thorough overview of the debate on American degeneration, The Dispute of the New World: The History of a Polemic, 1750-1900. On the climate and syphilis, Jean Astruc argued that the hot and humid climate promoted promiscuity, which in turn produced venereal diseases (see De Morbus Veneris and Kelly Wisecup's analysis in Medical Encounters, 173180). Others, like Nicolas de Monardes in Historia Medicinal and Ulrich von Hutton in De Morbo Gallico, argued that the New World climate produced herbals like guaiacum and sassafras to treat syphilis - yet another piece of evidence for New World origin. See Charles Manning and Merrill Moore's "Sassafras and Syphilis." 
leading to visual and auditory impairments, strokes, paresis, and dementia. On the one hand, we do understand syphilis' etiology and symptoms. Moreover, it can be cured with antibiotics_-at least for now. ${ }^{7}$ On the other hand, much is still unknown: its relationship to other treponemic diseases like pinta, yaws, and bejel is unclear ${ }^{8}$; its origin remains contested; its violent, epidemic entrance into Europe is not fully understood; its symptoms have changed radically over the last four centuries. ${ }^{9}$ Though modern science certainly understands many of the disease's biological mechanisms, it is a mistake to think that we understand it completely. Some part of it remains withdrawn, is inaccessible to modern science as well as to the natural history.

\footnotetext{
${ }^{7}$ Antibiotic resistance is proving a problem, and the rates of syphilis are increasing. Penicillin remains effective, but "second line" antibiotics are proving ineffective. See Lola V. Stamm's "Global Challenge of Antibiotic-Resistant Treponema pallidum."

${ }^{8}$ Scientists are still undecided on the exact relationship between treponemic diseases, include pinta, yaws, bejel, and syphilis. Contracting one confers immunity to the rest, which certainly suggests a close, but perhaps not identical relationship (as cowpox conferred immunity to smallpox). They could be one species with different strains, like influenza; they could differ because of climate and means of transmission; or, they could simply be closely related bacteria that evolved separately over time. Pinta seems to be the oldest of the four diseases and the mildest, producing a skin infection that is transmitted by regular body contact, particularly between children. Yaws, however, is a chronic skin infection that can degrade bones and joints over time. As the global climate cooled, and humans began to wear clothes and casual skin contact became less frequent, scientists think that the treponeme bacterium receded to the warmest and moistest parts of the body: the mouth and the genitals. Bejel, a nonvenereal form of syphilis, produces similar symptoms, but it is transmitted orally. See Baker and Armelagos, "The Origin and Antiquity of Syphilis"; Crawford, Deadly Companions, 124-30; Karlen, Man and Microbes, 52-53, 57, and 121-28.

${ }^{9}$ Early modern syphilis seems to have been more virulent. The venereal disease that ravaged Europe after Columbus' journey to America was far deadlier, far more quickly than the both the ordinary clap and modern syphilis. At the beginning of the sixteenth century, as Girolamo Fracastoro noted in 1530, the disease had already tempered into the slightly less horrific incarnation known to the seventeenth and eighteenth centuries. See Syphilis. The virulence of the post-Naples disease has led some scholars to argue that it was not syphilis at all, or not syphilis only but rather a mutation of yaws or perhaps the plague. See note 8 . Furthermore, some scientists have suggested that syphilis mutated again between the eighteenth and nineteenth centuries. The creative genius associated with progressive syphilis was not documented until the nineteenth century. See Hare, "The Origin and Spread of Dementia Paralytica."
} 
Yet even as syphilis withdraws, it renders the contours of its agency visible-if only to demonstrate the limits of human knowledge and mastery. Syphilis "itself” infects and intra-acts with natural histories like Hans Sloane's Voyage to Jamaica (1689), John Lawson's A New Voyage to Carolina (1709), and James Cook's Journals (1768-1779). It undermines the genre's mechanisms of control and veracity, including faithful observation, plain language, clear "emplotment," witnessing, and the figure of the author himself. In particular, the phrase "syphilis itself," appearing in each of these texts, exposes the gap between the natural history's purposeto represent the thing "itself" - and the thing “itself" that escapes representation. Syphilis withdraws from and revises the natural history, undermining its rhetorical conventions and ideological goals. These disruptions disclose both syphilis' intra-active agency and the limits of natural historical control: our narratives can never fully account for syphilis, neither a microbe's motivations and desires, nor a human's lived experiences. Syphilis reminds us that this impossibility is not historical — a product of early modern ignorance_-but imminently ethical. Whereas the natural history and certainly modern medicine assumes a knowable and controllable experience of syphilis, the disease itself posits the unknown and the uncontrollable as a more ethical orientation to the layered, intra-active, and multivalent experiences of disease.

Importantly, of the three texts analyzed here, none actually use the word "syphilis." Sloane and Lawson employ “pox," while Cook uses “venereal distemper.” Moreover, syphilis was not yet differentiated from gonorrhea or yaws. ${ }^{10}$ All of this would seem to undermine a new materialist argument. Yet new materialism doesn't require "retrospective diagnosis"—as Cristobal Silva and Sari Altschuler warn against. Rather, this chapter argues that syphilis'

\footnotetext{
${ }^{10}$ For more on medical differentiation, see Tampa et al.'s "Brief History of Syphilis" in the Journal of Medicine and Life.
} 
ontology — the great imitator, whose symptoms have evolved radically since the fifteenth century and vary over an individual's life—shaped its epistemology. When Sloane, Lawson, and Cook use ambiguous terms like "pox" and "venereal distemper," they may or may not be referring to what we now call syphilis — and that's exactly the point. Syphilis itself evades intelligibility and even naming, resisting and revising that genre most dedicated to comprehensive knowledge, static representation, and eternal names.

\section{Representing the Thing Itself: The Natural History and the Royal Society}

Founded in 1660, the Royal Society pioneered a new kind of science. It rejected the scholastic model, which required an extensive, classical education, conversation with ancient texts, numerous citations, and little to no "direct experience" with the natural world. ${ }^{11}$ Instead, as Thomas Sprat asserted in his 1702 History, the Royal Society sought "to make faithful Records, of all the Works of Nature," observing, experimenting, and writing on almost any "natural" subject. ${ }^{12}$ Such observation and record would ultimately benefit all "humane life" and “Mankind" (2).

In this nascent empiricism, an experiment, such as Robert Boyle's famous air pump, would be carefully conducted, attentively observed, faithfully recorded, and diligently disseminated to members. The validity of a discrete experiment—and of the experimental method itself — hinged on credible witnesses that could authenticate the projects. These witnesses

\footnotetext{
${ }^{11}$ For more on scholasticism and the Royal Society's development, see Peter Dear's Totius in Verba: Rhetoric and Authority in the Early Royal Society and Steven Shapin's "Pump and Circumstance: Robert Boyle's Literary Technology." On how "experience" influenced both early colonial writing and the development of the scientific revolution, see Jim Egan, Authorizing Experience, especially chapter 2.

${ }^{12}$ Sprat, The History of the Royal-Society of London, 61, hereafter cited parenthetically.
} 
need not be "eye" witnesses; rather, as Steven Shapin and Simon Schaffer argue, the Royal Society codified "virtual witnessing" through their Transactions, "obviat[ing] the necessity for either direct witness or replication." ${ }^{" 13}$ Readers could authenticate experiments and create matters of fact without actually seeing the experiment or reproducing it through a "literary technology" that strived to make words represent things themselves. Through the act of reading, they could function as eyewitnesses - that is, if the writing adhered to the Royal Society's literary protocols.

Because the reading of these reports was critical to establishing truth, their writing was carefully regulated. The Royal Society's initial statute on the matter is clear in this intention, if vague on its implementation: "In all Reports of Experiments to be brought into the Society, the matter of fact shall be barely stated, without any prefaces, apologies, or rhetorical flourishes."14 Sprat expands, "they have indeavour'd, to separate the knowledge of Nature, from the colours of Rhetorick, the devices of Fancy, or the delightful deceit of Fables" (62). He explains, "the luxury and redundance of Speech" can "give the mind a motion too changeable, and betwitching to consist with right practice" $(111,112)$. In other words, colorful language and ornamentation threatened the veracity that the experimental method required. In fact, Sprat finds himself so "warm'd with this just anger" describing these rhetorical flourishes that he himself devolves into elaborate fancy describing this "most profest enemy" $(112,113)$. This emphasis on simplicity was at least in part a response to the citational ornamentation of the era, what Boyle calls "acute Sentences, fine Expressions, or other Embellishments borrow'd from eminent writers." 15 However, this goal of simplicity also represented a desire to undo the linguistic chaos of Babel,

\footnotetext{
${ }^{13}$ Shapin and Schaffer, The Leviathan and the Air-Pump, 60, hereafter cited parenthetically. 14 "Statutes of the Royal Society Enacted in 1663," in A History of the Royal Society, 527.

${ }^{15}$ Boyle, Certain Physiological Essays, 38.
} 
to make words and things align in a natural, universal language, and, thereby, to move ever closer to divine truth, to the thing itself. ${ }^{16}$

Despite the repeated call for simplicity, there seems to have been no concrete rules for achieving the "barely stated," only rebukes of elaboration, ornamentation, rhetoric, luxury, and eloquence. Sprat concludes,

They have therefore been most rigorous in putting in execution, the only Remedy, that can be found for this extravagance and that has been, a constant resolution, to reject all the amplifications, digressions, and swellings of style: to return back to the primitive purity, and shortness when men deliver'd so many things, almost in an equal number of words. They have extracted from their members, a close, naked, natural way of speaking; positive expressions, clear senses; a native easiness: bringing all things as near the Mathematical plainness as they can: and preferring the language of Artizans, Countrymen, and Merchants, before that, of Wits, or Scholars. (113)

Notably, Sprat emphasizes "the primitive purity of language," when "words" and "things" were equal. Though he more clearly identifies what this kind of writing should resemble, he offers no clear path for an aspiring plain-speaking truth-seeker to follow.

While the rules may have been unclear, analysis of the Royal Society's published reports offers a picture of what writing features the society valued. In his discourse analysis of the Royal Society Transactions from 1675-1975, Dwight Atkinson identifies prominent rhetorical characteristics of early Society writing. Because the experimental method required "immediate

\footnotetext{
${ }^{16}$ For more on the relationship between Babel, writing, and the Royal Society, see John Wilkins, "An Essay Towards a Real Character, and a Philosophical Language" (1668). See also Susan Scott Parrish, "William Byrd II and the Crossed Languages of Science, Satire, and Empire in British America."
} 
experience," early writing was "author-centered," usually written in first person, the past tense, and with active verbs. It also emphasized "affective states and psychological processes of the author." ${ }^{17}$ Other linguistic markers include: identification of witnesses, who are used to authenticate an experiment or observation; modesty and humility; a collection of miscellaneous observations and/or experiments without a unifying thread; politeness to other members and the recipients of the report. Atkinson concludes that these markers demonstrate the importance of gentility and genteel modes of interaction to the nascent organization. Schaffer and Shapin add that accounts of failed experiments also characterized early Society reports, which not only "allayed anxieties in those neophyte experimentalists," but also "assured the reader that the relator was not willfully suppressing inconvenient evidence, that he was in fact being faithful to reality" (64). Because the end goal was truth, writers should be confident only in matters of fact and circuitous on everything else (67). While the modern premise of scientific "objectivity" did not flourish until the nineteenth century, natural philosophy and natural history were governed by what Lorraine Daston and Peter Galison call "truth-to-nature," the belief that the naturalist played a critical role in selecting, comparing, and generalizing hidden truths and principles about nature. $^{18}$

Up until now, I have been describing natural philosophy rather than natural history, but the two disciplines were intertwined, supported by the Royal Society and its literary protocol. In his essay, General Heads for the Natural History, Boyle describes the natural history as "the only sure Foundation of Natural Philosophy." 19 While natural philosophy emphasized laboratory experiments like Boyle's air pumps, the natural history involved the close study of flora, fauna,

\footnotetext{
17 Atkinson, “The Philosophical Transactions of the Royal Society of London, 1675-1975," 339.

18 Daston and Galison, Objectivity, chap. 2.

${ }^{19}$ Boyle, General Heads for the Natural History, 1.
} 
waterways, and geographical formations. Yet because so many natural histories described far-off locales and unimaginable animals, lands, and climates, and because the genre served the new empiricism, following the Royal Society's literary rules remained important. ${ }^{20}$ Unlike the nineteenth-century scientist, both the natural philosopher and the natural historian recognized that "mediation" was required to transmit "scientific facts," particularly those scientific facts of foreign places (Dalton and Galison 59). To ensure "truth-to-nature," both natural philosopher and natural historian employed literary protocol to standardize how idiosyncratic observations were transmitted across the globe.

Just as modern science is not as ideologically pure as we once believed, neither was natural history. As many scholars have shown, the genre and its practitioners were agents of colonization and imperialism. Richard Frohock argues that the seventeenth century's conquerors and the eighteenth century's "imperial scientists" form a single genealogy: "the scientist seemed to extend empire without bloody conflict...[and] inherited the conqueror's privilege, distinction, and importance to nation." ${ }^{21}$ Similarly, Mary Louise Pratt contends that it is "simultaneously innocent and imperial," purporting "to do virtually nothing in or to the world" but represent it, while also making it available for conquest. ${ }^{22}$ Natural history not only offered a "utopian, innocent vision of European global authority," but actively complemented that imperialist authority (Pratt 39). The natural historian's “truth-to nature," therefore, was truth-to-wealth, toempire, to-conquest, to-bondage.

\footnotetext{
${ }^{20}$ In fact, Percy G. Adams argues that these literary protocols had antecedents in travel writers like Martin Frobisher and Thomas Hariot. See Travel Literature and the Evolution of the Novel, chap, 10.

${ }^{21}$ Frohock, Heroes of Empire, 82.

22 Pratt, Imperial Eyes, 33, hereafter cited parenthetically.
} 
Still, even this imperial science was routinely undermined. As Susan Scott Parrish has shown, white American creoles were expected to mine flora, fauna, and data and send it to metropolitan centers in Europe to be refined by more learned men. In practice, however, indigenous Americans and Africans subverted the transatlantic production of natural historical knowledge. They collected specimens and theorized, sometimes revealing the natural world and at other times withholding it. ${ }^{23}$ Similarly, white creoles, including both men and women like Dr. Alexander Garden and Eliza Lucas Pinckney, discussed in the next chapter, insisted that they could do more than collect, pack, and mail. They too could analyze, deduce, and expostulate. Likewise, Kelly Wisecup has shown how medicine and medical knowledge were especially open to diverse input in the Americas. ${ }^{24}$ While the natural history served imperialist ends, these ends were never straightforward nor reliable.

Ultimately, the natural history attempted to understand the world as it truly was-to close the gap between things and language and thereby construct real knowledge. Coinciding with imperial colonization, the genre served the empire, collecting and describing places, peoples, plants, and animals not only in order to understand them but also to enable profit, expansion, and settlement. Indigenous people, Africans, women, and creole Americans, however, all complicated the relationship between natural history and imperialism, expanding who could make sense of the nonhuman world. Though officially restricted, the natural history's interests,

${ }^{23}$ Parrish, American Curiosity. See also Britt Rusert, Fugitive Science, which analyzes how African Americans contributed to science and natural history in many genres and venues. ${ }^{24}$ Wisecup, Medical Encounters. Though the natural history and medicine were not necessarily the same, they overlapped significantly in the eighteenth century. Many men practiced medicine in order to support their true natural historical interests. See Pratik Chakrabarti's Materials and Medicine for more on the relationship between American and Indian colonization and medical practice. 
features, and rhetorical techniques filtered into the wider Atlantic culture. ${ }^{25}$ Yet it was not only humans who challenged the authority required to fathom and control the nonhuman world; nonhumans like syphilis subverted the natural history as well.

\section{Hans Sloane's Voyage to Jamaica: Syphilis Itself Eludes and Revises the Natural History}

One of the earliest natural histories of the new world — written by a future President of the Royal Society_-Voyage to Jamaica is part travel narrative, part specimen description, part "manners and customs" proto-anthropology, part geographic survey, and part medical anthology. In short, it is the emerging natural history, including descriptions and drawings of plants and animals, observations on climate and geography, case studies of illness, and a firsthand account of his own travels. Though Voyage to Jamaica poses as straightforward "truth-to-nature," the transcription of things themselves, Sloane's discussion of syphilis shatters this illusion, rupturing the Royal Society's rhetorical standards. These formal and stylistic inconsistencies signal syphilis' presence, its textual intra-action. When Sloane employs the phrase, "the Lues Venerea...spread it self," he not only fails to close the gap between words and things as the natural history desired but also highlights the natural history's limits: it could never fully transcribe, codify, and understand illness - neither the disease itself nor the person's experience.

Elected to the Royal Society just a few years before he set off to Jamaica, Sloane was dedicated to the natural history, to what Pratt calls the "systematizing of nature" and "a European knowledge-building project." ${ }^{26}$ In his preface, Sloane asserts the Royal Society's values: "the

\footnotetext{
${ }^{25}$ For studies on the natural history's wide influence, see, for example, Pamela Regis, Describing Early America; Beth Fowkes Tobin, Colonizing Nature; and, especially, Christopher Iannini, Fatal Revolutions

${ }^{26}$ Pratt, Imperial Eyes, 38.
} 
Knowledge of Natural-History, being observations of Matters of Fact, is more certain than most Others, and in my Slender Opinion, less subject to Mistakes than Reasonings, Hypotheses, and Deductions are." 27 Rejecting the "Reasoning, Hypotheses, and Deductions" that had dominated European epistemology for centuries, Sloane conflates the natural history with "Matters of Fact"- “truth-to-nature," things themselves, and "certain" knowledge. He argues that the natural history, as a genre and a broader epistemology, is the only method for truly knowing the new world, for understanding and transmitting it (rather than a representation of it) across the Atlantic. $^{28}$

Sloane's most important goal, therefore, was to describe nature accurately, to transform words into things themselves. Yet, in a new context—literally a "new world" — Sloane struggles. ${ }^{29}$ He shifts genres, repeats himself, and employs multiple volumes and an unwieldy index. According to Christopher Iannini, Sloane struggled to represent "things" because chattel slavery radically reimagined what a "thing" was. A slave was "at once property and person, commodity and laborer, object of study and bearer of knowledge," challenging the very definition of "thing" and, thus, also challenging the Royal Society rules for representing "things." 30 To Iannini, Sloane's rhetorical failure exposes the deeply unsettling relationship between slavery and the natural history it supported; it reveals the textually embedded disconnect between a culture that knew slaves to collect specimens, perform music, practice medicine, and

${ }^{27}$ Sloane, Voyage to Jamaica, unpaginated preface, hereafter cited parenthetically.

28 Sloane also claims that observations of the natural world "afford great Matter of Admiring the Power, Wisdom and Providence of Almighty God" (unpaginated preface). Christopher Iannini reads this passage and, in fact, Sloane's entire text as a kind of formal clash between the emblematic method and an emerging empiricism. See Fatal Revolutions, chap. 1.

${ }^{29}$ See Wayne Franklin's Discoverers, Explorers, Settlers on the way discovery, exploration, and settlement of the Americas challenged both language and representation.

${ }^{30}$ Iannini, Fatal Revolutions, 37. 
mourn loved ones (all signs of humanity), and yet kept them as property and things nonetheless. Sloane's inability to conform to the Royal Society's rules demonstrates the problem of representation when an institution like slavery blurred the lines between subject and object - $\mathrm{a}$ line increasingly important to the natural historical and empirical method. ${ }^{31}$

Although slavery undoubtedly affected Sloane's text, this reading elides another of Sloane's textual peculiarities: the case studies. At the end of his introduction to volume one, following his observations on climate and geography, Sloane closes with a section entitled, "Of the Diseases I observed in Jamaica, and the Method by which I used to cure them" (xc). Here, he compiles his experiences as a medical doctor in the West Indies into a series of incidences or case studies. Organized according to individual people and illnesses, this section typically uses little more than a paragraph to describe an ill person's name, symptoms, treatments, and outcome. In the margin, a brief summary of the case (e.g., "Of a Tertian" or "Of a Colick") references the illness, presumably to facilitate a quick search as in an index. Sloane's case studies, therefore, seem to act both as an academic catalog of West Indian diseases in the way his collection of plant life does, and as a kind of practical medical guide for doctors searching for a diagnosis or cure. Although medicine would eventually be differentiated from other sciences, many colonial writers included medical information, including descriptions of diseases and especially of herbal remedies, in their natural histories. In fact, these herbal remedies, recorded and collated in natural histories, powered early colonization in the West Indies before crops like

31 Though science had not codified objects as passive and inanimate yet, it did privilege the knowledge and experience of the scientist-author and, thus, the human subject. See Atkinson and Dalton and Galison, chapter two. 
sugar were cultivated. ${ }^{32}$ Like his references to "observations" and "matters of fact," Sloane's case studies demonstrate his commitment to the natural history and the new empirical method.

As in the rest of his natural history, Sloane's case studies attempt to demonstrate their matter-of-factness by following the right rules of discourse. The case study, case narrative, or case history has ancient origins, but it gained popularity in Sloane's era through the work of Thomas Sydenham, the "English Hippocrates," who rejected the theoretical or scholastic approach to medicine in favor of close attention to individual patients - just as the Royal Society rejected classical citations for immediate experience. ${ }^{33}$ Case studies were circulated among physicians to collate and corroborate treatments or speculations on disease. One doctor only had so many patients, could only experiment with a new technique on a finite number of people, so circulating case studies allowed a network of doctors to pool resources, patients, and observations to make better, more informed choices in their practices. ${ }^{34}$ As Londa Schiebinger outlines, the case study's features "included a description of the patient, an account of his or her past patterns in sleep, diet, and exercise, description of therapies, their effects and outcomes'complete cure,' 'relief,' or death." ${ }^{35}$ Because doctors relied on these cases for accurate information to treat patients and save lives, they grew "uniform in style" (Schiebinger 160). Similarly, Kathryn Montgomery Hunter argues that the modern case study employs a strict

\footnotetext{
${ }^{32}$ James Grainger's The Sugar Cane and Richard Ligon's A True and Exact History of the Island of Barbados represent two more examples of colonial natural histories that privilege medical information. I return to Grainger in chapter four. See Londa Schiebinger's Plants and Empire for how natural histories used medicinal knowledge, particularly of herbal remedies, to fuel colonization and wealth accumulation.

${ }^{33}$ For more on Sydenham and his importance to seventeenth- and eighteenth-century medicine see Peter Anstey's "The Creation of the English Hippocrates."

${ }^{34}$ Additionally, a doctor could only experiment on himself so many times. See Londa Schiebinger's "Human Experimentation in the Eighteenth Century: Natural Boundaries and Valid Testing" for the importance of self-experimentation to medicine.

${ }^{35}$ Schiebinger, Plants and Empire, 160, hereafter cited parenthetically.
} 
formula so it can transform "incomplete and subjectively reported information" into science (51). The formula represents "a practical response to medicine's radical uncertainty," to "a science whose laboratory is the living person" (106). Both modern and early modern case studies, therefore, attempted to translate the individual experience of illness into the thing itself through strict literary protocol.

Although Sloane was writing before this formula was concretized, his commitment to the Royal Society and its methods of discourse suggest that even his early case studies were shaped by impulses to transparency and uniformity, to what he calls "observations of Matters of Fact." As Sydenham and his descendants would, Sloane opens with the patient's name, symptoms, former treatments, diagnosis, new treatments, and outcome, whether health or death. He transforms his patients' individual experiences into objective generalizations-e.g., "Of a Cholera Morbus" not "Of Captain Nowel” (xc)—so that prospective travelers and doctors could access accurate, general information quickly. Sloane evinces his commitment to the new language of natural history, which in turn legitimated his authority to discourse on science and medicine.

Yet Sloane's case studies are inconsistent. In particular, his case studies on syphilis (though he does not use that name) fail to conform to this style, undermining his ability to transcribe faithfully and, thus, authenticate himself - in short, to do natural history. Every other case delivers, at the very least, the ill person's first name. Presumably, Sloane includes the names of his patients to write empirically, to relate "Matters of Fact" by identifying witnesses; these names verify his case studies, in turn lending him the credibility and authority the natural history required. ${ }^{36}$ Yet no case of syphilis receives a name. Even yaws (ciii) and gonorrhea (cxli), which

\footnotetext{
${ }^{36}$ See Atkinson for the importance of witness naming to early Royal Society reports.
} 
were similar and as yet undifferentiated diseases, received names. ${ }^{37}$ In the studies of those with “the pox,” however, Sloane replaces names with blank spaces - “One ---- ---- who had a Gonorrhea often" (here, gonorrhea is used as a symptom of syphilis rather than gonorrhea proper; gonorrhea proper is described as “Of a gonorrhea” in the margins), and "One ---- ----, aged about Fifty" (xciii, ci). On the one hand, these blank spaces may aim to protect the sufferers' identities, to mitigate the scorn and shame of venereal disease, especially if they were well-known white planters. On the other hand, these empty spaces undermine the truth-telling, empirical function of witness-naming that the case studies conventionally establish. While Sloane carefully constructs these cases to emphasize his skill—anyone who dies dies through their own fault not his- these syphilitic cases subvert generic convention and, therefore, Sloane's credibility and authority. By failing to divulge the truth, he undermines his text's 'truthto-nature," the natural history's primary objective.

Though Sloane's case studies evince a desperate desire to control syphilis, they routinely demonstrate the opposite. In one account, an unnamed man seeks Sloane's aid, complaining of abdominal pain. Though Sloane prescribes "such things as usually avail in such Cases," the typical treatments fail, and the man grows worse. From this and the patient's pain in urination, Sloane realizes he has misdiagnosed the man and begins to suspect "the Pox to be the chief of his complicated Diseases, and questioning him very hard about the Matter, he at length confess'd it" (ci). While Sloane eventually discovers the truth (through an interrogation), this delay ultimately leads to the man's death. ${ }^{38}$ In another case, Sloane argues that a woman with syphilis had died

\footnotetext{
${ }^{37}$ See note 10 on medical differentiation.

${ }^{38}$ If Hunter locates the origin of the modern case study in the seventeenth century, then perhaps here we also find the root of medical paternalism, the "doctor knows best" mentality glimpsed in Sloane's interrogation. For a brief overview of literature on such paternalism, see Brian McKinstry, "Paternalism and the Doctor-Patient Relationship in General Practice." Though
} 
from being poisoned by her slave, "either designedly to do her good" or "maliciously" (cxxi). Still, he questions her death-"of what, or how," she died, "I know not" (cxxi). ${ }^{39}$ In the case studies of syphilis, Sloane shifts between a kind of bravado — through his great skill, he draws the true story from the man - and impotence- - he dies anyway. And, though he blames the woman's slave for her death, he admits that he might be wrong. Royal Society reports were supposed to be circumspect on anything uncertain, but here Sloane vacillates between circumspection and matter-of-factness. That is, as Sloane fails to cure these cases of syphilis, he also fails to control their textual representations.

Though he tries to blame the man's death on his own false story, and the woman's death on her slave, he only demonstrates the limits of own natural history-its failure to invoke the many stories that coalesce to form each case. He cannot explain why the man lies nor what the slave woman's motivations could have been, just as he cannot articulate syphilis' rationale or desires. Thus, these case studies demonstrate the impossibility of fully narrating syphilis, whether the person's or the microbe's experiences. In this context, those blank spaces evoke the many absences and failures of his natural history, of all that it could not collect, generalize, understand, and accomplish: the patients' feelings and experiences, physical and textual authority over illness, and, especially, a clear understanding of the disease itself. Their emptiness, therefore, signals the genre's inability to master syphilis.

It is not that Sloane could not ascribe to natural historical conventions. After all, he would lead the Royal Society from 1727-1741. Rather, syphilis “itself” infects, intra-acts, and

Sloane does not specify whether this patient is free or enslaved, if he were enslaved, his reticence could have derived from black fear of (and resistance to) white medicine and doctoring. See Sharla M. Fett, Working Cures, 142-58.

${ }^{39}$ On white fear of slave poisoning and on poisoning as black resistance, see Peter Wood, Black Majority, chap. 11; Fett, Working Cures, 159-67; and Parrish, American Curiosity, 273-79. 
revises his case studies - in turn, undermining and revising the natural history's faith that things "themselves" could be represented. In the preface, Sloane recounts the now familiar story of syphilis' entrance into Europe:

Columbus, likewise brought into Europe in his Ship, and First Voyage, from these places, the Pox, which spread so quickly all over Europe, that Antonio Benivenius, who was at that time a great and famous Practiser in Physick at Florence...tells us, that the Lues Venerea then beginning in Spain, had spread itself through Italy, and France, and that in the Year 1496, it had possess'd many People in all the Provinces of Europe. (ii) As the passage continues, however, Sloane cites another source, Dodonaeus, that describes accounts of a similar disease from 1270, 1305, and 1419—-far before Columbus sailed across the Atlantic (ii). Still, Sloane concludes,

I am of Opinion notwithstanding what these have said, and some other less material Passages in ancient Writers and Histories, and what Joanne sab Arderne has written about Anno 1360. And likewise what Stow says of the Laws of the publick Stews in Southwark, that this was a Distemper altogether new in Europe, Africa, and Asia, before it was brought from the West-Indies. (ii-iii)

Even as Sloane supports the Columbian origin story, he cites three sources that disagree with his conclusion and absolutely no sources that support him. In fact, his assertion- "I am of Opinion notwithstanding what these have said...that this was a Distemper altogether new in Europe" —is quite literally split in half by these contradictory sources. As Myra Jehlen argues, this inconsistency may highlight the fraught seams of history in process, of the attempt to understand what seemed like a new disease. In fact, this history is still being processed; modern scholars 
continue to debate syphilis' origin. ${ }^{40}$ Sloane's complex syntax and contradictory sources erode the certainty, credibility, and objective posture that the Royal Society and the natural history required, and which he himself attempted to employ. The phrase "spread itself," however, posits an alternative historical agent—neither lustful sailors and soldiers nor Sloane but syphilis itself. Syphilis "it self" complicates this passage textually and ideologically, undermining the importance of the human perceiver and transcriber to natural history. On the one hand, this pronoun acts intensively, adding emphasis to the subject-actor syphilis. On the other hand, it also acts reflexively, constructing syphilis as both the subject and object of the verb "spread"; syphilis is spreading syphilis. In his study of reflexivity, Edward T. Jeremiah describes the "peculiar effect" of the reflexive pronoun. It is meant to refer to its antecedent, but it frequently creates a "conceptual separation of the two," splitting the subject into pieces, creating "another level of the subject" that "forever eludes objectification." 41 The reflexive pronoun, therefore, ruptures the very concept of the singular, self-contained, human subject. In the case of "syphilis it self," however, it also ruptures the concept of the singular, knowable, and controllable object, hinting at the withdrawn and inaccessible syphilis. While the classic scientific divide between human subjects and nonhuman objects would not be formalized until the nineteenth century, the natural history relied on "the keenest and most experienced observer" and recorder to perceive clearly and transcribe faithfully (Daston and Galison 59). In this passage, then, syphilis eludes the natural history in at least two ways: the reflexive pronoun highlights an aspect of syphilis that "eludes objectification," that withdraws from the natural history's classifying eye and tongue.

\footnotetext{
${ }^{40}$ See note 5 on the continuing debate on origin.

${ }^{41}$ Jeremiah, The Emergence of Reflexivity in Greek Language and Thought, 31.
} 
Moreover, "spread it self" emphasizes an agency unchecked and unhindered by human subjectivity and control, including that of the natural historian.

While there are many reasons why Sloane may have chosen to minimize his agency and maximize syphilis', none fully explain this passage's strangeness. He could be trying to assuage the guilt of colonial transmission. If the disease moves "itself," the author and other European travelers can skirt blame for syphilis' transmission. In other words, Sloane may purposefully forfeit narrative control in order to promote colonialism's ends without taking on the burden of its means. ${ }^{42}$ By attributing agency to syphilis, he avoids his own, as in the germ theory of history. Or, Sloane may be working to mitigate the stigma of syphilis. Conjoined with the blank spaces in the case studies, the phrase "syphilis itself" could function to insulate vulnerable people from cultural disapprobation, social stigma, and antipathy.

Yet to fully disburden colonial guilt or combat shame, syphilis would need to be the subject-actor consistently. This passage, however, only haphazardly applies subjectivity, shifting between many human and nonhuman actors. Whereas Jehlen might argue that such discrepancies bear witness to an uncertain history, Michael Ziser reminds us that nonhumans shaped history and literature as well. Sloane's Jamaica was not just a "contact zone," where "subjects previously separated by geographic and historical disjunctures...now intersect[ed]," but a chaos zone where nonhumans like syphilis impacted both bodies and texts. ${ }^{43}$ Vacillating between agents, between subjects and objects, between revelation and elision, this passage reveals an agency unmoored from human subjectivity, from the natural scientist and his careful observation and record.

\footnotetext{
${ }^{42}$ For more on how natural historians fashioned innocence out of colonial violence, see Pratt, Imperial Eyes.

${ }^{43}$ Pratt, Imperial Eyes, 7.
} 
Syphilis ruptured early modern natural historical writing not because objects were inherently inanimate and passive, as in contemporary science writing, but because the author played such a central role in observing, describing, and narrating newly-discovered knowledge. As Atkinson notes, early Royal Society writing was "author-centered," with frequent use of firstperson pronouns and active verbs. This author-centered approach relied on the cultural figure of the gentleman, who was “'free' and independent—a disinterested social actor," and, therefore, credible and honest (362). Rhetorically, "they hoped to gain for themselves...special claims to authority, disinterestedness, and moral rectitude" (362); therefore, positioning oneself as the subject or actor of an observation or treatment "significantly warranted" the report (363). When this passage effaces Sloane as the writer and warrantor, when his sources and syntax contradict him, and when those blank spaces undermine his credibility, we glimpse syphilis. We glimpse how syphilis' ontological uncertainty ruptured the genre most dedicated to certainty and the rhetorical style necessary to validate and manufacture that certainty.

Natural histories were supposed to close the distance between words and things; Sloane's case studies—-his contributions to a nascent medical science-were supposed to observe faithfully and state plainly. Yet his natural history fails to meet these generic and ideological expectations. His textual inconsistencies - the blank spaces that evoke an unnamed, silenced history of human experience, the contradictory sources and confusing syntax, the phrase "spread itself"-reveal a real, albeit inaccessible, syphilis at work, intra-acting with physiological and textual bodies. Syphilis exposed the natural history's limits: it could never name, codify, and transcribe syphilis "itself"- - neither the varied human experiences nor the microbe's. Eluding the genre, syphilis revised it. 


\section{John Lawson's “No Nose Doctor”: Syphilis Itself Resists Colonial Science}

After Hans Sloane returned to England and rose to prominence in the Royal Society, he inherited a collection of a plant specimens gathered by another new world naturalist, John Lawson. Far less is known about Lawson than Sloane, and far more connect them than this inheritance: both composed natural histories that syphilis "itself” challenged. While syphilis withdrew from Sloane's classifying eye and pen, it “crowded itself” into Lawson's $A$ New Voyage to North Carolina (1709), rupturing the natural history's “emplotment." Instead of withdrawing, syphilis reveals alternative, indigenous, and empowering perspectives on itself. it not only undermines Lawson's credibility_ as it does in Sloane's Voyage_-but also challenges the imperialism that natural history as a genre and ideology served.

Lawson's natural history differs from Sloane's in at least two ways. First, it is more explicitly promotional. Its catalogs and descriptions of flora, fauna, disease, and Native Americans function to facilitate colonization and settlement. Though Sloane's did as well, this goal is more explicit in Lawson's work, especially considering he remained, lived, and died in the Americas whereas Sloane only sojourned in Jamaica for a little over a year. Second, the travel portion of his natural history is far more extensive than Sloane's. While the travel narrative and natural history were not synonymous, they were stylistically similar and frequently overlapped $^{44}$ Still, there were differences. In particular, Tobin argues that the natural history "is characterized by its 'objective' point of view, by its use of the list of topics to organize its contents, and by its historylessness and protoanthropological approach to human subjects, all of which have the effect of positing static, timeless cultures and unchanging natural

\footnotetext{
44 See Adams, Travel Literature, chapter 10, on the stylistic relationship between travel literature and the natural history.
} 
environments." 45 In turn, though the travel narrative "contain[s] similar subject matter," its "organizing principle" is "the traveler's movement from place to place, which, along with chronology, provides the travel account with a narrative frame" (57). Tobin overstates the natural history's commitment to "objectivity," but both genres did value accurate description and an apt observer. Yet the travel narrative required a particular plot—a clear, logical movement through time and space, one that Lawson's failed to deliver.

One of the most unique and contradictory facets of $A$ New Voyage is the space and the plotting it affords indigenous narratives. While the natural history conventionally did include descriptions of indigenous people, beliefs, and practices, Lawson locates these tales in the travel narrative, where they frequently unsettle his natural history's impulse to "innocent" imperialism. ${ }^{46}$ For the most part, however, Lawson denigrates indigenous Americans and their narratives in order to justify American colonization. In one complex set of passages, he describes Sewee depopulation. At first, he outlines the effects of European diseases like smallpox. Though the Sewees "have been formerly a very large Nation," they are "very much decreas'd since the English hath seated their land." ${ }^{47}$ The Sewee's experience is not unique, however, and "all other Nations of Indians are observ'd to Partake of the same Fate, where the Europeans come" (17). Yet he quickly shifts course, offering an alternative explanation. Determined to pursue trade with Europe directly and circumvent rapacious colonial middlemen, the Sewee reinforced their canoes, packed their wares, and sett off in the direction the European ships had traveled. Soon, however, "there rose a Tempest, which it's suppos'd carry'd one Part of these Indian Merchants, by Way of the other World, whilst the others were taken up at Sea by an English Ship, and sold

${ }^{45}$ Tobin, Colonizing Nature, 57, hereafter cited parenthetically.

${ }^{46}$ See note 42 on "innocent" imperialism.

${ }^{47}$ Lawson, A New Voyage to Carolina, 17, hereafter cited parenthetically. 
for Slaves to the Islands" (19). Lawson decides, "The Indians, I am now speaking of, were not content with the common Enemies" like smallpox "that lessen and destroy their Country-men, but invented an infallible Stratagem to purge their Tribe, and reduce their Multitude into far less Numbers" (18). Though Lawson recognizes the Europeans' toll on native peoples, his here plotting upstages smallpox and assuages colonial blame by ending on a tale of punished greed and hubris - ultimately the Sewee are to blame for their own deaths. ${ }^{48}$ The Sewee tale interrupts Lawson's travel narratives, his literal movement through time and space, in order to reorder and justify American colonization.

Lawson further tries to justify colonization by figuring disease as transactional, as an unfortunate but unavoidable result of trade between the Old and New Worlds: the Europeans exchange smallpox for syphilis. Like Sloane, Lawson describes the Colombian origin of syphilis, but he embellishes the story through a comic tone and series of economic puns:

We being well enough assured that the Pox had its first Rise (known to us) in this new World, it being caught of the Indian Women, by the Spanish soldiers that followed Columbus in one of his Expeditions to America; who after their Arrival in Old Spain, were hastened to the Relief of Naples, at that Time besieged by the French. Provisions growing scarce, the useless People were turned out of the City, to lessen the Mouths;

\footnotetext{
${ }^{48}$ As Cristobal Silva argues, early settlers justified colonization by obscuring or reimagining smallpox's timeline. They did not bring smallpox; rather, smallpox proved the righteousness of English colonization and rule. See Miraculous Plagues, chap. 1. For more on how colonists used disease to construct Native Americans as physically and constitutionally unfit to the American environment and thereby sanctioned colonial rule, see Joyce Chaplin, Subject Matter, chap. 5. Lawson's antipathy towards cold water derives from a humoral model of disease, in which cold water endangered the important cleansing act of perspiration (hot water also endangered the body by opening the pores too much). For more on humoralism and disease in the New World, see Parrish, American Curiosity, chap. 2. See Kathleen M. Brown, Foul Bodies on early modern beliefs about water and health.
} 
amongst these, the Curtesans were one part, who had frequently embraced the Spaniards, being well fraught with Riches by their new Discovery. The Leager Ladies had no sooner lost their Spanish Dons, but found themselves as well entertained by the French, whose Camp they traded in, giving the Mounsieurs as large a Share of the pocky Soils within their own Lines, as the Spaniards had, who took the Pains to bring it in their Breeches as far from America...The Siege was raised; the French and Spaniards retreating to Flanders, which was a Parade of all Nations; by which Means, this filthy Distemper crowded itself into most Nations of the known world. (25-26)

At its core, this passage delivers the conventional narrative: Spaniards bring syphilis from the West Indies to Naples, where it takes root and expands across Europe. Yet Lawson transforms this routine story into a comedy that cashes in on economic and physiological puns. Syphilis spreads through sexual transactions, whether between Native American women or European courtesans. The "Riches" the Spanish import to finance such trade include not only gold spoils but "pocky Soils," while the "Pains" they take to bring gold "in their Breeches" is quite literal. Whereas the Sewee narrative uses greed to erase the relationship between European disease and depopulation, the Columbian origin narrative uses humor to rationalize, defang, and ultimately tame the relationship between greed and, syphilis. Its comic tone renders syphilis, greed, and, thus, colonization a farce rather than a tragedy, undercutting the horror of American colonization by painting the burden of disease as equal.

The last sentence, however, abruptly shifts tone, undermining the narrative's relationship between humor and control. It summarizes the disease's dissemination starkly: "by which means, this filthy Distemper crowded itself in most Nations of the known world." Like Sloane's similar 
phrase, "crowded itself" highlights syphilis' reflexive agency. ${ }^{49}$ Yet, unlike the relatively innocuous verb "spread," "crowded" implies a much pernicious agency that not only advanced across the globe but also actively colonized it. Lawson's version of the Columbian origin story, therefore, condenses a relationship between trade, colonization, and disease. More importantly, this story reverses colonization's direction: Europeans colonized the Americas in pursuit of material wealth, but syphilis used those very same trade routes to colonize them. ${ }^{50}$ Though Lawson ridicules the Sewee for believing that they could travel to Europe, the drastic shift in tone at the end of this transactional passage reveals that some Americans-albeit, not humanshad survived the journey. It suggests that neither the natural history nor the imperialism it supported could codify, classify, or ultimately control syphilis.

Yet this is not the only narrative of syphilis. In fact, Lawson places the conventional Columbian origin story within an alternative, Santee paradigm. Unlike the Sewee narrative, this paradigm refuses to justify colonization, resisting the natural history's imperialism. Only a few nights into his journey, Lawson meets "the King of the Santee Nation" and the group's "chief Doctor" (25). The doctor, Lawson writes, "had the Misfortune to lose his Nose by the Pox" (25). This comment leads to a description of syphilis, the Columbian tale discussed above, and eventually the man's own narrative:

49 Though Lawson clearly identifies some of the human actors of these transactions, notably, none are English. Lawson here contributes to the "black legend" of Spanish colonization, which deflected all colonial atrocities onto the Spanish. By absenting the English in this passage, Lawson attempts to absolve both their blame for syphilis' dissemination and colonization more broadly. For more on the black legend, see Charles Gibson, The Black Legend. For how other Europeans, including the English, leveraged the black legend to legitimate their colonization, see Margaret R. Greer, Walter D. Mignolo, and Maureen Quilligan, Rereading the Black Legend. ${ }^{50}$ See note 4 on how syphilis was envisioned as retribution for colonization and slavery. 
our Doctor, who in the time of his Affliction with drew himself (with one that labour'd under the same Distemper) into the Woods...After these two had performed their Cures at no easier Rate than the Expence of both their Noses, coming again amongst their old Acquaintance so disfigur'd, the Indians admir'd to see them metamorphos'd after that manner; enquir'd of them where they had been all that Time and what were become of their Noses? They made Answer, That they had been conversing with the white Man above (meaning God Almighty) how they were kindly entertained by that Great Being; he being much pleased with their Ways, and had promised to make their Capacities equal with the white People in making Guns, Ammunition, \&c. in Retalliation of which, they had given him their Noses. (26-27)

In this story, two indigenous men choose to forfeit their noses through a pact with the Christian God. In exchange, God promises to give them the knowledge and power to manufacture guns and engage in European warfare. As in the Columbian narrative, syphilis figures as a product of trade, but syphilis coordinates with indigenous Americans to avenge colonialism. Though Lawson frames this story as an absurdity, asserting "the Indians" are "an easy, credulous People, and most notoriously cheated by their Priests and conjurers" (27), he nonetheless reveals an alternative paradigm of syphilis. On the one hand, by exposing Native peoples as gullible, Lawson bolsters his and a more general European authority. On the other hand, this tale empowers the Santee. Whereas the Sewee narrative faults indigenous people for their own genocide, the story of the "no nose doctor" envisions syphilis as empowering, a co-conspirator in the fight against colonization.

In particular, syphilis' most visible, unavoidable, marked symptom — the absent nose — is a source of wonder and power rather than a "Misfortune." Though Lawson claims the men are 
"disfigur'd," the Santee instead "admir'd to see them metamorphos'd" (26). In their seminal study, Narrative Prosthesis, Sharon Snyder and David Mitchell argue that disability frequently functions to catalyze narrative, propelling a plot or defining a character. Whereas Snyder and Mitchell emphasize how physical difference requires narration to understand, narrate, and ultimately normalize it, here, it is not necessarily the absent nose that requires explaining but the man's prominent cultural position. He is not stigmatized and ostracized as he would be in Europe; rather, he's afforded a prominent cultural position, dressing in fine clothes and convening with white colonials like Lawson as a second to the "King." And, it is this relationship between disease, visible disability, and power that Lawson feels the need to explain. The "no nose doctor" may not have liberated people from European imperialism, but he and his narrative resisted the natural historian's imperialism. He is empowered by what he lacks; physical difference becomes the source of his power rather than its flaw. That is, syphilis need not colonize. It could conspire, collude, and create, resisting colonization as well as colonizing rhetoric.

As before, the emplotment of these two syphilis stories is important: the empowering Santee narrative contains the Columbian tale, rather than vice versa. Lawson first introduces the "no nose doctor," then he outlines the Columbian tale. Finally, he ends with the noses-for-guns story. In other words, the Santee narrative of syphilis contains the European one. A frame should function to control or authenticate the knowledge it contains. For example, a Royal Society scientist might deliver a Native or African account of a disease or plant, but his authenticating persona and rhetoric would frame this explanation. While such non-European knowledge could bolster his credibility and authority, it only did so if it was carefully controlled through the correct literary protocol. Lawson, therefore, should frame and contain the Santee narrative, but 
his plotting constructs the opposite: the indigenous story frames the European one. He might nest the Columbian tale within the Santee narrative to minimize colonization's negative effects, intentionally resolving ambiguity and anxiety with a humorous tale about gullible indigenous Americans. On the other hand, each of the stories discussed here-the Sewee quest, smallpox's impact, the Columbian origin, and the no nose doctor — are framed by the travel narrative portion of Lawson's history. The layering of stories within stories, especially indigenous stories, subverts the chronology of the travelogue, taking the reader further and further away from the primary action. These stories may logically develop from Lawson's travel, but they also detract from his movement, credibility, and, thus, the form itself. Like Sloane's missing names, contradictory sources, convoluted syntax, and reflexive pronoun, this discordant emplotment and ineffective frame suspend the natural history's imperial ability to master and control syphilis "itself."

Syphilis, therefore, colonizes Lawson's natural history, crowding itself into the text. This crowding undermines his attempts at textual control, especially his frame and plotting, and reverses colonization's direction, attacking European bodies, lands, and markets. Lawson includes these narratives - the aborted Sewee trip, the Columbian origin, and the Santee doctorto authenticate his natural history and thereby justify colonization. Yet these stories subvert his purposes, suggesting that neither natural history nor imperialism can effectively master and control Americans' representations of themselves, whether those Americans are human or not. In particular, the Santee no-nose doctor reveals an alternative paradigm for understanding diseaseone of the natural history's primary functions. As the Santee proclaim, the relationship between humans and nonhuman disease need not be colonial or imperial, need not necessarily require 
mastering it through natural historical form and ideology. Instead, the experience of illness could be one of coordination, conspiracy, and resistance.

\section{James Cook's Journals: Syphilis Itself Develops an Ethics}

The natural history can never fully narrate, never fully control syphilis. No genre can. Even the Santee's paradigm does not exhaust the disease or the experiences of illness. Still, in the early modern era, the natural history tried the hardest to pin syphilis to the page like an insect or plant specimen sent to Linnaeus. Captain James Cook was not a natural historian, nowhere near as learned as Sloane nor as practiced as Lawson. Nonetheless, Cook increasingly employs the genre over the course of his three voyages and journals to the South Seas. In particular, he uses the form and ideology to manage both his own and his nation's colonial legacy, especially their legacy of spreading venereal disease.

Whereas Sloane and Lawson chronicle syphilis in the Atlantic world, Cook's journals range the Pacific, chronicling regions as distant as New Zealand and Alaska. Atlantic colonials could locate syphilis' origins in the region (if somewhat speciously), but Pacific colonials like Cook truly believed that they were responsible for importing syphilis to new regions and populations. As part of a Royal Expedition, moreover, Cook understood that his and his crew's interactions would "serve[] as parables of Europe's scientific, civilizing mission," a reflection and a portent of England's relationship with the Pacific world. ${ }^{51}$ Cook, therefore, attempts to regulate his sailors' sexual behavior and the record of that behavior. Yet both real and textual regulations fail. Instead of mastering syphilis and his own self-representation, Cook's journals settle into an unease that reminds us not only that we cannot fully understand syphilis but also

${ }^{51}$ Clayton, "Captain Cook and the Spaces of Contact at Nootka Sound," 114. 
that this unease represents an ethical response to the limits of human knowledge, imagination, and mastery. Syphilis represents what Timothy Morton might call a "strange stranger": "The more we know them, the stranger they become." ${ }^{52}$ The natural history attempts to domesticate the strange stranger, but syphilis posits an alternative epistemology and ethics: unease or disease. $^{53}$

Cook's bibliographical history is complex. He wrote his first journal (1768-1771) for his naval superiors, but the Admiralty gave it to John Hawkesworth to edit and publish.

Hawkesworth, however, added and subtracted freely from the original, combining it with Joseph Banks's account to create a popular but embellished publication. ${ }^{54}$ After learning of Hawkesworth's cavalier construction in 1775 when he returned from his second voyage (17721775), Cook sought an editor, John Douglas, to produce a more accurate and polished rendering of his most recent travels. The pair published A Voyage Towards the South Pole and Round the World (1777), which transformed the log and journal that Cook kept while in the Pacific into a more cohesive narrative. ${ }^{55}$

As Cook exerted more control over his narrative, he began to actively model his persona, syntax, and structure on the natural history. In Colonizing Nature, Beth Fawkes Tobin argues that the difference between the second voyage's original log and journal and the published account was not merely stylistic; rather, Cook and Douglas embraced "literary, natural history,

\footnotetext{
${ }^{52}$ Morton, The Ecological Thought, 41.

53 S. Scott Graham uses the term "dis-ease" to describe the way the modern pharmaceutical industry has medicalized "normal," human experiences, crafting "dis-ease" into "disease." I use the term to identify how syphilis' inaccessible reality discomfits the natural history genre and posits that discomfort as an ethical response to the limits of human knowledge.

54 Joseph Banks served as the natural historian on Cook's first voyage. Like Sloane, he would eventually preside over the Royal Society. See his Endeavour Journal.

55 Phillip Edwards, Introduction to The Journals of Captain James Cook, x-xi.
} 
and aestheticizing practices that would transform his 'mere' record into a learned and culturally sophisticated product" (145). Natural historians, like his own-Joseph Banks and George and Johann Forster - were usually learned gentlemen, but Cook was a military man from middling, if not low, rank. Because natural history was not natural to Cook, Douglas encouraged stylistic changes engineered to manufacture the proper form and rhetoric. According to Tobin, they, therefore, "removed the processes by which he apprehended the unknown, and in particular he excised references to his body and its engagement with the process of knowing" (145). Although "this distancing strategy was in keeping with the dislocating techniques of Enlightenment experimental science," it also "undermined" that crucial authenticating function of natural histories: the eyewitness (Tobin 167). While I disagree with Tobin's assertion that the natural history strove to eliminate the presence of the writer - as Daston and Galison have shown, the person of the scientist was vital in discerning nature's truths before the nineteenth centuryCook's journals do increasingly employ natural historical conventions over time, shifting away from the log format of his first journal. Tobin suggests that these changes made $A$ Voyage less visceral and exciting for the reader, but they also enabled Cook to master his own narrative and representation through natural historical conventions.

Though Cook died before publishing his final journal, even its unpublished, unedited form suggests that he was aiming to produce a text akin to the polished natural history, A Voyage Round the South Pole. ${ }^{56}$ In particular, this final journal reads less like the Captain's log of his

\footnotetext{
${ }^{56}$ Cook famously died in 1779 at the hands of native Hawai'ians on his third and final voyage. Exactly what happened leading up to the murder remains unclear. Marshall Sahlins has argued that the indigenous people took Cook to be a god, Lono, who was ritually murdered every year (that Cook's body and bones were afforded particularly special treatment seems to support this argument). See Islands of History, chap. 4, and How "Natives" Think: About Captain Cook, For Example, chaps. 1 and 2. In The Apotheosis of Captain Cook, especially chap. 5, Gananath Obeyesekere contends that it was the English who made Cook into a god; this colonial
} 
first and more like a book. It eschews ship's time, distance, and winds - formal linchpins in the first two - and instead uses civil time and a retrospective, summative point of view. That is, he was composing even his initial drafts with publication in mind. Still, despite this care and attention, his original journals would not be published until James Beaglehole edited them in the mid-twentieth century. Even then, Beaglehole had to choose between multiples drafts and versions of each voyage, except the last. Though extant texts may never reflect Cook's intentions - and any arguments must be necessarily tentative — he clearly imagined the natural history as the form to not only narrate but, more importantly, master his experiences.

The natural history especially served his desire to discipline unruly bodies. While Tobin argues that Cook's second and third journals "excise" his body, each of his journals is preoccupied with bodies, health, and disease. In fact, Cook was famous for making the health of his crew a priority. ${ }^{57}$ Though many Captains delegated matters of health to their doctors or surgeons, Cook played an active role in his sailors' well-being, expending significant resources on that scourge of the seas: scurvy. ${ }^{58}$ He understood that this occupational disease could destroy his crew and threaten the entire voyage. After arriving in Tahiti early during his first voyage, Cook takes time to remark upon the ship's general health. He writes, "we had but a very few men

\footnotetext{
framework had existed among Europeans since at least Cortes. Yet others, like James Watt, have suggested that Cook's death may have been precipitated by a vitamin B deficiency, which could have led to the uncharacteristically erratic behavior that preceded his death and colored his final relations with his crew and the Hawai' ians.

57 See Watt, "Medical Aspects and Consequences of Cook's Voyages."

${ }^{58}$ Scurvy is a disease of malnutrition caused by low or nonexistent vitamin $\mathrm{C}$ absorption. Its symptoms include weakness, lethargy, gum disease (including red, bleeding gums, spotted or pimpled tongues, and, eventually, loss of teeth), bone deformities, delusions, emotional extremes, and death, among others. Scurvy was a common and deadly disease during the exploration age. For more on the relationship between the disease and colonization, see Jonathan Lamb, Scurvy: The Disease of Discovery.
} 
upon the Sick list." ${ }^{59}$ Rather than luck, Cook cites his preemptive, prescribed diet of "sour krout, Portable Soup and Malt" for preserving the crew (38). Proactively searching for evidence of the scorbutic, Cook mandated that any man with "the least symptoms of Scurvy upon him" receive even more of these rations (38). ${ }^{60}$ Though scurvy represented a common yet serious illness, Cook is clear and confident in his preventative measures. Most importantly, he is successful: "by this Means and the care a Vigilance of MR Munkhous the Surgeon this disease was prevented from getting a footing in the ship" (38). While Cook could not have cured all cases of scurvy, he clearly believed that with the proper supplies, support, and implementation he could control disease and keep his crew healthy and safe. ${ }^{61}$ Moreover, his attention to scurvy demonstrated his ability to observe, identify, theorize, act, and record — all values of the natural history.

If scurvy proved manageable, however, syphilis proved utterly uncontrollable. And, if scurvy highlighted Cook's natural historical conventions, then syphilis ruptured them. ${ }^{62}$ In the

${ }^{59}$ Cook, The Journals of Captain James Cook, vol. 1, 38, hereafter cited parenthetically. Though Hawkesworth published a highly edited version of the first voyage, I use Beaglehole's edition throughout this chapter. Though Beaglehole also compiled multiple copies of the journal, his edition does not include Banks's language as Hawkesworth's does.

${ }^{60}$ See Watt,' "Medical Aspects and Consequences of Cook's Voyages," 146-47. Cook, Watts argues, sought not only to replenish vitamin C but to conserve it: "Cook's policy of short sea passages and frequent calls for fresh food rich in the vitamin ensured saturation of the body pools... Cook also reduced the rate of vitamin $\mathrm{C}$ utilization by providing his men with dry, warm clothes and putting them into three watches, thus significantly reducing stress, which increased requirements" (146).

${ }^{61}$ While the sour kraut contained vitamin C, malt did not and, thus, could not have cured scurvy. It could, however, cure vitamin B deficiency, which presents with similar symptoms as scurvy. Watt bemoans the fact that Cook emphasized malt to the exclusion of lemon juice, arguing that because Cook had such a reputation for health, his endorsement of malt impeded research into lemon juice and cost many lives. Yet even "true" natural historians like Joseph Banks were unsure about lemon; though Banks "flew to the lemon juice" when sour kraut failed to abate his symptoms, remarking on the "surprising" speed and efficacy of the cure, he nonetheless abandons this treatment and its scientific repercussions (n.pg.). See Watt, "Medical Aspects and Consequences" and The Endeavour Journal of Sir Joseph Banks.

62 Watt argues that by the third voyage the crew certainly was spreading and infecting natives with gonorrhea, given its short incubation period, but also was probably spreading 
first voyage, after some of his men develop symptoms of venereal disease, he reflects, "I had taken the greatest pains to discover if any of our Ships Company had the disorder upon him for above a month before our arrival here and ordered the Surgeon to examine every many the least suspected" (56). In this passage, Cook envisions himself as a proactive agent against syphilis, scouring his crew for the minutest evidence of infection. Over the course of his three voyages, Cook would try to limit the time his men spent on land, forbid women from entering the ship, and lash men who knowingly spread the disease - all with the intention of preventing syphilis' dissemination. Clearly, Cook understands that his voyage and his crew were responsible for spreading venereal disease. By framing himself as an observant Captain that imposed strict physical regulation, Cook attempts to deploy the same natural historical protocol against syphilis as he did against scurvy. In so doing, he aims to protect not only indigenous peoples from infection but also his voyage's legacy and the entire imperial project.

Yet venereal disease still spread. While in the first voyage Cook could still hope that another European crew was responsible for introducing syphilis to the South Seas, by the end of the third voyage, it was clear that his crew were active agents in its spread. Failing to regulate the material disease, Cook attempted to control it textually:

they [indigenous Tahitians] likewise say that these Ship[s] brought the Venerial distemper to this Island where it is now as common as in any part of the world and which the people bear with as little concern as if they had been accustomed to it for ages past. We had not been here many days before some of our people got this disease and as no

lymphogranuloma venereum, chancroid, and syphilis. In fact, many members of the third voyage were being re-infected by venereal diseases either they or their countrymen had left during the previous two voyages (Watt 149-53). At the time, all of these diseases were called simply "venereal distemper," the phrase Cook uses throughout his voyages. 
such thing happen'd to any of the Dolphins people while she was here that I ever heard off, I had reason (notwithstanding the improbability of the thing) to think that we had brought it along with us which gave me no small uneasiness and did all in my power to prevent its progress, but all I could do was to little purpose for I may safely say that I was not assisted by any one person in $\mathrm{y}^{\mathrm{e}}$ ship, and was oblige'd to have the most part of the Ships Compney a Shore every day to work upon the Fort and a strong guard every night and the Women were so very liberal with their favours, or else Nails, Shirts, \& $c^{\text {a }}$ were temptations that they could not withstand, that this distemper very soon spread it self over the greatest part of the Ships Compney but now I have the satisfaction to find that the Natives all agree that we did not bring it here. ${ }^{63}$

Here, Cook tries to understand how syphilis was introduced to Tahiti. Strikingly, this passage is only three sentences, the second of which both shoulders and displaces blame. Though this sentence begins with proof of the Tahitians' explanation (the crew catches syphilis after being on the Island), it immediately undermines this causal relationship by citing the Dolphin, whose crew never contracts the disease. Cook, therefore, is forced to suspect his sailors as the source, a thought that makes him "uneasy." He had tried "all in [his] power" to prevent this, but, he lists, none helped him, and he needed men ashore to build the fort, and, after all, the women were especially "liberal" in their sexual "favours." ${ }^{44}$ At the end of this anxious sentence, Cook concludes in a counter-intuitively confident assertion that he has "the satisfaction to find that the

\footnotetext{
${ }^{63}$ Cook, The Journals of Captain James Cook, vol. 3, 55-56, hereafter cited parenthetically. ${ }^{64}$ Joseph Banks also described the "free liberty of love" in the South Seas in his Journal (n.pg.). Though Banks and Cook were shocked by native women's sexual liberty, many of these women sought relations with Europeans to improve their status and the status of any potential offspring. For more on the sexual interactions and exchanges in these voyages and of South Sea Islanders more generally, see Margaret Jolly, "Desire, Difference and Disease."
} 
Natives all agree that we did not bring it here.” Though the Tahitians may "all agree," Cook's own narrative, even this single sentence, does not. He claims that he has "the satisfaction" to have cleared himself and his crew of spreading syphilis and to have resolutely deduced syphilis' origin as a good natural history should. Yet, while the Royal Society urged circumspection on the unknown, this overwrought, circuitous sentence only emphasizes the limits of Cook's knowledge and mastery. This passage's unease runs deeper than colonial guilt, even deeper than European prejudice. Syphilis' uncertain origin and uncertain spread-syphilis “itself”-dis-eases this passage.

Syphilis dis-eases the relationship between the natural history and "satisfaction." That is, it unsettles the genre's ideological commitment to satisfactory and satisfying knowledge. Cook initially claims to be satisfied by this story, to be sated by syphilis' narrative resolution: "now I have the satisfaction to find that the Natives all agree that we did not bring it here" (56). Yet he quickly revises this argument, admitting, "However this is little satisfaction to them who must suffer by it in a very great degree and may in time spread itself over all the Islands in the South Seas, to the eternal reproach of those who first brought it among them" (56). Knowledge of the disease's origin does not make the experience of illness any better; knowledge doesn't necessarily lead to a better world. In this revision, Cook unwittingly unravels the core tenet of natural history - that the careful collection of the world would eventually lead to perfect knowledge and, thus, a perfect world.

Moreover, "spread itself" is also revised here. The first iteration moves through the European crew, while the second moves through Pacific islands. Undoubtedly, Cook is attempting to distance himself from the disease, especially when he damns those "who first brought it" to the Pacific - a "who" that evidently doesn't include him. The second use, however, 
replaces humans with locations, distancing Cook and the text from the human consequences of disease and colonization. In other words, it is natural historical, affecting the distance between observer and observed that the form's conventions engendered required. Whereas the second "satisfaction" undermines the genre, the second "spread itself" seems to support it. Still, both of these contradictory realities exist in Cook's natural history-in the same sentence even. It is in this contradiction and oscillation that syphilis asserts itself, unsettling and dis-easing the genre.

In unsettling the genre, syphilis posits dis-ease - the discomfiting recognition of the limits of human knowledge, control, and imagination - as an ethical response to the experience of illness. He writes,

As there were some venereal complaints on board both the Ships, in order to prevent its being communicated to these people, gave orders that no Women, on any account, were to be admited on board the Ships, I also forbid all manner of connection with them, and order'd that none who had the venereal upon them should go out of the Ships. But whether these regulations had the desired effect or no time can only discover. It is no more than what I did when I first visited the Friendly Islands yet I afterwards found it did not succeed, and I am much afraid this will always be the case where it is neccesarry to have a number of people on shore; The opportunities and inducements to an intercourse between the sex, are there too many to be guarded against. It is also a doubt with me, that the most skillful of the Faculty can tell whether every man who has had it even is so far cured as not to communicate it further, I think I could mention some instances to the contrary. It is likewise well known that amongst a number of men, there will be found some who will endeavor to conceal this disorder, and there are some again who care not to whom they communicate it... (532) 
In this passage from his final, fateful voyage, Cook admits the obstacles to preventing syphilis' transmission: the impossibility of ending contact between the sexes, the admitted limits of medical knowledge, and the deviant men who purposefully spread the disease.

Though Cook certainly cites these obstacles in an attempt to mitigate blame and guilt, his retrospective perspective and dejected tone remind readers that these regulations were bound to fail - that neither natural historical nor medical regulations control syphilis. Even "the most skillful of the Faculty" struggle "to tell whether every man who has had it even is so far cured." This point does not absolve Cook or imperialism more broadly for their role in syphilis' transmission to the Pacific. Rather, it highlights the limits of the natural history to secure mastery over syphilis and over colonial history and literature. Syphilis ruptures the natural history and its "utopian, innocent vision of European global authority" (Pratt 39). It exposes the relationship between natural history and imperialism: faith in European mastery of the human and nonhuman world.

Instead of mastery, syphilis posits uncertainty — unknown origin, etiology, symptoms, and cure. In the context of the natural history and modern science, uncertainty is not necessarily negative, but it is temporary. What is unknown someday will be known. In Cook's journals, however, syphilis reminds us that uncertainty is not only inevitable but ethical — anti-imperial even. Syphilis highlights the limits of human knowledge as well as the relationship between such knowledge and imperialism, pointing toward but never revealing all that we cannot know.

\section{Conclusion}

When syphilis slips Cotton Mather's authorial intentions, seeping into other chapters to reveal symptoms and treatments, the disease writes itself. Mather denounces syphilis and its 
victims, claiming "Your Foul Disease is too filthy and odious to have the nasty symptoms of it mentioned," and "As for any Remedies...you are so Offensive to me, I'll do nothing for you." 65 Mather's refusal to divulge symptoms and cures represents a radical break from the rest of The Angel of Bethesda, especially in a text so devoted to description, collation, and control. Yet, by medical compendium's close, Mather discloses both. Though the reflexive pronoun may not appear in The Angel of Bethesda, these textual inconsistencies are also symptoms of dis-ease, of our inability to fully account for syphilis' intra-action. Mather fears that syphilis will "stain" his text, and it does.

Syphilis undermined the natural history's rhetorical conventions, rupturing its ideological assumptions in the process. Though the natural history attempted to close the gap between words and things themselves, syphilis itself both withdraws from representation as in Sloane's blank spaces and missing names and represents alternatives to colonization like Lawson's no-nose doctor. Moreover, syphilis itself subverts the paradigm of mastery that guides Cook and undergirds natural historical imperialism. Each of these writers probably desired a syphilis itself, an agential disease that absolved them of their own agency, an early modern germ theory of history. Yet, even if they had purposefully imbued the disease with agency, they should be able to control its representation. Between missing names, confusing syntax, contradictory sources, alternative narratives, and shifting tone, syphilis intra-acts not simply with the natural history but to form the genre, instilling uncertainty and even anti-imperialism at its core. It transforms representation of the thing itself into the partial thing itself. Though I do not return to the reflexive pronoun in each of the following chapters, the paradigm of disease itself nonetheless guides the remainder of this argument.

${ }^{65}$ Mather, The Angel of Bethesda, 118, 120. 
Ultimately, the pronoun "itself” undermines “it." As much as we cannot know Treponema pallidum, even with modern science, we cannot understand the lived experience of syphilis. What represents a "Misfortune" to some, as Lawson's Voyage reminds us, might represent a pact with God or resistance to colonization to others. Syphilis dis-eases the natural history's certainty, its faith that it can and will fully know the human and nonhuman world, but "itself" remembers that uncertainty is ethical, especially when "it" and "I" hang together as one. 


\section{Chapter Two: An Inoculated Body Politic: Inoculation as Metaphor and Agent}

When John Winthrop described the Puritan Massachusetts Bay Colony as "the most perfect and best proportioned body in the world... without spott or wrinkle," he drew on a longstanding tradition of understanding political and social collectives through the individual, physical human body — the body politic. ${ }^{1}$ Medieval political philosophers, seeking to reconcile divinity with corporeality, argued that the King had two bodies: a natural or physical body and the divine body, which superseded the mortal coil and included the entire state. By the seventeenth century, however, as Thomas Hobbes's Leviathan famously imagines, the King represented the head of the body politic, collecting and controlling the many unruly bodies that composed the state. Extending and distending the borders of the body politic, American colonization threatened this tenuous cohesion and thereby threatened the head's power and regulation. Moreover, the individual colonist's American experiences, including disease, famine, disaster, and abandonment, frequently alienated them from both English identity and the English body politic. $^{2}$

It should not be surprising that our metaphors are framed by our bodies, that we understand political collectives through our most fundamental lens for perceiving and ordering the world. ${ }^{3}$ Yet it also should not be surprising that this relationship is reciprocal: our metaphors also shape our bodies. For example, the way we describe disease affects lived experience;

\footnotetext{
${ }^{1}$ Winthrop, "A Modell of Christian Charitie," 40, emphasis in original.

${ }^{2}$ On the King's corporeal and divine bodies, see Ernst Kantorowicz, The King's Two Bodies. For more on the relationship between American colonization and the body politic, see Jim Egan, Authorizing Experience and Kathleen Donegan, Seasons of Misery.

${ }^{3}$ For the seminal work on bodies and metaphors, see George Lakoff and Mark Johnson, Metaphors We Live By.
} 
metaphors can cure and kill. ${ }^{4}$ Similarly, literary critics and historians have shown how changing medical knowledge and biological experiences of illness transformed how real communities of people identified themselves and others. ${ }^{5}$ This chapter extends the relationship between the human body and metaphor even further, arguing that microbes like the variola virus also shaped experiences of illness, the metaphors drawn from them, and the communities those metaphors warranted.

The variola virus, or smallpox, was one of the most important agents in the history of the Americas. It devastated Native American populations, seeming to divinely-sanction American colonization - to the New England Puritans at least. ${ }^{6}$ Yet the virus that caused smallpox was not singular. Scientists believe that sometime during the eighteenth century the virus diverged into its two modern strains, Variola major and Variola minor. Some have argued that human migration to the Americas pressured the disease to moderate, while others have suggested that it was inoculation and vaccination that moderated it. Regardless of which evolved the disease, it seems clear that human actions shaped the microbe. My argument, however, probes the inverse: how microbes like the variola virus shaped humans, human collectives, and the metaphor they used to understand that collective- - the body politic. ${ }^{7}$

\footnotetext{
4 "Metaphors can kill," Lakoff asserts in the opening line of his essay "Metaphor and War," arguing that language and metaphors power real-world consequences. On how metaphors can stigmatize illnesses like cancer and AIDS and, thus, adversely affect access to treatment and outcomes, see Susan Sontag, Illness as Metaphor and AIDS and Its Metaphors.

${ }^{5}$ See, for example, Cristobal Silva, Miraculous Plagues, and Priscilla Wald, Contagious. While Wald analyzes late-nineteenth- and twentieth-century American culture, and Silva examines colonial New England, both show how illness shaped ideas about American communities. ${ }^{6}$ See Silva, Miraculous Plagues, chap. 1 on the way disease shaped justification narratives. See also pp. 5-7 in the introduction for critical debate on the relationship between smallpox, indigenous Americans, depopulation, and colonization.

${ }^{7}$ For the standard history of smallpox's evolution and eradication, see Crawford, Deadly Companions, 106-11, and Arno Karlen, Man and Microbes, 38, 48-49, and 109. For new developments in our understanding of the disease's evolution, see Duggan, et al., "Seventeenth
} 
In particular, inoculated smallpox simultaneously enabled and resisted a paradigm of a bounded and bordered body politic. Although inoculation had been used in China and throughout the Muslim world for centuries, it did not become widespread in Europe and the Americas until the eighteenth century. ${ }^{8}$ The procedure itself varied, but it always required placing infectious material into an uninfected person's body. In the West, this was usually accomplished through an incision in the skin. By absorbing the disease through an abnormal avenue - the skin rather than the lungs - inoculation moderated smallpox, producing a minor skin irritation rather than a dangerous systemic infection. Inoculation clarifies Karen Barad's theory of intra-action, demonstrating how the collision and collusion of bodies could be made to reify the difference between those bodies. On the one hand, inoculation made smallpox and human inseparable, literally forging immunity in tandem. On the other hand, its function was to mediate and control this inseparability, to divide the human body into inside and outside, self and other. In this way, inoculation enabled a body politic with complex, even contradictory borders. While Europeans and colonial Americans undoubtedly employed inoculation to shore up their individual and collective identities, inoculated smallpox escaped their social and literary control. Its materiality — the way it paradoxically reified and dissolved borders — made it an uncertain medical technology and an uncertain metaphor.

The first section of this chapter develops how inoculation transformed real human bodies and metaphors about human bodies, while the second analyzes how these transformations shaped the metaphor of the body politic with real consequences. Beginning with Cotton Mather's The

\footnotetext{
Century Variola Virus Reveals the Recent History of Smallpox," and C. Thèves, et al., "The Rediscovery of Smallpox." For an analysis of both of these studies, see also Joel O. Wertham's "Viral Evolution."

${ }^{8}$ See Donald R. Hopkins, The Greatest Killer for nonwestern references, understandings, and treatments of smallpox.
} 
Angel of Bethesda, the first section focuses less on the thoroughly criticized 1721 Boston inoculation controversy and more on one of Mather's rationales for supporting inoculation so ardently, even after a grenade was thrown through his window: animalcules. Mather's protomicrobial theory transformed the human body into a "citadel"—a fortress with a clear internality that required the policing of external invaders. He employs "the citadel" to explain how inoculation worked, but inoculated smallpox confounded this metaphor as much as it enabled it, confusing the line between internal and external, self and other. Inoculated smallpox rewrote the human body and the metaphorical potential of that body, simultaneously powering and challenging Mather's usage.

The second section of this chapter, then, tests how this inoculated smallpox transformed the body politic by closely examining another early American site, Charlestown, South Carolina. Between 1758-1761 elite white Carolinians attempted to deploy inoculation as a metaphor to delineate the border between themselves and nonwhite others, to order and control their colony's chaos. In their letters and diaries, coastal slaveholders like Dr. Alexander Garden and Eliza Lucas Pinckney describe a colony on the verge of collapse, threatened from within by enslaved Africans and African Americans and from without by Cherokees. Although South Carolina was also endangered by fractures among whites, they wielded inoculation as a metaphor to elide their own differences and cohere as a province by externalizing nonwhites and delineating and policing the colony's borders. Smallpox and inoculation, however, permeated and resisted borders, whether of colonial territories or individual bodies, of white metaphors or racist intentions, challenging their own use as metaphors. In particular, the material circumstances of this epidemic, including its uncommon course and inoculation's failures and restrictions, actively subverted a racialized division of interior and exterior, highlighting fissures among whites and 
the extent to which nonwhite enemies were "internally" produced through white policies and actions.

It is a central insight of disability studies that metaphors and literature shape lived experiences of disability and illness, but this chapter aims to show how nonhumans also shaped those metaphors that shaped lived experiences. While white metaphors undeniably wrought material consequences, smallpox and inoculation demonstrated that the power of metaphor was not restricted to white peoples, that Cherokees, enslaved Africans, that even microbes and medical innovations shaped the material and metaphorical contours of the colony. They demonstrated that those without power, even without state-sanctioned humanity or personhood, could and did transform the contours of early American lives, history, and literature. If we are to revise those metaphors that frame how we live bodily difference, as well as how bodily difference structures the body politic, then we must extend our physical, historical, and literary borders to include the intra-active, trans-corporeal agency of disease.

\section{Inoculated Bodies: Animalcules and the Citadel in Mather's The Angel of Bethesda}

In the early eighteenth century, nearly all medical practitioners, whether formally trained or not, ascribed to some variation of humoralism, which maintained that a person's physical and emotional predisposition could be influenced through diet, exercise, evacuation, and the environment. Illnesses were caused by internal imbalances of the humors and treated by diet, purges, and bloodletting. New diseases like syphilis, specifics like cinchona, and epidemics of the plague and smallpox all failed to depose the humoral paradigm's reign. Yet, when Mather peered through a microscope—or, more likely, read the reports of others who had peered through 


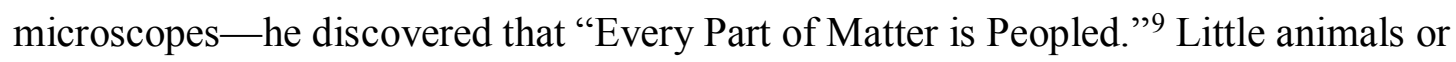
"animalcules" invisibly inhabited every surface and minute pore. These "unseen Armies of Numberless Living Things," Mather argues, are the divinely-sent source of all diseases, including smallpox (47). ${ }^{10}$ As Richard Harrison Shryock argues, Mather's animalcular theory may not have been inherently "unique"; what was "unusual" was "that he applied the hypothesis to a new field - to what would now be termed immunology." 11 That is, Mather innovated animalcular theory by applying it to inoculation, by using it to understand how inoculated smallpox could produce a weaker incarnation of the disease and still ensure lifelong protection. He did so through the metaphor of the citadel, which figured the human body as a fortress with clear, if porous borders. Mather's citadel, however, not only explains inoculation's mechanics but, more importantly, derives from those very same mechanics. Inoculated smallpox transformed the material body, which in turn transformed its metaphorical potential. But while Mather attempted to use the citadel to delineate clear borders between inside and outside, inoculated smallpox simultaneously enabled and confounded the difference between self and other.

Mather introduces animalcular theory in his seventh chapter, after a careful explanation of disease's providential origin but before his catalog of specific diseases. Grounding his argument in work by luminaries like Antonie van Leeuwenhoek and innovations like the

\footnotetext{
${ }^{9}$ Cotton Mather, The Angel of Bethesda, 43, hereafter cited parenthetically.

${ }^{10}$ Mather was the first to espouse such a proto-germ theory in the Americas, but his theory was built on the seed theories of Paracelsus and Van Helmont. See Jones, Introduction to The Angel, xi. Moreover, Richard Harrison Shryock argues in Medicine in America that Mather based his animalcular theory on the works of Athanasius Kircher, Antonie van Leeuwenhoek, and Benjamin Martin. On the relationship between the microscope and animalcular theory, see Catherine Wilson, Invisible World, chap 5.

${ }^{11}$ Shryock, Medicine in America, 253, 254.
} 
microscope, Mather describes these proto-microbes as minute, innumerable, and penetratingthe nearly invisible source of all disease, the physical corollary and vehicle of God's judgment. ${ }^{12}$ He writes,

Every Part of Matter is Peopled. Every Green Leaf swarms with Inhabitants. The Surfaces of Animals are covered with other Animals. Yea, the most Solid Bodies, even Marble itself, have innumerable Cells, which are crouded with imperceptible Inmates... The Animals that are much more than Thousands of times Less than the finest Grain of Sand, have their Motions; and so, their Muscles, their Tendons, their Fibres, their Blood, and the Eggs wherein their Propagation is carried on. The Eggs of these Insects (and why not the living Insects too!) may insinuate themselves by the Air, and with our Ailments, yea, thro' the Pores of our skin; and soon get into the Juices of our Bodies. (43)

Mather describes these animalcules as tiny and infinite, populating every possible "surface," whether leaf or person. Yet they do not simply sit on these surfaces but "insinuate themselves" into various bodies. As in the last chapter, the reflexive pronoun signals the animalcules' agency. Moreover, their insinuation reveals the human body's porosity. While humoralism also posited a porous body, Mather's animalcular theory envisioned discrete, external beings rather than internal imbalances as the source of disease. ${ }^{13}$ Taken together, this agency and porosity explain

\footnotetext{
${ }^{12}$ Silva argues that "animalcular theory was meaningful" to Mather "only insofar as it provided an opportunity to use science and medicine as evidentiary frameworks for theological conclusions" (Miraculous Plagues 159). While we cannot overestimate the importance of theology to all of Mather's beliefs, we also should not underestimate his investment in science and medicine. In addition to the preparationist doctrine that Louise A. Breen and Robert Tindol analyze, the animalcular theory of disease dissemination also helps to explain Mather's passionate defense of inoculation.

${ }^{13}$ Mather also maintained that disease derived from imbalances of the Nishmath-Chajim-the "Spirit... of a Middle Nature" that enabled communication between "the Rational Soul, and the Corporeal Mass" (Angel 177) — but he also argued that invasive agents like animalcules could provoke that imbalance. See "Nishmath-Chajim. The Probable Seat of All Diseases, and a
} 
how living things penetrated the human body "thro' the Pores of our skin," noting and bypassing the body's purported border, and created disease.

Mather returns to animalcular theory in his chapter on smallpox, arguing, "It begins now to be vehemently suspected that the Small-Pox may be more of a animalculated Business than we have been generally aware of. The Millions of ------ [sic] which the Microscopes discover in the Pustules have confirmed the Suspicion" (201). Elsewhere, however, he attributes the disease to a more conventional scapegoat, miasma. In a description of smallpox taken in the natural way, he contends, "The venomous Miasms (Lett That Word serve at the present) of the Small Pox, entering in to the Body, in the Way of Inspiration, are immediately taken into the Blood of the Lungs: And, I pray, how many Pulses pass before the very Heart is pierced with them?" (111). Miasma, the effluvium of rotting matter or swamp air, and animalcules may not have been an antithetical explanation for disease; perhaps the little animals were transmitted through miasma. ${ }^{14}$ Yet "miasma" had a far more ancient pedigree and entrenched culture than animalcules. In fact, Mather may employ this word for that very lineage, to warrant the radical and controversial procedure of inoculation.

More importantly, Mather emphasizes materiality rather than semantics. This miasmatic smallpox functions similarly to an animalculated smallpox: it is an external agent that infiltrates a porous and vulnerable human body. Mather compounds this similarity when he retreats from

General Cure for Them, Further Discovered" in The Angel, chap. 5. For more on the NishmathChajim, see Margaret Humphreys, "Vindicating the Minister's Medical Role."

${ }^{14}$ Miasmatic theory holds that certain environmental conditions, including swamps, rotting vegetable matter, and decomposing bodies, produced toxic gases that could poison humans and create epidemics. This theory was especially important in Philadelphia's 1793 yellow fever crisis, with climatists or localists arguing that the environment had produced the disease. See Apel's Feverish Bodies, Enlightened Minds, chaps. 1-3, on the intersection of miasma theory and yellow fever. 
his use of "Miasms," claiming parenthetically, "Lett That Word Serve at the present" (111). Here, Mather suggests that the word is an inaccurate, if serviceable placeholder to describe smallpox's etiology. In the context of his chapter on animalcular theory and a direct mention in his chapter on smallpox, Mather's use of "Miasms" does not necessarily undermine his argument for an animalculated smallpox or an animalcular theory of disease but instead might represent a rhetorical choice to make his argument more persuasive, signal the limits of language, or, most simply, indicate his own uncertainty over such a radical ontological and epistemological shift.

Thus, Mather introduces the citadel metaphor to describe inoculated smallpox - to justify its use by explaining how it worked. He writes,

What if we should find out a Way, that the Contagion of the Small-Pox, may not (by the Salival Juices, as tis commonly thought,) enter the Stomach, and make a furious and fatal Combustion in the Phlegmatic and Biliose Matter there, nor enter the Lungs more immediately, as with many perhaps it may; but enter by the Outworks of the Citadel, and carry off what it has to sieze with very gentle Symptoms, and when it reaches the Stomach in that Way yet be presently conquered with an easy Emetic there? (106-7) Mather asks, "what if" smallpox could enter the human body differently; "what if" those miasmas or animalcules could be induced to permeate "the Outworks of the Citadel" rather than the stomach or lungs, critical seats of human health? In this formula, the human body is a fortress that guards its perimeter against external enemies like smallpox through inoculation.

Mather's citadel was not necessarily unique. As Susan Sontag describes, "The fortress image has a long prescientific genealogy, with illness itself as a metaphor for mortality, for human frailty and vulnerability." 15 In this "prescientific" use, Michael C. Schoenfeldt argues, the

${ }^{15}$ Sontag, AIDS and its Metaphors, 96. 
fortress or castle symbolized health, which was "an edifice perpetually being constructed, and in need of continual maintenance."16 Typically, he contends, "the self is imagined as a castle fortified against its own insurrectionary forces"—-sinful impulses, psychological quagmires, and humoral imbalances (99). Building on this entrenched, humoral image, Mather claims a familiar language and credibility for his unfamiliar and incredible medical innovation. Yet he shifts this metaphor's focus from "insurrectionary" or internal enemies to external invaders. ${ }^{17}$ The body is not a "castle of health" at war with itself but an "Invaded Party" at war with an external, animalcular "Enemy" (112). By framing this radical innovation on the familiar metaphor as a question - "what if...?"-Mather attempts to mitigate his controversial take on the body, animalcules, and inoculation. Ultimately, he uses the metaphor and the metaphor-as-question to explain inoculation's material mechanisms and make a case for its widespread use.

The citadel, however, is not simply a metaphor for what inoculation does to the body-a rhetorical choice that Mather makes. Rather, inoculation remade the human body and, thus, remade the body's metaphorical potential. He returns to the citadel when he explains the difference between natural and inoculated smallpox, highlighting not just how the two forms of the disease differed, but also how inoculated smallpox radically transformed the human body. In natural smallpox, he argues, "the Enemy at once gott into the very Center of the Citadel: And the Invaded Party must be very Strong indeed, if it can struggle with him, and after all Entirely Expel and Conquer him" (112). Mather emphasizes animalcular theory’s division of inside/outside: external invaders strike at "the very Center." In inoculated smallpox, however,

16 Schoenfeldt, Bodies and Selves, 66, hereafter cited parenthetically.

${ }_{17}$ While many scholars in the medical humanities locate martial metaphors of disease in the modern, post-microbial era-see, for example, Sontag, AIDS and its Metaphors, Anne Hunsaker Hawkins, Reconstructing Illness, and Emily Martin-Mather reveals a much earlier genealogy for this usage. 
"Approaches are made only by the Outworks of the Citadel, and at a Considerable Distance from the Center of it" (112). While the "Enemy, tis true, getts in so far as to make Some Spoil...the Vital Powers are kept so clear from his Assaults, that they can manage the Combats bravely" (112). Natural smallpox vitiates the human body by attacking the "Vital Powers" like the stomach and lungs (the ultimate inside), whereas inoculated smallpox produces a few symptoms but proves easily conquered because it enters by the "Outworks of the Citadel," the skin. Though Mather did not understand precisely how inoculation worked, this metaphor works surprisingly well to explain the procedure's essential mechanics: inoculated smallpox produces a localized skin infection, which the immune system can neutralize easily, whereas natural, airborne smallpox produces a systemic infection that proves much more difficult for the body to "fight." The citadel metaphor, therefore, is more than an historical legacy, a response to a psychological threat, or a rhetorical device; it is the result of the way that inoculation materially transformed the human body. To put it differently, inoculated smallpox enabled, even revised and rewrote the familiar "castle of health."

Yet while inoculated smallpox warranted and even created the citadel paradigm, it also undermined it. Inoculation warranted the citadel metaphor because it allowed the human body to fortify itself against invasive smallpox; it became a citadel because it could no longer be invaded. At the same time, inoculation undermined an enclosed, impenetrable fortress-body because its isolation was a byproduct of its invasion; the human body became self-enclosed only after granting smallpox access to its interiority, by recognizing that the body is never really isolated. As Bernd Herzogenrath argues, "Mather sees the body as being enveloped by a permeable skin," which was "porous and infinitely folded...a 'meeting site' of inside and outside." ${ }^{18}$ Unlike

${ }^{18}$ Herzogenrath, An American Body $\mid$ Politic, 155, hereafter cited parenthetically. 
Herzogenrath, I am not arguing that this complicated metaphor reveals Mather's philosophy of the body. Rather, it is an animalculated, inoculated smallpox that drives this complexity, that created the material vehicle for Mather's metaphor while also exceeding his control. That is, it is not Mather who collapses "inside" and "outside" but inoculated smallpox.

Transforming metaphors for the body, inoculation also transformed metaphors based on the body - the body politic. According to Jonathan Gil Harris, medical discourse and the figure of the body politic were mutually constitutive. Humoralism, for example, asked citizens to look inward for sources of "social illness," while the ontological model of infectious disease externalized disorder, mapping it onto the "foreign" and "invasive" bodies of social outcasts. By locating disorder in "external, infiltrating threat[s]," the body politic could elide "genuinely disruptive problems generated within" it, "as a result of which the locus of social conflict is symbolically (if not actually) displaced from inside the body to its boundaries and vulnerable apertures." 19 Inoculation derived not only from such an ontological paradigm but also from "the poisonous pharmacy," which asserted that poison could combat poison (50) — a tiny amount of infectious matter could ward against the natural disease as a small number of dangerous outsiders could protect the collective from the larger group, one faction of outsiders could be used to fight another, or outsiders could function as a foil to prescribe appropriate insider behavior (145). In Harris's model, inoculation enacted a body politic attuned to its borders, to who and what was inside and outside, literally and imaginatively.

While The Angel of Bethesda never explicitly names the "body politic," the citadel metaphor nonetheless recalls a medieval collective joined through shared physical space and

${ }^{19}$ Harris, Foreign Bodies and the Body Politic, 13, emphasis in original, hereafter cited parenthetically. 
borders. In his Political Fables, Mather meditates on insiders and outsiders, warning that those who might balk at a royally-appointed governor endanger the entire colony by mistaking the English for outsiders. In-fighting, "snapping and snarling at one another," would allow true enemies like the French "wolves" to attack. ${ }^{20}$ On the one hand, Political Fables, circulated three decades before The Angel, anticipates inoculated smallpox's premise: true danger derives from without rather than within the body politic. On the other hand, this fable foreshadows inoculated smallpox's central paradox: what happens when the distinction between inside and outside, self and other, relies on the dissolution of that distinction? Herzogenrath argues that Mather believed that the body and, thus, the body politic could "organize and regulate" themselves (146). As such, he locates Mather in a "revolutionary tradition" (146). Yet, as Cristobal Silva and Kelly Wisecup have shown, Mather's support for inoculation was attuned medicine's epistemological borders; he carefully invoked and insulated his argument from its source, his slave Onesimus. ${ }^{21}$ Moreover, as Silva observes, "inoculation meant thinking about illness as a personal rather than national affliction," which undermined civil authority and social cohesion. ${ }^{22}$ So, while Mather may never use the phrase "body politic" in the context of inoculation, his abiding interest in politics along with his concern for borders all suggest that he perceived the relationship between single and collective bodies along a central axis. More importantly, as I have been arguing, Mather's intentions here are less important than what inoculated smallpox itself made possible: a permeable yet bounded and bordered body and body politic.

By virtue of its animalculation, therefore, inoculated smallpox materially changed human bodies; these transformed bodies necessitated new metaphors like the citadel; and these

\footnotetext{
${ }^{20}$ Mather, Selections, 332.

${ }^{21}$ See Silva, Miraculous Plagues, chap. 4, and Wisecup, Medical Encounters, chap. 3.

22 Silva, Miraculous Plagues, 147.
} 
physically and figuratively altered bodies consequently reshaped metaphors that were grounded in them, including the body politic. The "castle of health" may have been a familiar image, but Mather's animalcular theory transformed it into a permeable body at war with external invaders rather than itself. In her study of international relations, the metaphor of the body politic, and microbes, Stefanie R. Fishel argues that the paradigm of war elides " the adaptive role" that microbes played and continue to play in the creation of the immune system and humanity itself. ${ }^{23}$ Another word for "adaptive" might be "creative" or "intra-active." Mather employs animalcular theory and the citadel metaphor to explain how inoculation worked, but inoculated smallpox built the literal and metaphorical borders that it simultaneously confounded. Inoculated smallpox and the metaphor it makes possible reminds us that what was "external" is always also "internal," and that what is inside is always potentially outside.

\section{An Inoculated Body Politic: South Carolina, 1758-1761}

Almost forty years after Boston's inoculation controversy and Mather's animalcular explanation of inoculation, South Carolina braced itself for the apocalyptic collision of three distinct catastrophes: a war, a rebellion, and an epidemic. The Cherokees were combatting settler encroachments and colonial aggression. Exploiting the distraction, enslaved and free Africans resisted their oppression and began a rebellion. At the same time, smallpox raged after an absence of over two decades. If these dangers were not enough, tensions among white South Carolinians were also high. The British distrusted the French-Acadian refugees; the backcountry resented the coast; Carolinians begrudged Virginians and Georgians; and, finally, colonists

${ }^{23}$ Fishel, The Microbial State, qtd. in 87. 
doubted, even began to oppose the British empire and colonial rule. ${ }^{24}$ The combined forces of war, rebellion, and epidemic should have shattered the colony along these deep and significant fault lines, but instead white South Carolinians united through inoculation, a material metaphor that elided white divisions by casting the colony as a cohesive and coherent body endangered by dangerous, invasive outsiders. ${ }^{25}$ Yet, even as white Carolinians harnessed the imaginative power of the epidemic and inoculation, the material agencies that undergirded their metaphors undermined them.

By shifting from Mather and Boston 1721 to writers like Dr. Alexander Garden, Eliza Lucas Pinckney, James Adair, and Revered Archibald Simpson in South Carolina, 1758-1761, I do not mean to argue that these later writers were influenced by Mather's writing or theories. Rather, I am arguing that inoculated smallpox's particular materiality, which complicated borders and boundaries, shaped its own representation and the metaphor of the body politic similarly across multiple sites, including Mather's The Angel of Bethesda and white Carolinians' letters, diaries, and texts. That is, I trace not Mather's literary genealogy but inoculated smallpox's. This focus enables a dual vision: we can perceive how elite white Carolinians mobilized a metaphorical inoculation, and we can glimpse how inoculated smallpox itself challenged those uses, demonstrating how those exiled from the body politic including

\footnotetext{
24 James H. Merrell criticizes the terms "backcountry" and "backwoods" in "Second Thoughts," arguing that they privileged and continue to privilege the perspectives of white colonists at the expense of indigenous peoples' insights and rights. Still, these phrases are integral to this essay, which emphasizes how such language imaginatively incorporated Cherokee lands into South Carolina's "body" politic.

${ }^{25}$ For thorough studies of South Carolina's turmoil during this period see: David H. Corkran, The Cherokee Frontier; Tom Hatley, The Dividing Paths, part 3; Fred Anderson, Crucible of War, chap. 47; John Oliphant, Peace and War on the Anglo-Cherokee Frontier, 1756-63; Tyler Boulware, Deconstructing the Cherokee Nation, chaps. 5 and 6; Daniel J. Tortora, Carolina in Crisis.
} 
Cherokees and enslaved peoples could and did transform the contours of early American lives, history, and literature.

\section{Converging Threats}

By 1758 South Carolina was composed of the coastal city, Charles Town, the plantation Lowcountry, and an ever-expanding backcountry. While enslaved black people greatly outnumbered whites in Charles Town and the Lowcountry, sometimes by three to one, the backcountry was primarily white. ${ }^{26}$ Cherokee Country hugged these back settlements and white colonists, ranging from the Appalachian Mountains to the Carolina piedmont. 10,000 people and 2,500-3,000 warriors lived there. ${ }^{27}$ Between 1758-1761 South Carolina's territorial uncertainty exploded into war, its disproportionate demography swelled into rebellion, and fissures between coastal elites and backcountry settlers and the colony and the homeland threatened to destabilize the colony from within — all while a smallpox epidemic flourished. It certainly seemed, as Dr. Alexander Garden, a wealthy physician and naturalist, cried, "never was there a province more abused"- to white Carolinians at least. ${ }^{28}$

The Anglo-Cherokee War (1758-1761) began for many reasons: unregulated trade, settler encroachments, horse stealing, the fallout of the Seven Years' War, including the misunderstanding and mismanagement of Anglo-Cherokee relations, and the assassinations of Cherokee warriors. ${ }^{29}$ As these Cherokees were returning home from their role as British allies

\footnotetext{
${ }^{26}$ Peter McCandless, Slavery, Disease, and Suffering in the Southern Lowcountry, 11.

${ }^{27}$ Corkran, The Cherokee Frontier, 3.

28 Alexander Garden to John Ellis, April 12, 1760, A Selection of the Correspondence, 1:484. For more on Garden's biography, see Edmund Berkeley and Dorothy Smith Berkeley, Doctor Alexander Garden of Charles Town.

${ }^{29}$ See note 25 on the Anglo-Cherokee War. For more on the Seven Years' War's impact on Anglo-Cherokee relations, specifically, see Paul Kelton, "The British and Indian War."
} 
during the war, Virginia settlers attacked and murdered them. According to trader and protoethnographer James Adair, the Cherokees "earnestly applied to Virginia for satisfaction, without receiving any; in like manner to North-Carolina; and afterwards to South-Carolina, with the same bad success." ${ }^{30}$ Only after these entreaties had failed did they avenge their murdered kin according to custom, and, even then, they precisely targeted their victims. ${ }^{31}$ Though two separate delegations set out to Charles Town to negotiate a peace at the end of 1759 , Governor William Henry Lyttelton responded by taking these Cherokees hostage, mustering a militia, and marching to Cherokee Country to demand satisfaction. He received a few accused killers, releasing some of his hostages in turn, and returned to Charles Town where he was met "with a wild ridiculous parade" and "crowned with laurels." 32 Eliza Lucas Pinckney, a wealthy slave-owner now known for her indigo production, believed that Lyttelton's actions had put white South Carolinians "upon a better footing with" the Cherokees "than we have been many years." 33

Pinckney's faith, however, was misguided. Lyttelton did not return with peace but with war. According to Garden, the Cherokees "had played a game with the Governor, too well

\footnotetext{
${ }^{30}$ James Adair, The History of the American Indians, ed. Kathryn E. Holland Braund, 263. For more on Adair's biography, see Braund, "James Adair," The History, 1-53.

${ }^{31}$ The law of "blood vengeance" required that the Cherokees avenge murder with murder. If the murderer fled or was foreign, then any person from their clan or nation could be substituted. See Oliphant, Peace and War, 5-7. See also John Phillip Reid, A Law of Blood, chap. 9. In 1759, specifically, the kin of the murdered men "sent out a large company of warriors, against those Germans...to bring in an equal number of their scalps, to their own murdered relations." Adair, The History, 264. Boulware argues that this ethnic and regional precision mirrors the importance of town and region, in addition to kinship, to Cherokee identity. Moreover, it indicates how limited, careful, and politically savvy the Cherokees were at this time. See Boulware, Deconstructing the Cherokee Nation, 105.

${ }^{32}$ Adair, The History, 267, hereafter cited parenthetically; Garden to Ellis, March 13, 1760, A Selection of the Correspondence, 1:473.

${ }^{33}$ Eliza Lucas Pinckney to Vigorous Edwards, March 12, 1760, in The Letterbook of Eliza Lucas Pinckney, 1739-1762, ed. Elise Pinckney, 141. For more on Pinckney, see Harriott Horry Ravenel, Eliza Pinckney. On her indigo production, see, for example, David L. Coon, "Eliza Lucas Pinckney and the Reintroduction of Indigo Culture in South Carolina.”
} 
planned and concerted for him to see through." They "followed him close at the heels, and laid waste the whole back settlements with fire and sword." ${ }^{34}$ Reverend Archibald Simpson, a slaveowning preacher in Beaufort, similarly described the Cherokees "burning, murdering, ravaging all before them," and whites fleeing "in the most deplorable state of complicated misery \& distress." ${ }^{35}$ Actually, the Cherokees were responding to the brutal and cowardly murders of the remaining hostages at Fort Prince George. ${ }^{36}$ What Simpson and many other whites felt was senseless violence was the Cherokees' response to white "savagery," to a series of injustices that included ignoring border treaties, manipulating trade, murdering innocent people, and enslaving a peace delegation. Thus, the war escalated until General Jeffrey Amherst sent two separate missions, under Archibald Montgomery and James Grant, to subdue the Cherokees. Where Montgomery faltered, Grant destroyed the Lower, Middle, and Out Settlements. ${ }^{37}$ Despite this damage, the war ended on relatively favorable terms for the Cherokees, who lost some hunting grounds but avoided executions and maintained their sovereignty. ${ }^{38}$

Yet the Anglo-Cherokee War was not the only peril South Carolina faced. Slave rebellion also threatened the colony. By the time the war loomed, South Carolina's population was almost evenly split between black and white. ${ }^{39}$ This ratio was probably heartening; whites had actively

\footnotetext{
${ }^{34}$ Garden to Ellis, March 13, 1760, A Selection of Correspondence, 1:474.

35 Archibald Simpson, February 3, 1760, in The South Carolina Diary, ed. Peter N. Moore, 149. On Simpson, see Peter N. Moore, "Archibald Simpson and the Care of Souls in Lowcountry South Carolina."

${ }^{36}$ A "white savage...cut through a plank, over their heads" and shot them dead. Adair, The History, 267.

${ }^{37}$ On these campaigns, see Corkran, The Cherokee Frontier, chaps. 15 and 16, and Oliphant, Peace and War, chap. 4.

38 Anderson, The Crucible of War, 468; Oliphant, Peace and War, 186. Despite this agreement and the Proclamation of 1763, settler encroachments and land cessions increased in the preRevolutionary period. See Boulware, Deconstructing the Cherokee Nation, chap. 7.

${ }^{39}$ McCandless, Slavery, Disease, and Suffering, 11.
} 
attempted to balance the colony's hues in the wake of the Stono Rebellion. In 1739 a number of enslaved people had waited until their masters were at church, raided arms, and began to march to St. Augustine, Florida, where the Spanish were offering freedom to escaped slaves. They killed between twenty and twenty-five whites in the pursuit of freedom. Although this rebellion was eventually suppressed, and many participants were executed, some evaded authorities for months and even years, while others may have slipped back into plantation life without their owners ever having noticed they were gone. ${ }^{40}$ While the rebellion itself may have been checked, white fear only grew.

The General Assembly responded to the Stono Rebellion by strengthening the slave code and by coordinating an effort to balance the colony's demographics through white settlement. In particular, they would tax imported slaves and other goods, for the effectual raising and appropriating a sufficient fund for the better settling of his Majesty's townships and the other frontier parts of this Province with white inhabitants, by which we may be the better enabled to suppress any future insurrection of negroes and slaves, and to repel any attempts of his Majesty's enemies against the peace of this Province. $^{41}$

That is, instead of abolishing or even simply restricting their own slaveholding, the coastal and Lowcountry elites that controlled the Assembly attempted to import poorer whites to the backcountry to act as a buffer. They imagined that this new white populace would correct the

40 On the Stono Rebellion, particularly in the context of South Carolina's demography, see Peter H. Wood, Black Majority, chap. 12.

41 "An Act for the better strengthening of this Province" in The Statues at Large of South Carolina, ed. Thomas Cooper, 3:556-57. 
demographic consequences of chattel slavery and insulate them from the Indian nations that circumscribed their perimeter and the Spanish and French beyond.

Still, a more "balanced" colony could not undo the harrowing fact of enslavement. In the summer of 1759, two black men, Phillip John (or Johns) and John Pendarvis, used the distraction of the Anglo-Cherokee War to plot a slave rebellion. ${ }^{42}$ According to Governor Lyttelton, they had been inspired by a millenarian preacher who had predicted that South Carolina would soon face an apocalyptic disaster. ${ }^{43}$ John interpreted this premonition as a slave rebellion: " "the white People shou'd be all underground, that the Sword shou'd go thro' the Land, and it should shine with their blood, that there should be no more white King's Governors or great men, but the negro's should live happily \& have Laws of their own." ${ }^{44}$ Reverend Simpson reported that his preaching was interrupted in June 1759, when a black man was "siezed and carried off...on suspicion of his being concerned in some evel designs. ${ }^{45}$ Both John and Pendarvis were sentenced to death, but while John was killed, Pendarvis managed to escape and evade capture. ${ }^{46}$ Although no viable revolt ever manifested, and perhaps never even existed, slave resistance, including marronage and poisonings, increased during the Anglo-Cherokee War. ${ }^{47}$ The missing Pendarvis, therefore, represented the collective threat that slaves and slavery represented to

\footnotetext{
42 On this rebellion, see Tortora, Carolina in Crisis and Hatley, The Dividing Paths, 110-12.

${ }^{43}$ Ibid., 111.

${ }^{44}$ William Henry Lyttelton, quoted in Tortora, Carolina in Crisis, 66.

45 Simpson, June 17, 1759, The South Carolina Diary, 143.

46 Tortora, Carolina in Crisis, 67.

${ }^{47}$ Ibid., 145. For more on these kinds of resistance, see Wood, Black Majority, chap. 11; Sharla M. Fett, Working Cures, 159-67; John K. Thornton, Africa and Africans in the Making of the Atlantic World, 1400-1800, chap. 10.
} 
South Carolina. But he also represented the risk of collusion - that Africans and African Americans might escape and eventually collude with the Cherokees to destroy the colony. ${ }^{48}$

At the same time, tensions between whites also endangered the precarious colony. The Acadian refugees, exiled from Nova Scotia, could help France invade, while Virginians threatened South Carolina's trade monopoly and peace negotiations with the Cherokees. ${ }^{49}$ More importantly, the war set the backcountry against the coast as backwoods settlers began to feel acutely and resent deeply their role as a geographical buffer. In February 1760, Simpson wrote in his diary, "This day saw a good number of famelies passing down from the back settlements, where many have been cut of by the Indians, and that all those parts are in the most deplorable state of complicate misery and distress. ${ }^{, 50} \mathrm{He}$ blamed the coastal elites and the General Assembly for the back colonists' plight, arguing that the war was "much owing to our own Inactivity, the Kings troops not having been properly supported by the country." ${ }^{11}$ Yet he also exclaimed, "blessed be God" for the "many settlements behind us on all parts," which shielded his town and community from "danger." ${ }^{2}$ As the General Assembly had intended, even sympathetic inland whites envisioned their fellow colonists as a defense against enemies. Ultimately, backcountry whites felt that their province had deserted them, that the General

\footnotetext{
${ }^{48}$ John allegedly changed the date of the rebellion to accommodate indigenous peoples' agricultural work. On the fear of African and Cherokee collusion, see Hatley, The Dividing Paths, 110-12, and Tortora, Carolina in Crisis, 65-67.

${ }^{49}$ See, for example, Tortora, Carolina in Crisis, 34-47 and McCandless, Slavery, Disease, and Suffering, 55-56 on the fear of the French Acadians; on how the Cherokees played Virginia, South Carolina, and Georgia against each other, see Boulware, Deconstructing the Cherokee Nation, chaps. 5 and 6; on the dissonance between the backcountry and the coast, see Richard Maxwell Brown, The South Carolina Regulators; and, finally, on divisions between the colony and the metropole, see Tortora, Carolina in Crisis, chap. 11.

${ }^{50}$ Simpson, February 12, 1760, The South Carolina Diary, 149-50.

${ }^{51}$ Ibid., [June-September] 13, 1760, 157.

${ }^{52}$ Ibid., February 13, 1760, 150.
} 
Assembly could not and would not represent and provide their particular social, economic, and political needs. ${ }^{53}$

As these inland settlers resented the powerful coastal elites, the coastal elites themselves began to resent metropolitan governance. At first, many simply felt abandoned by their homeland. Garden scolded his friend in England, "You have forgot us at home-you think not of our situation," while Pinckney chided her British interlocutor, "I hope the good people of england wont give all their superfluous mony away to French prisoners and to build foreign churches, but reserve some for their poor fellow subjects in America." 54 Between Garden's dejection and Pinckney's sarcasm, coastal elites smarted at British mistreatment.

Eventually, they believed that this desertion was something more insidious — not just an active disregard but an abuse or deprecation of colonial intelligence and life. In particular, Garden argued that metropolitan "ignorance" and an unwillingness to defer to local knowledge had caused the war: "Our extreme ignorance of the history of those [Indian] nations that we are best acquaintanced with, often and daily exposes us to commit these blunders." 55 One such “blunder" Adair explained was Lyttelton's "not knowing aright the temper and customs of the savages," not knowing or ignoring the "well-known" fact that the Cherokees equated hostages with slaves. ${ }^{56}$ Garden continued, "we err greatly likewise in not getting a better and more accurate geographical knowledge of the continent." 57 Thus, he judged that Montgomerie's siege

\footnotetext{
${ }^{53}$ Although the Anglo-Cherokee War was not the only cause for resentment - the coast routinely refused to allocate funds for public works and the administration of laws - the war would ignite the Regulator movement, a crusade of vigilantism that filled the void in the backcountry by policing laws and dispensing justice. See Brown, The South Carolina Regulators. ${ }^{54}$ Garden to Ellis, June 1, 1760, A Selection of Correspondence, 1:493; Pinckney to Mrs. King, July 19, 1760, The Letterbook, 155.

${ }^{55}$ Garden to Ellis, August 11, 1758, A Selection of Correspondence, 1:422.

56 Adair, The History, 265, 267.

${ }^{57}$ Garden to Ellis, August 11, 1758, in A Selection of Correspondence, 1:422.
} 
failed because of his "ignorance of the various passes, \&c. through the [Cherokee] nation; and indeed our gross ignorance of the geography... will be the fruitful source of many rebuffs to any army that attempts to reduce them." ${ }^{58}$ While "our" seems to blame both the Empire and the colony, Garden's next line clarified: “often used to mention it to Mr. Lyttelton, but not a word has ever been said of it." ${ }^{59}$ It was not just that Britain had seemed to abandon the colonists, but that it had ignored and underestimated their capacity to solve their crisis, to lead themselves. The repetition of "ignorance" suggests that Garden and other coastal elites were especially sensitive to British prejudice toward colonial intelligence. ${ }^{60}$

In the midst of this chaos, of war, rebellion, and infighting, a smallpox epidemic ravaged Charles Town and parts of Cherokee Country. The colony's last epidemic was in 1738, when approximately 295 people in Charles Town and nearly half of the Cherokees died. ${ }^{61}$ By 1760 , therefore, an entire generation lacked immunity. Garden explained, "We have not had it for two and twenty years before, so that of whites and blacks there must be more than two thirds of the people to have it." ${ }^{62}$ David Ramsay, a doctor, politician, and historian writing in the early nineteenth century, estimated that nearly 3500 people contracted the disease in 1760 and 848 died, nearly half of whom were black. ${ }^{63}$ By March, Pinckney had moved to her Belmont estate

\footnotetext{
${ }^{58}$ Ibid., July 17, 1760, 1:497.

59 Ibid.

${ }^{60}$ On the Revolutionary implications of this dynamic, see Tortora, Carolina in Crisis, chap. 11 and the conclusion.

${ }^{61}$ Suzanne Krebsbach, "The Great Charlestown Smallpox Epidemic of 1760," 31; Hatley, The Dividing Paths, 81. McCandless, however, estimates that 300-400 died in Charles Town, while one third of the Cherokees died. Regardless of this discrepancy, the death toll was vast and unmatched until 1760. For more on the 1738 epidemic, see Krebsbach and McCandless, Slavery, Disease, and Suffering, 160-65, 204-10.

${ }^{62}$ Garden to Ellis, January 13, 1760, A Selection of Correspondence, 1:469.

${ }^{63}$ David Ramsay, The History of South-Carolina, 2:79; Hatley, The Dividing Paths, 141. The epidemic was particularly deadly and demoralizing for enslaved people, who were unable to
} 
"to keep my people of the way of the violent distemper for the poor blacks have died very fast by inocculation." 64

There were two potential origins of the outbreak: a young, enslaved boy who escaped the mandatory port quarantine and the soldiers returning from Lyttelton's abortive march to Cherokee Country. ${ }^{65}$ By the time Lyttelton and company had arrived at Fort Prince George, the surrounding Lower Town Cherokees were already in the throes of an epidemic. ${ }^{66}$ Thus, Garden claimed, "Our Governor returned from the Cherokee Country...bringing pestilence along with him," and "The soldiers...brought a most fatal and malignant smallpox from the Cherokees, which, in two or three weeks, began to spread in this little place so furiously." ${ }^{67}$ Smallpox spared no one, but the enormity of the epidemic disproportionately burdened Africans and Cherokees, who lacked access to inoculation and isolated country retreats. ${ }^{68}$

While the war, rebellion, and epidemic affected Native, black, and white populations alike, the confluence of these horrors seemed especially apocalyptic to many white colonists. Garden decried, "the double enemy" of "the smallpox and the negroes," and similarly lamented, "We know not whether our Indians or negroes be our greatest enemies." 69 Pinckney judged that "a great cloud" had settled over South Carolina: "We are continually insulted by the Indians on

escape the city, work, and congregate to bury and mourn the dead because of white fear of insurrection. See Tortora, Carolina in Crisis, 85-86.

${ }^{64}$ Pinckney to Mrs. Evance, March 15, 1760, The Letterbook, 147.

65 Tortora, Carolina in Crisis, 82.

66 The Cherokees probably contracted the disease either directly from their own participation in the Seven Years' War or indirectly from Catawba raiders. See Tortora, Carolina in Crisis, 83. For more on this epidemic's effects on the Cherokees, see Kelton, Cherokee Medicine, chap. 3. ${ }^{67}$ Garden to Ellis, March 13, 1760, A Selection of Correspondence, 1:473.

${ }^{68}$ Many enslaved people who lived and worked in the city were inoculated, but very few on plantations were. See McCandless, Slavery, Disease, and Suffering, 215-16. Moreover, doctors like Alexander Garden perfected their inoculation technique by experimenting on enslaved people. Garden to Ellis, April 12, 1760, A Selection of Correspondence, 1:473.

${ }^{69}$ Ibid., May 13, 1760, 1:474; Ibid., June 1, 1760, 1:493. 
our back settlements, and a violent kind of small pox rages in Charles Town." ${ }^{\prime 70}$ Likewise Reverend Simpson bemoaned the conjunction of "this awful malignancy" and "the Indians," crying, "O for sparing mercy and pity to this poor land."71 Though Garden, Pinckney, and Simpson sometimes alluded to those other tensions among white colonists, their horror centered on and coalesced around the Cherokees, enslaved and free black people, and smallpox. Occurring at the same time and in the same colony, these events were materially and imaginatively inextricable. As they converged, whites found in their experiences of inoculation a powerful, material metaphor for ordering their colony's chaos, for eliding white sources of danger and for excising nonwhite peoples from their collective and its future.

\section{Inoculation as White Metaphor}

Inoculation produced lifelong immunity to smallpox by placing infectious matter, usually the scrapings of a pox pustule or scab, directly into an incision in the skin. Whereas natural smallpox was airborne and induced a systemic infection, inoculation instigated a localized skin infection that many immune systems could neutralize easily. ${ }^{72}$ Early Americans did not fully understand how inoculation worked, but by South Carolina's 1760 epidemic, four decades after the infamous Boston inoculation controversy, they knew that inoculation offered a far safer method of contracting the deadly disease though it still remained dangerous. Unlike vaccination, which would not be developed until the end of the eighteenth century, inoculation utilized the live smallpox virus, which meant that the inoculated could still spread the natural disease.

\footnotetext{
${ }^{70}$ Pinckney to Evance, March 15, 1760, The Letterbook, 147.

${ }^{71}$ Simpson, February 23, 1760, The South Carolina Diary, 151.

72 On the immunological mechanisms of natural, inoculated, and vaccinated smallpox, see Dorothy Crawford, The Invisible Enemy, 199-206, and Ethne Barnes, Diseases and Human Evolution, 221-25.
} 
Inoculation, therefore, was rarely used to prevent epidemics. Instead, it defended against an active outbreak.

In 1760 white South Carolinians deployed inoculation to defend against other enemies as well. In particular, they used inoculation as a metaphor to transform people who were economically and geographically vital to the colony — internal in many ways though not all_-into poisonous, infectious, and dangerous outsiders. By locating the colony's disorder in these external bodies, white Carolinians elided both white tensions and the extent to which the war, rebellion, and epidemic were at least partially produced by their own policies and actions. Ultimately, inoculation warranted a fantasy of control, the belief that they could cohere as a single, powerful white body politic by policing their borders.

Though they used inoculation to externalize danger in the figure of racial outsiders and to elide white or internal sources of disorder, they exercised this metaphor differently upon enslaved Africans and Cherokees. Black Carolinians represented a paradoxical threat: they were physically and economically vital to the colony, but this integration was itself dangerous. Describing the colony's chaos in March 1760, Garden explained, "From one of the most flourishing provinces, we are...brought into a situation too terrible for us, who have a double enemy, within ourselves to fear, viz. the small pox and the negroes." ${ }^{\text {73 }}$ Smallpox and black people were not just "enemies" of the province, according to Garden, but "within" or internal enemies. As he continued to report the chaos, he refined this description using anatomical language: "about 70,000 negroes in our bowels!" and "70,000 intestine enemies."74

\footnotetext{
73 Garden to Ellis, March 13, 1760, A Selection of Correspondence, 1:474.

74 Ibid., June 1, 1760, 1:492; Ibid., July 16, 1760, 1:495.
} 
Undoubtedly, this corporeal imagery drew on the symbol of the body politic to illustrate the geographic location of enslaved people, within the colony and within white homes.

More pointedly, the terms "bowels" and "intestines" implied not only location but necessity. Black people were critical to South Carolina's economy, culture, and the material state itself, building roads that connected back settlements to Charles Town, constructing defensive fortifications, and piloting goods and people along waterways. ${ }^{75}$ Black Carolinians may have been vital to the colony's formation, but this necessity also rendered the white body politic vulnerable. After all, the Stono Rebellion was engineered by men assembled to work on state infrastructure. ${ }^{76}$ Similarly, when Reverend Simpson's wife was "left by herself without a white person in the plantation, she...not being used to be only among negroes," and in the vitiated position of "lyn in" after childbirth, grew "melencholy." 77 Mrs. Simpson's anxiety condensed the colony's: whites did not simply feel outnumbered but outnumbered in a particularly vulnerable internal space —in the bowels and intestines. Paradoxically, black Carolinians were both vital enemies and enemies situated in the vitals of the white body politic.

Inoculation, however, resolved this paradox by demonstrating how something internal could also be external. Smallpox could be in the body, invited in even, but ultimately it was not of the body. Garden's phrase "in our bowels" is telling: black Carolinians could be "in" South Carolina and its body politic, even vital to its existence, but were not "of" that collective "our." They were physically rather than culturally or politically within the colony, located in what we might call the body geographic rather than the body politic. Inoculation, like chattel slavery, may have invited "poison" within, but it did so by reframing smallpox as something necessarily

${ }^{75}$ Ryan A. Quintana, Making a Slave State, 15-16.

${ }^{76}$ Ibid., 16.

${ }^{77}$ Simpson, September 11, 1756, The South Carolina Diary, 101. 
different from and external to the human body. It enabled white Carolinians to imagine black people as both external and vital and, thus, internal but not constitutive. Inoculation allowed them to form the collective "our bowels" - their white body politic_-by eliding their responsibility for creating their own "intestine enemies."

If whites required inoculation to externalize black Carolinians, then the Cherokees represented a different material problem for the medical metaphor to solve. The Cherokees were “external enemies," in Garden's words, but their lands were critical to the colony's safety and thus potentially internal to the colony itself. ${ }^{78}$ Yet the Cherokees were a sovereign nation, distinctly separate from South Carolina's body politic and its body geographic. While the nation was neither unified nor monolithic, with different regions and towns pursuing different goals in their relations with South Carolinians and colonists more broadly, the Anglo-Cherokee War facilitated an unprecedented consolidation. ${ }^{79}$ Between 1758-1761 they were knit together not only by language, culture, and kinship but also by Carolinian aggression. Even though they were intimately tied to South Carolina through trade, and the colony's politics and culture inevitably affected their own, the Cherokees remained independent.

Still, white Carolinians understood that Cherokee Country was critical to South Carolina's longevity and integrity. As Garden's persistent calls for mapping the territory attested, Cherokee Country was geographically important because it represented "a back door to the province," one through which the French or other Native peoples could enter and escaped slaves could flee. ${ }^{80}$ Moreover, in the minds and actions of many whites, Cherokee Country seemed to

\footnotetext{
${ }^{78}$ Garden to Ellis, June 1, 1760, A Selection of Correspondence, 1:492.

${ }^{79}$ On the diffuse and shifting nature of the Cherokee nation during the eighteenth century, see Boulware, Deconstructing the Nation. For more on how the Anglo-Cherokee war affected the nation's divisions and consolidation, see chaps. 5 and 6.

${ }^{80}$ Hatley, The Dividing Paths, 124.
} 
be theirs already. After all, settler encroachments had precipitated the war. Garden succinctly surmised, "we rightly judge here that most, if not all, the Cherokee Country lies within our limits." $" 1$

Their encroachments, however, were not only physical but also imaginative. In particular, they used the language of the province's "back" and "behind" to incorporate Cherokee Country into their body politic. ${ }^{82}$ While the language of the back country and its settlements was not necessarily unique, especially during the Seven Years' War, these terms resonated in the context of the Anglo-Cherokee War, the contested border, and the smallpox epidemic. When Garden demanded that "our back settlements" be mapped, Pinckney decried the "Murders and Outrages in our back settlements," and Simpson alternately lamented the "destruction" in "our back settlements" and praised the "many settlements behind us on all parts," these elite Carolinians materially and imaginatively collapsed the distinction between South Carolina and Cherokee country. ${ }^{83}$ These "back settlements" formed the colony's border and, in the paradigm of inoculation, its skin. That is, this language allowed white Carolinians to stretch the skin of their body geographic, if not body politic, to include Cherokee Country.

But it also revealed a fear of this skin's porosity and erosion, a fear that the colony might shrink rather than expand. Garden warned that the Cherokees "no doubt will cover our backs before we be awakened, and may be and are ready to pour destruction on us before we open our eyes." ${ }^{84}$ Reverend Simpson similarly worried that the Cherokees "raging still in our back

\footnotetext{
${ }^{81}$ Garden to Ellis, August 11, 1758, in A Selection of Correspondence, 1:423. ${ }^{82}$ See note 24 on Merrell's critique of the terms "backcountry" and "back settlements." ${ }^{83}$ Garden to Ellis, January 13, 1756, A Selection of Correspondence, 1:363; Pinckney to King, February 1760, The Letterbook, 138; Simpson, April 15, 1760, The South Carolina Diary; Ibid., February 13, 1760, 150.

${ }^{84}$ Garden to Ellis, June 1, 1760, A Selection of Correspondence, 1:493.
} 
settlements" are "coming nearer and nearer daily." ${ }^{85}$ In fact, the Cherokees had pushed the border back 100 miles ${ }^{86}$ While whites needed to excise enslaved peoples from the body politic but not the body geographic, they needed to incorporate Cherokee Country rather than the Cherokee people into their colony and needed to minimize the fact that the Cherokees could and were incorporating them.

They did so through inoculation, which allowed them to delineate their colony's boundary and to control its permeability. Inoculation admitted that the body could be changed, could incorporate the outside, much as whites aimed to incorporate Cherokee lands into themselves, but it also stressed control. The individual intervened in the natural course of an epidemic to manage when, how, and in what way he or she would contract the disease. To use Barad's and Alaimo's language, inoculation enabled humans to control their trans-corporeal intra-action with smallpox and, thus, to transform "intra"-action into "inter"-action. That is, they manipulated smallpox to improve themselves and, in doing so, imagined that they controlled smallpox, not that they shaped each other and certainly not that smallpox shaped them. Despite the realities of the Anglo-Cherokee War and eventually the Proclamation of 1763, inoculation similarly enabled white Carolinians to believe that they controlled their border's permeability, that while they could expand their colony's skin, the Cherokees could not alter or permeate it. In short, they used inoculation to delegitimize Cherokee sovereignty and agency and to justify their own expansion.

Inoculation, therefore, enabled white South Carolinians to cohere at a time when their colony and its political and territorial integrity were in jeopardy by locating danger and blame in

\footnotetext{
${ }^{85}$ Simpson, May 17, 1760, The South Carolina Diary, 154.
}

86 Tortora, Carolina in Crisis, 113. 
external others. Black people were forcibly and paradoxically externalized, while Cherokee land was increasingly internalized. Inoculation framed nonwhite resistance, rebellion, and war as within South Carolina's control, suturing white tensions and fortifying the tenuous colony. Most importantly, it absolved whites of their own role in creating and perpetuating the horrors of chattel slavery, colonization, and expansion, of the extent to which their "external" problems were truly "internal." In other words, the metaphor of inoculation ultimately functioned to elide the colony's formative intra-actions and the power of nonwhite agents - to erase how enslaved and free Africans and the Cherokees shaped the colony itself.

\section{Inoculation as Material Agent}

Smallpox, however, resisted. The course of the epidemic, the variable success of inoculation, and its eventual restrictions subverted white South Carolinians' beliefs about health and disease and thereby undermined their attempts to use inoculation as a metaphor to understand and master their colony. This epidemic's particular, material circumstances challenged white South Carolinians' division between a healthy, unified, white internality and dangerous, invasive, nonwhite outsiders. Smallpox, inoculation, and inoculated smallpox animated and transformed their own use as metaphors of oppression and suppression, highlighting how nonwhite and nonhuman intra-actions transfigured the material and figurative contours of the colony — with or without the permission and recognition of Carolinian elites.

Diseases like smallpox were typically considered external threats to early America, imported into urban coastal cities like Boston and Charles Town through migration, trade, and slavery. In these cities, global traffic collided with high population density and poor sanitation to encourage the propagation of infectious disease. Unlike in Charles Town, the country's 
population was neither large enough nor dense enough to support sustained epidemics though some plantations and parts of Cherokee Country certainly were. As Pinckney correctly observed in March 1760, "the smallpox, as it does not spread in the country, must soon be over for want of subjects." 87

Cities, therefore, learned to imitate the country, instituting quarantines to arrest epidemics. After a slave ship introduced smallpox in 1738, Charles Town established a series of acts aimed at preventing and managing disease, including one in 1744 that created Sullivan's Island, an isle dedicated to quarantining incoming ships, and a comprehensive quarantine act in 1759. ${ }^{88}$ They were successful; the city did not experience another smallpox epidemic until 1760. But while these laws also sometimes barred rural entry into Charles Town, they only did so to prevent the disease from spreading to the economically vital plantations in the Lowcountry. South Carolina's quarantine procedures, therefore, were not designed to cure individual cases of diseases nor to alleviate pain and suffering but rather to protect Charles Town and South Carolina from diseases believed to originate from outside of the colony. As Silva's work on New England immunologies has shown, this belief may have held true for the earliest generations of settlers, but as populations increased and grew denser smallpox could no longer be considered foreign. ${ }^{89}$

\footnotetext{
${ }^{87}$ Pinckney to Evance, March 15, 1760, The Letterbook, 148.

${ }^{88}$ On the creation of Sullivan's Island, see "An Act for the further preventing the spreading of contagious or malignant distempers in this Province," The Statutes at Large, 3:773-74. See also McCandless, Slavery, Disease, and Suffering, 210-11, 228-33. For the comprehensive act, see "An Act for the preventing, as much as may be, the spreading of malignant and contagious distempers in this Province," The Statutes at Large, 4:78-86. For more on South Carolina's quarantine laws, see Marion Stange, Vital Negotiations, 193-202.

${ }^{89}$ See Silva, Miraculous Plagues, chap. 3.
} 
The unusual course of the 1760 epidemic reflected this change, challenging white South Carolinians' beliefs about the disease and their colony. Although there were two possible origins of the epidemic — the quarantine escapee and Lyttelton's army—white South Carolinians blamed the returning militia: "Our Governor returned from Cherokee Country...bringing the pestilence along with him." ${ }^{90}$ In this epidemic, smallpox was not imported by a slaver nor an immigrant vessel but by Lyttelton and his returning militia. This transit circumvented both Charles Town's quarantine measures and its understanding of the disease; it spread not from without the colony but from within it. While Cherokee Country was not "within” South Carolina, whites plainly envisioned it as the skin, the "back" and "behind" of the colony, that delineated the province from a more certain "outside" that included the French. Moreover, the soldiers had contracted the disease at Fort Prince George, an official state outpost, albeit one on Cherokee land. ${ }^{91}$ That is, this epidemic spread not just from the colony's physical interior but also from its political inside-Lyttelton, the local militia, and a military fort.

By challenging white South Carolinians' beliefs about how smallpox spread, this epidemic's transit also undermined their metaphorical use of inoculation. Although they employed inoculation to reaffirm the boundaries of their colony, to isolate and externalize nonwhites, this epidemic troubled any easy distinction between inside and outside. That the quarantine did not prevent the epidemic demonstrated that the colony's interior was just as, if not more, dangerous than its exterior. That it was the marching white soldiers - the ultimate symbols of the white state-who spread smallpox demonstrated that Africans and Cherokees were not the only sources of the province's disorder. And, finally, that the epidemic was spread from the

\footnotetext{
${ }^{90}$ Garden to Ellis, Mar 13, 1760, A Selection of Correspondence, 1:473.

91 Though the Cherokees did not cede this land, Governor James Glen would assert so in official communication with the Board of Trade. See Oliphant, Peace and War, 12-13.
} 
ambiguous territory of Fort Prince George (to whites, at least) demonstrated that the colony did not fully control their borders. The epidemic's uncommon transit, therefore, undermined inoculation's ability to locate danger "outside" of the province exclusively.

Inoculation's poor success rate in 1760 also challenged its metaphorical usage. As Garden estimated, somewhere between 2400-2800 people were inoculated within twelve days. ${ }^{92}$ Yet he acknowledged that "a very great number" of those inoculated "did not come so well off as might have been expected." 93 Simpson similarly remarked, "it does not answer any way so well as expected."94 While Simpson did not ruminate on why inoculation was unsuccessful, Garden diagnosed the problem: "the inhabitants were driven precipitately to have many more inoculated than could be attended by practitioners of physic." 95 Likewise, Pinckney claimed that those in Charles Town were "inocculation mad" and "rushed into it with such presipitation that I think it is impossible they could have had either a proper preparation or attendance had there been ten Doctors in town to one." 96 Both Garden and Pinckney attempted to locate the inoculation's failure in the "precipitous" public, which hastened to inoculation without professional consultation or care, but they nonetheless admit that failure.

If inoculation resolved their colony's disorder metaphorically, then material inoculation's failure exacerbated this disorder and its danger. Inoculation promised safety by manipulating and controlling how smallpox entered the body, how a clear outside and inside inter- rather than intra-acted. In turn, it promised that white Carolinians could control their colony, its borders, and racialized outsiders. Inoculation's failure, however, upended this promise, demonstrating that the

92 Garden to Ellis, March 13, 1760, A Selection of Correspondence, 1:473.

93 Ibid., April 12, 1760, 1:483.

94 Simpson, February 23, 1760, The South Carolina Diary, 151.

95 Garden to Ellis, March 13, 1760, A Selection of Correspondence, 1:473.

${ }^{96}$ Pinckney to Evance, March 15, 1760, The Letterbook, 148. 
colony's safety and control were illusory, a metaphor with material power certainly, but not a reflection of reality. Cherokees and black Carolinians had already punctured their fantasy of a self-contained and self-controlled colony. Thus, it is not just that inoculation's failure highlighted the colony's inability to manage the interaction of inside and outside, but that it exposed the lie of the dichotomy itself.

Eventually, Charles Town responded to inoculation's failure by restricting it. Yet these restrictions only revealed the internal white fissures that inoculation-as-metaphor intended to elide. In May 1760, wealthy whites pressured the General Assembly to outlaw inoculation near and within the city for a year. ${ }^{97}$ They did not object to the practice on social or religious grounds, as in Boston's famous rejection, but for economic reasons. Epidemic smallpox inevitably depressed profits, and inoculation prolonged these economic consequences by prolonging the epidemic. After all, the inoculated remained contagious. ${ }^{98}$

These restrictions, however, disproportionately burdened rural whites. Though nearly all urbanites and many in the Lowcountry could procure inoculation early in the epidemic, smallpox did not spread in the country, and its infectious matter did not travel well, so inoculation could not be had easily outside of the city. Country folk, therefore, traveled to Charles Town to inoculate themselves and their families. Just as wealthy coastals had disenfranchised rural whites by using them as a buffer against the Cherokees and as a demographic check on their own slaves, they subjugated backcountry settlers through these restrictions, compounding extant classed and geographical fractures. If the metaphor of inoculation was employed to elide tensions among whites, then these restrictions revealed that white tensions did not disappear or dissolve into the

97. "An act for preventing (as much as may be) the continuance of the Small Pox in Charlestown," The Statutes at Large, 4:106-09.

${ }^{98}$ McCandless, Slavery, Disease, and Suffering, 216. 
danger of externalized outsiders like the Africans and Cherokees. Rather, inoculation's materiality highlighted the very tensions - the internal, white problems - that the metaphor of inoculation intended to resolve.

Inoculation's materiality, therefore, could not and did not serve white intentions. Where whites wanted to externalize nonwhites, internalize Cherokee lands, elide white friction, and cohere as a self-contained and healthy colony, the epidemic's transit, inoculation's failure, and its restrictions conspired to undermine both their metaphor and its material consequences. The epidemic's course demonstrated that South Carolina's interior was not inherently healthy and that outsiders did not have a monopoly on deadliness. Inoculation's failure demonstrated that whites had failed to control their body politic's boundaries. More importantly, it exposed the paradigm of inside/outside as false. Whites created the material and imaginative conditions that rendered non-whites dangerous outsiders. Finally, restrictions on inoculation exposed the internal white tensions that inoculation attempted to hide. That is, both the epidemic and inoculation their particular and material circumstances and effects - actively challenged the way whites framed and manipulated them, undermining their attempts to consolidate the colony through straightforward, racialized insiders and outsiders.

\section{Conclusion}

Inoculation was a bad metaphor. Though it seemed to warrant externalizing enemies and fantasies of control, its materiality made it an uncertain and unstable vehicle to manage the colony's crisis. By depositing the live variola virus into an open wound, inoculation dissolved rather than fortified the division between inside and outside. White Carolinians attempted to control this interaction and its metaphorical implications, but it was, more accurately, an intra- 
action. As Barad has asserted, "There is no absolute inside or absolute outside. There is only exteriority within, that is, agential separability." 99 If intra-action represents the base ontological state of all bodies and agencies, then difference, what Barad calls "agential separability," must be made through a purposeful "cut" that divides this from that, virus from human, white from nonwhite. White Carolinians wanted the metaphor of inoculation to function as this "cut," to parse the agencies involved in the colony's crisis as easily as it seemed to parse "smallpox" and "human." Inoculation, however, did not resolve their crisis. It embodied it—vital enemies and enemies situated in the vitals, internalized others and semi-permeable skins, and, most importantly, inseparable, intra-acting agencies. It was not just that they misunderstood their metaphor's materiality, but that inoculation's materiality rejected their metaphor.

Likewise, though Mather mobilized the citadel metaphor to explain how an animalcular inoculation worked, inoculated smallpox resisted its usage. He described natural smallpox as an enemy invader, plunging directly into the center of the unprotected human body. Inoculated smallpox, however, transformed that body into a citadel with clear and carefully regulated borders. Still, inoculated smallpox belied this straightforward imagery: the body only became bounded through intra-action, by traversing and dissolving the purported borders between human and microbe, self and other, inside and outside. In this way, inoculated smallpox transformed material bodies and their metaphorical potential, planting a paradox at the heart of representations of bodies and body politics, a paradox that would bloom in South Carolina, 17581761.

To argue that smallpox and inoculation affected history is not revolutionary; they, in conjunction with human actors, profoundly and intimately shaped human bodies and lives, entire

${ }^{99}$ Barad, Meeting the Universe Halfway, 377. 
populations, and cultures across the globe. To argue that humans used their experiences of disease to understand their world is equally unsurprising. But to argue that smallpox and inoculation are agents that transformed not only bodies but also their own use as metaphors seems radical. New materialism, however, reminds us that neither agency nor communication are uniquely human. Identifying and charting how nonhumans like diseases and medical procedures escaped humanity's imaginative constructs illustrates how even those without official, state power or even the capacity to write shaped the lives and language of early America. White Carolinians wanted to minimize the agency of their nonwhite and nonhuman kin, to use their control of smallpox to consolidate their control of Africans and Cherokees, but smallpox and inoculation's materialities revealed that in spite of white posturing, writing, and destruction these agencies nonetheless shaped and transformed early America — materially and imaginatively. Disability studies strives to reimagine the metaphors that shaped lived experience of disability and illness. If we are to revise those metaphors that frame bodily differences and body politics, then we must attend to how disease structures our physical, historical, and literary borders. 


\section{Chapter Three: The Pandemic Roots of the Early American Novel: Yellow Fever and the}

\section{Haitian Revolution}

Yellow fever emerged in the New World as early as 1648. Though it struck Charleston and Philadelphia in the early eighteenth century, it seems to have "disappeared" from mainland America until after the Revolution. ${ }^{1}$ In the last decade of the century, however, the disease surged as a pandemic, coursing through the Caribbean and the Republic's eastern seaboard, tracing the Haitian Revolution's diaspora. ${ }^{2}$ Saint-Domingue's rebellion moved susceptible Europeans to the West Indies, as West Indians fled to an immunologically vulnerable North America, creating a pandemic network.

At the very same time, the novel entered the American literary marketplace. Though the genre had been popular in England since the beginning of the eighteenth century, it only belatedly began to thrive with the rise of the Republic, a response to new social and cultural relationships, including those gendered and raced inequalities enshrined in the Constitution. ${ }^{3}$

\footnotetext{
${ }^{1}$ Kenneth F. Kiple and Mary Himmelsteib King, Another Dimension to the Black Diaspora, 39; Peter McCandless, Slavery, Disease, and Suffering, 72; Oscar Reiss, Medicine in Colonial America, 382. Some medical historians like John Duffy have suggested that yellow fever "disappeared" from colonial British America between roughly 1760 and 1790 (Epidemics in Colonial America 162). McCandless, however, argues that in Charleston, South Carolina, at least, "yellow fever did not disappear...but was often present without being explicitly acknowledged or perhaps recognized as such" (72). It could have been ignored because of adverse market reactions; it may have been relatively benign, and thus went unnoticed; or, its symptoms could have been attributed to other diseases. Even Duffy admits that why the disease should have "disappeared" is a "puzzling question" (Epidemics in Colonial America 163). ${ }^{2}$ In "Republic of Medicine," Cristobal Silva emphasizes the pandemic nature of this period's yellow fever outbreaks, arguing more broadly for a hemispheric reading of early Republican literature. This argument builds on Silva's work by addressing the relationship between yellow fever, the Haitian Revolution, and the early American novel.

${ }^{3}$ On the English novel's origins, see Ian Watt, The Rise of the Novel, and Michael McKeon, The Origins of the English Novel. For studies on the concurrent rise of the United States and the novel, see Leslie A. Fiedler, Love and Death, and Cathy N. Davidson, Revolution and the World. In The Early American Novel, Lillie Deming Loshe argues that early Republican novelists responded to British literary dominance by attempting to craft a uniquely American version of
} 
This chapter argues that this timing - the concurrence of yellow fever, black Revolution, and the novel - is not coincidental but rather coevolutionary. Both the disease and the rebellion shaped the "instability," "uncertainty," and "confusion" that early American novels are known for, probing the relationship between whiteness and agency, agency and intentionality, and intentionality and efficacy. ${ }^{4}$ At the novel's inception, therefore, resides a challenge to the white, bourgeois, decidedly human subjectivity that the genre would eventually epitomize.

Early American novels largely followed two scripts: the gothic or the seduction.

Although there were many other related types, including the picaresque and the sentimental, this pair dominated. Some have argued that gothic novels anxiously responded to the gap between Republican ideals and reality, particularly the real horror of chattel slavery. ${ }^{5}$ Sîan Silyn Roberts, however, critiques this "guilt thesis," arguing that the "symptomatic reading," in which "social, political, and racial Others" become gothic horrors, elides the "generic obligation"” to elicit fear. ${ }^{6}$ That is, such analyses subjugate form to history. In turn, the seduction narrative purportedly reveal anxieties about sympathetic identification, about how the new American

the genre. More recently, Nancy Armstrong and Leonard Tennenhouse have argued in Novels in the Time of Democratic Writing that the genre did not aim "to produce a comprehensive perspective" of American life (13), but instead "link[ed] alternative and often incompatible perspectives in a composite view" (14). Thus, the early form's heterogeneity was linked to its social and political environment. I expand Armstrong and Tennenhouse's argument to consider how nonhumans like yellow fever influenced the genre as well. On the relationship between social inequalities and the genre, the gap between democracy's promise and reality, see Julia A. Stern, Plight of Feeling, and Teresa A. Goddu, Gothic America.

${ }^{4}$ Jeffrey Rubin-Dorsky, "The Early American Novel," 6. While scholars have tackled the relationship between yellow fever and race, yellow fever and the Haitian Revolution, and even the Haitian Revolution and the novel (see Gretchen Woertendyke, "Haiti and the New-World Novel"), yellow fever, the Haitian Revolution, and the novel have yet to be fully analyzed together.

${ }^{5}$ See, for example, Fiedler, Love and Death; Davidson, Revolution and the Word; Goddu, Gothic America; and, Stern, Plight of Feeling.

${ }^{6}$ Roberts, Gothic Subjects, 21, emphasis in original. 
democracy would cohere as a social body. ${ }^{7}$ Yet, recalling Roberts's reminder, the seduction narrative also operated via a strict, scripted, didactic logic: those whose actions challenged cultural norms, including rakes and fallen women, were disciplined. As Nina Baym argues, plot rather than character "defined the form" of the early American novel": a good plot and good novel were one where "all events...cohere[d]." Regardless of what these two, overlapping forms "revealed" about early American culture, they functioned — and grew incredibly popularthrough infinitely replicable plots and typological characters.

This chapter, however, argues that yellow fever and black revolution disrupted these familiar formulas. As nonhuman and purportedly non- or subhuman agents, they challenged the relationship between white humanity and agency and, even more precisely, between intentionality and efficacy. They exposed the myth of clear causes and calculable effects, undermining the very premise of plot, character, and gothic and didactic denouements. In Charles Brockden Brown's yellow fever novels, Arthur Mervyn; or, Memoirs of the Year 1793 and Ormond; or, The Secret Witness, the disease and black rebels divorce plot from white agency and character from accessible interiority. Both novels transform into a series of effects with no traceable causes - plots without character, as white Americans imagined yellow fever and the Haitian Revolution. Brown's novels do not pull back the curtain to reveal the villain's machinations as a good gothic novel should, but instead expose the myth of an exclusively white, human, intentional, and effective agency—including that of the author himself.

In turn, Leonora Sansay's novels, Secret History; or, The Horrors of St. Domingo and Laura, attempt to submit yellow fever and black agency to the discipline of form and plot.

\footnotetext{
${ }^{7}$ See, for example, Elizabeth Barnes, States of Sympathy.

${ }^{8}$ Baym, Novels, Readers, and Reviewers, 71.
} 
Whereas Secret History minimizes yellow fever's presence in the Haitian Revolution, Laura minimizes black agency in its yellow fever plot. These rebellious agents prove too disruptive for her seduction narrative's didactic plotting, so Sansay eliminates one and then the other to conform. If Brown's novels record characters without interiors, plots without human drivers, and causes that do not add up to effects, then Sansay attempts to control such chaos by compelling conventional plots that excise potential sources of rebellion.

Though their novels differ, both Brown and Sansay demonstrate how nonhuman and purportedly nonhuman agents transformed the central concerns of the American novel at its very inception. Amitav Ghosh has argued that the modern novel's form-its emphasis on the individual, the quotidian, and its concealment of the exceptional—contributes to the imaginative paucity that allows climate change to go unchecked. To tarry with the exceptional "risk[s] banishment to... 'the Gothic, 'the romance,' or 'the melodrama," to "“fantasy,' 'horror,' and 'science fiction." "9 Brown's and Sansay's novels may predate the decidedly "modern" novel that Ghosh critiques, but they reveal an exceptional nonhuman seed planted at its incipience: the experience of illness - the experience of the nonhuman and, as disability studies reminds us, of being culturally constructed as non- or subhuman. By focusing on disease in the form most closely aligned with modern humanity, we can begin to unravel how the category of the human maligns both human and nonhuman variation. ${ }^{10}$

\footnotetext{
${ }^{9}$ Ghosh, The Great Derangement, 24.

10 Though my argument is limited, cleaving to some of the era's most exceptional, most frequently criticized works, my hope is that my emphasis on plot and character can and will be applied to other early American novels, even those without explicit references to yellow fever, including Adventures of Jonathan Corncob (1787), Constantia Neville (1800), Monima, or the Beggar Girl (1803), and Margaretta (1807).
} 


\section{Yellow Fever and Race}

Unlike smallpox and syphilis, yellow fever is an arbopod disease, a virus transmitted by a mosquito vector. Aedes aegypti contracts the virus from an infected human or primate during a blood meal and passes the virus to susceptible humans or primates during other blood meals. Every stage of this transmission cycle requires precise conditions in order to be successful: first, A. aegypti must be present (and imported to nonnative locales like the Americas); second, for $A$. aegypti to thrive, the weather should be hot and humid, and there should be ample breeding grounds in the form of water vessels like wells, cisterns, and casks, rather than swamps, as other mosquitoes prefer; third, in the absence of sylvan yellow fever, or endemic primate repositories, the virus must be introduced from Africa or the Caribbean (the slave trade first introduced yellow fever to the New World and was the primary source of early Republican epidemics); finally, the herd immunity, whether on board a ship or in a port city, must be sufficiently low to ensure the chain of infection. Thus, an epidemic or pandemic yellow fever required the most precise choreography or intra-action of human and nonhuman actors. ${ }^{11}$

As Philadelphia's famous climatist and contagionist debates dramatized, however, early Americans did not fully understand the disease's etiology. ${ }^{12}$ Instead, throughout the new United

\footnotetext{
11 This information is collated from a number of scientists and medical and environmental historians. For the former, see Thomas P. Monath and Pedro F. C. Vasconcelos, "Yellow Fever," and Monath and Alan D. T. Barrett, "Pathogenesis and Pathophysiology of Yellow Fever." On the latter, see J.R. McNeill, Mosquito Empires, and Kiple and King, Another Dimension to the Black Diaspora, chap. 2, which provides readable descriptions of yellow fever's mechanisms. For popular science accounts, see Dorothy Crawford, The Invisible Enemy, 21-27, and Deadly Companions, 118-24.

12 Early American etiological debates, particularly of Philadelphia's 1793 epidemic, have been widely studied. See, for example, Thomas Apel, Feverish Bodies, Enlightened Minds; Simon Finger's The Contagious City, chap. 8; and, for perhaps the most famous take on the political stakes of the debate, see Martin S. Pernick, "Politics, Parties, and Pestilence." Additionally, Stephen Shapiro's Culture and Commerce implies that the importationist debates were also tied
} 
States and the Caribbean, many associated yellow fever with race. Though early apologists justified slavery by arguing that Africans were better able to toil in the hot weather of the South and West Indies than indigenous and white peoples, by the end of the eighteenth century, apologists, scientists, and lay people alike began to believe that black people were inherently or racially immune to specific diseases like yellow fever and malaria. ${ }^{13}$ Even if they contracted yellow fever they seemed to experience a more benign disease and rarely died.

Yet scientists and medical historians have had a harder time identifying physical evidence for racial resistance to yellow fever. Many scholars take this immunity or refractoriness as fact: Arno G. Motulsky and Kenneth Kiple and Virginia Himmelsteib King have suggested that there must be a genetic component to black immunity, arguing that resistance persisted after the end of the transatlantic slave trade and environmental immunity, while others like Philip Curtin have argued that exposure to disease in childhood, which would have been more benign, sometimes even asymptomatic, could account for differential morbidity and mortality between races. Additionally, exposed housing, difficult labor, and the inability to move freely — say, to the North to escape the pestilence, as many whites of means did-could all have contributed to early and perhaps unrecognizable exposure and resistance to yellow fever. ${ }^{14}$

Still, all of these arguments take refractoriness as a given, presumptively searching for a physiological or environmental explanation. Mariola Espinosa, however, argues that the historical evidence these medical historians and scientists employ is incomplete and biased.

Black people may not have contracted the disease less frequently or more benignly; rather, white

to shifting attitudes on trade. Pernick and Phillip Gould, "Race, Commerce, and the Literature of Yellow Fever," also discuss the impact of trade on this yellow fever epidemic and its debates.

${ }^{13}$ McCandless, Slavery, Disease, and Suffering, 134.

${ }^{14}$ See Motulsky, "Metabolic Polymorphisms"; Kiple and King, Another Dimension to the Black Diaspora; Curtin, "Epidemiology and the Slave Trade." 
medical professionals might not have noticed, not recorded, or simply ignored their cases and suffering. ${ }^{15}$ Some Africans and African creoles were genetically immune or resistant to some malarial strains, but there remains no clear evidence for a genetic resistance to yellow fever. ${ }^{16}$

Yet in the early white Republican imagination, yellow fever was bound to both black bodies and black revolutionary agency, to enslaved people, free Philadelphians, and the rebels in Saint-Domingue. In the aftermath of the 1793 epidemic, white Americans like Matthew Carey accused Philadelphia's free black population of exploiting their purported immunity and white susceptibility to extort exorbitant prices for nursing, removing dead bodies, and digging graves. 17

While Absalom Jones and Richard Allen, free black ministers, contested Carey's account of black immunity and treachery, many white Americans persisted in associating yellow fever with race, especially during the Haitian Revolution. Philadelphia's contagionists believed that SaintDominguans were the source of the city's 1793 epidemic, but even climatists, who believed the disease generated from local conditions, cited rotting Saint-Dominguan coffee as a potential origin. $^{18}$

${ }^{15}$ See Andrea Stone, Black Well-Being, and Sharla M. Fett, Working Cures, both for how white medical institutions legitimated black enslavement, and for how free and enslaved black people resisted the disciplinary mechanisms of white medical authority.

${ }^{16}$ For a thorough historiography of how medical historians have almost universally ascribed to the belief in black genetic immunity, and why this belief is invalid, see Espinosa's "The Question of Racial Immunity to Yellow Fever.”

${ }^{17}$ See Carey's “A Short Account." Jones and Allen published a rebuttal, "A Narrative," that detailed how many black people had suffered during the epidemic and yet still assisted their black and white brethren. For an overview and reading of Carey and Jones and Allen's debate, see Gould, "Race, Commerce, and the Literature of Yellow Fever" and Shapiro, Culture and Commerce, 295-96, which argues that the black community's response to the epidemic was strategic; it could serve as an especially persuasive piece of evidence for legal and moral arguments against the Fugitive Slave Act, even as such black benevolence could be used to shield runaway slaves.

${ }^{18}$ Gould, "Race, Commerce, and the Literature of Yellow Fever," 65. 
Moreover, many historians have argued that yellow fever played a pivotal role in the Haitian Revolution (1791-1804): it ravaged British troops who had been assisting white creoles against the gens de couleur, the free mixed race population, between 1794-98, and utterly destroyed French troops and Napoleon's New World ambitions between 1802-1804. ${ }^{19}$ By one estimate, yellow fever killed between $60-70 \%$ of French troops in Saint-Domingue. ${ }^{20}$ General Charles Leclerc himself, Napoleon's brother-in-law, died of the disease. As Silva describes, the influx of Europeans lowered the herd immunity in port cities and camps where the troops were concentrated, creating the perfect conditions for a pandemic.

Africans and African creoles in Saint-Domingue and Southern ports, as well as white refugees, were certainly more immune to yellow fever than European soldiers and northern early Republicans, but this was because of environmental exposure not genetic resistance. Moreover, if African creoles-Haitian or American —-were more resistant than white creoles, it was only because they were unable to flee to colder climes or to send their children to Europe to be educated (thus avoiding early exposure). But while slavery provided a compelling reason to link yellow fever to blackness and the Haitian Revolution, it is also true that the rebellion drove Europeans to the West Indies and West Indians to North America, setting in motion a circumAtlantic pandemic. Black people were not genetically immune or resistant, but the Haitian Revolution indelibly linked yellow fever to black revolutionary agency.

${ }^{19}$ On yellow fever's role in the Haitian Revolution, see McNeill, Mosquito Empires, chap. 7, and Silva, "Republic of Medicine." For thorough histories of the disparate events of the Haitian Revolution, including Britain's occupation and relationship with white creoles, and Leclerc's deadly expedition, see Jeremy D. Popkin, A Concise History, and Laurent Dubois, Avengers of the New World. On the end of Napoleon's New World empire, including the relationship between the Haitian revolution and the Louisiana Purchase, see David Geggus, "The Louisiana Purchase and the Haitian Revolution," which offers a useful historiography of the topic, and Ashli White, Encountering Revolution.

${ }^{20}$ McNeill, Mosquito Empires, 259. 
Yet other historians, including Michel-Rolph Trouillot, have criticized white historians for overemphasizing yellow fever, and, thereby, minimizing black loss of lives, black military prowess, and, ultimately, black agency in the Revolution's outcome. Like critics of the "germ theory of history," Edward E. Baptish argues that locating the Haitian Revolution in biological forces like yellow fever exculpates Europeans' role in disease morbidity and mortality and delegitimizes black power and agency. ${ }^{21}$ Interestingly, J.R. McNeill has modified these positions, claiming that Toussaint L'Ouverture and Jean-Jacques Dessalines sought to use "the power of the rainy season," and, thus, yellow fever, strategically as an "ally" in the fight against European slavery and colonial power. ${ }^{22}$ In this formulation, nonhuman agency does not necessarily dehumanize or deanimate humans; rather, humans and nonhumans worked in concert.

In a study of early America, disease, and a disease particularly linked to black people and bodies, it is important to remember that both yellow fever and black people were considered non or subhuman. As Joan Dayan describes of the French colonies' Code Noir, "Legally, their being was 'a being-for-others,' and their civil status, that of things," alternating between a "movable asset" and "garbage." 23 Their "only rights and duties... are those shared in society by beasts and objects" (204). Nicholas T. Rinehart, however, has argued that enslavement did "not operate by treating slaves as things_objects, commodities, goods," but by "treating them as persons who could suffer." 24 Even if black Americans were not considered non- or subhuman, black experiences in the new world challenged early modern paradigms of identity, autonomy, and

\footnotetext{
${ }^{21}$ See pp. 5-6 on "the germ theory of history." See Edward E. Baptish, "Hidden in Plain View," which examines the Haitian Revolution's historiography, including how yellow fever has functioned in this history.

${ }_{22}^{2}$ McNeill, Mosquito Empires, 261, 262.

${ }^{23}$ Dayan, Haiti, History, and the Gods, 203, hereafter cited parenthetically.

24 Rinehart, "The Man That Was a Thing," (35).
} 
even humanity. Monique Allewaert introduces the "parahuman" to explain enslaved humanity. They were "not legally or conceptually equivalent to human beings, while at the same time not being precisely inhuman. They were thus beside the human." ${ }^{25}$ Parahumanity was not just a colonial ideology of disempowerment and disenfranchisement; rather, Allewaert argues that black Americans were empowered "by staying in parahumanity," by staying in relation to fragmented bodies, animals, ecologies, and objects and, thus, resisting colonial definitions of identity, autonomy, and humanity (98). Like L'Ouverture allying with microbe, yellow fever and black rebels challenged the colonial ideologies that enabled both the white human and the novel: agency, intentionality, autonomy, interiority, and accessibility.

\section{Arthur Mervyn: A Plot without Character}

Widely considered the father of the American gothic, Charles Brockden Brown watched his close friend, Dr. Elihu Hubbard Smith, die of yellow fever during New York’s 1798 epidemic. Soon he contracted the disease as well. After these tragedies, in a "feverish two-year period," he composed Arthur Mervyn, part one (1798), Wieland (1798), Ormond (1799), Edgar Huntly (1799), and, finally, Arthur Mervyn, part 2 (1800). ${ }^{26}$ Published two years apart, Arthur Mervyn's two sections have been described as "practically two independent works." 27 The first part opens with Dr. Stevens, who finds the eponymous protagonist dying of yellow fever on the streets of Philadelphia. As Arthur recovers, he recounts his life: expelled from his home by an unscrupulous stepmother, he had travelled to Philadelphia to make a living. There, however, he

\footnotetext{
${ }^{25}$ Allewaert, Ariel's Ecology, 6, hereafter cited parenthetically.

${ }^{26}$ Goddu, Gothic America, 32. On Smith and Brown's relationship, see Bryan Waterman, Republic of Intellect, chap. 5.

${ }^{27}$ Loshe, The Early American Novel, 44.
} 
fell in with a confidence man and libertine, Thomas Welbeck. When Welbeck killed a man and seemed to kill himself, Arthur returned to the country. Yet yellow fever beckoned him back to the city, where he promptly contracted the disease. The second part follows Arthur as he tries to right Welbeck's wrongs, save his own reputation, and ascend the social ladder. Jane Tompkins has argued that the second half provides the rational, sentimental solution to the corrupt, gothicism of part one, but others have argued that the novel coheres through its consistent concern with early Republican dangers, including commerce, slavery and racism, and print culture. $^{28}$

As Davidson has contended, criticism of the novel's ambiguities-is Mervyn telling the truth? How and why does he look like multiple characters? How are the first and second parts connected? — has sought "a totalizing reading that largely resolves ambiguities and inconsistencies through explanation, judicious evasion, or, more often, by recourse to some overriding ideology that 'makes sense' of difference." ${ }^{" 29}$ She argues that "the author resolutely refuses to delimit his intentions," but here her own "overriding ideology" is too humanist (355). Arthur Mervyn's structure - the nesting of stories within stories within stories—challenges the relationship between agency and white, human subjectivity. The novel shows how nonhuman and purportedly nonhuman agencies—yellow fever and black rebels—-power a plot without accessible subjectivity or interiority, erasing Arthur's bourgeois subjectivity and interiority in the

\footnotetext{
${ }^{28}$ Tompkins, Sensational Designs, chap. 3. On commerce, see Goddu, Gothic America, chap. 2; on commerce and slavery, see Gould, "Race, Commerce, and the Literature of Yellow Fever"; Carrol Smith-Rosenberg, "Black Gothic"; Sean X. Goudie, "On the Origin of American Specie(s)"; and Shapiro, Culture and Commerce, chap. 6. On print, see Louis Kirk McAuley, "Periodical Visitations." On how narrative functions as prophylactic in addition to danger, see Waterman, "Medical Repository."

${ }^{29}$ Davidson, Revolution and the Word, 348-49, hereafter cited parenthetically.
} 
process. Ultimately, these aberrant agencies undermine the genre's focus on the protagonist and his heroic plotting.

It is notoriously difficult to summarize Arthur Mervyn's plot, but an important thread is Vincentio Lodi's story. Lodi is a young Guadeloupean planter who dies of yellow fever in Philadelphia, unwittingly bequeathing his money, narrative, and identity to Welbeck, the novel's villain. Though Welbeck promises to help Lodi's sister, Clemenza, he actually seduces and impregnates her. In fact, Welbeck only saves Arthur, because he looks exactly like Lodi and, thus, could serve the con. When Welbeck shoots and kills another man, he reveals this past and the real Lodi's story:

His father's name was Vincentio Lodi. From a Merchant at Leghorn, he had changed himself in to a planter in the Island of Guadeloupe. His Son, had been sent, at an early age, for the benefits of education to Europe. The young Vincentio was, at length, informed by his father, that, being weary of his present mode of existence, he had determined to sell his property, and transport himself to the United States. The son was directed to hasten home, that he might embark, with his father, on this voyage.

The summons was cheerfully obeyed. The youth on his arrival at the Island found preparation making for the funeral of his father. It appeared the elder Lodi had flattered one of his slaves with the prospect of his freedom, but had, nevertheless, included this slave in the sale that he had made of his estate. Actuated by revenge, the slave assassinated Lodi in the open street and resigned himself, without a struggle, to the punishment which the law had provided for such a deed. ${ }^{30}$

${ }^{30}$ Brown, Arthur Mervyn, 92-93, hereafter cited parenthetically. 
Lodi's narrative condenses the novel's abiding attention to the relationship between the West Indies, slavery, yellow fever, and the early Republic, but this relationship is complicated through its narrative structure: the frame tale. ${ }^{31}$

At first, Arthur Mervyn seems to be Dr. Stevens's transcription of Arthur's oral testimony. Teresa A. Goddu describes part one as "a series of framed narratives": Stevens (Arthur (Welbeck)). ${ }^{32}$ She argues that Stevens ultimately controls Welbeck's "gothic narrative" through "his enlightenment frame" (46). In turn, the second part reveals that the novel is actually, “Arthur's version of Steven's narrative of Arthur's oral autobiography” (47): Arthur (Stevens (Arthur (Welbeck))). ${ }^{33}$ Yet Goddu misses what Lodi's story reveals: Welbeck is never the center of the frame.

Rather, the frame centers the unnamed slave, who kills Lodi for denying his promised liberty: Welbeck (Lodi, Jr. (Lodi, Sr. (unnamed slave))). Inside Welbeck's story is Lodi's, and inside Lodi's is his father's, and inside his father's is the unnamed slave - a nonhuman human and an agential thing. This matryoshka's heart, therefore, interrogates agency. If black people were without agency, subjectivity, or humanity, as racist and pro-slavery discourses maintained, then how could they rebel, fight for liberty, and understand and meet the repercussions of the law as Lodi's slave does? Or, to put it another way, if black slaves act, possess interiority, remember promises, and exact justice, then how can they be things or property? By killing Lodi, Sr., the man refuses not just his status as transferable property but also the inextricable relationship between agency and white humanity.

${ }^{31}$ On this nexus of concerns, see, especially, Shapiro, Culture and Commerce, chap. 5, and Goudie, Creole America, chap. 6.

${ }^{32}$ Goddu, Gothic America, 46, hereafter cited parenthetically.

${ }^{33}$ Goddu, Gothic America, 47, hereafter cited parenthetically. 
At the heart of the novel, therefore, is an agent that should not be but that nonetheless powers the plot. Without him, Lodi, Jr., would not have returned to Guadeloupe, would not have inherited his father's wealth, would not have contracted yellow fever and died. In turn, Welbeck would not have sheltered Arthur, and Arthur would not have felt compelled to correct Welbeck's injuries in the second part. Welbeck, telling Lodi's story, claims the unnamed man was motivated by revenge, but we never access his unmediated story or interiority — only the effects of his actions. Thus, the novel becomes a series of causes and effects without motivation or intention - or without accessible motivation and intention, a plot without character. The unnamed slave challenges the relationship not only between agency and white humanity but also between white human interiority and narrative.

Yellow fever similarly compels the novel without accessible reason or rationale. In her network-theory analysis, Stacey Margolis argues that though critics have used the metaphor of contagion to explicate the novel, Brown never represents the disease as contagious—or, at least, does not consistently represent the disease as contagious. Instead, yellow fever is simultaneously "invisible" and "hypervisible"; though it spread in random, disordered ways, its symptoms are unavoidably manifest. Ultimately, she contends, there is no "dark, hidden agency" that explains the relationships between characters, the plotting, or yellow fever's spread, no conspiracy "governed by individual intention and comprehended by individual knowledge"_only senseless movement and unpatterned networks. ${ }^{34}$ While Margolis denies Brown a contagionist position, Sari Altschuler forwards a more qualified reading, arguing that Arthur Mervyn represents both climatist and contagionist positions but "resists aligning itself with either side of the medical

\footnotetext{
${ }^{34}$ Margolis, "Network Theory," 353, 351.
} 
debate." ${ }^{5}$ " $[\mathrm{D}]$ welling in uncertainty," she argues, "produces the feeling of disease in Brown's reader," placing them in the uneasy, unclosed position and perspective of illness (76). Margolis and Altschuler may disagree on Brown's intentions, but they and I agree on its effect: an uncertain and senseless plot that resists reason and logic. The feeling that this plotting produces is not only that of illness, as Altschuler contends, but that of the nonhuman — both of being made non- or subhuman by illness and of the nonhuman that produces illness. Like the unnamed slave, yellow fever drives the plot even though we cannot access its intentions or desires, its character.

In this way, the novel yokes yellow fever to black agencies—first, through the Lodi family's aborted genealogy. Whereas a black man kills the elder Lodi, yellow fever claims the younger. If we collapse the characters, as their shared name begs, then the relationship between black rebels and yellow fever becomes clearer: nonwhite and nonhuman agents not only affect and effect, but through that affecting and effecting radically undermine white supremacy. Both yellow fever and the unnamed, rebellious slave imperil the Lodi family, disassociating agency from whiteness and narrative from white humanity. And if Arthur himself recalls Lodi through their "uncanny resemblance," then yellow fever and the unnamed slave imperil Mervyn's narrative - the novel —as well. ${ }^{36}$ After all, Lodi's death introduces yellow fever to the plot, linking yellow fever to the West Indies (albeit to Guadeloupe rather than Saint-Domingue). ${ }^{37}$

\footnotetext{
${ }^{35}$ Altschuler, The Medical Imagination, 76, hereafter cited parenthetically.

${ }^{36}$ Goudie, Creole America, 187.

${ }^{37}$ Perhaps Lodi is Guadeloupean rather than Saint-Dominguan to mitigate the contagionist position and complicate the novel's medical position, as Altschuler argues. Interestingly, White argues in Encountering Revolution that white Americans perceived Guadeloupe's transition from slavery to freedom as "relatively smooth" (111), demonstrating the importance of "white consensus" in cultural stability (112). Yet, as Dayan points out, Guadeloupe's restoration of slavery in 1802 lost French General Leclerc an alliance with Saint-Dominguan General Dessalines, losing the entire colony (150-51).
} 
Second, Arthur Mervyn conjoins yellow fever and black rebels in the famous mirror scene. After his disastrous encounter with Welbeck, Arthur quits Philadelphia for the bucolic Hadwin farm, but yellow fever beckons. Reversing the course of those fleeing the epidemic, Arthur hastens to the city to return Lodi's fortune and find Susan Hadwin's missing paramour, Wallace. When Arthur finds Wallace, he is nearly dead, mutated by yellow fever into a cold, pulseless "object" (147). As Mervyn turns from this man-made-object, he peers into a mirror and sees "a human figure" or an "apparition" in the glass, thinking "that the dying man had started from the bed" (148). Instead, Arthur actually sees a large, scarred man "with tawny skin," who promptly knocks him unconscious (148). Both Sean X. Goudie and Carroll Smith-Rosenberg read this scene as a gothic interrogation of race and class in the making of the early Republic. Stephen Shapiro suggests that this black man could be a runaway slave, his violence a rational reaction to Arthur, who acts like a slave-catcher when he breaks into the house during the epidemic. ${ }^{38}$ Thus, as Goudie, Smith-Rosenberg, and Shapiro argue, this mirror scene asks the reader to perceive the black man and Arthur as reflections of each other, as intertwined and constitutive as chattel slavery and the new United States

What these readings elide, however, is that the reflection also includes Wallace-a manmade-object by yellow fever and, thus, yellow fever itself. Moreover, when Arthur peers into the mirror he himself is already undergoing yellow fever's "work of corrosion and decomposition," having "imbibed" the seeds of the disease while searching for Wallace (144). Like Wallace, Arthur will soon be dying of -objectified by—yellow fever. When he awakes from the black man's blow, he discovers that he has been stuffed into a coffin, prematurely but suggestively

\footnotetext{
${ }^{38}$ Goudie, Creole America, 189-90; Smith-Rosenberg, "Black Gothic," 254-55. Shapiro, Culture and Commerce, 295-96.
} 
classified as dead, an inanimate corpse, thing, or object. During the extraordinary circumstances of the epidemic, the reflection collapses these characters, lateralizing and even conflating the bourgeois upstart Mervyn, the black man, and the disease. Yellow fever, therefore, not only imperils Mervyn's narrative or the novel's plot but also his very identity and character.

The mirror scene is reflected and refracted in the pivotal stagecoach sequence in the novel's second part. In this scene, Arthur travels to Baltimore to make amends for Welbeck's crimes. As he rides the coach, he analyzes his travelling companions, "a sallow Frenchman from Saint Domingo, his fiddle-case, an ape, and two female blacks" (370). He watches the SaintDominguan hum and yell at the ape, the ape eat an apple, and the black women "gaze[] with stupid wonder, and an exclamatory La! La! upon the passing scenery" and "chatter[] to each other in a sort of open-mouthed, half articulate, monotonous, and sing-song jargon” (370). Goudie argues that Mervyn uses "racist ethnological discourse to frame the scene," transforming into a bourgeois natural historian under Dr. Stevens's tutelage. ${ }^{39}$ Waterman similarly contends that the scene proves "a natural history diorama," in which Mervyn "catalogs and categorizes these others without ever throwing himself into the mix, creating for himself a sense of critical attachment." 40 While the black women "observe" the ape, and Mervyn observes them, Mervyn believes that they "are unable to comprehend or articulate what they see" (237). Both Goudie and Waterman argue that this scene pointedly highlights anxieties about race, including the Republic's indebtedness to slavery and the contagious threat of Saint-Domingue's slave rebellion. ${ }^{41}$

\footnotetext{
${ }^{39}$ Goudie, "On the Origins," 75.

40 Waterman, "Medical Repository," 237, hereafter cited parenthetically.

${ }^{41}$ On commercial anxiety, slavery, and this scene, see Goddu, Gothic America, chap. 2. On the relationship between these anxieties and the West Indies more broadly, see Woertendyke, "Haiti and the New World Novel"; Smith-Rosenberg, "Black Gothic"; and Goudie, Creole America,
} 
Arthur may frame this scene, but nothing is at its center. Though Arthur observes like a natural historian and racist ethnographer, we never gain access to his conclusions:

As to me my thought was busy in a thousand ways. I sometimes gazed at the faces of my four companions, and endeavored to discern the differences and samenesses between them. I took an exact account of the features, proportions, looks, and gestures of the monkey, the Congolese, and the Creole-Gaul. I compared them together, and examined them apart. I looked at them in a thousand different points of view, and pursued, untired and unsatiated, those trains of reflection which began at each change of tone, feature, and attitude. [emphasis in the original] (370)

If, as critics have argued, Arthur partakes in a dehumanizing scientific observation, why does he not theorize about "the differences and samenesses" or draw any conclusions about what he sees? When he begins to consider what might happen in Baltimore, he decides, "I will not describe my dreams. My proper task is to relate the truth. Neither shall I dwell upon the images suggested by the condition of the country through which I passed. I will confine myself to mentioning the transactions connected with the purpose of my journey" (371). In this scene, then, the reader observes Arthur observing, but does not learn his scientific conclusions, impressions of the scenery, or "dreams" about the future. Though Bill Christopherson argues that Arthur's "singular presence... unifies the novel," he also admits that the novel "threatens to become a tale told by several idiots, signifying nothing." 42 At the heart of this scene, just as at

chap. 5. For more on how white Americans reacted to white Saint-Dominguan refugees, a reaction that ranged from charity to skepticism, see White, Encountering Revolution; James Alexander Dun, "(Mis)reading the Revolution"; and Alfred N. Hunt, Haiti's Influence on Antebellum America, chap. 2.

${ }^{42}$ Christopherson, Apparition in the Glass, 88. 
the heart of Lodi's tale, is a character who acts without interiority, who observes without concluding — a plot without character.

Though Mervyn's scientific gaze is objectifying whether he draws any conclusions or not, his evacuated interiority actually conflates him with rather than distances him from his travelling companions. On the one hand, the correlation of the black women and the ape, enabled by adjectives like "open-mouthed" and "half articulate," is overtly racist, foreshadowing the way nineteenth-century apologists would use science to define black people as "subhuman" and thereby justify slavery. On the other hand, Arthur's missing interiority, his silent monologue, aligns him with the women who talk but are not understood (by Mervyn and the reader at least), who act and effect but are not known. Like the reflection that lateralizes a white man, a black man, a diseased man, and yellow fever, this stagecoach scene begins to collapse into Mervyn's lateralizing list of uknowable agents—“a sallow Frenchman from St. Domingo, his fiddle-case, an ape, and two female blacks" (370). Ian Bogost argues, "Lists remind us that no matter how fluidly a system may operate, its members nevertheless remain utterly isolated, mutual aliens." ${ }^{43}$ When Mervyn's observations prove empty, he too joins this list of “mutual aliens.” As critics have argued, Arthur's interiority, morality, and truth are as opaque to us as the women's are to him. In fact, at least one critic has argued that Mervyn himself is the novel's true villain. ${ }^{44}$ Ultimately, he remains an alien to us.

At the end of this scene, Mervyn rejects hypotheses, inferences, and dreams, dedicating himself to his "proper task"- "the truth" (371). The truth, he christens, is "transactions":

\footnotetext{
${ }^{43}$ Bogost, Alien Phenomenology, 40.

${ }^{44}$ See James R. Russo's “"Chameleon of Convenient Vice”" and Patrick Brancaccio's "Studied Ambiguities." For a quick overview of the literary debate on Mervyn's reliability, see Davidson, Revolution and the Word, 339-40.
} 
observing his companions, the women chatting with each other, the ape eating an apple, the Saint-Dominguan yelling at the ape, the fiddle case housing the fiddle. In this way, he privileges action and interaction rather than interiority and intentionality. The Royal Society's rules for natural historians may have warned against overly confident assertions of hypotheses and deductions, but they also emphasized the natural historian himself. Without his authenticity and credibility, the genre could not succeed. ${ }^{45}$ While Stevens claims, "the face of Mervyn is the index of an honest mind," Arthur has misled and lied to him (229-30). ${ }^{46}$ What the novel and especially the stagecoach scene reveals, then, is transaction without interiority, or action, interaction, and intra-action without an accessible and effective intentionality. The novel, therefore, represents a plot without character.

While Baym has argued that plot was far more important to early novel readers and reviewers than character, Arthur Mervyn demonstrates something finer - that plot does not need character. Causes and effects do not require intentional agents with accessible interiority — the restricted domain of white humans at the time. Instead, yellow fever and black rebelsnonhuman, subhuman, parahuman, or, at the very least, not white humans - impacted real lives and real stories. The novel does not seem to argue that enslaved people and disease do not have interiority or intentionality; rather, their interiorities and intentionalities are as opaque as the eponymous hero's. Arthur Mervyn recognizes that agency is not limited to white humans, that yellow fever and black rebels affected material lives and literary genres, but Arthur remains the titular protagonist. Thus, it is not my argument that Brown intended to explore aberrant agencies, but that these aberrant agencies nonetheless shaped his first novel.

${ }^{45}$ See chap. 1, pp. 34-39, on the Royal Society and natural historical form.

${ }^{46}$ See Margolis, "Network Theory," and Goudie, Creole America, 182-84, on Mervyn's face and reliability. 


\section{Ormond: A Novel without an Author}

Yellow fever dominates the first half of Arthur Mervyn, but it is far less pervasive in Ormond; or, the Secret Witness. While the disease similarly enables Ormond's plot, it fails to follow any etiological or symbolic logic. Christopherson asserts that yellow fever represents a "comprehensive vision of evil." ${ }^{47}$ Yet, though sometimes contagious and deadly, the disease is also liberating, relieving, "false social pressures," including sociability and commercialism. ${ }^{48}$ The narrator, Sophia Westwyn, avers, "none can tell whether this destructive pestilence was, on the whole, productive of most pain or most pleasure. ${ }^{49}$ Thus, in Ormond, yellow fever signifies inconsistently, failing to conform to its more conventional tropes as gothic horror or didactic punishment. ${ }^{50}$

Like Arthur Mervyn, Ormond's plot is difficult to pin down: Constantia Dudley is impoverished by a confidence man and a gullible father, but she steers her family through destitution and epidemic through thrift and hard work. When the titular Ormond enters the text, he at first seems a savior to Constantia, curing her father's blindness, remunerating their debts, and offering stimulating conversation. Yet the novel quickly reveals his villainy. Despite already keeping a mistress, he desires Constantia as well, whether she accepts his advances or not. Again, like Arthur Mervyn, characters are doubled and tripled; almost every character looks and acts like another. Whereas Arthur Mervyn's reflections delegitimate the interiority that ground

\footnotetext{
${ }^{47}$ Christopherson, Apparition in the Glass, 63

${ }^{48}$ Robert A. Ferguson, "Yellow Fever and Charles Brockden Brown," 299.

49 Brown, Ormond, 94, hereafter cited parenthetically.

${ }^{50}$ Criticism of both of Brown's yellow fever novels usually center the disease as a gothic convention: on Brown's canon, see, for example, Loshe, The Early American Novel, 44-50, and Fiedler, Love and Death, 133-42; on Arthur Mervyn, Goddu, Gothic America, chap. 2; and, on Ormond, Stern, Plight of Feeling, chap. 4.
} 
exclusionary definitions of agency, character, and novelization, Ormond's doubling empowers, aligning and allying those who refuse to meet the villain's white male standards-yellow fever, Constantia, her revolutionary double, Martinette, and the black Saint-Dominguans she recalls. Allied with its doubles, yellow fever resists Ormond's machinations, his belief that his intentions are necessarily effective. The disease challenges the novel's emphasis on the singular, eponymous, plot-driving character — and, thus, the singular, plot-driving author — and instead emphasizes complicated yet vital human-nonhuman intra-action.

Though Enlightenment principles inform both Arthur Mervyn and Ormond, yellow fever proves an irrational, unmappable adversary. ${ }^{51}$ The novel initially seems to position fear and irrationality as the source of disease and death. In turn, rationality functions as prophylactic and cure for the Dudley's poverty and yellow fever. ${ }^{52}$ When Whiston, the Dudleys' neighbor, discovers that his sister has developed symptoms of yellow fever, he flees the city and leaves her to die, "allow[ing] his terrors to overpower the sense of what was due to his sister and to humanity" (74). Though the country should have been safer, he soon develops the disease. A family, too terrified of contagion to help, watches as he dies alone, driven mad by thirst. They soon die too. Both Whiston and the family die — seem to be punished—because they allow their irrational fear of contagion to sever their filial and social bonds.

Likewise, fear of the disease rather than the disease itself kills Baxter, the husband of Constantia's friend and washerwoman, Sarah. Awakened one night by a strange light emanating from his French neighbor's house, Baxter creeps from his home and climbs the partition to peer

${ }^{51}$ On rational individualism in Arthur Mervyn and contractualism in Ormond, see, for example, Roberts, Gothic Subjects, chaps. 1 and 2. See also Stern, Plight of Feeling, chap. 4, on sensibility and fellow feeling in Ormond.

52 See Maureen Tuthill, Health and Sickness in the Early American Novel, chap. 4, on the relationship between rationality and health in the text. 
into the adjacent yard. Baxter voyeuristically watches his neighbor inter a body, a body he assumes is dead of yellow fever. His "teeth chattered" at the terrifying thought of "how near he might now be to the source of infection" (91). Although "caution had hitherto availed him...[n]ow, through his own inadvertency, he had rushed as he believed into the jaws of the pest" (92). The narrator closes this scene with its lesson: "His case may be quoted as an example of the force of the imagination" (93). Thus, between these two scenes, Brown seems to argue that those who allow their fear to overpower their reason, whose emotional disequilibrium compels them to abandon their sentimental ties, will be punished. Though the narrator offers a mechanical explanation — "panic" ripens "the seeds of this disease" already planted (93)—Brown's narrative metes out narrative justice by killing men who act irrationally and reprehensibly.

Two points, however, mitigate this symbolic logic: Constantia, the novel's exemplar of rationality, contracts the disease, and Dudley, the most fearful character after Whiston, does not. Although the novel has carefully crafts and even champions Constantia's supreme rationality, we learn that she lapses: she "judged like the mass of mankind from the most obvious appearances, and was subject, like them, to impulses which disdained the control of reason" (70). ${ }^{53}$ And although she attempts to quarantine her body and mind from poisonous miasmas, she "found it vain to contend against the inroads of sadness," and soon "the grave seemed to open for her reception” (82). Maureen Tuthill argues, "Constantia illustrates how strategic thinking and temperate behaviors can accentuate good health"; while she "is not immune to anxiety...she manages it through continual effort." ${ }^{54}$ Yet even the most rational character in the novel cannot properly protect herself from yellow fever.

${ }^{53}$ On Constantia's rational education, see, for example, Elizabeth Jane Wall Hinds, "Private Property."

54 Tuthill, Health and Illness, 90, hereafter cited parenthetically. 
Moreover, Dudley, the most terrified member of the household, neither dies nor even contracts the fever. Despite wildly expounding on the family's inevitable doom - "it will surely reach us at last, and then, whither shall we fly? For the rich, the whole world is a safe asylum; but for us, indigent and wretched, what fate is reserved but to stay and perish? If the disease spare us, we must perish by neglect and famine" (65) —Dudley somehow survives the epidemic. Tuthill implies that Dudley avoids the infection by choice, that his earlier ailments were a "calculated" ruse designed to "relinquish him from the responsibility of self-care without completely destroying his health" (94). Still, this does not explain how the most fearful character evades the pestilence. If, according to the logic divulged in Whiston's, Baxter's, and even Constantia's cases, disease breads through fear, Dudley should be utterly ravaged by yellow fever, probably even dead of it. If health is a choice reducible to a person's rationality, Dudley, certain that he will be "the next victim," has effectively thrown a welcoming party for the disease's generation. And if rationality really rules health and the text, the novel's medical and textual logic shouldn't unravel as completely as they do in Dudley's case.

In Ormond, therefore, it is not that yellow fever is "patternless," as Margolis argues about Arthur Mervyn; rather, Brown creates a pattern but does not apply it evenly. Elsewhere Brown clearly uses disability to punish villainy: Dudley's alcoholism is disciplined by blindness. ${ }^{55} \mathrm{In}$ this logic, Dudley should die, and Constantia should never even contract the disease. Yet yellow fever, however, provokes both "pain" and "pleasure" (94). It is not Christopherson's "comprehensive vision of evil," and, thus, cannot neatly serve as narrative justice. Rather, it disrupts Dudley's and Constantia's characterization, the novel's symbolic economy, and the plot

\footnotetext{
${ }^{55}$ Christopherson argues that Dudley's blindness actually punishes incest. Apparition in the Glass, 59-61.
} 
itself. When Sophia, the narrator, concludes this portion of the tale, she claims, "Such is the motley and ambiguous condition of human society, such is the complexity of all effects, from what cause soever they spring" (94). She foregrounds "human society," but her emphasis on palpable causes and unknowable effects speaks to yellow fever's inaccessible presence in the historical moment and in the text itself. Like Arthur Mervyn, which recognizes that action, movement, and plot do not require a liberal, bourgeois intentionality, Ormond acknowledges that effects can rarely be traced to their causes. Yellow fever is not necessarily irrational, but Brown cannot submit the disease to his rationale - to the constraints of the gothic and didactic disciplinary mechanisms, nor to the genre itself.

Ormond, the text's undeniable villain, refracts this ideology. Though he admits the limits of human intentionality, he also actively manipulates situations, others, and his race in order to control and deliver his desired outcomes:

A mortal poison pervaded the whole system, by means of which every thing received was converted into bane and purulence. Efforts designed to ameliorate the condition of an individual were sure of answering a contrary purpose. The principles of the social machine must be rectified, before men can be beneficially active. Our motives may be neutral or beneficent, but our actions tend merely to the production of evil. (127) As critics have noted, this passage and Ormond's general character seem to reflect many of the anxieties of the new Republic, including tensions between the social contract and a diverse population and liberty and equality. ${ }^{56}$ Ormond, however, also probes intentionality: things tend towards "evil" regardless of human "motives." Whereas the text emphasizes yellow fever's “complexity of effects," Ormond argues that a particularly human definition of agency-

\footnotetext{
${ }^{56}$ See, for example, Roberts, Gothic Subjects, chap. 1.
} 
intentionality—is ineffectual; intentions and consequences rarely align. In this way, Ormond not only perverts early Republican ideals but also devalues human agency.

Yet, even though Ormond rejects the concept of "good intentions" and, thereby, the concept of intent in toto, he conspires to manipulate, control, and dominate others. He aspired to nothing more ardently than to hold the reins of opinion, --to exercise absolute power over the conduct of others: not by constraining their limbs or by exacting obedience to his authority, but in a way of which is subject should be scarcely conscious. He desired that his guidance should control their steps, but that his agency, when most effectual, should be least suspected. (180)

Ormond, therefore, seeks to exert his agency by both dominating others and hiding that very domination. He does not want to use violence or commands but subtlety, so that the dominated believe they remain the masters of their own actions, agents with intentionality and purpose. On the one hand, his logic is contradictory: a belief in the limits of human intentionality would seem to contradict such a profound faith in one's own agency. On the other hand, a belief in the general limits of human intentionality does not necessarily impair one's own sense of exceptionalism. As a villain, it comes as no surprise that Ormond thinks himself above the law, even his own. Ormond does not personify yellow fever, as Christopherson argues. Rather, both are variations on a central theme. ${ }^{57}$ Whereas yellow fever disrupts the relationship between rational, traceable causes and effects, Ormond disrupts the relationship between a particularly human intentionality and efficacy—except where he's concerned.

The villain, however, is also doubled in his purported sister Martinette. Until the end of the novel, Martinette compels Ormond's plot in largely invisible ways, buying the Dudley's flute

${ }^{57}$ Christopherson, Apparition in the Glass, 68. 
and burying the body that terrifies Baxter to death. When she and Constantia finally meet, she reveals her backstory over a series of interviews, describing action in the American and French Revolutions and her role in Baxter's tale. Constantia questions how she was able to find "shelter" in the aftermath of her father's death, when " the fear of infection would have shut"” all doors against her (208). Martinette responds,

"Hast thou forgotten that there were at that time at least ten thousand French in this city, fugitives from Marat and from St. Domingo? That they lived in utter fearlessness of the reigning disease,--sung and loitered in the public walks, and prattled at their doors, with all their customary unconcern? Supposest thou that there were none among these who would receive a countrywoman, even if her name had not been Martinette de Beauvais? Thy fancy has depicted strange things; but believe me that, without a farthing and without a name, I should not have incurred the slightest inconvenience." (208)

She explains that the city was full of French and Saint-Dominguan refugees who were unafraid of yellow fever and, thus, hospitable to strangers (unlike the family that watches Whiston die). French creoles may have been immune to the disease from prior infection in the West Indies, but French metropolitans were likely as susceptible as most Republican Americans. Still, fleeing Saint-Dominguans' resistance may have given rise to the belief that "Frenchmen were exempt from this disease," as Baxter maintains while watching Martinette bury her father (87). Thus, Martinette not only reflects Ormond's hidden agency but also assumes Saint-Dominguan immunity and identity, condensing yellow fever and the Haitian Revolution as well.

Yet this Saint-Dominguan identity exposes the limits of her revolutionary fervor. Though Martinette fights in both the American and French Revolutions, "kill[ing] thirteen officers at Jemappes," and though she thrills at Robespierre's death and her return to the Revolution, her 
"love of liberty" does not extend to Saint-Domingue, or, at least, to black Saint-Dominguans (206). Not only does Martinette obviously know about the Revolution, blending in with its white refugees, but she even briefly stops in the colony on her way to fight in the American Revolution. And while the Haitian Revolution had not yet begun, a stop in the most infamous New World slave colony en route to combat colonial tyranny pointedly highlights her hypocrisy (not to mention the American Revolution's). Most importantly, like Lodi in Arthur Mervyn, Martinette's life and livelihood is supported by slavery, by her adoptive father's Guyanese plantation and "fortune" (204). Both her liberty and her love of liberty are predicated on black bondage. Shapiro suggests that Martinette may be a mixed-race woman, who kills and buries her master rather than her father (or master-father), hiding runaway slaves in her retinue and thus secretly aiding the revolutionary cause. ${ }^{58}$ Shapiro's argument is compelling, but it does not necessarily change mine. If we read Martinette as white, she not only fails to join the Haitian Revolution — a glaring absence for a self-described "adorer of liberty" (205)—but also survives through the stolen liberty of others. If we read her as mixed-race, as Shapiro suggests, she assumes a white, Saint-Dominguan identity. In either case, she paradoxically doubles and condenses Ormond, the Haitian Revolution, and yellow fever.

While Martinette's fortune and freedom is powered by slavery (regardless of whether she is white or mixed race), Ormond explicitly appropriates black identities, dressing in black face, changing his dialect, and posing as a chimney sweep in order to infiltrate the Dudley home. Julia A. Stern argues that Ormond "profits from assuming the (negative) power of blackness." ${ }^{59}$ His "racial cross-dressing, while affording the libertine a certain social invisibility, paradoxically

\footnotetext{
58 Shapiro, Culture and Commerce, 287-88.

59 Stern, Plight of Sympathy, 213, hereafter cited parenthetically.
} 
enables his unlimited access to the private sphere; the very property that makes blackness a liability can also prove a source of intimate knowledge about white culture" (215). Ormond assumes black agency, all the more potent because the culture assumed it was a non-agency.

Although Brown compels the reader to see Martinette and Ormond as parallel, particularly in their use of false identities, gender disrupts this similarity. In particular, it is important to remember that Martinette is a woman, who like black Americans and black Haitians fought for rights in a system that refused her any. Thus, while Ormond appropriates the "(negative) power of blackness" to pass as a non-person, the better to dominate, Martinette never poses as black. Instead, she appropriates the decidedly positive power of masculinity, crossdressing in order to fight in the Revolutions. Moreover, Shapiro argues that she also appropriates the positive power of whiteness - the direct inverse of Ormond. Martinette's freedom may or may not be predicated on slavery, she may or may not be mixed race, and she may or may not have supported the Haitian Revolution; nonetheless, the text aligns this complex, contradictory character with those black agents who rejected their culture's script, claiming the freedom and agency that the culture denied them. In this way, Martinette recalls yellow fever's ambiguity, its capacity to induce both "pain" and "pleasure." Yellow fever and black rebels may undermine her revolutionary characterization and expose her hypocrisy, but they also suggest more potent alliances than her manipulative brother. After all, both enable her to survive the epidemic.

To make things even more complex, Martinette also proves a double for the novel's heroine, Constantia. When Constantia first meets Martinette, she finds herself transfixed by the woman's similar appearance. Sophia, our narrator, presumes that Constantia was "unconscious of this resemblance," but she also claims that it was this uncanny similarity that "influence[d]" the heroine to "reverence" (98). As Constantia listens to the revolutionary's life story, she learns 
that they also share an abnormally masculine education. Though she is also "sensible" of "all the differences between them," she imputes these differences to "diversities of situation," nurture rather than nature (192). But when Martinette reveals that she has killed at least thirteen people, Constantia realizes, "The likeness which she had feigned to herself was no longer seen. She felt that antipathy was preparing to displace love" (207). With her ardor waning, Constantia decides that she and Martinette are nothing alike.

Yet Constantia grows more rather than less like her martial double in the remainder of the novel. When her father suggests a move to Europe, Constantia claims, "her mind had undergone the most signal revolution" (211). Primed by Martinette's revolutionary tale, Constantia thrills at the prospect of discoursing "with nature in her most august forms, with men in diversified states of society, with the posterity of Greeks and Romans, and with the actors that were now upon the stage" (211). In other words, Constantia is excited to close the gap between her and Martinette's "diversities of situation" (192). And while Constantia never takes this trip with her father, she does end the novel by travelling to Europe, but only after she has grown like Martinette in a more dangerous way—through murder.

Ormond and Constantia's tale closes with a duel. Even though she's rebuffed Ormond's advances repeatedly, he does everything in his power to claim her: first, he convinces Craig to kill Dudley, removing her father as an impediment to their consummation; then, when Sophia proves yet another obstacle, hiding Constantia from his licentious grasp, he discovers her hiding place. In the novel's final scene, Ormond determines to take what she will not give freely, arming himself with his phallus and the threat of rape- - "an evil worse than death" (274). Constantia, however, wields a penknife and kills Ormond. When Sophia finally arrives on the scene, Constantia explains, “"My stroke was desperate and at random. It answered by purpose 
too well...His heart was pierced, and he sunk, as if struck by lightning, at my feet" (274). Her attack might have been "desperate" and "random," the odds stacked against her, but righteousness was on her side. As in the didactic novels of the time, the heroine survives, while the villain dies.

Ormond may or may not have raped Constantia successfully, but he does succeed in objectifying and dehumanizing her. Roberts argues that Brown's description of Constantia"Her hands were clasped on her breast, her eyes fixed upon the ceiling streaming with tears, and her hair unbound and falling confusedly over her bosom and neck" (272) — suggests that Ormond actually has raped her. While Roberts reads this scene as an American commentary on British paradigms of purity, it also highlights how Ormond transforms Constantia into something not entirely human - at first, an object of lust, and, eventually, an inhuman murderer like Martinette. Roberts argues that Brown disciplines Constantia for refusing to creolize, that she becomes what she abhors as punishment. Yet her objectification also keeps her alive. She does not rely on human intentions and domination like Ormond. Instead, her efficacy is disassociated from her intentions, the causal "stroke" "desperate" and "random."

Following the likenesses and doubles in any of Brown's novels is a Herculean feat, but, in Ormond, the chain of connections that coalesces in the final scene-Constantia, Martinette, yellow fever, and the black rebels of the Haitian Revolution against Ormond, himself a double for Constantia, Martinette, yellow fever, and even blackness - functions similarly to Lodi's tale and the stagecoach scene in Arthur Mervyn. Constantia and Ormond condense the same agencies, but while Ormond maintains the efficacy of his subjectivity and his white male intentionality by manipulating others, Constantia's disconnect between intentions, cause, and effect aligns her with those aberrant agents that similarly challenged rational plots and accessible 
character. Ormond's death demonstrates the lesson that he fails to apply to himself - that "human" intentionality is limited, an unsatisfactory foundation for "agency" in a world where women murder, things rebel, and epidemics fail to signify. If Arthur Mervyn challenges the relationship between white humanity and agency, then Ormond's doubling, tripling, and quadrupling of characters suggests that intra-action powers and empowers character and narrative. In this way, both Arthur Mervyn and Ormond undermine the thrust of the author's intentionality that charges most literary scholarship. Brown's intentions certainly existed, but that does not mean they were effective, does not mean that other agents, including yellow fever and black rebels, did not also shape his novels

\section{Secret History: A Novel that Erases Yellow Fever to Save Form}

Leonora Sansay's yellow fever novels attempt to redress this formal quagmire, submitting those very same agents to the disciplinary mechanisms of form. Of all the texts gathered here, Secret History most explicitly grapples with the events of the Haitian Revolution. Whereas Brown's Arthur Mervyn is set at the beginning of the Revolution, Secret History takes place in its closing moments between 1802-1804. After Toussaint L'Ouverture fought alongside the Royal French forces to repel the alliance between white creoles and the British, and after Napoleon rose to power, L'Ouverture declared himself the Emperor of Saint-Domingue. Though he did not formally declare independence from France, he drew up a constitution and encouraged white refugees to return to their plantations to begin rebuilding the shattered economy - a call that the Secret History's protagonist, Clara, her refugee husband, St. Louis, and her sister, Mary, answer when they return to the island. In turn, Napoleon assembled "one of the greatest overseas military efforts any European power had ever undertaken" under the direction of his brother-in- 
law, General Leclerc, whose mission was to capture L'Ouverture, quash resistance, and reinstate slavery. ${ }^{60}$ Although Leclerc succeeded in seizing L'Ouverture, yellow fever ravaged the French troops, killing Leclerc and some 35,000-45,000 of his men. ${ }^{61}$ Of course, even more French men died at the hands of Jean-Jacques Dessalines, L'Ouverture's more violent replacement as leader of black Saint-Dominguans. Sansay's novel charts this moment in the Haitian Revolution and its aftermath, depicting Leclerc's death and his replacement by General Rochambeau, a man known for throwing lavish parties as the colony crumbled and for using starving dogs to kill black rebels. $^{62}$

Yet Secret History spends the least time on yellow fever of all the texts gathered here. Instead, the novel largely follows Clara's unhappy marriage to St. Louis, as recorded by her sister, Mary, in a series of letters to Aaron Burr. ${ }^{63}$ Clara escapes from St. Louis and Haitian creole life, tracing the circum-Atlantic rim where she eventually reunites with her sister before returning to Philadelphia. In Secret History, yellow fever is largely present by its conspicuous absence (like the Haitian Revolution in Ormond) — an absence made all the more perplexing given Sansay's historical context and form.

${ }^{60}$ Jeremy D. Popkin, A Concise History, 119. Though there is debate on when Napoleon decided to reinstate slavery - before or after Leclerc left for Saint-Domingue - his intention was clear by October 1802, when Leclerc promised freedom to the already freed population as payment for fighting for the French. See Dubois, Avengers of the New World, chaps. 11 and 12.

${ }^{61}$ McNeill, Mosquito Empires, 258-59.

${ }^{62}$ See Popkin, A Concise History, and Dubois, Avengers of the New World, for this history.

${ }^{63}$ Sansay's affair with Burr is infamous and probably over determines how her work is read. Dayan argues about Laura, "Cheated of marriage to one who was her lover as well as mentor...Laura's sad story is Leonora's own, and is also the story of the narrative of Secret History" (169-70). Sansay herself invited this reading, for as Drexler argues, she "leveraged her relationship with Aaron Burr" through the novel, "converting what for her had become a potentless patronage into something of value" ("Introduction" 32-33). The genre of the secret history applies not only to Madame Leclerc and General Rochambeau's scandals in SaintDomingue but also to Sansay's own with Burr. 
As many scholars have acknowledged, Sansay’s Secret History resists generic description. Brown himself placed it in the "History" section of his magazine; Elizabeth Maddock Dillon reads it as a particularly creole novel; Roberts emphasizes the "almost dizzying confluence of generic registers," including "the captivity narrative, the Barbary narrative, and the epistolary novel"; Gretchen Woertendyke argues that it is a "secret-history-as-novel," straddling the two genres. ${ }^{64}$ Sansay's work includes vestiges of a literary past, such as the secret history's emphasis on political history's scandalous truths, even as it strains toward the newer codes of the didactic novel. Still, Michael Drexler argues that debate on Secret History's genre "has been a cause for critical disinterest in the particularity of the text itself." 65 Secret History's particulars, including its absent particulars like yellow fever, are not antithetical to an analysis of form but constitutive contributors.

In particular, Sansay attempts to discipline the aberrant agencies that challenged Brown's novels - yellow fever and black rebels - through form. The secret history genre demanded historical and political verisimilitude, while the novel demanded didactic lessons. Yet yellow fever, associated with black liberty and white destruction, proved too dangerous and disruptive for the narrative to control. Her text cannot contain and tame their lesson: that black rebels were on the righteous side of history. Thus, in order to save form, Sansay eradicates yellow fever entirely, both as an historical phenomenon and as a literary symbol. Whereas Brown's novels undermine white, human intentionality, including that of the author, Sansay's attempts to reaffirm the figure of the intentional and effective writer through the disciplinary mechanisms of

${ }^{64}$ Dillon, "The Secret History"; Roberts, Gothic Subjects, 251; Woertendyke, "Romance to Novel." Additionally, Henri Petter includes it in his study, The Early American Novel, describing it as "picturesque," "martial," "romantic," and even a "tourist guide" (377-78) 65 Drexler, "Brigands and Nuns," 184. 
form. Still, this same affirmation nonetheless exposes a how yellow fever ruptured the early novel's formal seams.

Yellow fever is largely but not entirely absent from the text. In Mary's very first letter, she explains, "Clara has had the yellow fever. Her husband, who certainly loves her very much, watched her with unceasing care, and I believe, preserved her life, to which however she attaches no value since it must be passed with him" (63). Despite yellow fever's omnipresence in SaintDomingue, these two sentences constitute the text's entire meditation on the subject. They seem to function to foreshadow the text's primary concern: the gothic state of Clara and St. Louis's marriage. To Mary, the marriage seems perfect. St. Louis cares for Clara, and his careful attention saves her life. Yet Clara would rather die than continue living with St. Louis. Initially, therefore, yellow fever functions sentimentally, allowing the lover to care for the loved (replayed in Laura), but the representation quickly turns gothic, revealing a marriage worse than pestilence. While any illness could suffice, yellow fever was particularly associated with the emergent American gothic, as Brown's earlier novels suggest. ${ }^{66}$ Moreover, it was an historically accurate disease, an important value of the secret history genre. That is, Sansay strategically employs yellow fever as a gothic and historical vehicle, unmasking the sentimental scene of illness and the sentimental marriage itself. ${ }^{67}$

Despite Sansay's use of the disease, and despite the pervasive connections between yellow fever and the Haitian Revolution, she never explicitly links black Saint-Dominguans to yellow fever. Instead, she links black rebels to the environment:

${ }^{66}$ Despite actually dying of yellow fever, Sansay's Leclerc dies of a "fever" (69).

${ }^{67}$ Similarly, Roberts argues that Sansay uses the extreme setting of the Revolution to explore how marriage functions as a gothic household; Clara and Mary's incessant movement at the end of the novel suggests an alternative to the domestic model of the home. Gothic Subjects, chap. 2. 
The negroes have felt during ten years the blessing of liberty, for a blessing it certainly is, however acquired, and they will not be easily deprived of it. They have fought and vanquished the French troops, and their strength has increased from a knowledge of the weakness of their opposers, and the climate itself combats for them. Inured to a savage life they lay in the woods without being injured by the sun, the dew or the rain. A negro eats a plantain, a sour orange, the herbs and roots of the field, and requires no cloathing, whilst this mode of living is fatal to the European soldiers. The sun and the dew are equally fatal to them, and they have perished in such numbers that, if reinforcements do not arrive, it will soon be impossible to defend the town. (73-74)

This passage regurgitates one of the retroactive justifications of slavery - that the environment was better suited to black over white people, an argument also applied to differential disease morbidity and mortality. Moreover, by claiming that "the climate itself combats for them," Sansay foreshadows those historians who would emphasize yellow fever's role in the Haitian Revolution, seemingly incapable of recognizing black agency in the outcome.

Though yellow fever would seem a logical extension of the "climate," particularly during the time, it is conspicuously absent. Sansay explicitly cites the sun, dew, and food as allies in the war, she fails to mention yellow fever, understood to be at least partially environmental, as Philadelphia's debate between contagionists and climatists highlighted. Moreover, before early Americans understood disease vectors and immunity, they believed "that the native-born enjoyed immunity because they were accustomed since birth to tropical heat and humidity, while the 'unacclimated stranger' was highly vulnerable because he had not yet adapted to the climate."68 Yellow fever was conflated with the local climate- hence the moniker "stranger's disease. If

\footnotetext{
68 Jo Ann Carrigan, "Yellow Fever: Scourge of the South," 63.
} 
Sansay knew the disease's historical context (its omnipresence during the revolution, particularly at the moment of Leclerc's death, recorded in the text) and employed the disease elsewhere for gothic effect, then why is yellow fever missing here, where it could also function historically and gothically?

She erases yellow fever where its inclusion would seem most logical and narratively functional, because it exposes too dangerous a lesson about white fantasies about SaintDomingue. In the same letter that she claims, "the climate itself combats for them," Mary fantasizes about a pre-Revolution life, where the rebelling slaves were reduced to order... where I should repose beneath the shade of orange groves; walk on carpets of rose leaves and frenchipone; be fanned to sleep by silent slaves, or have my feet tickled into extacy by the soft hand of a female attendant...to wander over flowery fields of unfading verdure, or through forests of majestic palm-trees, sit by a fountain bursting from a savage rock frequented only by the cooing dove... (73)

As Drexler maintains, "Mary temporarily yields to Creole fantasy," finding herself "seduced by the object of their collective desire: a return to slaveholding and luxurious ease." ${ }^{69}$ Dayan, however, suggests that Mary's "sentimental idyll of plantation life" derives from the material circumstances of the Revolution. ${ }^{70}$ By fall of 1803, the French were circumscribed to Le Cap, "a piece of land about two miles long," blocked "by the English at sea and the blacks on land" (152). Thus "imprisoned in one area of Le Cap," Sansay "can only imagine what she does not know" (158). Mary fantasizes about a prelapsarian immersion in the environment, underwritten and enabled by chattel slavery. This fantasy, however, erodes when the letter reveals that the

${ }^{69}$ Drexler, "Brigands and Nuns," 190.

${ }^{70}$ Dayan, Haiti, History, and the Gods, 158, hereafter cited parenthetically. 
environment refuses to naturalize black bondage and white plenitude, and instead works in concert with black rebels to overthrow white oppression. Revolution rather than bondage becomes "natural" and right—a terrifying lesson for a white American writer.

As the following letter demonstrates, Sansay represses yellow fever because its lesson is too damning and disruptive to the novel's form. Mary recounts a duel between a French officer and a creole planter. The newly arrived French officer mistakenly addresses the creole's wife as citoyenne, the moniker applied by all good Republicans to other citizens after the French Revolution. She is offended, her husband intervenes, and the French officer challenges him to a duel. After a spat about weapons (the officer wants to use a rifle, to which the husband retorts that he would fight with a canon), "the officer fired without effect. Monsieur C---, with surer aim laid his antagonist lifeless on the ground" (78). Though the riff on weapons reads as a humorous criticism of the performative masculinity that undergirds the duel, a consistent point of criticism for Sansay, the duel seems to properly punish the impudent party, the French officer-impudent not only in carelessly addressing a woman but also by presuming to simply transfer French codes of conduct to the Creole situation. ${ }^{71}$ Sansay would seem to emphasize the latter when Mary writes, "the Europeans are so insolent that a few such lessons are absolutely necessary to correct them" (78).

Yet the sentence before paradoxically expounds, "On what trifles depends the destiny of man!" (78). Here, "trifles" and "lessons," two antithetical positions on the duel's resolution, are fused together in a single phrase. In the first half, Mary could be lamenting the duel itself — that something as silly as a word should lead to a man's death, or that something as serious as death

\footnotetext{
${ }^{71}$ Hence, Dillon argues in "The Secret History" that the novel is particularly focused on the creation of a creole identity and culture.
} 
should be decided by a game of chance. In both, "trifles" and "destiny" are ironically counterpoised for "destiny" boils down to coincidence, a misplaced word and a stray bullet. Yet the next line directly contradicts this reading for Mary applies a "lesson": the duel punishes the French officer, teaching him and the reader that Creole life is fundamentally different from French life. The duel, therefore, would seem to confirm Dillon's argument that the novel is particularly interested in Creole social reproduction: the scene strives to consider the difference between the French and the creoles, exacerbated by the war. Furthermore, Mary's recourse to both "trifles" and "lessons" suggests both the impossibility and the necessity of making sense of the insensible, of gleaning a "lesson" from chaos, especially during an era of Revolutions.

However, this duel and its logic of "trifles" and "lessons" also help to explain yellow fever's conspicuous absence. First, yellow fever's etiology and epidemiology were unfathomable. The high numbers of European deaths from yellow fever and the comparatively low morbidity of African and African creoles, who had either been born in spaces of endemic yellow fever or whose suffering was invisible to whites, would have heightened the disease's mystery. In other words, the disease seemed "trifling" — its spread, morbidity, and mortality as illogical, irrational, and coincidental as in Ormond.

Second, then, is what yellow fever would seem to teach. If the duel instructs the French on the creoles, then yellow fever, associated as it was with race and climate, would seem to deliver a lesson on the black Revolution to white, would-be masters. According to didactic logic, in which the righteous prevail and the villains perish, extensive white mortality should remind white creoles that they were the evil in this particular narrative - that the black rebels were on the right, perhaps even predestined side of history. While Sansay, through Mary, is sometimes sensitive to the plight of the free and freed black Saint-Dominguans_- "The negroes have felt 
during ten years the blessing of liberty, for a blessing it certainly is” (73) — Secret History ultimately prohibits yellow fever's revolutionary "lesson."

Early novels were overtly didactic, instructing readers on cultural dangers and right conduct — all the more important considering how the form was initially vilified. Yet, when Secret History erases yellow fever rather than owning up to its lessons, the form's didactic logic ruptures. While Brown's novels undermine the intentional, effective author, Sansay attempts to recuperate this figure in Secret History. By expunging yellow fever from the historical and generic record, however, the novel inadvertently reveals just how much the disease and the Haitian Revolution shaped the early form.

\section{Laura: A Novel that Erases Black Agents to Save Form}

Sansay's novel, Laura, published only a year after Secret History, faces the same dilemma, but solves it differently. After the eponymous Laura is orphaned, she meets a young man, Belfield, who surreptitiously courts her. Her stepfather wants her to marry another man, but she runs away and consummates her relationship with Belfield. In the midst of this ardor, her lover contracts yellow fever, and she nurses him to health. After an estrangement-Belfield hides her in a brothel where she's accosted - the pair decide to wed. Yet on the day of their nuptials, Belfield enters a duel to save Laura's honor and dies. Laura survives, but she is never happy again. Though Laura's plot is more overtly didactic and sentimental than Secret Historythe preface declares its goal "to promote virtue" (156)_Laura operates via an inverse logic. Whereas Secret History foregrounds the Haitian Revolution at the expense of yellow fever, Laura foregrounds yellow fever at the expense of that vexing aspect of the Haitian Revolution, black agency. Laura's genre, the sentimental seduction novel, compels a particular kind of 
plotting that makes yellow fever narratively pliable — if, and only if, black bodies and agencies are evacuated.

In Laura, the yellow fever plot complicates the seduction narrative, transforming both Laura and Belfield into sympathetic and even virtuous (if somewhat naïve) lovers. Though the pair have been illicitly interacting (and copulating) for some time, yellow fever affords Laura the narrative space to demonstrate her virtue-critical to a heroine of the genre. When Belfield fails to visit her country retreat for a number of days, Laura rushes to Belfield's rescue, helping strangers along the way. In some of the novel's most gothic scenes, which recall Brown's pestilential cityscapes, Laura witnesses a woman crying for water in the street as her baby unsuccessfully tries to suckle, howling dogs, starving cats, and gravediggers carting not-yet-dead people to the grave, people who were "tearing their hair with frantic gestures and painful shrieks, endeavoring to escape from the vehicle where they were forcibly detained" (179). She eventually finds Belfield, "abandoned...to the care of a negro" by his friends (177), struck down by the fever, "pale and exanimate" (179). His "sallow cheek confessed the direful touch of disease," and his "inflamed eyes rolled with an expression of wildness in their hollow orbits, and rested on Laura without giving a sign of recognition" (179). Slowly, however, Belfield's health returns through Laura's care. Yellow fever allows Laura to demonstrate her worth and allows Belfield to appreciate that worth: her "unbounded...devotion," "the ardor of that attachment which had rendered her unmindful of danger when attending him in his illness," and "the purity of her confidence" (180), proved to him that she was "no common object," providing him the evidence necessary to decide that he should "call her his" through marriage (181). Yellow fever would seem to transform the seduction narrative into a sentimental plot, demonstrating Laura's benevolence, swaying Belfield's heart and ushering them on the righteous path—marriage. 
Though yellow fever does not immediately net their nuptials, it solidifies and seems to sanctify their relationship. According to Davidson, Belfield is a "seducer who is himself seduced by delusions," who "embod[ies] the consequences of a fall more subtle than mere physical seduction." 72 Petter similarly contends that Laura both utilizes and critiques the underlying code of the seduction novel: "less regard is paid by society to genuine virtue," like Laura's expansive compassion in the yellow fever scenes, "than to its reputed absence," her seduction. ${ }^{73}$ She "is a victim above all of the world's shallow values and customs" (Petter 266). Laura's yellow fever scenes, therefore, undermine the conventional plotting of the seduction novel by portraying Laura as truly virtuous, a real heroine rather than a superficially pure one.

If the novel, at least in the yellow fever scenes, undermines some of the tropes of the seduction novel, it closes with conventional didacticism in the form of a duel. When Belfield stows Laura in a brothel to hide their illicit love affair, a man named Melwood presumes she is a prostitute. As their twinned names foreshadow, the two men eventually meet, and Melwood remarks of Laura, “'I have myself seen her only once at the house of an accommodating friend, who has, however, promised to procure me another interview"' (213). When Belfield tells him to not "trifle" with Laura's name, Melwood boldly retorts, “'I presume that I may mention the name of a girl at met at Mrs. W—s, in any manner I please!'” (213). Melwood challenges Belfield to a duel, and although Belfield initially resists, he ultimately decides that because he is the source of Laura's shame, he must prevent "future attacks on her reputation" (216). He decides, "To die is nothing, but to live and suffer is dreadful. Eternal justice cannot have marked a being so fair for a destiny so cruel; all must end well. I will meet my fate without delay; and

\footnotetext{
${ }^{72}$ Davidson, Revolution and the Word, 216-17.

${ }^{73}$ Petter, The Early American Novel, 266, hereafter cited parenthetically.
} 
then have peace,--be married and be happy" (216). Thus, Belfield enters into the duel not only because he must protect Laura, but also because he believes that Laura's righteousness, her rightness will prevail against the villainous Melwood. "Eternal justice" is on his side, so "all must end well”- — with marriage and happiness.

All, however, does not end well for Belfield (nor for Laura). The duel itself is short, almost perfunctorily written: "The distance was measured; the parties took their stand; the word was given - they fired. Belfield bounced as if struck by and electric shock, and then fell flat on the ground" (218). But while this scene does not accord with Belfield's notion of justice, it does accord with the seduction novel's typology: Belfield seduced Laura. While he may represent a "humanized antagonist," he remains the narrative's villain, ruining Laura's honor, and, thus, deserves to die. ${ }^{74}$ Likewise, Laura, by forfeiting her maidenhead, deserves to be punished as well. The story, therefore, neatly punishes its fallen protagonists as the seduction novel's conventions require. The final line of the novel declares, "“that perpetual uneasiness, disquietude, and irreversible misery, are the certain consequences of fatal misconduct in a woman; however gifted, or however reclaimed" (222). Unlike Ormond, where "the complexity of effects" cannot be untangled into certain causes, "fatal misconduct" necessarily leads to "certain consequences." No matter what Laura or Belfield did — no matter how much yellow fever redeemed them - the plot was already scripted.

While Laura flirts with unconventional form, such as Laura's courage and her survival (after all, she gets to live, albeit unhappily, unlike her more famous compatriot, Charlotte Temple), and Belfield's complexity, the novel closes with the proper didactic lesson that the seduction novel requires. Unlike Secret History, which repressed yellow fever because its lessons

${ }^{74}$ Davidson, Revolution and the Word, 216. 
were too disruptive, Laura tames yellow fever by divorcing it from its relationship with black revolutionary agency. First, though this novel has some sense of transatlantic context—Laura's parents are Irish and emigrate to the United States-it includes no references to Saint-Domingue or the West Indies. While this is not necessarily bizarre, it is strange given: how closely yellow fever and the West Indies, particularly Saint-Domingue, were connected at the time; the Philadelphia setting, which suffered epidemics in $1797,1798,1799,1802,1803$, and $1805^{75}$; and Sansay's earlier novel, Secret History.

Second, and, more importantly, the novel almost immediately erases the one black character it introduces. When Belfield falls ill, the narrator relates, "His friends, as was too generally the case, abandoned him to the care of a negro on the first appearance of the disorder, and left the city" (177). This line obviously draws upon both white and black experiences of yellow fever in Philadelphia in 1793: yellow fever severed the sentimental bonds that purportedly cohered early white Republican life, as black people, believed to be immune, stepped in to fill critical roles, including nurses and carters of dead bodies, as Brown describes in Ormond and Arthur Mervyn. ${ }^{76}$ When Laura finally finds Belfield after his absence, a "little negro boy who knew her opened the door," probably the same "negro" that remained even as his friends abandoned him (179). As Belfield finally begins to recover, the narrator declares, "at length Belfield's constitution, the skill of his physician, and the care of Laura prevailed" (180). Nowhere in this list is the "negro boy," the only person besides Laura who did not abandon

\footnotetext{
75 Apel, Feverish Minds, 2.

${ }^{76}$ On how African Americans participated in the 1793 epidemic, see Gould, "Race, Commerce, and the Literature of Yellow Fever," and Philip Lapansky,“"Abigail, A Negress." See also pp. 123-24 and note 17.
} 
Belfield. The boy does not seem to be a narrative necessity; in fact, his complete absence could have heightened Belfield's desperation, Laura's benevolence, and the pair's reunion.

Instead, by introducing and abandoning the character, much as yellow fever is used and erased in Secret History, Sansay recalls the black people that circulated in Philadelphia's 1793 epidemic and the Haitian Revolution without impairing the novel's need to make a lesson of Laura and Belfield's romance. In other words, whereas Secret History erases yellow fever because it highlights black agency too pointedly, exposing too dangerous a "lesson" about white creole agency, Laura erases black agency from its depiction of yellow fever so that yellow fever might function to ensure proper narrative closure and justice. Yellow fever functions didactically, but it can only guarantee Laura's generic conventions because it expunges subversive revolutionary black agency.

\section{Conclusion}

In the pandemic context of the Haitian Revolution, yellow fever and black rebels challenged definitions of agency - the relationship between clear causes and calculable effects, between intentionality and efficacy, between interiority and accessibility. In turn, they also challenged and shaped the genre most dedicated to these restrictive and normative relations. They disrupt Brown's yellow fever novels, undermining plot and characterization as well as the figure of the intentional and effective author. Sansay's novels attempt to redress such disruption by repressing yellow fever and then black agents through form, but even this repression belies the extent to which her novels and herself as a writer were shaped by the very agents she tries to discipline. Yellow fever and black revolutionaries planted insurrection—aberrant, inaccessible, nonhuman agency —at the very heart and inception of the American novel. 
Though my argument is necessarily limited, the relationship between yellow fever and race would persist into the nineteenth century and even into nineteenth-century novels. Yellow fever ravaged the south in the antebellum years, but New Orleans's 1853 epidemic was “the worst single epidemic ever to strike a major American city," killing at least 9,000 people. ${ }^{77}$ By the middle of the nineteenth century, yellow fever had largely abandoned northern ports like New York and Philadelphia where it once wreaked havoc, transforming into a regional, Southern disease. It soon became a focal point in debates on abolition: apologists argued that white susceptibility to diseases like yellow fever required slavery, while abolitionists argued that yellow fever represented divine judgment for the gross sin of chattel slavery. ${ }^{78}$

During the 1853 epidemic, however, black people seemed to contract the disease at unprecedented rates (to white Southerners at least). ${ }^{79}$ Apologists argued that only Northern black people contracted the disease because God was punishing them for their "“attempt...to exist in climates and regions which are adapted to the organization of the white man." $" 80$ In turn, Dr. Samuel Cartwright, noted taxonomist of "drapetomania," the disease that led black slaves to run away, argued that poor whites died more frequently during the epidemic than wealthier whites, because they had subverted "Nature", and " the aristocracy of the white skin"” by doing the work more properly reserved for black slaves. ${ }^{81}$ As Philadelphia's 1793 epidemic was memorialized in Brown's novels and to a lesser extent Sansay’s, New Orleans 1853 epidemic, including its relationship to the Haitian Revolution, would be immortalized in works like

\footnotetext{
77 John Duffy, Sword of Pestilence, vii, 167.

${ }^{78}$ On yellow fever as a Southern disease, particularly in the context of debates over slavery, see Carrigan's "Yellow Fever: Scourge of the South." See also Chaplin, Anxious Pursuit, chaps. 3 and 4., and Albert E. Cowdrey, This Land, This South, chap. 2.

${ }^{79}$ Kiple and King, Another Dimension, 44.

${ }^{80}$ Qtd. in Duffy, Sword of Pestilence, 144.

${ }^{81}$ Qtd. in Carrigan, "Yellow Fever," 352.
} 
Ludwig von Reizenstein's The Mysteries of New Orleans and William Wells Brown's Clotel; or, the President's Daughter. ${ }^{82}$

Brown's Clotel especially traces questions of yellow fever, black revolution and agency, and form. Written in 1853, Clotel describes yellow fever as integral to New Orleans as fog to London. Though the novel includes no explicit reference to the Haitian Revolution, its description of yellow fever is almost completely cribbed from John R. Beard's The Life of Toussaint L'Ouverture, The Negro Patriot of Hayti, also published in $1853 .{ }^{83}$ Moreover, New Orleans itself was closely associated with Haiti. Many Saint-Dominguans fled and settled in Louisiana, a territory that the United States acquired in part because of the Haitian Revolution. ${ }^{84}$ Though Brown borrows from Beard, he changes one part, adding "The negro, whose home is in a hot climate, was not proof against the disease." ${ }^{85}$ To Roberts this line "suggests that Brown consciously set out to dismiss the racist logic of autochthony and immunity," to demonstrate that "differences between race break down at the level of the biological rather than inhere within

\footnotetext{
${ }^{82}$ Although I do not have the space for close analysis, Reizenstein's novel, written in German and unpublished in English until 2002, closely follows the experiences of German immigrants during New Orleans' 1853 epidemic. In particular, Reizenstein characterizes yellow fever as punishment for slavery and envisions a biracial liberator christened Touissant L'Ouverture. The novel does not argue that black people are immune or especially resistant to yellow fever but instead suggests that the disease is as deeply an American problem as slavery, and that the health of the American body politic depends on extirpating the root cause, slavery.

${ }^{83}$ Roberts, Gothic Subjects, 157. Much of Clotel, in fact, is taken from other sources, including short stories, slave narratives, newspaper accounts, and Brown's own autobiography (Roberts 160). Moreover, Brown would republish Clotel with unique variations three more times by 1867 . ${ }^{84}$ On the Louisiana Purchase, see note 19. Refugees did not begin to move to Louisiana and New Orleans in mass until 1809, after it had become clear that Saint-Domingue would never again become a slave colony under French rule. On migratory patterns and the Saint-Dominguan influence on Louisiana, see Nathalie Dessens, From Saint-Domingue to New Orleans, Paul Lachance, "Repercussions of the Haitian Revolution in Louisiana," and White, Encountering Revolution.

${ }^{85}$ Brown, Clotel, 204.
} 
it." 86 Thus, she argues, Clotel critiques antebellum America's scientific racism "by reconstituting" the nation "as a single biological mass" (154). Yet yellow fever, historically associated with blackness as Brown's amended plagiarism highlights, also contributes to that "biological mass." After all, if the conditions of slavery render "proprietary subjecthood" impossible, even farcical, Brown's plagiarism highlights what Brown's and Sansay's novels also attest: if white, intentional, effective agency was no longer sacrosanct for characters, plots, and the genre itself, then neither was the figure of the author.

None of these novels is what one would call clear or perhaps even coherent. This is not just a coincidence of the genre's earliness, as the later novel suggests, but a formal disruption written by those agencies that ascribed neither to Republican definitions of agency nor to novelistic conventions. Yellow fever and black rebels argued that causes did not add up neatly to particular effects - that plot was not always coherent. They argued that intentions were not necessarily effective - that character did not necessarily drive plot. And they argued that interiority was not necessarily accessible - that character could be empty or simply unknowable. At the beginning of the American novel and the center of the form, therefore, is the inhuman and nonhuman experience of illness - of uncertain identity, invisible agents, rebellion, unknown motivations, and a suspended plot. In his seminal work, The Wounded Storyteller, Arthur W. Frank argues that the medical doctor subsumes the narration and, thus, the experience of illness: “The physician becomes the spokesperson for the disease, and the ill person's stories come to depend heavily on repetition of what the physician has said." 87 Yet early American novels reveal that neither the narration nor experience of illness is singular.

\footnotetext{
${ }^{86}$ Roberts, Gothic Subjects, 158, hereafter cited parenthetically.

${ }^{87}$ Frank, The Wounded Storyteller, 6.
} 


\section{Chapter Four: A Rotting Sensibility: Dysentery's Putrefaction and the Limits of Human- Centered Ethics}

In the beginning of August 1775, Abigail Adams wrote to her husband, John, explaining his brother's illness and impending death:

Tis with a sad Heart I take my pen to write to you because I must be the bearer of what will greatly afflict and distress you, yet I wish you to be prepaired for the Event. Your Brother Elihu lies very dangerously Sick with a Dysentery. He has been very bad for more than a week, his life is despaired of. Er'e I close this Letter I fear I shall write you that he is no more. ${ }^{1}$

Elihu's illness heralded a devastating dysentery epidemic that Adams would chronicle in tragic detail in her letters to John. This initial missive foreshadowed both the Adams family's suffering and their response to that suffering-sensibility. An eighteenth-century paradigm that spanned the Atlantic, sensibility referred to the universal capacity to feel and to a refined emotional life. It was a physiological experience as well as a moral philosophy and cultural value. Elihu's illness and imminent death activate Adams's "Heart"; his pain becomes hers. In turn, she worries that this news will "greatly affect" and "distress" John, that Elihu's suffering will be transferred to John through her. In this way, Adams's “sad Heart” anticipates John's; his future suffering prompts her present misery. Sensibility not only helped to explain how this pain travelled across bodies but also provided a powerful cultural framework for easing that pain as well.

Yet it was not only sensibility that united these three people; dysentery also knitted them together. The disease provided the material basis that activated their sensibility, while at the same time exposing the paradigm's inherent limitations. After all, sensibility's cultural reign

\footnotetext{
${ }^{1}$ Abigail Adams to John Adams, August 10, 1775, Founders Online
} 
coincided with chattel slavery. Dysentery putrefied human embodiment and, thus, relations based on a particularly limited definition of human embodiment and feeling. Instead, the disease emphasized nonhuman relations and affinities, positing an ethics of shared materiality rather than shared humanity.

Like syphilis, dysentery is hard to track in the historical record. ${ }^{2}$ It went by many names, including flux and bloody flux, and its symptoms overlapped with cholera and gastroenteritis. As the preeminent physician Thomas Sydenham described, dysentery "sometimes begins with a chilness and shaking... and soon after gripes and stools follow," which "are very frequent; and all mucous, not excrementitious...[and] generally streak'd with blood."33 It was both a chronic, endemic illness and an epidemic disease as Adams's letters detail. ${ }^{4}$ It killed many outright, but it also killed by attenuating human health, paving the way for other disorders. As Adams observed in the months following Braintree's epidemic, "Many, very many people who have had the dysentery, are now afflicted both with the Jaundice and Rhumatism, some it has left in Heckticks, some in Dropsies." 5

Ultimately, in the language of the time, dysentery was a corruption, mortification, or putrefaction of bile or aliment, what William Cullen called "a putrid Diathesis." 6 The bloody

\footnotetext{
2 "Dysentery" is an umbrella term for two distinct diseases. Amebic dysentery is typically chronic with no fever, while bacillary dysentery is usually responsible for epidemics and onsets more suddenly. See the "Amebic Dysentery" and "Bacillary Dysentery" entries in The Cambridge Historical Dictionary of Disease.

3 Thomas Sydenham, The Entire Works, 142, 144, hereafter cited parenthetically.

${ }^{4}$ The amebic and bacillary strains probably account for these different presentations. For historical accounts of American epidemics and contexts, see John Duffy, Epidemics, 214-22, Richard B. Sheridan, Doctors and Slaves, 209-10, and Reiss, Medicine in Colonial America, 330. ${ }^{5}$ Abigail Adams to John Adams, November 27, 1775, Founders Online. ${ }^{6}$ See Cullen, Lectures on the Materia Medica (1772), 294. In his A Commentary on the Dysentery: or, Bloody Flux (1767), Mark Akenside contends that the disease was produced by "morbid mucus" (80). Likewise, in An Inaugural Dissertation on Dysentery (1794), David G. Abeel describes the "morbid secretion" of the irritated intestines (18) and the "putrid
} 
excrement was not a symptom of the disease, per se, but the body's attempt to purge-literally, purify — an internal rot. ${ }^{7}$ Sydenham explains, "in a dysentery the morbific matter is discharg'd by stool” (8), while leading Republican physician, Benjamin Rush, argued that it was not dysentery's "evacuations" that "destroy[ed] life," but rather "the fever with the emaciation or mortification" in the bowels. ${ }^{8}$ If unpurged, the putrefaction would not stop at rotting excrement. It would rot the entire body, mutating a sensible, feeling human being into insensible, dead matter.

Early American writers, including Abigail Adams, West Indian poet and physician James Grainger, and Virginian plantation owner, Landon Carter, deployed "rhetorics of sensibility" to mitigate their personal suffering and reaffirm their own sensitivity and virtue. ${ }^{9}$ Yet dysentery consistently disturbed these goals and exposed their hypocrisy. Adams's letters describe her mother's dysenteric death in acute sentimental language, but they also record her servant Patty's death in gruesomely dehumanizing terms. As Patty putrefies, so too does Adams's sensibility, highlighting the limits of an ethics based on a decidedly limited definition of humanity. Similarly, Grainger's poem, The Sugar-Cane, and his medical treatise, An Essay on the More Common West-India Diseases (1764) detail the danger of a human-centered sensibility and morality, which failed to check chattel slavery and its lust for profit. In turn, Carter's Diary (1752-1778) attempts to deploy sensible hierarchies of parent-child, master-slave to regulate his

appearance" of the dissected bowels (10). See also Sydenham, The Entire Works, section 4, chap. 3.

7 “Purge, v. 1," Oxford English Dictionary.

${ }^{8}$ Rush, "An Account of the Bilious Remitting Yellow Fever," 251.

${ }^{9}$ Brycchan Carey uses this phrase to describe how both abolitionists and apologists mobilized sensibility to persuade an audience on the topic of slavery. Although I also expand on this topic in the sections on Carter and Grainger, here I am using the phrase to consider how early Atlantics attempted to persuade themselves of their acute sensibilities. 
plantation's chaos during an epidemic, but the wormy dysentery only exposes this false order. Both sensibility and dysentery connect these disparate writers and their texts: each strived to write and act sensibly, but dysentery putrefied human bodies and the physiological and ethical paradigm based on human bodies, sensibility. The disease's materiality, its sensual, poisonous putrefaction, ruptured the bonds of human relations. Instead, it emphasized material affinities, decomposing the distance between human self and nonhuman other.

Moreover, putrefaction posited an alternative, material foundation for ethical relations. As sociological and psychoanalytic studies have shown, attitudes towards excrement are culturally constructed and highly variable, only accruing their modern negative valence with the rise of the bourgeoisie. ${ }^{10}$ Yet excrement was also immanently material. Dung heaps could produce smelly, poisonous miasmas, and feces was used to diagnose disease and sometimes even to treat it. ${ }^{11}$ Joshua Ozias Reno argues, it is "meaningful to speak of 'waste' as a set of objects in the world that pre-exist symbolic categorization."12 Excrement reminds humans of our own “embodied animality" (Reno 8). In turn, putrefying excrement like dysentery and manure remind us of our shared materiality. "Compost," Serpil Opperman argues, "means being a part of a

${ }^{10}$ As Mary Douglass famously asserted in Purity and Danger, "There is no such thing as absolute dirt: it exists in the eye of the beholder" (2). Norbert Elias, Dominique Laporte, and David Inglis have shown how excrement became "absolute dirt" with the rise of the bourgeoisie, whose emphasis on order and cleanliness regulated where defecation took place and how it was talked about - through euphemism or not at all. Likewise, scholars of the middle ages, like Jeff Persels and Russell Ganum, Susan Signe Morrison, and Peter J. Smith have demonstrated that excrement signified more than disgust or danger pre-microbes. After the rise of the bourgeoisie, Freudian psychoanalysis linked excrement to the repressed anality of childhood, in which feces symbolized play, gift, property, and weapon. See Norman O. Brown, Life Against Death, chaps. 10-14, and Inglis, A Sociological History, chaps. 3 and 4. While this argument emphasizes excrement's materiality, these studies are important in that they remind us that that materiality has signified multivalently across time and space.

${ }^{11}$ On both the danger of poisonous smells and the medical uses of feces, see Corbin, The Foul and the Fragrant, chaps. 1 and 2, and Inglis, A Sociological History, 83-86, 197-98.

12 Reno, "Toward a New Theory of Waste," 4, hereafter cited parenthetically. 
fertility cycle...part of things that are dead but are in a way not dead." ${ }^{13}$ It is "the poetics of transformative matter" that "draws its existential meanings from its relation to other matter" (139). Early Americans' paradigm of putrefaction meant that dysentery could decompose and recompose; it could rot sensibility and relations between humans, highlighting the paradigm's limits, but it could also offer alternatives. In each of these texts, dysentery's putrefaction reembodies and rematerializes humanity, reminding us that we are not exempt from the biological and chemical processes of entropy, aging, and death. By emphasizing our material affinity, dysentery ultimately suggests that ethical care should not revolve around the limiting paradigm of shared humanity. After all, shared humanity did not and does not ensure the just treatment of enslaved, disabled, and aging or otherwise "rotting" people. Instead, dysentery posits ethical relations based on shared, mutating materiality, a radical alternative both to eighteenth-century sensibility and to the modern discourse of humanity that animates disability studies and the medical humanities.

\section{Sensibility, Sympathy, and Sentiment in the Atlantic World}

Sensibility was a moral philosophy and cultural value based on the material human body. At its simplest and earliest, it referred to the physical senses, to the ability to perceive what John Locke called "impressions" made by "outward Objects." ${ }^{14}$ Physician George Cheyne refined Locke's seminal theory, arguing that nerves and fibers "communicate[d] the Impression they receive[d] from outward objects, or the muscular Fibres to the Sensorium in the Brain."15 These

\footnotetext{
${ }^{13}$ Opperman, "Compost," 136, hereafter cited parenthetically.

${ }^{14}$ Locke uses this language throughout "An Essay Concerning Human Understanding” (1690).

${ }^{15}$ Cheyne, "The English Malady," 64.
} 
nerves and fibers enabled communication between the disparate parts of the human body like the eyes and the brain, as well as between the self and the outside world.

This physiology soon became a philosophy of human relation. Adam Smith begins his canonical Theory of Moral Sentiments, arguing for a physiological basis for human connection and morality: "How selfish soever man may be supposed, there are evidently some principles in his nature, which interest him in the fortune of others, and render their happiness necessary to him, though he derives nothing from it except the pleasure of seeing it." ${ }^{16}$ In his famous image of the man being tortured on the rack, he contends, "our sense will never inform us of what he suffers. They never did and never can carry us beyond our own person" (2). Rather, "it is by the imagination only that we can form any conception of what are his sensations" (2). Although we can only imagine how the tortured man feels, this imagining is enabled by our own senses. Our physiological sensibility allowed us to see the man on the rack, sending the visual stimuli throughout our bodies to be understood. Moreover, I could imagine his experience based on my own experience of a body. Physiology, therefore, activated affectivity. Sensitive nerves and fibers meant sensitive human beings, receptive and responsive to a friend's joy or a stranger's pain. In turn, the receptive and responsive person wore their sensibility quite clearly — blushing, crying, and fainting.

As a physiological fact of human relations, sensibility soon became a moral imperative, a sign of "humanity." As G. J. Barker-Benfield argues, "The word human became very closely associated with sensibility." ${ }^{17}$ Humanity, however, "denot[ed] sympathy and sympathetic action" (116). If all humans could feel, then the best humans not only felt keenly but also acted to

\footnotetext{
${ }^{16}$ Smith, Theory of Moral Sentiments, 1, hereafter cited parenthetically.

${ }^{17}$ Barker-Benfield, John and Abigail Adams, 115, hereafter cited parenthetically.
} 
alleviate suffering. Ann Jessie Van Sant argues, "sensibility accounts for an intensely felt humanity or philanthropy; it is an 'inward pain' in response to the sufferings of others." 18 Ideally, it should motivate this pain's alleviation or amelioration though it was not always successful.

While sensibility was physiologically universal, its moral mandate was limited by gendered, classed, and especially raced prejudice. ${ }^{19}$ In eighteenth-century Britain, for example, sensibility motivated both abolitionists and apologists. As Brycchan Carey argues, abolitionists invoked the universal experience of human suffering to persuade, while apologists used “sentimental diversion" - their own or poor Europeans' suffering — “to divert attention away from slavery and the slave trade." ${ }^{20}$ Even though the eighteenth-century Atlantic failed to apply sensibility evenly, the paradigm's moral probity derived from a purportedly universal physiology.

In the early Republic, sensibility and sympathy functioned to create a nation out of a disparate populace. Elizabeth Barnes argues that sensibility "imagin[ed] diverse individuals connected in a sympathetic chain," flattening a true "democratic politics" into "a politics of affinity." 21 This "affinity" was "idealized" in the "bond between parent and child" and "filial attachment" (23). Kristin Boudreau similarly contends that "consanguinity" animated American sympathy from the colonial period until after the Civil War. ${ }^{22}$ While studies on sensibility and

\footnotetext{
${ }^{18}$ Van Sant, Eighteenth-Century Sensibility and the Novel, 5.

${ }^{19}$ On gender and class, see, for example, Barker-Benfield, The Culture of Sensibility and John and Abigail Adams. On race, see Markman Ellis, The Politics of Sensibility and Brycchan Carey, British Abolitionism and the Rhetoric of Sensibility.

${ }^{20}$ Carey, British Abolitionism, 120. Apologists especially highlighted miners' plights, pp. 11929.

${ }^{21}$ Barnes, States of Sympathy, 1, 4, hereafter cited parenthetically.

22 See Boudreau, Sympathy in American Literature, $\mathrm{x}$.
} 
America have tended to emphasize the early Republic, John Winthrop's sensibly embodied community in "A Modell of Christian Charitie" suggests that physiological and cultural affinity were important before the Revolution as well. ${ }^{23}$ Sensibility and sympathy may have been put in the service of abolition, and may have even helped free and enslaved Africans empower themselves, but it did so through an exclusionary vision of human similitude. ${ }^{24}$

Sensibility, sympathy, and sentiment were not necessarily synonymous, but they were closely related. Van Sant argues that "sensibility is associated with the body," with physical sensitivity and the processes of sensation," while Sarah Knott contends, "sympathy was a 'special case' of sensibility," referring to the "nervous connection between divergent bodily organs that integrated the body's overall functioning."25 "Sentiment," however, was correlated "with the mind" and "refinement of thought." ${ }^{26}$ Neither early Atlantics nor modern critics agree on the precise differences between these interrelated terms. All shared a physiological foundation, and all referred to how individual and communal bodies related. For the purpose of this argument, I use sensibility and sympathy interchangeably, referring to the way physiology underwrote morality. I use "sentiment" and "sentimental" to refer to particular literary tropes enabled by sensibility and sympathy. Each of these terms emphasized a universal human

\footnotetext{
${ }^{23}$ Boudreau analyzes Winthrop's speech, emphasizing how physiological sympathy conditioned social cohesion. Sympathy in American Literature, 4-5. Similarly, Sarah Knott argues, "What changed between 1630 and $1776 \ldots$ was the grafting of a complex set of moral, social, and psychological meanings onto physical 'sensibleness." Sensibility and the American Revolution, 326. By the late eighteenth century, the period I analyze, the "social and cultural—and political - reach" of sensibility was well at work (Knott 326).

${ }^{24}$ On how Africans in the Atlantic world used sympathy and sensibility, see Christine Levecq, Slavery and Sentiment.

${ }^{25}$ Van Sant, Eighteenth-Century Sensibility, 4; Knott, Sensibility and the American Revolution, 10 .

${ }^{26}$ Van Sant, Eighteenth-Century Sensibility, 4.
} 
similitude, even if that universality was only theoretical—but dysentery showed how early American affinities were shaped not only by human sympathy but also nonhuman rot.

\section{Abigail Adams Rotten Humanity}

"Remember the ladies" may be Abigail Adams's most famous line, but her regular record of her aches and pains and her inquiries after John's health suggest that she just as easily may have chided, "Remember the body." ${ }^{27}$ Edith B. Gelles, however, argues that her form was "disembodied," enabling her to "speak" more freely than she could in actual conversation. ${ }^{28}$ Adams herself admits in the aftermath of the dysentery epidemic, "My pen is always freer than my tongue. I have wrote many things to you that I suppose I never could have talk'd." ${ }^{29}$ Yet her letters were not quite "disembodied." In the same missive, she describes how her heart has been "made tender by repeated affliction," and worries about "wound[ing]" John's: "Why should I? Ought I to give relief to my own by paining yours?” Adams's writing was embodied through sensibility, through her awareness of her own feeling body and mind and that of her reader's. ${ }^{30}$

Braintree's 1775 dysentery epidemic, however, challenged her sensibility. She strived to order the epidemic's chaos through this familiar frame, but it faltered under the disease's putrefying pressure. Adams's servant Patty slowly rots to death, gruesomely devolving into a rotting mass of flesh and stench. As dysentery rots Patty's sensing body, it also rots her

27 See Edith B. Gelles, First Thoughts, chap. 2 for an overview of interpretations of this line. ${ }^{28}$ Gelles, First Thoughts, 7.

${ }^{29}$ Abigail Adams to John Adams, October 22, 1775, Founders Online.

${ }^{30}$ Barker-Benfield analyzes the Adams family, especially Abigail, through the lens of sensibility in John and Abigail Adams. He argues that this "Americanization" entailed sensible white Americans defining themselves against indigenous people, the lower and working classes, and African Americans. This argument, however, emphasizes how dysentery warped Adams's sensibility. 
humanity, decomposing Adams's sensible humanity in turn. When the disease claims her mother, she attempts to isolate and repress the disease's putrefaction in Patty and, thereby, shore up her mother's and her own quickly eroding sensibility. Yet this repression fails. Dysentery putrefies Patty, Adams's mother, herself, and her letters, decomposing sensible, human relations and recomposing them through their shared capacity to rot. In these discrepant representations, the disease revealed the danger of relying upon human senses and, thus, a limited definition of humanity to power ethical care and relations.

From the beginning of the dysentery epidemic in early August 1775 to its first anniversary a year later, Adams describes in excruciating detail the disease's sensible toll. Less than a month after John's brother died, Adams and a number of friends and family had also contracted the disease:

Since you left me I have passed thro great, distress both of Body and mind... You may remember Isaac was unwell when you went from his home. His Disorder increasd till a voilent Dysentery was the consequence of his complaints, there was no resting place in the House for his terrible Groans...Two Days after he was sick, I was seaz'd with the same disorder in a voilent manner...The next person in the same week was Susy...Our Little Tommy was the next, and he lies very ill now...Yesterday Patty was seazd and took a puke. Our House is an hospital in every part, and what with my own weakness and distress of mind for my family I have been unhappy enough. ${ }^{31}$

Chanting a litany of the ill, Adams repeats three words that capture the disease's sensible burden: seized, violent, and distress. "Seized" and "violent" suggest the disease's sudden and explosive onset and, thus, the effects on both the sufferer's sensing body and the caretaker's, while

\footnotetext{
${ }^{31}$ Abigail Adams to John Adams, September 8, 1775, Founders Online.
} 
"distress" indicates how palpably the epidemic weighed on Adams's "Body and mind," her sensibility. With the majority of her family ill, John away at the Continental Congress in Philadelphia, and the "distress of the Neighbourhood" such that she could "scarcly find a well person to assist," Adams supported the family, administering medicines, cleaning bodies and linens, and fumigating the house. ${ }^{32}$ As Isaac's inescapable "Groans" illustrate, dysentery permeated and began to erode the sensible home.

Although Patty is just one of many names in the preceding tally of the sick, she soon occupies a central place in Adams's home and letters. Others recover, but Patty slowly and gruesomely rots to death. A week after she notes Patty's onset, Adams notes, "we live in daily Expectation that Patty will not continue many hours. A general putrefaction seems to have taken place, and we can not bear the House only as we are constantly clensing it with hot vinegar. I had no Idea of the Distemper producing such a state as hers till now." ${ }^{33}$ Although she does not delineate Patty's symptoms explicitly, the term "putrefaction" signified decomposition, especially the smell of decomposition. As Adams's use of "hot vinegar" implies, Patty's rotting smell was so pungent that the house required fumigation to "bear" it. ${ }^{34}$ Yet this smell was not only noisome but poisonous. "The fetid, penetrating odor of the rotting body," Alain Corbin argues, "could not be regarded as a simple symptom of decomposition"; rather, the odor "was an integral part of the process of decomposition." 35 If the smell could rot Patty, then it could also rot

\footnotetext{
32 Ibid.

33 Ibid., September 17, 1775.

${ }^{34}$ See Alain Corbin, The Foul and the Fragrant, 63-64 on the use of vinegar, along with gunpowder and spices, to cleanse poisonous spells. On poisonous stenches and miasmas, see Corbin, The Foul and the Fragrant, chap. 1; Laporte, History of Shit, 76-95, and Inglis, A Sociological History, 85, 197-98.

${ }^{35}$ Corbin, The Foul and the Fragrant, 17.
} 
the Adams family. Thus, the word "putrefaction" captured the disease's danger: Patty was slowly decomposing, and her decomposition threatened to infect the others.

As Patty's body rotted, her humanity did as well. Adams complains, "I...am obliged to return home to the most gastly object my Eyes ever beheld, who is continually desirous of my being with her the little While she expects to live, and who is now become such a putrid mass as scarcely to be able for any one to do their Duty towards her." ${ }^{36}$ Patty devolves into a "gastly object" and a "putrid mass," dehumanizing characterizations that emphasize her rotting body. In another letter describing Patty's death, Adams again emphasizes her decomposition:

She has lain 5 weeks wanting a few days so bad as that we had little hopes of her Recovery; the Latter part of the Tim she was the most shocking object my Eyes ever beheld, and so loathsome that it was with the utmost difficulty we could bear the House. A mortification took place a week before she dyed, nothing but duty and humanity could and renderd her a most pityable object. ${ }^{37}$

While "mortification" could function as a synonym for putrefaction, it could also refer to "a state of torpor and insensibility preceding death." ${ }^{38}$ Patty may represent "a most pityable object," but Laura M. Stevens reminds us that pity "tends to describe relationships marked by an imbalance of power, between those feeling and those provoking this emotion." 39 Modifying "object," the sensible and sentimental adjective "pityable" isolates, dehumanizes, and objectifies Patty, distancing her from Adams and from humanity more broadly. Though the sensible body was

\footnotetext{
${ }^{36}$ Abigail Adams to John Adams, September 29, 1775, Founders Online.

${ }^{37}$ Ibid., October 9, 1775. Adams deleted "nothing but duty and humanity could," an important deletion in reference to sensible humanity, which I discuss below.

38 "mortification," n. 3, Oxford English Dictionary.

${ }^{39}$ Stevens, The Poor Indians, 8. While Stevens argues that "pity" and "sympathy" "began to overlap in the eighteenth century" (9), Adams's use of "pityable object" recalls the earlier usage's "imbalance of power" (8).
} 
physical, it also required a subjective interiority that descriptions like "gastly object," "putrid mass," "shocking object," and "pityable object" mitigated against. ${ }^{40}$ Dysentery, therefore, rots Patty's clear human embodiment, putrefying her into an insensible mass. As she becomes more material, she draws nearer to nonhuman objects and masses and further away from humans like Adams. And as dysentery rots her humanity, it also rots her claim to sensible bonds with other humans, including Adams.

Patty infects and decomposes Adams's sensibility. Conflating sensibility and humanity, as many did at the time, Adams asserts, "Humanity obliges us to be affected with the distresses and Miserys of our fellow creatures." ${ }^{41}$ Sensible humanity should have enabled both "sympathy and sympathetic action"; however, Adams struggles to feel and care for Patty as a fellow human should. ${ }^{42}$ She admits, Patty "is now become such a putrid mass as scarcely to be able for any one to do their Duty towards her." ${ }^{43}$ She confesses, albeit in the dispersed figure of "any one," that she is incapable of doing her "Duty." She cannot care for Patty—can barely "bear" the housebecause she can no longer perceive her as a fellow, feeling human being. Similarly, when Adams describes Patty's final "mortification," she begins to write but deletes, "nothing but duty and humanity could..." ${ }^{44}$ Adams implies that though sensible humanity should enable her to perform her "duty," it has failed her here. She deletes this reference to fellow feeling because it would

\footnotetext{
${ }^{40}$ In Sentiment and Sociability, John Mullan argues, "it is the body which acts out the powers of sentiment...Tears, blushes, and sights — and a range of postures and gestures - reveal conditions of feeling which can connote exceptional virtue or allow for intensified forms of communication. Feeling is above all observable, and the body through which it throbs is peculiarly excitable and responsive" (201). As Mullan's language intimates, the sensible body's physical and visible responses "reveal[ed]" a hidden, feeling interiority.

${ }^{41}$ Abigail Adams to John Adams, August 11, 1763, Founders Online.

${ }^{42}$ Barker-Benfield, John and Abigail Adams, 116.

${ }^{43}$ Abigail Adams to John Adams, September 29, 1775, Founders Online.

${ }^{44}$ Ibid., October 9, 1775.
} 
expose this lapse too acutely. When Patty finally dies, Adams admits, "the heavy stroke which most of all distresses me is my dear Mother," callously minimizing the young woman's life and death. ${ }^{45}$ In her final reference to Patty, she concludes, "I hope it will make me more continually mindful and watchfull of all those who are still committed to my charge," acknowledging what she should have done and what she did not. ${ }^{46}$ If Adams could not responsively feel for Patty, then her own sensible humanity was at risk. Dysentery rotted Patty's humanity — the universal body that grounded sensibility as a moral imperative — and, in doing so, rotted Adams's humanity as well.

Yet this effect was not inevitable. When her mother, Elizabeth Quincy, succumbs to the disease, Adams uses sensibility to fathom the tragedy. With her heart "Bursting" from grief, she tells John, "my Dear Mother...left this world for an infinitely better... Nature fainted and she fell asleep." ${ }^{47}$ Whereas Patty rots to death, Elizabeth Quincy simply falls asleep. Adams expands on this sensible and sentimental imagery in another description of her mother's death:

My dear parent knew in whom she had Believed, and from the first attack of the distemper she was perswaded it would prove fatal to her. A solemnity possess'd her soul, nor could you force a smile form her till she dyed. The voilence of her disease soon weakened her so that she was unable to converse, but whenever she could speak, she testified her willingness to leave the world and an intire resignation to the Divine Will. She retaind her senses to the last moment of her Existance, and departed the World with

\footnotetext{
${ }^{45}$ Ibid.

${ }^{46}$ Ibid., October 22, 1775.

${ }^{47}$ Ibid., October 1, 1775.
} 
an easy tranquility, trusting in the merrits of a Redeamer. Her passage to immortality was marked with a placid smile upon her countenance... ${ }^{48}$

On the one hand, these descriptions are classic examples of the Christian good death. Elizabeth is resigned to "Divine Will"; "trusting in the merrits of a Redeamer" and the promise of an afterlife, she dies peacefully "with a placid smile." Adams certainly would have found comfort in such a death and such writing about death. On the other hand, this passage also carefully emphasizes Elizabeth's senses. Although she may have been unable to speak-one of, if not the defining characteristics of "human"_- "she retaind her senses," her physical, intellectual, and emotional awareness, "to the last moment of her Existance." Adams emphasizes her mother's senses and sensibility — a far cry from Patty the "putrid mass." Using Christian, sentimental, and sensible tropes to preserve her mother's humanity, Adams also preserves her own.

Though both Elizabeth and Patty die of dysentery, Adams describes Patty's death far more gruesomely than her mother's. ${ }^{49}$ In fact, Adams confesses, that "the same Scene" of suffering was "only varied by a remoter connexion." 50 Undoubtedly, Adams writes so sentimentally about her mother, because she's her mother- "one of the Best of parents." 51 As Barnes argues, all forms of sympathy and sensibility were grounded in the "idealized...bond between parent and child." ${ }^{52}$ Moreover, Patty's class, her status as a servant, may have also contributed to this "remoter connexion" and, therefore, the discrepant representations.

Yet this discrepancy's particularity — the rotting body—is governed by dysentery itself. As Patty illustrates, the dysenteric body was a horrifying spectacle, a noisome stench, a

\footnotetext{
48 Ibid., October 9, 1775.

49 Ibid., September 29, 1775.

${ }^{50}$ Ibid.

${ }^{51}$ Abigail Adams to John Adams, September 29, 1775, Founders Online.

52 Barnes, States of Sympathy, 23.
} 
putrefying mass, a poisonous object, and, eventually, an insensible corpse. As Patty's body and humanity rotted, so too did Adams's own sensibility - her ability to feel and care for others as kin. Adams represses her mother's similar rot by isolating its material and dehumanizing effects in Patty. In turn, she reconsolidates and reaffirms Elizabeth's sensible humanity and her own.

This insulation, however, fails. Adams's letters rot over the course of the epidemic. First, her grief takes on an increasingly physical cast: "My Heart is made tender by repeated affliction"; "my Heart bleeds"; "the Hand of God presseth me soar"; and "O my (Bursting Heart)." ${ }^{53}$ While much of this language was commonplace in sentimental literature, it resonates differently in the context of Patty's rotting, dysenteric materiality. Adams cannot "overcome her selfish sorrow," correct her grief, or restrain her bursting heart. ${ }^{54}$ Her grief is not only material but overflowing and uncontrolled like dysentery. It cannot be restrained in Patty, and instead seeps into and putrefies her writing.

Second, her letters rot as they abandon almost all discussion of local politics and events, even though she usually includes such information. She writes, "As to politicks I know nothing about them. The distresses of my own family are so great that I have not thought about them"; "You will not expect me to look abroad for any news"; "I hope for the future to be able to give you more intelegance with regard to what passes out of my own little circle, but such has been my distress that I know nothing of the political world." ${ }^{55}$ Adams's embodied grief takes material form, decomposing her typical content. As she recognizes, these rotting letters are insensibly insular, affecting, even potentially infecting, John.

${ }^{53}$ Ibid., October 22, 1775; September 21, 1775; October 1, 1775.

54 Ibid., October 22, 1775.

55 Ibid., September 8, 1775; September 29, 1775; October 9, 1775. 
Third, then, her letters threaten to transmit or infect John with her grief. According to the logic of sensible rhetoric, writing could and did transmit feeling. Though both Abigail and John considered each other's writing pleasurable and even medicinal, words could inflict pain as much as they could soothe. Abigail's embodied grief could become John's. Describing her mother's death, she begs him, "Forgive me then; for thus dwelling upon a subject Sweet to me, but I fear painfull to you." ${ }^{56}$ In a later letter, again describing Elizabeth's death, she writes, "I know I wound your Heart. Why should I? Ought I to give relief to my own by paining yours?"57 She worries that she might communicate her grief to John, that they will become connected not by sympathy or sensible humanity but by dysentery's rot.

Finally, despite this fear of infection, her letters persist in describing her grief. She writes, "I hope to be properly mindful of the correcting hand," but, in the very next line, she beseeches John, "You will pardon and forgive all my wanderings of mind I cannot be correct." ${ }^{58}$ Although she should submit to God's will and the correcting hand as gracefully as her mother, she can't. Dysentery escapes from Patty to infect her letters - which in turn threaten to infect John. Although she tries, sensibility fails to control and contain the disease, her identity, and her letters; dysentery rots sensibility, linking microbes or smells, humans, and texts into a chain of shared decomposition rather than shared humanity.

As Adams's letters demonstrate, dysentery rots, decomposes, and putrefies humans and humanity. By seizing and perverting our waste processes, dysentery turns us into human wastea putrid smell, an inhuman "mass," a corpse. It putrefies our subjectivity, emphasizing our material rather than human relations. And, finally, it rots sensibility, undermining fellow feeling

\footnotetext{
56 Ibid.

${ }^{57}$ Ibid., October 22, 1775.

${ }^{58}$ Ibid., October 1, 1775.
} 
as the basis for ethical care. In her "Manifesto for Waste Studies," Morrison argues, "Excrement provides us with a reason for acknowledging affinity among all people... Waste is the great leveler linking us all." ${ }^{59}$ Dysentery, however, reminds us that our affinities stretch not only toward other people but also toward nonhumans. Moreover, it exposes the lie at the heart of sensibility: if Adams could not perform her "duty" — could not act humanely—because Patty was not human enough, then "human" represented and continues to represent a seriously inadequate foundation for ethics and ethical action.

\section{James Grainger's "Reptile" Rot}

After all, neither sensibility nor humanity effectively challenged slavery. Abolitionists may have invoked human sympathy, but apologists mobilized the very same rhetoric. William Wright advertised James Grainger's An Essay on the More Common West-India Diseases, the

first compendium of medical advice for plantation masters, as a "humane and sensible tract." 60 Grainger himself explained that such advice would, "save many valuable lives; a circumstance not less profitable to the owner, than pleasing to humanity." ${ }^{\prime 1}$ Conflating humanity with profitability, Grainger outlines how slavery, economy, and sensibility commingled in the Atlantic world ${ }^{62}$ His more famous work, The Sugar-Cane, notoriously struggles to incorporate

\footnotetext{
${ }^{59}$ Morrison, Excrement in the Late Middle Ages, 156.

${ }^{60}$ Wright, Introduction, 3.

${ }^{61}$ Grainger, An Essay, 6.

${ }^{62}$ For example, see Ellis, The Politics of Sensibility, and Carey, British Abolitionism. On slavery, profit, sensibility, and Grainger specifically, see Richard Frohock, Heroes of Empire, epilogue; Ellis, "Incessant Labour"”; Cristobal Silva, "Georgic Fantasies"; Anna M. Foy, "Grainger and the 'Sordid Master"'; and, Tristan J. Schweiger, "Grainger's West Indian Planter."
} 
enslaved labor into the classic georgic structure. ${ }^{63}$ Formal irregularities pervade the text. ${ }^{64}$ John Gilmore, however, asks readers if Grainger's strange writing and formal discrepancies might be evidence of "an essentially humane man who realises that he is compromised by his economic dependence on the fundamentally inhumane system of slavery" - someone recognizing (if not fixing) his own hypocrisy. ${ }^{65}$ Grainger was not an abolitionist, but both his poem and his treatise argue for amelioration, for the better medical treatment of slaves, a position that ambivalently straddled sensibility and prosperity.

To traverse the discrepancies between slavery and sensibility, Grainger's writing effects multiple transformations: plantation slavery into georgic labor, West Indian content into proper poetic material, degenerate creole into metropolitan author. In particular, Grainger draws on the georgic figure of manure to illustrate these transformations. Yet manure and dysentery's shared materiality, putrefaction, upsets his poetic, rhetorical, and medical control. Manure may seem to

${ }^{63}$ Essentially, the georgic's "modal orientation to the world," as Timothy Sweet argues, "is labor," but Grainger's source of labor is slavery, potentially setting the poem up for thematic and formal failure (American Georgics, 11). Frohock argues that the muse "laments slavery in abstract terms," while the poem nonetheless forwards its use (179). Similarly, Silva maintains that Grainger displaces slavery from "an ethical problem in the world" to "a formal problem of poetry" ("Georgic Fantasies" 143). Ellis, however, argues that the form mitigates the content: "While the poem is ineluctably pro-slavery, the intelligence of the poetic form is abolitionist" ("'Incessant Labour'" 52). While I do not explicitly analyze the relationship between slavery and the georgic form, I do address how putrefaction exposes the hypocritical reliance on slavery that underwrites both the poem and the poet's claims to sensibility.

${ }^{64}$ Most critics note the georgic's footnoting apparatus, which frequently overwhelms the poetry on the page. Kelly Wisecup and Britt Rusert argue that African medical knowledge and the West Indian environment, respectively, disrupt the poem's form. See Wisecup, Medical Encounters, chap. 4, and Rusert, "Plantation Ecologies." In "Georgic Fantasies," however, Silva argues that footnotes characterized Grainger's poetry even before he lived in the West Indies. While Grainger may have been fond of footnotes before his life in St. Kitt's, they were still an unusual in poetry. Silva's reminder - that the poem's "many thematic and formal disruptions" are not "failures" but "traces of Grainger's own attempt to aestheticize colonial landscapes in the service of his literary and commercial ambitions" (130)_emphasizes how Grainger attempted a new, perhaps impossible task, reconciling slavery with the georgic.

65 John Gilmore, “Introduction,” 59. 
offer a flexible metaphor for transformation — waste matter into fertilizer, fertilizer into vegetable life, agriculture into poetry — but it also reveals that neither Granger-the-farmer nor Grainger-thepoet can effectively harness its transformative power. Ultimately, dysentery's putrefying bowels posited a life and ethics beyond human feeling, intentions, and control.

Grainger introduces manure's transformative power within the first 200 lines of The Sugar-Cane, writing about it both practically and imaginatively:

Planter, if thou with wonder wouldst survey

Redundant harvest load thy willing soil

Let sun and rain mature thy deep-hoed land,

And old fat dung co-operate with these.

Be this great truth still present to thy mind;

The half well-cultur'd far exceeds the whole,

Which lust of gain, unconscious of its end,

Ungrateful vexes with unceasing toil. ${ }^{66}$ (I.197-204)

Grainger warns the reader that the "lust of gain" that leads to "redundant" planting will make "lands grow poor" (I.205). Monoculture unchecked by crop rotation or "not indulg'd" by manure will net less productive fields and thus less wealth (1.205). "[O]ld fat dung," however, can replenish and renew "the poorest soil" (I.227). This recommendation may not have been unique, but the frame is evocative: manure is vital because of its capacity to transform matter - to renew the soil, to produce plants, and, ultimately, to create wealth.

${ }^{66}$ Grainger, The Sugar Cane, I.197-204, hereafter cited parenthetically. 
If feces beget fecundity, as Grainger argues, it powered this alchemical transformation through its own materiality. Manure had to be composed or, rather, decomposed. Grainger writes,

Then, Planter, wouldst thou double thine estate;

Never, ah never, be asham'd to tread

Thy dung-heaps, where the refuse of thy mills,

With all the ashes, all thy coppers yield,

With weeds, mould, dung, and stale, a compost form,

Of force to fertilize the poorest soil. (I.218-227)

In this passage, Grainger locates manure's economic power in its materiality, homologously linking wealth to the physical processes of composition and decomposition. Beccie Puneet Randhawa argues that these lines speak to "the West Indies' image as a tropical cesspit," recuperating "the repellent vision of a Creole colony which may be full of undesirables, whether they be slaves, criminals, indentured servants, prostitutes, depraved planters, or opportunists" by "reorienting the reader's gaze toward the indispensable commercial value of waste products." 67 Yet, as Monique Allewaert reminds us, Grainger's “fecal orientation is not simply symptomatic but substantive." 68 The georgic's manure was also always literal manure. Describing the "weeds, mould, dung, and stale," Grainger defines manure's materiality as the putrefaction required to decompose and recompose this plantation "refuse." Beyond agricultural byproduct and necessity, manure was a process of material change and transformation.

${ }^{67}$ Randhawa, "The Inhospitable Muse," 74.

${ }^{68}$ Allewaert, "Insect Poetics," 328-29. 
As such, Grainger attempts to use manure to frame his poetry, to effect the transformations of content, form, and language that a poem, especially a West Indian poem, required. After recommending "old fat dung" (I.200), he returns to the subject to ponder manure's poetic propriety:

Of composts shall the Muse descend to sing, Nor soil her heavenly plumes? The sacred Muse Nought sordid deems, but what is base; nought fair Unless true Virtue stamp it with her seal. (I.218-221) Grainger begins this section by asking whether addressing "composts" or manure must necessarily debase his Muse, which ambivalently stands in for himself and the poem more broadly. ${ }^{69}$ The word "soil" offers at least three meanings in this context: first, it refers to manure's use as a fertilizer to enrich literal soil or earth; second, it implies contamination, that manure could dirty the Muse's garments and potentially the poem; finally, "soil" could be reflexive, suggesting that poem might "soil itself," might literally turn to waste by simply mentioning manure. Grainger acknowledges that manure could ruin his poem and his literary reputation, but his layered use of soil attempts to redirect manure's potentially contaminating effects into poetic fodder. More pointedly, he attempts to equate the farmer's production of manure with the writer's production of poetry. Manure, therefore, illustrated his central problem and its resolution: the poet, like the farmer, needed to transform the dung heap into gold.

\footnotetext{
${ }^{69}$ Ellis argues, "the muse is the poetical embodiment of the disciplinary force of the genre," which enables Grainger to displace his personal and poetic investment in chattel slavery, to "pretend that someone else, namely his female and English muse, dictates our attention to the details of slave plantation life" ("Incessant Labour"" 53). Likewise, Silva contends that "the muse of poetry" rather than Grainger himself "bore responsibility for the failure to abolish slavery" ("Georgic Fantasies" 151).
} 
In his material focus and imaginative use of manure, however, Grainger clashes with the ideology of sensibility. As Norbert Elias and Dominique Laporte have shown, both the presence and language of excrement were highly regulated by the second half of the eighteenth century. ${ }^{70}$ Sensible people simply did not discuss it. Yet, of all poetic genres, the georgic certainly seems like the most appropriate space for excrement, especially manure. The OED even lists John Dryden's translation of Virgil's Georgics under its entry for "manure." ${ }^{71}$ Still, just as agricultural waste had to be turned into manure, the poet had to transform manure into poetry. John Gilmore argues that the georgic accomplished this transmutation through "self-consciously lofty terms" or euphemisms and "elaborate paraphrases."72 As Joseph Addison described Dryden's translation, “'He delivers the meanest of his precepts with a kind of grandeur, he breaks the clods and tosses the dung about with an air of gracefulness." 73 The good georgic poet, therefore, elevated his lowly material topic — "basically grubbing around in the dirt" (Gilmore 27)—through his own literary skill, including language, imagery, and meter.

Contemporary reviews of the poem were generally good but acknowledged missteps. According to John Langhorne, The Sugar-Cane was "“rather an useful than an entertaining poem."”74 If Grainger needed to transform agriculture into poetry, manure into "grandeur" and "gracefulness," then eighteenth-century critics were not sure he had accomplished his task. ${ }^{75}$

His poetry and sensibility were threatened by his West Indian location, content, and degeneration. Many eighteenth-century metropolitans and even many colonists maintained that

\footnotetext{
${ }^{70}$ See Elias, The Civilizing Process, and Laporte, History of Shit.

71 "manure, n.1," Oxford English Dictionary.

${ }^{72}$ Gilmore, "Introduction," 27, 28, hereafter cited parenthetically

${ }^{73}$ See Addison, "An Essay on Virgil's Georgics," qtd. in Gilmore, "Introduction," 27.

${ }^{74}$ Qtd. in Gilmore, "Introduction," 39.

${ }^{75}$ For more on the poem's reception, see Gilmore, "Introduction," 36-53, Steven W. Thomas, "Doctoring Ideology," 196-98, and Silva, "Georgic Fantasies."
} 
just as the tropical heat and humidity quickly rotted meat and provoked incessant perspiration, it physiologically and culturally decomposed European transplants. As Silva explains, while Grainger's choice of a georgic indicated both "his continuing literary ambitions" and "his desire to set himself apart from the creoles who now made up the bulk of his social world," the West Indian setting forced him "to mediate between the conventional form and function of the georgic on the one hand, and the unfamiliar geographic space of the cane plantation on the other." 76 Samuel Johnson noted in his review, "“it was not an easy to task to reconcile the wild imagery of an Indian picture to the strict rules of critical exactness." "77 Any deviation, such as his strange invocation of manure, could prove his tropical degeneration and endanger his intelligence, sensibility, and even his humanity. ${ }^{78}$

Ultimately, the most fundamental threat to Grainger's sensibility and his poem's efficacy was slavery and the pursuit of profit. Sensibility and the market economy were constitutively intertwined, and Grainger's argument for amelioration was essentially economic. He acknowledged, albeit parenthetically, "(For spite of vanity, thy slaves are men)" (III.178), and beseeched, "planter, let thy humanity prevail" in the treatment of slaves (IV.211). Yet, though he allows for enslaved peoples' sensible bonds_- "Perhaps he wails his wife, his children, left / To struggle with adversity" (IV.217-18) — he couches his plea for "humanity," for planters to perceive their slaves as humans, in material possessions:

\footnotetext{
76 Silva, "Georgic Fantasies," 135.

${ }^{77}$ Qtd. in Gilmore, "Introduction," 42.

${ }^{78}$ Moreover, as Gilmore explores, Grainger was both "a Scotsman by birth and a Kittitian by adoption," a "doubly colonial writer," who potentially endangered the empire by "asserting the dignity and importance of the Caribbean," as well "appropriating a well-established form in contemporary English literature" (35). On Grainger's "double" colonialism, including his complex promulgation of British imperialism, see, for example, Gilmore, "Introduction," 59-60, 135; Jim Egan, "The 'Long'd for Aera"”; Thomas, "Doctoring Ideology"; Randhawa, "The Inhospitable Muse"; Silva, "Georgic Fantasies"; and Foy, "Grainger and the 'Sordid Master.",
} 
Perhaps thy Negroe, in his native land,

Possest large fertile plains, and slaves, and herds:

Perhaps, whene'er he deign'd to walk abroad,

The richest silks form where the Indus rolls,

His limbs invested in their gorgeous pleats... (IV. 212-16, emphasis mine)

Grainger imagines humanity defined by possessions. ${ }^{79}$ As dysentery's putrefaction drew Patty, Abigail, and John into a chain of rotting materiality, here, pursuit of profit draws Africans, creoles, and the empire itself into a network of slavery that similarly rots sensibility, exposing its tangible limits as a moral paradigm. Grainger cannot effectively humanize Africans and, thus, cannot effectively humanize himself.

He attempted to mine manure's transformative power to enable his poetic project, but manure only highlighted his own degeneration and eroding sensibility. In the passage above, Grainger attempts to recuperate the figure of "soil" by emphasizing its "true Virtue," the capacity to bear vegetable and thus human life: he claims, only "base" things are "sordid," and only virtuous things are "fair." The word "base," however, complicates this argument. Base signifies "low," physically, culturally, and economically. Physically, Grainger claims soil is not "base," but the Muse must "descend" to acknowledge it. Culturally, he claims soil's virtue, but he still self-consciously addresses its poetic propriety and his own sensibility. Economically, Grainger claims that slavery will not soil his poetry, but even his arguments for amelioration are based in

\footnotetext{
${ }^{79}$ In "Georgic Fantasies," Silva argues that Grainger encourages "sympathetic identification" between the reader and the enslaved African in these lines, urging readers to "recognize themselves in the African": "Grainger brings slavery home by mapping Africans onto a model of the cosmopolitan liberal subject who is homologous to his reading public" (149). While Silva emphasizes the role that "domestic freedom" plays in this identification, it seems like that freedom was rendered in terms of economic consumption (149).
} 
profit rather than shared human senses. "Soil" and "base" cannot prove his poetic prowess, because their material referent, manure, is a process rather than a product—decomposing and recomposing that extends before and after the farmer's or the poet's interventions. Opperman contends, composting "is a metaphor of change in which a continual storying of the world is unalterably scripted." "80 Manure does transform, translate, and transmute, but its "script" does not privilege or serve humans and, thus, cannot function as the straightforward, malleable metaphor Grainger desires. Instead, it undermines his claims to sensibility, highlighting the "sordid" and "base" sediment of chattel slavery that soiled his professions of "humanity." It revealed the hypocrisy at work in the poem and, thus, the real danger of locating ethical action in sensible humanity.

Even as it points toward material processes beyond the writer's purview and control, putrefaction — manure and dysentery's shared materiality—binds the poem and the medical treatise together. Whereas manure exposes sensibility's hypocrisy, dysentery offers an alternative. In An Essay on the More Common West-India Diseases, Grainger explains, "fluxes kill more people in the West Indies than all other diseases." ${ }^{81}$ The flux “"“is either watery with blood, or bilious with blood, and excrement. Both these dysenteries are difficult to cure" (22). He advises, "vomits and purges," a seemingly redundant therapeutic course given the flux's characteristic symptom was already diarrhea (23). Yet these purges were designed to supplement the body's natural excretory processes. The majority of eighteenth-century therapeuticsbloodletting, emetics, diuretics, sudorifics, etc.- -were cathartics that aimed to build on the

\footnotetext{
${ }^{80}$ Opperman, "Compost," 137.

${ }^{81}$ Grainger, An Essay, 18, hereafter cited parenthetically.
} 
body's natural cleansing properties by expelling dangerous humors. ${ }^{82}$ If these humors were not released, they could accumulate and eventually rot the body from within. ${ }^{83}$ For example, Grainger notes, "sweating is an highly healthful evacuation," especially "in warm climates," because it "preserv[es] the juices from putrefaction" (10). By releasing pent up humors, sweating and other "evacuation[s]" recalibrated the body, preventing "putrefaction" and disease. In the case of the flux, which Grainger argued derived from "watery crude vegetables," "corrupted bile," or "suddenly suppressed perspiration," purges assisted the body in carrying off and out corrupted and putrefied humors (22). Bloody stool represented the body's attempt to cure itself, to purify some putrefaction, whether rotten vegetable, bile, or sweat. Putrefaction was not simply a theme that linked Grainger's two texts; more importantly, it drew manure and dysentery, nonhumans and humans, into intimate, material, and rotting relation.

In Book II of The Sugar-Cane, manure and dysentery form a continuum of rot when a "plague" of insects putrefies the sugar (II.202). Grainger declares, "pity the poor planter" (II.201), whose cane has mutated from delicious, profitable "waving gold" into poisonous waste (II.203):

First pallid, sickly, dry, and withered show;

Unseemly stains succeed; which, nearer viewed

By microscopic arts, small eggs appear,

Dire fraught with reptile-life; alas, too soon

\footnotetext{
${ }^{82}$ Sudorifics or diaphoretics induce perspiration ("sudorific, adj. and n."). Of The Sugar-Cane's 32 medicinal footnotes, 13, or over a third, explicitly grapple with excrement. Seven describe "astringents" meant to halt different types of diarrhea, including lax, flux, and "fish poison." Six detail purgatives or vermifuges meant to produce diarrhea. Grainger's remaining 19 footnotes offer recommendations on other cathartics, antidotes, and poultices for sore throats and inflammations.

${ }^{83}$ See Charles E. Rosenberg, Explaining Epidemics, chap. 1.
} 
They burst their filmy jail, and crawl abroad,

Bugs of uncommon shape; thrice hideous show! (II.210-15)

The insects infect the cane, staining and rotting the plant. As Patty's putrefaction infects Abigail and then John, the rotting cane soon infects the human body:

...In vain, its [the cane's] pith

With juice nectarious flows; to pungent sour,

Foe to the bowels, soon its nectar turns:

Vain every joint a gemmy embryo bears (II.222-25)

The cane's putrefying materiality transfers from insects to produce to person. Allewaert argues that these insects "convert[] human bodies into excremental parts and the plantation to an unproductively fecal terrain." 84 While she admits that "Grainger attempts to show how various sorts of dung are useful to agriculture," she ultimately contends that his "proleptic conversion of green into gold is a cover for another prolepsis where green runs to scat" (328). Grainger's writing certainly reveals a latent fear that the insensible pursuit of profit will rot his poetry and himself. Yet it is not just that "green runs to scat" - that crops can be destroyed, that the plantation economy is corrupted by its reliance on enslaved labor and thus doomed—but that scat also runs to green. Manure could produce life and wealth that was not oriented to human needs and concerns.

Manure and dysentery's shared rot united humans and nonhumans through shared materiality rather than shared humanity. The putrefying cane, like Patty's putrefaction, links disparate humans and nonhumans together in a chain of shared materiality: household waste contributes to manure; the "well-manur'd" land nourishes the cane; enslaved Africans raise and

${ }^{84}$ Allewaert, "Insect Poetics," 317, hereafter cited parenthetically. 
harvest it; the insects rot it; the humans consume its sugar; and, the sugar putrefies the bowels. Manure, produce, insects, and humans are drawn together through their shared capacity to mutate and to mutate others. These humans and nonhumans are linked not by shared feeling, which did little to stem the mistreatment and enslavement of fellow, feeling humans, but by a shared, mutating, and affecting materiality.

Moreover, manure and dysentery's rot spawned life beyond human goals and needs. The putrefying cane may signal human rot in both the bowels and the coffer, but it also generated new nonhuman life as well. The visible signs of the cane's putrefaction—“"pallid," "sickly," "dry," "withered," and "unseemly stains" — are also the signs of birth as the phrases "small eggs," "embryo," and "reptile-life" demonstrate. Grainger certainly does not romanticize this life, mourning the loss of "waving gold" and cursing the insects. Yet, as Allewaert argues, his poem nonetheless forwards an "insect poetics": the insects "catalyze[] animating processes," in which "the movement and combination of the particulate precedes, and directs, form and system" (313). Though Allewaert downplays manure's importance—in fact, she acknowledges the utility of dung and Grainger's substantive "fecal orientation" in a footnote ${ }^{85}$ — putrefaction actually illustrates her argument, representing a process of combination and recombination that coalesces humans and nonhumans into new forms and beings. In this passage, the insects represent participants in rather than the sole cause of putrefaction, setting in motion processes of rot and life that neither they nor the human farmer, not to mention the human poet, can fully control. Ultimately, this nonhuman life posits an alternative to the ethics of sensibility, an ethics of rot that reminds us that our shared, mutating, and affecting materialities could produce life and wealth beyond a circumscribed definition of "human."

${ }^{85}$ Allewaert, "Insect Poetics," 328-29. 
Manure and dysentery's putrefaction rejected sensibility's implicit and hypocritical premise of human supremacy, especially as it enabled chattel slavery. Allewaert argues that Grainger's "insect poetics" revise conventional personification from an "affective operation" that effectively erases "diversity" to "a disaffecting operation... [that] tends toward division" rather than "connection" (302). On the one hand, putrefaction divides, breaking human subjects down into material parts, and, thus, severs bonds based on affective similitude as Adams's letters describe. On the other hand, putrefaction also connects, combining cane stalks and dung into manure and rotten cane and humans into a dysentery. In short, putrefaction connects by dividing, evolves by devolving. It decomposes a paradigm of common humanity by privileging common materiality. It rots Grainger's writing, sensibility, and humanity, but it also produces new "reptile-life," as the insect infestation illustrates, pointing toward the positive and possibly ethical relations these shared materialities could animate.

\section{Landon Carter's Wormy Sensibility}

While Grainger almost certainly intended The Sugar-Cane for a metropolitan audience, he directed his medical treatise to the untrained plantation owner or manager whose profit margins, if not humanity, needed to know how "to treat the diseased, till proper advice can be called in" (8). Landon Carter, a wealthy plantation owner in Virginia, may have been Grainger's ideal audience. Carter was not a professional doctor - in fact, he frequently criticized the local doctors, touting his superior skill—but he carefully documented plantation medical practice in his Diary $(1752-78) .{ }^{86}$

\footnotetext{
${ }^{86}$ In one entry, Carter recounts a quarrel with Dr. Flood, who refused to divulge his medicine's ingredients (637-38). In another, he describes to Dr. Jones his own therapeutic system, but the doctor, "as Flood did of old, condemned the Practice." Carter self-importantly concludes, "I
} 
Additionally, he recorded his own aches and pains, both literal and affective. He repeatedly notes his children's disobedience, ungratefulness, and perceived treachery. His daughter elopes, his son gambles, and none of them visit him as he dies. When one of his grandsons hides an illness, Carter complains,

I wish the Child don't conceal his sickness long before he speaks of it, for it is impossi[ble] such a load [of vomited bile] could be to come off without a complaint sooner: he scarcely owned a sickness at his stomach and pretends he has been at stool yesterday, but I fancy it is a mistake and have ordered a Clyster in about an hour or two after his vomit is over... ${ }^{87}$

With vomits and enemas awaiting him, one can imagine why the boy might have lied. ${ }^{88}$ Carter's diary thus traces the fault line between disobedience and sympathy, hierarchy and sensibilityparticularly between himself and his children and enslaved Africans. Attempting to understand Carter's obscurity, Rhys Isaac argues that the diary's Southern origin, size, and "erratic," unedited prose all probably contributed to its historical insignificance. ${ }^{89}$ James Greene argues that Carter has been forgotten, because he "failed...to make any lasting impression upon his

\footnotetext{
disregarded him" (776). While medicine was not yet fully professionalized, Carter's arrogance is striking.

${ }^{87}$ Carter, Diary, 508, hereafter cited parenthetically.

${ }^{88}$ Gail Kern Paster argues that purges and enemas "offered an alluringly ambivalent bodily experience" in early modern England, "of pleasure and shame, of erotic release within the sanctioned precincts of current therapeutic practice," which "recall[ed] memory traces of infantile sensation." The Body Embarrassed, 161. Purging, she argues, represented a vital moment "in the early history of the subject: the contest for physical autonomy every child wages with his/her primary caregivers" (114). See chap. 3. Here, the enema seems to function as a disciplinary mechanism of sensibility, delineating and mandating the proper relations of the home.

${ }^{89}$ Isaac, Landon Carter's Uneasy Kingdom, xi, hereafter cited parenthetically.
} 
generation. ${ }^{90}$ Certainly, his personality contributed as well: obsessed with his superiority, hierarchy, and self-righteousness, Carter was acutely unlikeable and unsympathetic.

Though it would seem like Carter was less governed by sensibility than Adams and Grainger, and certainly less worried about persuading anyone of his sensibility—after all, he was writing a diary—he nonetheless obsesses over the paradigmatic sensible bond: kinship..${ }^{91} \mathrm{In}$ particular, he maintains a steadfast belief in the hierarchy that ruled relations between kin, including his children, grandchildren, and slaves. Isaac notes that Carter's response to his daughter's elopement "rewrote Clarissa," a classic text of sensibility, "from the point of view of old Mr. James Harlowe" (47). Isaac explains, "In the forms of his stories—now sentimental, now authoritarian — we can see Landon clearly as a divided individual facing two ways: he wanted to be a lordly patriarch like his father, and he wanted to be loved and understood like Pamela or Clarissa" (48). This hierarchical sensibility is disrupted, however, when a dysentery epidemic and worm infestation upend his plantation and thwart his medical acumen. According to Reno, scat is biologically "notable," because it demonstrates "the ability to incorporate another life form without destabilizing organismal form and identity," indexing the individual's capacity to consume without fundamentally changing. ${ }^{92}$ Yet the plantation's bloody, wormy excrement threatened not only "organismal form and identity" — what disrupts both more than death? — but also the hierarchy implied by excrement itself. Morrison argues, "excrement... is both self and other, food made me, and me made waste," but this wormy dysentery was me made food and me

90 Greene, "Introduction," 10. For more on his relative obscurity, see 9-10, 28-48.

${ }^{91}$ See pp. 176 on the importance of the family to sympathy and sensibility, especially after the Revolution.

92 Reno, "Toward a New Theory of Waste," 13. 
made waste. ${ }^{93}$ It rejected sensibility’s hypocritical premise of human supremacy, redefining ethical relations in material, anti-hierarchical terms.

Carter was not averse to sensibility and sentiment, but his feelings and his diary were scripted along strict patriarchal and authoritarian lines. When his daughter Susannah died after a protracted malarial illness, Carter illustrates his sincere grief: "Severe stroke indeed to A Man bereft of a Wife and in the decline of life because at such periods 'tis natural to look out for such Connections that may be reasonably expected to be the support of Greyhairs and such an one I had promise myself in this child in Particular" (221). Still, he frames this grief through a limited and hierarchical paradigm of the parent-child relationship; parents "natural[ly]" provide for their children so that one day they will support them in age and infirmity, a quid pro quo. As Boudreau argues, the ideology of sensibility fulfilled a disciplinary function: "through repetition and example," sensibility "could be made to seem natural and original to the individual, not to the law...personal feelings are brought into the service of social concord even as subjects believe themselves to be acting as individuals" (23). Thus, when Carter invokes sentimental language to reaffirm a hierarchical relation, he engages in complementary rather than antithetical disciplinary mechanisms.

While Carter's beliefs were not necessarily unique, his discipline frequently failed. He was plagued by disobedient and disorderly children, in-laws, and grandchildren. "I am much mistaken," he sarcastically muses, "if duty to Parents is not within the Scripture Rule. How can you love God whom you have not seen, and dispise Parents who you have seen. I am tortured with this species of filial disrespect" (736). Invoking the Bible, Carter aims to be obeyed and respected as his family's earthly God. When he discovers that one of his grandchildren has been

\footnotetext{
${ }^{93}$ Morrison, Excrement in the Late Middle Ages, 155.
} 
"sawsy" with his mother, he "gave him one cut over the left arm with the lash of my whip" (310). The mother "then rose like a bedlamite that her child should be struck with a whip and up came her Knight Errant [her husband, Carter's son] to his father with some heavy God daming's, but he prudently did not touch me. Otherwise my whip handle should have settled him if I could" (310). In this passage, Carter attempts to correct "filial disrespect" with physical remonstrance. As the parents' responses demonstrate, however, such abuse was no longer considered appropriate or sensible, leaving little guesswork as to why his children might have disliked and disobeyed him. In one of his final entries, Carter sighs, "I see it is in vain to expect much of my Children's Company" (1149). Carter expected the sensible bonds of family to "support" him at the end of life, but his authoritarianism, his need to reassert filial hierarchies, seems to have strained if not completely severed these affective relations.

Thus, as he struggles to discipline his "indoors family," he also fails to discipline his outdoors family_his slaves (168). While eight of his slaves used the Revolution as an opportunity to escape their fetters and claim freedom, his diary is peppered with small-scale rebellions as well. ${ }^{94}$ Mary purportedly "shams her fits" (604), and "sicke people" suddenly "refuse to complain on Sundays because they look on that as holy day and don't care to be confine by physic" (174). As Sharla M. Fett has shown, many Africans feigned illness to resist enslaved labor, while many others feigned health to resist the slave master's invasive, dehumanizing, and frequently dangerous physic. ${ }^{95}$ Most frequently, Carter complains about Nassaw, his purportedly alcoholic slave and medical apprentice. He records,

\footnotetext{
${ }^{94}$ For an analysis of this rebellion and its effects on Carter, see Isaac, Landon Carter's Uneasy Kingdom, chap. 1.

95 See Working Cures, especially chap. 7.
} 
I have been obliged to give Nassaw a severe whipping this day. He has every day drunk ever since Mulatto Betty [Nassaw's wife] was taken ill...I have threatened him, begged him, Prayed him, and told him the consequences... and yet all will not do; he seems resolved to drink in spight of me, and I beleive in order to spight me. (779) While Carter does not meditate on Betty's illness, it seems possible that Nassaw's binge was precipitated by anxiety for his wife's well-being. Overall, Carter chronicles tale after tale of small-scale resistance to his hierarchical relations and discipline.

Like many of his time and position, Carter underestimated African and African Americans' sensibility. When his "faithful and...profitable servant," Jack Lubbar, dies, Carter observes, "I fancy not a child of mine but would refuse even their duty. In short an Old Parent is not so happy as old Jack Lubbar was; for he with only common feelings was blessed with his children's Company" $(835,836)$. Although Carter acknowledges and even pines for Lubbar's filial affection, he still manages to reject his sensible humanity. Lubbar has "feelings" and devoted children, but Carter qualifies this sensible humanity with the adjective "common." Lubbar's feeling was not and could never be as refined as Carter's. Yet while Carter strives to order his plantation in a strict and racist hierarchy of obedience and refined feeling, Lubbar's story illustrates how sympathetic relations evaded his control: he could not negate his slaves' filial affections, just as he could not manufacture his own. To use Isaac's terms, "the sentimental" and "authoritarian" collided as Carter attempted to order the affective relationships between himself and his children, his children and their children, and even his slaves and their families.

When a dysentery epidemic strikes, however, it rots the hierarchies that govern Carter's sensibility. As the entire neighborhood falls ill, Carter, the untrained but well-read and well- 
stocked medical practitioner, notes the ailment: "a violent purging with much gryping and bloody stool" (624). Diagnosing "the flux," which was ravaging settlements along the York and James Rivers, Carter orders "Vomits for all" (627). He hoped that the emetics would purge the poisonous humors for he was "certain [that] without speedy and carefull evacuation the acrid and prodigeous quantity of bile must grow putred and turn into a mortal flux" (627). A "mortal" dysentery, he argues, develops from excess, unpurged bile, which could rot or putrefy the body from within. He theorizes, "even by the fruit they have eaten their bile grown so rancid as to grype them much and tear their bowels which produces these bloody purgings" (632). Moreover, if this bile was not purged, it could "concreat[]" the excrement and produce a dangerous "Mortification" in the bowels (555). Like Adams and Grainger, Carter describes the dysentery epidemic through the common paradigm of putrefaction or mortification. Like Grainger, Carter believes that he can safely combat the flux by harnessing and amplifying the body's natural purgings.

Yet Carter struggles to manage the epidemic, growing increasingly anxious about the limits of his medical acumen and treatment. On the one hand, Nassaw informs him that the enslaved children are faring better, "their stools...only soft" now (627). On the other hand, "the mothers say they [the children's "stools"] are quite blood and water so that I know not what to do" (627-28). When a seven-year-old enslaved girl named Eve "was seized with a cramp in her bowels and died in an Instant," Carter seemed especially shaken:

She had been setting up at usual times this week, eaten and drank well, walkt about, and stooled as regular as can be without any complaint... I don't know what to think of it... No one thought her the least in danger...Something very uncommon must have happened or have been done to her that I don't know of...(631-32) 
Not only has Carter's curative regimen failed; his certainty in his own medical knowledge, skill, and superiority has eroded as well.

Worms further complicate the epidemic. When Carter first diagnoses the "very bloody stools" of the flux, he also notes "many worms" (627)..${ }^{96}$ Consuming the bowels even as the rotten bile putrefied them, the worms added to the epidemic's danger. One enslaved girl, Charlotte, who was suffering a "combined disorder of a bilious purging Joined with an unconquerable fund of worms," sipped some beer and suddenly "screamed out...complaining of her belly and immediately voided a stool of real excrement, with dead worms and maggots in it" (635). She died that day. Carter decides that those "Corrupted worms within must have brought on instant death" (636). Though these worms could rot the bowels, like the bile that caused dysentery, Carter also characterizes them as voracious consumers. He cries, "these poor children... are almost eaten out with the worms" (633). In another case, a man named Phil is "devoured" by "a prodigeous number of these animals" (663). Like the "reptile-life" born from the Grainger's rotten cane, these worms survive and persist by consuming and rotting the human body.

Dysentery's bloody flux could be understood as the body purging itself of corruption and, thus, as reconsolidating the human body and subject. The worms, however, disrupted this paradigm. Whereas excrement demonstrated how humans retained "organismal form and identity," the wormy dysentery demonstrated how nonhumans maintained their forms and

\footnotetext{
96 Though he initially blames the worms for the plantation's illness, he himself soon developed "a watry purging" without worms, which suggests that they were probably not the sole cause of the epidemic (637). Benjamin Rush notes in his Medical Inquiries and Observations that "epidemic dysentery" could be caused by worms, and that worms "frequently... accompan[ied] the dysentery" (176). Thus, Carter's initial diagnosis was in line with the era's medical teachings.
} 
identity by consuming us (Reno 13). After all, the presence of worms in feces, whether dead or alive, attests to the fact that they have not been digested and incorporated into the human body and self. Instead, we have been incorporated into them - a terrifying threat to the hierarchies that governed Carter. The wormy dysentery reminded him that "kin" was neither human nor deferential. Kin stretched from feeling humans like himself to his rebellious children to his unrefined and insensitive slaves to rotten bile, bowels, and worms. As the wormy dysentery suggested, humans are embedded in processes that decompose our bodies and selves, but these processes also compose new relations that resist human-centered hierarchies.

Though Carter was strikingly sensitive to perceived wrongs, he rarely extended such sensitivity to others. Instead, Carter's sensible bonds were strictly hierarchical: children followed parents, African slaves obeyed white masters, and diseases submitted to astute medical practitioners. Yet Carter's children, his slaves, and the wormy dysentery epidemic rot this hierarchy. Carter attempts to reaffirm his authority, arguing that the children "might have been saved" if only "anybody followed my orders" $(636,633)$. By displacing blame, however, he only draws attention to his inability to rule effectively. As Fett argues, "Any suggestion of independent care for the body signaled a potential threat to the slaveholder's control over enslaved laborers." 97 Ultimately, this wormy dysentery resisted Carter's particular brand of authoritarian sensibility, highlighting the dangerous, hierarchical, disciplinary power that sensible humanity enabled. Instead, the wormy dysentery posited an ethics of putrefactionshared, mutating materiality — that undermined sensibility's static and hierarchical relations between humans and between humans and nonhumans.

${ }^{97}$ Fett, Working Cures, 141. 


\section{Conclusion}

In the final years of his life, Carter was afflicted by a "costive tendency" and colicconstipation and gas (730). He was unable to ride his horse, visit his fields, doctor his family, neighbors, and slaves, and eventually could not walk, sleep, or even eat. He attempted many cures, including wine, egg yolk, and sleeping fully dressed, but nothing availed. At 67, Carter eventually decided, "No such an intimate with old age seldom leaves" (974). While Carter never uses the words rotted, putrefied, or corrupted in this context, he believes that old age has "weak[ened]" his stomach and bowels, that he is doomed to suffer because of his age (831). As the wormy dysentery epidemic highlighted humanity's mutating materiality, Carter's aging, colic, and constipation rooted him in his mutating, material body. An ethics of putrefaction could account for his changing abilities and offer an alternative, more responsive and responsible mode of relating and caring for our mutable relation to senses, sensibility, and humanity.

In his final entry, just three days after he claimed, "it is in vain to expect much of my Children's Company," Carter reported, “A backwoods visit to see an aged, Very sick almost unto death, and very infirm father whose constant care has been to provide well and the best he could for his Children" $(1149,1150)$. Writing of his own "harbinger of death" just weeks before, Carter seems to see himself in this dying father (1146). Like Adams, Carter wants to be perceived as sensible - and to be treated sensibly. Yet, if the goal of sensibility or sympathy was to be responsive to others' pain and suffering by imagining how one would feel in a similar situation, here, Carter projects rather than responds. As Boudreau argues, "sympathy...erase[s] the gap between subject and object — not by bringing the two together, but by superimposing the spectator's perceptions onto the body of the perceived image." 98 Carter's sympathetic

\footnotetext{
${ }^{98}$ Boudreau, Sympathy in American Literature, 12.
} 
identification not only elides important differences, but also exposes sensibility's core limitation: the gap between subject and object, human and nonhuman, and human and human perceived to be nonhuman. An ethics of putrefaction, however, revised sensibility's human supremacy, including white human supremacy, emphasizing shared, rotting materiality as a potential wellspring of responsive relation.

Each of these writers engaged rhetorics of sensibility to persuade their audiences and themselves of their keen and sensitive humanity. Adams desperately struggled to inscribe both her mother's and her own humanity into her letters, while Grainger tried to reconcile slavery and sensibility through the figure of manure. Likewise, Carter attempted to mandate his family's and his plantation's sensible relations through strict hierarchies. As these writers demonstrate, sensibility was a vital paradigm for ordering individual identities and personal relations across early America and the early Atlantic world.

Dysentery, however, disrupted their rhetorics of sensible humanity. It knitted Patty's putrefying body to Adams's rotting sensibility and letters and, thus, to John, fusing them into a chain of putrefying materiality that undermined fellow feeling as the basis for ethical care and attention. It revealed the hypocritical paradox at the heart of Grainger's and the larger Atlantic culture's profession of sensibility—-the fact of chattel slavery—but it also envisioned decomposition, rot, and putrefaction as productive, engendering life unrestrained by a limited paradigm of humanity. It challenged sensibility's fundamental hierarchies and instead posited an ethics based on their putrefaction, the decomposing of standard methods of relating and responding to others. In this way, it also joined these disparate writers and their texts together across time and space. Ultimately, this ethics of putrefaction revised sensibility, proposing relations and connections bred through materiality rather than a circumscribed humanity or 
human feeling — a lesson that could enable more expansive ideas about human ability and diversity as called for by the medical humanities and disability studies. 


\section{Chapter Five: How the West was Undone: Malarial Seasoning in Narratives of Western Imperialism}

In the earliest years of colonization, white settlers marveled at the land's health. Their epidemiological environment was not "virgin soil," but the crowd diseases that plagued Europe and England—smallpox, measles, and tuberculosis—seemed nonexistent. ${ }^{1}$ Yet seasoning diseases like malaria forced them to admit that the land itself was not a vacant, salubrious paradise. ${ }^{2}$ While white settlers and chattel slavery probably introduced malaria to the Americas, the paradigm of seasoning allowed them to believe that the illnesses that followed their settlement—headaches, rhythmic fevers, sweats, wracking chills, and delirium—were local, indexing their acclimation to a new environment. ${ }^{3}$ By the nineteenth century, they imagined seasoning illnesses as a rite of passage, a routine stage in the inexorable march of western expansion and colonial progress. As surely as they would survive the illness, they would colonize the land. ${ }^{4}$

\footnotetext{
${ }^{1}$ See pp. 4-6 on the virgin soil model.

${ }^{2}$ Many other diseases like dysentery and typhoid fever were included under the rubric of the seasoning. One of the most routinely described seasoning diseases, however, was malaria. Because it is impossible to diagnose malaria accurately, I focus on the relationship between the environment and illness, which enabled the cultural-historical paradigm and the disease itself. On other seasoning diseases, see Gerald L. Cates, "The Seasoning Disease," and Oscar Reiss, Medicine in Colonial America, 267.

${ }^{3}$ In this chapter, I am particularly interested in a "white" paradigm of seasoning, how white colonists used seasoning to encourage Western expansion. Slave seasoning included disease acclimation, but it also referenced psychological acculturation to slavery.

${ }^{4}$ In Seasons of Misery, Kathleen Donegan provides an important rereading of seasoning, arguing that the paradigm was not so teleological during the initial period of American settlement, when successful colonization was not guaranteed (6-9). While I am focusing on a later period, Donegan's argument is helpful in explaining the gap between the cultural paradigm of seasoning and lived experiences of seasoning diseases like malaria. On early American seasoning more generally, see, for example, Joyce Chaplin, An Anxious Pursuit, chap. 4.
} 
Yet no one was every fully seasoned by malaria. Fevers and chills could cycle for months at the slightest provocation, relapses could recur for years, and complete immunity was biologically impossible. ${ }^{5}$ Colonists imagined malaria to be a natural byproduct of the land, one that white civilization would inevitably eradicate, but their civilizing actions-felling trees, planting crops, and establishing homes — actually created the perfect environmental conditions for the disease to thrive. ${ }^{6}$ As Kathleen Donegan has argued, "Seasoning was something to pass through, an inevitable byproduct" or stage "of settlement," but the actual experience of seasoning was far more harrowing than the paradigm itself implied and promised. ${ }^{7}$

While malaria did recede from the cold, quickly industrializing North at the beginning of the nineteenth century, two strains - the benign $p$. vivax and the deadlier $p$. falciparumpersisted in the South until the twentieth century. Moreover, as white pioneers traveled past the Appalachian mountains toward the Pacific, p.vivax immigrated west with them. As critics from Frederick Jackson Turner and on have argued, the Western frontier represented a particular white, male fantasy of unlimited, inexorable expansion. Yet, as Annette Kolodny argues, the frontier was also a material place: "a physical terrain that, for at least one group of participants, is newly encountered and is undergoing change because of that encounter." ${ }^{8}$ One such active

\footnotetext{
${ }^{5}$ For an overview of malaria's symptoms, strains, and history in America, see Margaret Humphreys, Malaria, introduction and chaps. 1-2.

${ }^{6}$ In "The Seasoning Disease," Cates contends, "the very changes that most colonists felt were necessary to a prosperous and vital society produced an environment favorable to the growth and dispersal of parasites that would prey upon it" (153). On the relationship between "civilizing" forces like deforestation and malaria, see, for example, Cates, J.R. McNeill, Mosquito Empires, 54-55, and Albert E. Cowdrey, This Land, This South, 83-85.

${ }^{7}$ Donegan, Seasons of Misery, 7.

${ }^{8}$ Kolodny, "Letting Go of Our Grand Obsessions," 5. Here, I invoke the classic formulations of "Manifest Destiny" and "the frontier": Frederick Jackson Turner, "The Significance of the Frontier in American History"; Henry Nash Smith, Virgin Land; Leslie A. Fiedler, The Return of the Vanishing American; Richard Slotkin, Regeneration through Violence and The Fatal Environment; Annette Kolodny, The Lay of the Land; and Amy S. Greenberg, Manifest
} 
participant was malaria. Its material symptoms and history exposed the lie at the heart of seasoning and imperialism. If immunity was impossible, seasoning's promises-acclimation, acculturation, and colonization —were also impossible or, at the very least, unguaranteed.

It is impossible and unnecessary to diagnose malaria in the narratives of Western imperialism collected here. Instead, this argument analyzes how the cultural paradigm of seasoning failed to account for complex, contradictory lived experiences of environmental illness - and, thus, how such illnesses resisted colonialism's mythic teleology. From the late eighteenth century through the early nineteenth century, western immigrants like Elizabeth House Trist, Timothy Flint, and Caroline Kirkland conflated their illnesses with their local environments, invoking the seasoning to fathom their unfathomable experiences and to assure themselves of their own survival. Yet each writer experiences an illness that unsettles the certainty the paradigm should ensure. In her Travel Diary (1783-84), Elizabeth House Trist unsuccessfully searches for signs of familiar civilization as she travels to her new home in Natchez, Mississippi. Instead, she discovers an environment that resists her physical and literary incursions; environmental illness settles and, therefore, unsettles her body, her journey, and her writing. While the powerful promise of inexorable progress was not yet available to her, Timothy Flint witnesses the mythos' proof some thirty years later (in many of the same spaces Trist had travelled). Yet, as Flint attempts to settle in the Missouri and Arkansas territories, he realizes that the seasoning is neither guaranteed nor certain; malarial illness rejects his fantasy of inevitable expansion and ejects him from the West. Similarly, Caroline Kirkland's more famous works on

Manhood and the Antebellum American Empire. Though only Kolodny and Greenberg explicitly gender the paradigm, the others implicitly emphasize men's relationship to the frontier. My argument is that "seasoning" complemented the paradigm of manifest destiny, while malaria itself undermined it. 
frontier life-A New Home—Who'll Follow? (1839), Forest Life (1842), and “Western Clearings (1845) - also invoke the teleological myth of Western imperialism. Malarial illnesses, however, engender a "fitful" integration into Michigan life, disrupting her elitism as well as her colonial rhetoric. The seasoning may have functioned to bolster Western imperialism, but actual seasoning illnesses like malaria belied the certainty of civilization's progress, resisting both Western imperialism and the writing of that imperialism.

Moving through time and space, this argument contends that even as Western imperialism became more entrenched in American culture, malarial illness resisted its inscription. Even as colonists attempted to actualize Western imperialism, they record seasoning as a complicated, unfixed, and unfinished exchange with their environment. Yet the environment, as David Mazel, argues, is not a static backdrop for human drama but " "the action of environing,"” an "“encircl[ing] or 'surround[ing]." "' Another word for environing might be seasoning. Ultimately, a malarial environing and seasoning rejected the certainty that all disease could and would be conquered and, thus, that the West itself could and would be conquered.

\section{Malaria's Region and Regionalism}

Malaria is not a single disease, but a constellation of similar symptoms produced by different strains of the plasmodium parasite. Nineteenth-century America hosted at least two strains: . vivax and p. falciparum. P. vivax is not typically fatal, but its symptoms-headache, rhythmic fever and chills, hallucinations, all of which can relapse for months and even years-

\footnotetext{
${ }^{9}$ David Mazel, American Literary Environmentalism, 35. Mazel, however, is suspicious of any ecocritical recourse to being, matter, and materiality, emphasizing how culture and history condition "the environment." My hope is that my understanding of seasoning, as a "naturalcultural" intra-action (to use Donna Haraway's term), resists the paradigm of the environment as an "ontologically stable, foundational entity" (xii).
} 
can lead to chronic anemia and opportunistic infections. If these ailments did not kill immediately, they nonetheless made labor difficult and sometimes impossible, and thus poverty, malnutrition, and death more likely. In turn, p. falciparum is far deadlier, far more quickly, sometimes impairing the central nervous system and causing cerebral malaria. Though both of these strains (and possibly more) were present in early America, $p$. vivax was more widespread. ${ }^{10}$

Like yellow fever, malaria is spread by mosquitoes that contract the parasite and infect humans during blood meals. In its human host, the parasite retreats to the liver, eventually entering the bloodstream to feed and reproduce. In turn, the immune system responds to this periodic reproduction, producing the disease's characteristic rhythmic cycles of fevers and chills. Some populations have genetic protections for some strains, while others develop partial or acquired resistance through prolonged exposure. Still, even this resistance wanes if the individual leaves their malarial environment. Unlike smallpox or yellow fever, malaria never produces full immunity. Reinfection is possible and likely in endemic areas. Despite the disease's vast toll, it remains prevalent and virulent, especially in Africa. Though scientists, governments, and the World Health Organization have waged coordinated eradication campaigns, much like those they successfully implemented for smallpox, quinine, DDT, mosquito nets, and geneticallyengineered mosquitoes have not yet extirpated the dangerous disease. There are at least 156 plasmodium parasites and 30 anopheles mosquito vectors, and each permutation of the disease poses a new complicated life cycle for a vaccine or genetic engineering to solve. ${ }^{11}$

\footnotetext{
${ }^{10}$ Humphreys, Malaria, introduction and chaps. 1-2.

${ }^{11}$ On etiology and genetic resistance, particularly in the context of race, see Humphreys, Malaria, chap. 1, and Kenneth F. Kiple and Virginia Himmelsteib King, Another Dimension to the Black Diaspora. For a readable overview of malaria, including eradication attempts, see Randall M. Packard, The Making of a Tropical Disease. Packard also contends that eradication has failed because the disease is perceived as a "third world" or "tropical" disease. See "Malaria"
} 
Of course, early Americans did not fully comprehend malaria's complex pathology. In fact, they rarely used the word "malaria" at all. Instead, the disease's periodic cycles of fevers and chills went by "the ague." To them, the ague spread not by infected mosquitoes but by the swamp's poisonous miasmas - the "bad air" of mal aria. Agues were associated with swampy areas prone to flooding like rice plantations and the banks of the Mississippi River. Hot, humid weather and unprotected strolls in the dew produced fevers that induced delirium and chills that chattered teeth. While we cannot know if ever reference to the ague was actually malaria, its environmental conditions certainly sound malarial. ${ }^{12}$

The swamp's poisonous miasmas may not have produced disease, but the swamp itself provided the ideal breeding conditions for Eastern North America's most pervasive malarial vector, Anopheles quadrimaculatus, which preferred "stagnant, sunlit pools of fresh water," a temperature in the low $80 \mathrm{~s}$, and $85 \%$ humidity to breed and bite. ${ }^{13}$ Hot, humid summers enabled the sturdier $p$. vivax to survive as far north as Southern Canada during the nineteenth century, while the "more fastidious" p. falciparum required even warmer temperatures and rarely traveled farther north than South Carolina. ${ }^{14}$ In short, malaria thrived in the exact environment that early Americans believed disease it did.

Though they may not have understood malaria's complex etiology, nor have even diagnosed "malaria" at all, they did have a paradigm for explaining the ague and its

and "Anopheles Mosquito" at the CDC on the disease's lifecycle, including descriptions of various parasites and vectors.

${ }^{12}$ On nineteenth-century attitudes toward swamps and health, including how white and black Americans perceived swamps differently, see Conevery Bolton Valenčius, The Health of the Country, chap. 5, and Monique Allewaert, "Swamp Sublime." On rice plantations and disease, see Peter H. Wood, Black Majority, chap. 3 and McNeill, Mosquito Empires, 203-07.

${ }^{13}$ Andrew Mcllwaine Bell, Mosquito Soldiers, 19; Darret B. Rutman and Anita H. Rutman, "Of Agues and Fevers," 36.

${ }^{14}$ Humphreys, Malaria, 11. 
environmental conditions: seasoning. White immigrants to the West believed that the illnesses that followed their settlement—sweating, fevers, and diarrhea —indexed their acclimation to a new environment. The land was "seasoning" them. In turn, they used "seasoning" to describe both the ague and the cultural attitudes toward it — that is, the belief that it was routine and transitory, and that civilization would eventually erase it entirely. Immigrants would survive and conquer the disease and, thus, survive and conquer the West itself.

Just as not every reference to the ague was necessarily malaria, not every reference to the seasoning was necessarily malaria. The seasoning probably included diseases like dysentery and typhoid fever, but where malarial conditions are described—swamps, deforestation, irrigation, and immigration—references to the seasoning ague invariably followed, and malaria was certainly probable. ${ }^{15}$ All three represent decidedly regional phenomenon. Both the ague and malaria only survive in particular climates and conditions, while the disease's cultural framework, seasoning, emphasizes place as well. This argument, therefore, is not invested in quixotic, retroactive diagnosis; rather, it emphasizes what bound the seasoning, ague, and malaria together, culturally, historically, and materially: the local environment.

If all three were regional, then they also shaped the writing of region. Conventionally, regionalism is considered a nineteenth-century genre that responded to New England's literary dominance by representing places outside of the nation's mainstream. On the one hand, regionalism, as Richard Brodhead argues, could fetishize such geographical and cultural others and thereby reify a genteel, Anglo, New England audience. ${ }^{16}$ On the other hand, as Judith Fetterley and Marjorie Pryse contend, regionalist literature could critique the sedimented

\footnotetext{
${ }^{15}$ See notes 2 and 6.

${ }^{16}$ See Brodhead, Cultures of Letters.
} 
hierarchies of gender, race, and class that dominated the East. Place-based literature could naturalize difference as "strange, exotic, or queer," but Fetterley and Pryse differentiate this writing from regionalism, labeling it "local color." ${ }^{17}$ While Josephine Donovan contends that local color critiques male supremacy, if not always racism and classism, Edward Watts maintains that local color "strives for a certain placelessness" that ultimately bolsters a kind of Eastern colonialism. ${ }^{18}$ Whether regionalism and local color are parsed, criticism of these intertwined genres revolves around whether a writer's representation of geographical other either challenges or reinforces Eastern cultural hierarchies.

In spite of their names, however, criticism of regionalism and local color find material, geographical, climatic places to be relatively unimportant. Watts maintains that local color's "placelessness" is imperial in its universalizing impulse, implicitly highlighting the importance of place, but his interest still resides in the human culture of a place. Likewise, Fetterley and Pryse define region and regionalism through social "rather than physical and 'natural' borders." "19 Though they both contend that good regionalism deconstructs Eastern hierarchies by attending to a particular place, neither links this meaning to the land itself.

Gary Snyder's bioregionalism, however, could help emphasize the region in regionalism. He asserts, "Our relation to the natural world takes place in a place": it is not only local culture that creates a region but also "natural criteria" like waterways and rock shelves. ${ }^{20}$ Malaria may not have been a "natural" byproduct, shaped as it was by human immigration and deforestation,

${ }^{17}$ Fetterley and Pryse, Writing Out of Place, 29.

${ }^{18}$ Watts, An American Colony, 183.

${ }^{19}$ Fetterley and Pryse, Writing Out of Place, 4.

${ }^{20}$ Snyder, The Practice of the Wild, 42, hereafter cited parenthetically. 
but it did inform how people lived in a place. ${ }^{21}$ When Snyder claims, "We have the terms enculturation and acculturation, but nothing to describe the process of being placed or replaced," he misses the (admittedly outmoded) paradigm of seasoning, which not only derived from the material experience of living in a place — from acquired immunity—but subsequently framed how newcomers lived that place (27). The malarial region seasoned and environed, shaping how humans lived a place and, thus, how humans wrote about the place they lived.

Of the writers analyzed here, only Kirkland could be considered a regionalist in the conventional sense (and even then, critics disagree on her representation of region, discussed below). Whether Trist, Flint, or Kirkland considered themselves regionalists or not—not to mention whether critics consider them regionalists or not—-their malarial illnesses embed their writing in region. In turn, these illnesses shaped their experiences of the West, their writing of the West, and myths about the West, including seasoning and Manifest Destiny. They may not be regionalists, but malaria makes their writing regional.

\section{Elizabeth House Trist's Oppressive Seasoning: When the Environment Settles the Settler}

Elizabeth House Trist's Travel Diary is considered the first of its kind: "the earliest surviving travel diary of a white woman" to cross the Allegheny Mountains. ${ }^{22}$ In December 1783, she left her young son and mother in Philadelphia to join her husband in Natchez, in the

\footnotetext{
${ }^{21}$ As theorists like Bruno Latour and Donna Harraway have shown, the paradigm of "natural" falsely separates nature from culture. Malaria's growth and eventual disappearance in the Old Northwest illustrate how human-engineered changes in the environment shaped the region beyond the false dichotomy of nature/culture.

${ }^{22}$ Kolodny, The Land Before Her, 37. Trist's diary was never published in her lifetime but probably circulated among friends and family, including Thomas Jefferson. Susan Clair Imbarrato suggests that such diaries could have reached an audience of 20-30 people. Travelling Women, 27. Kolodny recovered the diary, including analysis in The Land Before Her, and edited and annotated it for publication in the collection, Journeys in New Worlds.
} 
internationally disputed Mississippi Territory. Her diary breaks this journey into three parts: the trek from Philadelphia to Pittsburgh, featuring daily accounts of her lodgings; one long, retroactive entry recounting her time in Pittsburgh waiting for the Ohio to thaw; and, the final leg from Pittsburgh to Natchez down the Ohio and Mississippi Rivers, including near daily entries on the environment. When she finally arrived in Natchez, she discovered that her husband had died months earlier, so she immediately began to plan her voyage home. While Trist's travels and writing predate the nineteenth-century's faith in Western expansion, she actively sought familiar signs of Eastern civilization on the frontier. As Susan Clair Imbarrato writes, Trist was "less interested in conquering a land than in finding a comfortable place to rest for the night."23 Yet, as Amy Kaplan has shown, women's Western writing frequently deployed “manifest domesticity" rather than "manifest destiny," constructing the home as the site of empire. As one of, if not the first woman to describe her journey West, however, Trist envisions the wilderness not as refuge, fortune, or potential but as an unsettlingly oppressive environment of raging waters, nagging mosquitoes, and wracking fevers and chills. Her harrowing descriptions are inseparable from her intent: to settle. She does not make a home of the wilderness; the wilderness makes a home of her, settling and unsettling her attempts to domesticate her Western region through familiar tropes, including domesticity and the sublime.

The first part of House's diary establishes the importance of home and domestic spaces, not only for "traveling women," as Imbarrato contends, but also for women colonizing the West. For the most part, however, the accommodations en route to Pittsburgh are less than satisfactory. One home is "so dirty that I would rather have slept out of doors," while others force her to

\footnotetext{
${ }^{23}$ Imbarrato, "Ordinary Travel," 32. On Trist's emphasis on home, see Kolodny, The Land Before Her, 37-47, and Imbarrato, Travelling Women, 187-200.
} 
cohabitate with smelly "pickling tubs" and even men. ${ }^{24}$ Imbarrato argues that such descriptions could have functioned as a travel guide, instructing others, particularly women, on where and where not to stay. ${ }^{25}$ Yet in the context of her own journey's intention, Trist's abiding interest in accommodations and domestic spaces reveal a potent anxiety about home on the frontier.

Trist's desire for a familiar, Eastern standard of home was not unique. In "Manifest Domesticity," Amy Kaplan famously argues that nineteenth-century white women engaged in Western imperialism through their domestic rhetoric: "Through the process of domestication, the home contains within itself those wild or foreign elements that must be tamed; domesticity not only monitors the borders between the civilized and the savage but also regulates the traces of the savage within itself." 26 If white men used guns and agriculture to colonize the West, women used silverware, doilies, and gentility. Other critics, however, have argued that women writers were rarely able to establish such dominion. ${ }^{27}$ Rain and dirt snuck through crevices, cooking took hours without Eastern amenities, and good help could rarely be found. In other words, living on the frontier challenged the white woman's authority over her personal fiefdom and thereby destabilized her purportedly imperial function. Cathryn Halverson posits, "if prescriptive domestic texts reinforce the ideology of imperialism, then perhaps those that allow domestic upheaval," as Western texts invariably do, "undermine it."28 Though "Manifest Domesticity" was still imaginatively viable, an undeniably powerful colonial tool, the frontier's material conditions undermined its rhetorical potential. Trist may precede the primary era of "Manifest

\footnotetext{
24 Trist, Travel Diary, 204, 205, 206, hereafter cited parenthetically.

${ }^{25}$ See Imbarrato, "Ordinary Travel."

${ }^{26}$ Kaplan, "Manifest Domesticity," 582.

${ }^{27}$ See, for example, Kolodny, The Land Before Her; Brigitte Georgi-Findlay, The Frontiers of Women's Writing; and Janet Floyd, Writing the Pioneer Woman.

${ }^{28}$ Cathryn Halverson, Playing House in the American West, 25.
} 
Domesticity" - the nineteenth century — but her routine criticism of domestic spaces foreshadows its rise. Moreover, her persistent quest for signs of civilization inadvertently revealed how the frontier itself undermined such gendered, classed, and colonial rhetoric.

Trist's skepticism of the frontier home is compounded by the diary's second part-her extended stay in Pittsburgh, the then gateway to the West. At first, she seems elated to have reached the outpost, claiming, "I like the situation of Pittsburg mightily" (213). Yet she quickly qualifies her ardor: "I shou'd be contented to end my days in the Western country" if only there were "good Society" (213). After five months, however, none of this admittedly limited passion for Pittsburgh remained. She leaves the city "with as little regret as I ever did any place that I had lived so long in" (214). Undoubtedly, she was anxious to begin the final leg of her journey and reunite with her husband, but her shift in tone also recalls her initial qualification. She could have considered Pittsburgh home if it had "good Society" —in other words, if it weren't the frontier. Similarly, on an excursion to "Cherties settlement," outside of Pittsburgh, Trist contends, "Here and there a farm wou'd present it self to our view with a few acres around it clear'd. But the country is yet in a very rude state or else it wou'd afford many beautifull prospects" (213). As Kolodny asserts, "Trist everywhere sought out...the open clearings of recognizable settlement or, where these were lacking, the signs that such settlement might soon be possible." ${ }^{29}$ Trist, like many other women immigrants, Kolodny argues, sought signs of familiar environmental patterns in attempt to assuage some of the trauma and anxiety of male-driven immigration. She clearly desired familiar, Eastern signs of home and settlement, but home seemed impossible rather than inevitable.

${ }^{29}$ Kolodny, The Land Before Her, 37. 
Though the absence of settlement unsettled Trist, the wilderness's overwhelming presence also provoked her. During this same excursion, she cannot imagine the land's potential for cultivation and utterly fails to assuage her anxiety:

For my part, I felt oppres'd with so much wood towering above me in every direction and such a continuance of it. A little opening now and then, but a very confined Prospect: nothing but the Heavens above and the earth beneath...I began at last to conceit myself Attlass with the whole World upon my shoulders. My spirits were condenc'd to nothing. My head began to ach[e], and I returned to town quite sick. (213-14) Overwhelmed by the infinite expanse of the forest, her "spirits...condenc'd to nothing," Trist imagines herself to be Atlas, the Greek God who holds the world upon his shoulders. Her head aches, she grows sick, and she abandons the trip entirely. She is "oppres'd" by her environment not invigorated by its potential, adventure, or sublime terror.

This passage rejects the sublime paradigm for perceiving and writing a frontier home, echoing, modifying, and perhaps even influencing Thomas Jefferson's infamous description of the Natural Bridge in Notes on the State of Virginia. Trist and Jefferson became close friends and correspondents after meeting at the House family's inn in Philadelphia, and Trist and eventually died at Monticello in 1828. Kolodny argues that Jefferson was the diary's intended audience, its descriptions of flora and fauna in the third part a reflection of Jefferson's own natural historical interests. ${ }^{30}$ In a letter to him from her time in Pittsburgh, she writes, "Whatever observations I am capabl of making I shall not fail to communicate to you," but admits that she cannot match "a Philosophical mind like yours," which "can gather information from all you see... and make such

${ }^{30}$ Kolodny, "Introduction," 184-88, 196-97. 
observations as will benefit Mankind in general." ${ }^{31}$ Jefferson probably did not read the diary before publishing Notes, but their correspondence could have shaped it. ${ }^{32}$

At the time, the sublime represented one of the most prominent paradigms for ordering the overwhelming experience of human finitude at the expense of nature. In his classic treatise on the subject, Edmund Burke writes, "Whatever is fitted in any sort to excite the ideas of pain, and danger, that is to say, whatever is any sort terrible... is a source of the sublime." 33 If "danger or pain press too nearly," however, "they are incapable of giving any delight" (13-14). Thus, the sublime is produced "at certain distances, and with certain modifications" (14), such as "looking down from a precipice" rather than "looking up" (52). Jefferson, however, experiences the inverse: he falls to his knees and develops "a violent head ach" while looking down from the famous natural bridge, finding this perspective "painful and intolerable." ${ }^{34}$ Yet he finds "the view...from below...delightful in an equal extreme" (23). As Gordon M. Sayre argues, Jefferson modifies the scene's "painful" sublimity by numerically and economically measuring the bridge. Ultimately, then, "the sublime tempts reason to abandon itself, only to return and reclaim sovereignty." ${ }^{35}$ Both Burke and Jefferson suggest that the experience of the sublime revolved around perspective—-both physical and literary.

Outside of Pittsburgh, however, Trist is too physically and emotionally near her environment to invoke the sublime aesthetic. After all, it was out of this wilderness that she was

\footnotetext{
${ }^{31}$ Eliza House Trist to Thomas Jefferson, April $13^{\text {th }}, 1784$, Founders Online. On this correspondence, see Imbarrato, Declarations of Independency, 77-84.

${ }^{32}$ On Trist and Jefferson's relationship, see Kolodny, "Introduction," 184-88, and Imbarrato, Declarations of Independency. 77-84, and Travelling Women, 187-200.

${ }^{33}$ Burke, A Philosophical Enquiry into the Origin of Our Ideas of the Sublime and the Beautiful, 13 , hereafter cited parenthetically.

${ }^{34}$ Jefferson, Notes on the State of Virginia, 23, hereafter cited parenthetically.

${ }^{35}$ Sayre, "If Thomas Jefferson had Visited Niagara Falls," 160.
} 
tasked with building a home. As she looks up at the vast, infinite expanse of the trees, she imagines herself not as the heroic Atlas supporting the world but as the burdened Atlas tasked with maintaining order and cohesion amidst chaos. While Jefferson manipulates his perspective, maintaining his "reason" and "sovereignty," as Sayre contends, Trist finds both utterly unsettled. She is made sick because she gazes upon her new home-a harrowing perspective compounded by the fact that she, as a woman, was the one burdened with carving genteel, domestic order from the chaotic wilderness. As Judith Fetterley argues, "Assigned the task of home-making and committed to the values associated with the home, women nevertheless frequently experienced homelessness on the frontier," while men's "agenda of upward mobility" provided "little incentive to make homes," only to move further West. ${ }^{36}$ Trist's perspective is fixed in a way that Jefferson's is not; she gazes upon home- not an interesting natural phenomenon or potential site for industry. While later colonists and writers could invoke the certainty of manifest destiny and domesticity, Trist, travelling and writing at the very beginning of the Republic, found little surety in any ideological or rhetorical framework.

As she finally begins the last leg of her journey, the environmental oppression that she experiences outside of Pittsburgh is only exacerbated by the Mississippi River and its implacable mosquitoes. "The land" does not "remain[] external" to her, as Imbarrato argues, because "she has neither the spirit nor inclination toward communion with nature alone." ${ }^{37}$ Rather, the environment penetrates Trist, physically and psychologically infiltrating and overwhelming her. On the Mississippi, she describes, "our teasing visitants," mosquitoes, who are "not to be borne" and who "have allmost done for me already" (222). She remains hopeful in this entry, noting the

\footnotetext{
${ }^{36}$ Fetterley, Provisions, 122.

${ }^{37}$ Imbarrato, Declarations of Independency, 82.
} 
netting she plans to use to keep them at bay. Yet just a week later, she writes, "The Musquitos bite and tease me so much that my life is allmost a burthen to me. I do sincerely think that all the wealth of the Indias wou'd not induce me to live in a Musquitoe country" (227). Two days later, "I am so stung with the Musquitos that I look as if I was in the hight of the small pox...I am in a continual fever with the effects of their venom" (228). Exceedingly distressed by the mosquitoes and so extensively bitten that she looked as if she had smallpox, Trist asserts that all the wealth in the world could not persuade her to live in "Musquitoe country." Of course, this was exactly her journey's intent: to make a home in Natchez, Mississippi, which would suffer from arbopod viruses like yellow fever and malaria through the twentieth century. ${ }^{38}$ Trist cannot distance herself or manipulate her perspective as the sublime required, because she encounters an environment that encounters her. The mosquito bites unsettle her intent to settle the land by settling her.

Moreover, Trist connects these mosquitoes to the illness that soon claims her. Though mosquitoes would not be identified as malarial vectors until the twentieth century, Trist claims that they provoke "a continual fever with the effects of their venom" (228). Given the land she passes through, it is probable that malaria was present. The inundated and humid banks of the Mississippi River in the summer would have been an ideal breeding ground for anopheline vectors, while extensive immigration (including Native American removal)—evidenced by the fact that her group cannot catch game close to the shore (217) — would have introduced the plasmodium parasite. Trist's travelling companion, Polly, is unwell with a fever and headache in

\footnotetext{
${ }^{38}$ See Humphreys, Malaria, chaps. 3-5 and Yellow Fever and the South, chap. 5 for how both diseases persisted in the deep south until nearly the mid-twentieth century.
} 
late May (216-17), and Trist herself complains of "a continual fever" (228). ${ }^{39}$ At the end of her trip, she describes being attacked by "a violent headach," feeling so ill that her "heart sinks": "I feel so weak that I can hardly keep my self a live" (232). Both Kolodny and Imbarrato suggest that news of her husband's death, which she learned about just before arriving in Natchez, could have caused this distress. ${ }^{40}$ It is also possible, even probable, that Trist was suffering from malaria. Instead of making an impossible diagnosis, however, her fever and lassitude become meaningful in the context of her earlier environmental illness outside of Pittsburgh and her attention to how this new region, including the mosquitoes, affected her body and mind. Trist never uses the word seasoning, but her penetrating and oppressive environment refuses the certainty that the paradigm would eventually ensure.

Ultimately, Trist's frontier region is oppressive, because it is frighteningly reciprocal. It settles her as she attempts to settle it, refusing familiar frames like the sublime, the seasoning, and civilization. Trist's distress culminates in an apocalyptic passage about the Mississippi River:

My patience is allmost exausted. What with the Musquitos and head winds, I am allmost sick. The passage early in the Spring wou'd be pleasant, but at present there is nothing but trouble. I have various ideas about this river: --[I] sometimes conceit-I am got to the fag end of the world; or rather that it is the last of Gods creation and the Seventh day

\footnotetext{
${ }^{39}$ Kolodny initially posited that Polly was Trist's slave or servant in The Land Before Her, but she argues in her introduction to the text that Polly was probably "a younger relative or family friend who joined Trist to provide companionship and for her own [unknown] motives as well" (198). Importantly, Polly made Trist's journey "possible as propriety decreed that middle-class white women did not travel alone to the frontier" (198). She is infrequently referred to in the journal.

${ }^{40}$ Kolodny, "Introduction," 194, and The Land Before Her, 47; Imbarrato, "Ordinary Travel." 45.
} 
came before it was quite finnish'd. At other times, I fancy there has been some great revolution in nature, and this great body of water has forced a passage were it was not intended and tore up all before it. (227)

Here, Trist conjures three devastating scenarios to explain her malarial, windy, diluvial environment: the end of the natural world; an unfinished, un-providential natural world; or, a rebellious, self-designed natural world. Each of these possibilities bespeaks terror of an agential environment, unchecked by God or by her pen. Moreover, each of these descriptions of the Mississippi River suggests the impossibility of successful colonization. After all, if God couldn't get it right, how could Trist? It is not, therefore, that Trist only hopes to see the natural world as a garden as Kolodny argues, nor that her "relationship with her environment is primarily a pragmatic one," focused on food and travel as Imbarrato contends. ${ }^{41}$ Rather, between her experience outside of Pittsburgh, the fevers and headaches on the Mississippi, and this passage, the frontier environment rejects those ideological frames like the sublime, seasoning, and civilization that would enable her to settle herself and the land. Instead, the malarial region penetrates her body and her writing, provoking physical and psychological illness.

The seasoning paradigm held that humans would acclimate to their environment through a period of illness, and that with time and white, human civilization would eradicate such illnesses entirely. Trist's frontier, however, was not so neat and orderly. Whereas the seasoning promised that a human actor would acclimate and eventually dominate a static land, Trist's illnesses and writing reveal an active and penetrating environment that resisted the seasoning's teleology. Though Western colonization was not yet considered inexorable in 1783 when Trist was writing, her experiences of the Western frontier's active, penetrating, and reciprocal

${ }^{41}$ Imbarrato, Declarations of Independency, 71. 
environment marked an important uncertainty at the heart of the seasoning paradigm and the colonization it would eventually function to secure. Malaria knit region into her regional writing.

\section{Timothy Flint's "Extraordinary" Seasoning: When the Environment Expels the Settler}

Whereas Trist yearned for signs of Eastern civilization, Timothy Flint, following the same path through Pittsburgh and down the Ohio and Mississippi Rivers thirty years later, witnessed proof of colonization's inexorable progress at every turn. As he records in his Recollections of the Last Ten Years (1826), by 1815 Pittsburgh was not only "romantic and delightful," but "so often described as to render uninteresting any new attempt of the kind." 42 While Trist lamented the lack of "good Society" (213), Flint admitted that the city had already peaked; any description would be redundant, and the "wealth, business, and glory of this place are fast passing away, transferred to Cincinnati, to Louisville, and other places on the Ohio" (17). Trist's boundless forests and inundated banks had transformed into large, thriving cities like Cincinnati and Natchez that very nearly rivaled the East.

Though Flint would only temporarily settle in the Missouri territory, he fully intended to make a home in the West, repeatedly affirming his faith in Western expansion and romantic notions of early settlement and trailblazing frontiersmen - a mythos unavailable to Trist by virtue of her time and gender. Eventually Flint would settle in Cincinnati and even publish classic Western narratives, including a biography of Daniel Boone (1833). Yet his first foray on the frontier, documented in Recollections, fails to establish the linear, inexorable myth of Western progress. ${ }^{43}$ Flint's seasoning is neither uniform nor guaranteed; deadly swamps, fevers, and

\footnotetext{
${ }^{42}$ Flint, Recollections of the Last Ten Years, 17, hereafter cited parenthetically.

${ }^{43}$ In his postcolonial study of the Midwest, An America Colony, Watts argues that Flint's writing resisted Eastern colonization of the West, "ventur[ing] an alternative and pluralized" United
} 
mosquitoes evade his physical and literary control, puncturing the mythic West that animates his writing. Unlike Trist, Flint believed colonization and settlement was inexorable, but as his illness failed to progress to a guaranteed end — to the state of being seasoned-Recollections failed to chronicle, even if it still valued, a teleological Western imperialism.

Like many of his white, male compatriots, Flint both fetishizes early, rustic frontier settlement, and imagines colonization and civilization as inevitable and teleological. ${ }^{44} \mathrm{He}$ delights in "the exploits of the old race of men," their "undaunted heroism" and "more than mortal endurance" in their combat with Native Americans and nature, even as he tags them as "old" and outdated (161). That is, he fetishizes the earliest frontier settlers, what Watts calls "the leftovers of the Middle Ground, the 'new-made Indians,' the frontiersmen, settlers, and voyagers." ${ }^{45}$ Yet he also fantasizes about future stages of colonial progress:

In the midst of these primeval scenes, the patient and laborious father fixes his family. In a few weeks they have reared a comfortable cabin, and other out buildings. Pass this place in two years, and you will see extensive fields of corn and wheat...Pass it in ten years and the log buildings will have disappeared... The Arcadian aspect of humble and retired abundance and comfort, will have given place to a brick house... (53)

Elicited by the "primeval" forest, this fantasy both "admit[s]" the "inexpressible charm in the pastoral simplicity of those [early] years" and imagines further Western progress as inexorablethe "comfortable cabin" is slowly expanded to a large farm and eventually a "brick house" (53).

States rather than "“a universal Yankee nation"” (139). While Flint's later works, including the Western Monthly Review, may evince such pride in Western life, his much earlier Recollections, written on the margins of civilization in the Missouri Territory, evidences no such faith-let alone pride - in the frontier's progress.

${ }^{44}$ See note 8. On how many Western writers advanced more nuanced, less "mythic" conceptions of expansion and "Manifest Destiny," see David M. Wrobel, Global West, American Frontier. 45 Watts, An American Colony, 124. 
Thus, Flint charts the progress that Henry Nash Smith's seminal study of the West codified—the wild, "half savage" frontiersman "[b]lazed trails that the hard-working farmers could follow"aestheticizing and mythologizing Frederick Jackson Turner's "perennial rebirth" of the Western frontier. ${ }^{46}$ In this negotiation of romantic past and inexorable future, Flint was not unique, particularly at a moment when that past was receding quickly in places like Cincinnati where he wrote. As he waited for the Ohio to thaw, his clearly imagined his own immigration as part of that inevitable march of Western expansion across the frontier.

His tales of seasoning, however, undermine the inexorability of the pioneer's progress by highlighting a powerful, active, and deadly environment. When Flint finally begins to traverse the Mississippi River, its flooded, brackish water, humid heat, and mosquitoes puncture his faith in Western expansion. Whereas the banks of the Ohio "are destined shortly to become almost a continued village" (39), the Mississippi bespeaks only danger and depression, as it did to Trist before him. He writes, "Cultivation becomes more unfrequent" (84); “The country begins to exhibit the sombre aspect of swamp and inundation," and while the "perfect regularity" of the trees "excites a momentary feeling of pleasure...it soon becomes dreary to the eye, from its sad monotony, and from mental associations with it, of fever and ague, and musquitoes" (84). Flint cannot conjure the efficient farmer that cleared the woods and planted brick houses outside of Cincinnati; instead, the swamp only conjures fevers, agues, mosquitoes, and, thus, the "perpetual destitution of human habitations" (84). In Cincinnati, the march of trailblazers and farmers is inevitable and infinite, but on the Mississippi only the absence of civilization seems "perpetual." Swamps, therefore, figure as deadly locales. On the banks of the Mississippi, Flint records muddy water, thick tree roots, snakes, mosquitoes, algae, and Spanish moss rather than

\footnotetext{
${ }^{46}$ Smith, Virgin Land, 53; Turner, "The Significance of the Frontier in American History," 32.
} 
people, houses, and farmland. The water "is covered with a thick coat of green matter," where mosquitoes "swarm...in countless millions" (262). Water moccasins hide and hiss under the "funereal drapery" of Spanish moss, while only "the hum of musquitoes" breaks "the death-like silence" (262). Flint concludes, "There is not, that I know, an object in nature, which produces such a number of sepulchral images as the view of the cypress forests" and their swamps (262). As Conevery Bolton Valenčius argues, most nineteenth-century Americans believed swamps were "intrinsically unhealthy": "the overabundance of water... was like the overabundance of humors...unbalanced and dangerous. ${ }^{\circ 7}$ Moreover, as Monique Alleweart argues, swamps "confounded Anglo-European efforts to mine American landscapes to produce commodities, to further science, and to fulfill conventional aesthetic categories" like the sublime, and, thus, undermined white men's ability to delineate and reify their subjectivities through "empiricism, reason, or aesthetic appreciation." ${ }^{48}$ If the sublime functioned to affirm human sovereignty, as Sayre argues, then the swamp's watery and feverish nature seemed to unsettle human bodies and subjectivities. Hence, Flint renders the landscape in exceedingly gothic terms. The fevers that the land conjures ultimately remind him that he is enmeshed in and potentially unmade by this "sepulchral" region.

Unsurprisingly, Flint and his family suffer repeatedly from bilious, remittent, and intermittent fevers. Fevers designated "bilious" were typically sustained and severe, like yellow fever, which Benjamin Rush would christen "malignant bilious" to differentiate from "the common bilious fever." ${ }^{49}$ Both remittent and intermittent fevers waxed and waned, but

\footnotetext{
47 Valenčius, The Health of the Country, 146, 146-47.

${ }^{48}$ Allewaert, Ariel's Ecology, 34, 36.

${ }^{49}$ Rush, Observations upon the Origin of the Malignant Bilious, or Yellow Fever in Philadelphia, 5.
} 
"intermittent" typically classified those fevers that recurred regularly, after a particular length of time had elapsed, as in the classic symptom of malaria. A quotidian fever recurred daily, while tertian and quartan fevers recurred every third or fourth day. Still, none of these terms were entirely fixed at the time. Moreover, some malarial infections can present a sustained fever in a person's first infection. ${ }^{50}$ For example, in A New Home, Who'll Follow? Caroline Kirkland's narrator, Mary Clavers, first suffers an intense fever before developing the more conventional symptoms of the "ague." At any point, a bilious fever could transform into an intermittent and vice versa. As Flint's family grows increasingly ill during their Western settlement, he employs all of these terms to describe their ailments.

Though it is impossible to definitively diagnose Flint's illness as malaria or not, he links his repeated bouts of fever to what we now know were malarial environments. On an excursion to the Illinois River from his farm outside of St. Louis, Missouri, Flint develops a "bilious fever" from "heat, bad food, and exposure"-not to mention "the air of the Illinois, charged at this sultry season with miasma," that ague's traditional scapegoat (131-32). Thoroughly "prostrated" for almost two months by "infantine weakness" (133), he hallucinates: he is "unable to recognize" his "friends," but able to "repeat[] whole passages" of poetry in "different languages," a feat he could not recreate after his illness (132). He hears "two flutes playing harmonies in the most exquisite and delightful airs," and witnesses visual apparitions as well, seeing "an insufferable glare of light" around peoples' heads, "like a dazzling glory" (133). Malaria's high fever can produce confusion, but auditory and visual hallucinations are less common. ${ }^{51}$ Typhoid fever, however, could produce these symptoms and remains difficult to

\footnotetext{
${ }^{50}$ Humphreys, Malaria, 28. See also Dorothy Crawford, Deadly Companions, 36.

${ }^{51}$ Crawford, Deadly Companions, 36.
} 
differentiate from malaria. ${ }^{52}$ Similarly, cinchonism, an overdose of the Peruvian or Jesuit bark's active ingredient quinine, could also produce tinnitus and minor hallucinations ${ }^{53}$ Caroline Kirkland's description of quinine's effects_-"a prismatic halo—an edging of rainbow"resembles the "glare of light" Flint sees around peoples' heads. ${ }^{54}$ It is likely that Flint ingested the bitter bark as part of the "painful process" of healing; quinine was prescribed for all fevers, even though it only works against malaria. While it is probable that Flint suffered at least one malarial infection during the ten years that Recollections records, it is impossible and unnecessary to diagnose his case.

Instead, his indictment of the environment provides a better frame - seasoning - to analyze his illness. Even before Flint describes his symptoms, he identifies his disease as the seasoning, explaining, "Emigrants generally suffer some kind of sickness, which is called 'seasoning,' implying that it is the summit of the gradual process of acclimation" (131). He defines seasoning as the final stage in the utterly normal process of environmental acclimation, noting that the locals are utterly unimpressed and unperturbed by it: "when a person has no more than simple fever and ague, he is hardly allowed to claim the immunities of sickness" (266). (In fact, long-standing settlers probably did contract less severe malarial infections through acquired resistance. ${ }^{55}$ ) The language of "the summit" suggested that the "gradual process" of seasoning would eventually net a finished product — the state of being "seasoned." Undoubtedly, the paradigm of seasoning made the harrowing experience of a disease like malaria livable by

\footnotetext{
$\mathbf{5 2}$ See note 2 and, especially, John Wain et al., "Typhoid Fever."

53 Sonia Shah, The Fever, 97.

${ }^{54}$ Kirkland, Forest Life, 14.

${ }^{55}$ See Humphreys, Malaria, chap. 1 and Alyssa Barry and Diana Hansen, "Naturally Acquired Immunity to Malaria."
} 
ensuring that the disease would end. Yet, as the language of "gradual progress" and inevitable ends implied, it also functioned to warrant the imperial project.

Flint's seasoning, however, is neither routine nor finished. Despite claiming his disease was one that all immigrants "generally suffer," he insists that his experience was "extraordinary," marshalling the authority of his physicians who "agreed with all who saw me, that my case was so" (131). He even notes that he must record his symptoms because "very few live to record the issue of a sickness like mine" (31). Along with the adjective "extraordinary," this assertion contradicts the relative ordinariness implied by the seasoning paradigm and teleology.

Moreover, he and his family never actually reach seasoning's "summit"; they remain fevered and chilled the remainder of their time in the West. In the fall of 1818, all but one of his family were "siezed...with the bilious fever" (217). Flint and his wife "both had fever and ague long after the regular fever had left us. I had seventy fits of the ague, laboring under this dreadful complaint the greater part of the year" (217). At another point, Flint escapes the fever that claims the rest of his family, but he nonetheless suffers from the "excessively sultry" climate, "the groans of my family, calls for medicine and drink, suffocation behind my [mosquito] curtain," and "the agony of musquitoe stings as soon as I was exposed to the air" (271). Even after the family decides to quit their Western life, they fall victim to the ague on the banks of the Mississippi on their return journey (284-85). As Flint concludes, "I saw that I could not long survive in that region... and commence[d] a journey...for my native land" (374). Though we cannot know if Flint truly suffered from malaria, we do know that his illness belied seasoning's guarantee. 
Flint's "extraordinary" seasoning insists that acclimation to the environment was not an easy, linear process with a guaranteed end — seasoned — but a reciprocal, ongoing relationshipseasoning. After all, even acclimated insiders were never truly immune. Though they may have acquired some resistance, they could never be immune to malaria like they were to viral diseases like smallpox and yellow fever. Flint is never fully seasoned or acclimated to the land; instead, the fevers and chills expel him from it, undermining that myth of inexorable progress. If being seasoned was no longer guaranteed, then neither was frontier civilization.

Flint fails to create a home on the frontier, but the frontier makes a home in him. When he and his family finally return to New England, he has changed so much that his friends must "suppress surpize and exclamation" at how "time and disease" had ravaged his "countenance" (381). Flint does not conquer the West like the heroic trailblazer he lionizes or even like the efficient farmer he considers inevitable. Instead, the West conquers him, penetrating, transforming, and ejecting him from the land. Though the paradigm of seasoning recognized that the human body and environment necessarily intra-acted, it also promised that this intra-action would net a hardier, more robust human by the end. Flint's altered appearance, however, exposes the limits of this promise, demonstrating that seasoning was a messy, uncertain, reciprocal, and ongoing process that never necessarily led to a finished product, whether that product be “seasoned" or "civilization." After all, civilization could only be ensured if white people remained there to produce it.

Both Trist and Flint encounter lands that encounter them, but Flint's settlement was founded in a faith in civilization's progress that was inaccessible to Trist because of time and gender. Flint eventually settled in the West, in Cincinnati, but by the late 1820 s Cincinnati was no longer a backwoods outpost but a thriving city of over 16,000 people. The Ohio was outfitted 
with all the accoutrement of civilization that Trist could have desired: "brick houses, ornamented court-yards, trellis-wrought summer-houses, fruit-gardens, and within, carpets, side-boards, and sofas" (378-79). Recollections, therefore, may close with Flint writing from his new and lasting home, but he wrote from a new seat of civilization rather than from the outskirts of the frontier. In other words, Flint settled in a land where civilization seemed fixed, where his seasoning experience could not undermine his faith in the frontier myth. Yet the malarial illnesses immortalized in Recollections refused to index and naturalize white colonists' acclimation, acculturation, and colonization of the West, insisting that imperialism and expansion were not natural nor inexorable. Watts argues that it is Flint's acculturation to the West that makes him a truly regional writer, but it is actually his unsuccessful acclimation—his malarial seasoningthat makes his writing regional.

\section{Kirkland's Fitful Seasoning: When the Environment Writes the Region}

Nearly half a century after Trist found herself penetrated and fevered by mosquitoes on the journey to her new home, Caroline Kirkland immigrated to Michigan, where she too realized that creating a frontier home could provide solid literary fodder. She published her first and most famous work, A New Home-Who'll Follow? Or Glimpses of Western Life in 1839, quickly followed by Forest Life (1842) and Western Clearings (1845), a collection of previously published sketches and tales. Henry Nash Smith calls Kirkland a "traveler," and Edward Watts a "tourist," but Annette Kolodny reminds us that when Kirkland immigrated to the frontier, she "anticipated a permanent removal." ${ }^{56}$ In fact, both of her first two works and many of the stories

\footnotetext{
${ }^{56}$ Smith, Virgin Land, 225; Watts, An American Colony, 170; Kolodny, The Land Before Her, 131.
} 
collected in Western Clearings were all published while Kirkland was still settling Michigan.

Kirkland did not find making a frontier home easy: mudholes, snakes, prying neighbors, gossip, and the ague conspired to make a genteel, Eastern home impossible. As such, critics have emphasized how Kirkland's gender and class influenced her Western oeuvre. Sandra A. Zagarell argues that a female "ethic of interdependence" animates Kirkland's Western writing, but others contend that her Eastern elitism undercuts such a universal protofeminism. ${ }^{57}$ At the very least, her writing is decidedly unromantic, labeled local color, regionalism, and even realism over the years. Despite centuries of analyzing her gender, region, and form, no critic has fully addressed what links these themes and stylistic choices-illness and healing. In particular, malaria, or the seasoning ague, knits Michiganders to their local environment and women to each other in improvised networks of care.

Like Trist and Flint, Kirkland undergoes a reciprocal, ongoing, and unfinished seasoning. Although she only uses the word once in the texts discussed here, the seasoning paradigm resonates throughout her canon, indicating acclimation to Michigan's environment as well as acculturation to frontier mores. ${ }^{58}$ While seasoning constructed illness as a rite of passage that sanctioned white Western immigration and colonization, as in Flint's Recollections, Kirkland exposes the gap between the cultural paradigm and lived experiences of malaria. No one was every fully seasoned, and the seasoning could compound rather than relieve pain. The disease, therefore, engenders a "fitful" regionalism—a depiction of Michigan life and perspectives as

\footnotetext{
${ }^{57}$ Zagarell, "Introduction," xxxix. On her elitism, see, especially, Leverenz, Manhood and the American Renaissance, chap. 5. Still others suggest that Kirkland both praises and condemns Michigan's lack of Eastern hierarchies. Kolodny, The Land Before Her, 131-58, Brigitte Georgi Findlay, The Frontiers of Women's Writing, 27-37, and Halverson, Playing House in the American West, 13-26.

${ }^{58}$ Kirkland, Forest Life, 2.88, hereafter cited parenthetically.
} 
shifting and mercurial as the region's characteristic disease. The ague, a physiologically and culturally regional phenomenon, shapes how Kirkland writes about her region, how she positions herself both within and without the community, especially the community of women. While many take Kirkland's inconsistent approach to the West as evidence of her elitism (and moral failure), and others like Zagarell seem to romanticize Kirkland, her perspective is malarial, vacillating between and among these extremes. Malaria shapes Kirkland's writing of the West, disrupting Eastern hierarchies of gender, class, and medical authority, even when Kirkland herself aimed to support them.

\section{The Seasoning Ague: When Lived Experience and Culture Misalign}

Although she only uses the word "seasoning" once, Kirkland routinely describes the ague across her canon, conflating the disease with the local environment. She draws attention to "the prodigious amount of wet prairie or "marsh," which produces "agues of the first quality" ( $F L$ 1.166), deforestation ( FL 1.45-53), and the danger of walks at dusk, an "imprudent indulgence" to which they "trace the agues which soon prostrated most of us." ${ }^{59}$ Moreover, she bemoans, "mosquito-time" (FL 1.185), which left "white walls spotted with human blood, like the den of some horrible ogre" (FL 1.183). Swamps provided ideal breeding grounds for the malarial vector, while the anopheline mosquito preferred and lay eggs in the sunlit areas off felled trees, to bite at dusk, and rest on surfaces like walls to digest after feeding. ${ }^{60}$ While we cannot know if every reference to the ague was actually malaria, her descriptions suggest she was living in a malarial environment.

\footnotetext{
${ }^{59}$ Kirkland, A New Home, 50, hereafter cited parenthetically.

${ }^{60}$ On these environmental conditions, see Packard, The Making of a Tropical Disease, 12-13, 61; McNeill, Mosquito Empires, 55; Valenčius, The Health of the Country, 30-31.
} 
The paradigm of seasoning represented a cultural response to these particular, local, and biological conditions, but Kirkland's canon reveals the wide chasm between culture and lived experience, between seasoning and the ague. In particular, she juxtaposes how locals perceived the ague with how newcomers experienced it. To the established Michiganders, Kirkland's “indigenous" locals, the ague was common and inevitable, painful but never deadly, but to recent transplants the disease was physically and psychologically harrowing. ${ }^{61}$ The seasoning paradigm, which seemed to minimize the newcomers' pain, only compounded their trauma. Locals like Silas Ashburn, a fictional character in Western Clearings, figure the ague as so routine as to be unavoidable: “every body knows if you've got to have the ague, why you've got to, and all the high land and dry land, and Queen Ann [quinine] in the world wouldn't make no odds." 62 In Forest Life, the narrator similarly asserts, "In our neighbourhood...every body has, or has had, or expects to have the ague...indeed, ague begins to be looked upon as a condition of humanity" (1.88). To the locals, malarial illness was an inescapable fact of Michigan life and humanity itself.

As such, the established Michiganders never fret over it. If the ague was common and unavoidable, it must not have been too dangerous. Ashburn contends, "“If the agur could kill...we'd all ha' been dead long ago"” (WC 1.70). In fact, Michigan's vivax malaria was not especially deadly, and longtime Westerners like Ashburn would have acquired some resistance to malaria and thus would have had less painful and severe fits. The newcomers, however, had

\footnotetext{
${ }^{61}$ Zagarell uses this term throughout her introduction to $A N H$. According to Halverson, Kirkland "posits the true struggle for territory as that between working"-what Zagarell calls "indigenous" - "and middle-class whites," rather than actual native or indigenous people (21). As such, indigenous people are largely but not entirely missing in Kirkland's oeuvre. See Floyd, Writing the Pioneer Woman, 110-11; Halverson, Playing House in the West, 20-22; and Dawn E. Keetley, "Unsettling the Frontier."

62 Kirkland, Western Clearings, 1.66, hereafter cited parenthetically.
} 
no such resistance. ${ }^{63}$ In both $A$ New Home (61) and Forest Life (1.95), unimpressed neighbors react without "sympathy" to the newcomers' agues: “"[I]t is nothing but the ague!' is very commonly all the consolation one gets" (FL 1.95). Ultimately, "All old people, who have weathered the storm tell us that these troubles are concomitants only of new settlements, and that we shall see them diminish year by year" (FL 1.81). To the locals who had acquired resistance, who had suffered the ague and survived, the disease was not only routine but inevitably surmountable. The ague's disappearance was tied to the inevitability of Western immigration and colonization as "new settlements" implied. And, if the ague was already diminishing, then it could not be that terrible. Thus, the seasoning paradigm rendered the ague routine and survivable, not only responding to local immunology—acquired resistance—but also functioning culturally to mitigate the disease's horror. The ague was made livable, because seasoning made it part of the local culture and identity.

Yet Kirkland's harrowing first-person descriptions of the ague contradict this seasoning logic. In A New Home, Mary Clavers, Kirkland's semi-autobiographical narrator, recounts her family's first bout of ague, describing "a severe head-ache, and racking pains in every bone," in addition to a fever so "intense" that it "almost, although not quite, amounted to delirium" (60). With her characteristically acerbic humor, she pronounces, "I used to think I should certainly die in my ten or twelve hours' fever-and Mr. Clavers confidently asserted, several times, that the upper half of his head was taking leave of the lower" (61). Caroline Gebhard argues that Kirkland uses humor to translate "the very real traumas she experienced" into acceptable writing. ${ }^{64}$ In this scene, Kirkland's humor also negotiates the farcical gap between the lived

\footnotetext{
${ }^{63}$ See note 55.

${ }^{64}$ Gebhard, "Comic Displacement," 163.
} 
experience of illness and the seasoning paradigm. Where she thinks she will promptly die, her neighbors "showed but little sympathy" (ANH 60). In Forest Life, the narrator even asserts, "One is sometimes (in the fever) almost desperate enough to wish to die just once to make people a little less unfeeling" (1.95). Though Kirkland clearly emphasizes how traumatic the ague's material symptoms are, she also highlights how the seasoning paradigm compounds that trauma. As she writes, "The same amount of pain and suffering under any other name would excite abundant commiseration" (FL 1.95, emphasis mine). For Kirkland, the paradigm of seasoning not only farcically underestimated the material experience of the ague but also warranted her neighbors' "unfeeling" attitudes.

Despite the teleological pull of acclimation and acculturation, Kirkland remains suspicious of seasoning in her second book. Whereas she and her family function as the unacclimated outsiders in A New Home, she enlists the fictitious Sibthorpe family to fulfill a similar role in Forest Life. ${ }^{65}$ In a first-person epistle, Mr. Sibthorpe describes how the ague has consumed his very being: "I have no other thought. I can no longer say-'My mind to me a kingdom is.' I am deposed, and this vile blue-visaged fiend has usurped the throne" (2.170). The ague "call[s] up dreams... which terrify": his wife "pale and ghastly," his daughter "stiff—cold— dead," and "graves yawning, and vile shapes impatiently waiting for my last breath" (2.170). Although his neighbors would only designate his illness "a slight ague," Mr. Sibthorpe's great suffering undermines the seasoning paradigm just as Mary Clavers's does (2.179). His experience is rendered even more harrowing and horrifying than Mrs. Clavers's, who at least mitigates her suffering through humor. This missing humor suggests that though Kirkland may

\footnotetext{
${ }^{65}$ Although Kirkland obviously uses a fictional persona to narrate $A N H$, it is less clear who is narrating $F L$. Given the fact that Kirkland's identity had been revealed by $F L$ 's publication (noted in the text's preface), I describe Kirkland as the narrator of $F L$.
} 
no longer be a naïve transplant, she is not yet an "unfeeling" or seasoned insider. She still sympathizes with the newcomer's experience and thus still finds fault in the seasoning paradigm.

In her third collection, Kirkland shifts her attention from immunologically naïve newcomers like Mrs. Clavers and the Sibthorpes to partially resistant natives like the Ashburn family. In particular, the short story "The Bee-Tree" demonstrates the impossibility of full immunity and complete seasoning. ${ }^{66}$ In this story, Silas Ashburn represents an earlier, poorer, and less-educated class of settlers, while his nemesis, Mr. Keene, represents the later, wealthier gentility, of which Kirkland herself was a part. She pits these classes against each other in a honey hunt: Ashburn tracks the bees to their hive and claims the honey in "the established mode" of the West, by marking it with his initials, but Mr. Keene takes the prize because the tree is on his property (1.71). Pitting these archetypal classes of white Westerners against each other, Kirkland and the story seem to crown Keene and his genteel, Eastern ideology the righteous winners of the honey and the West.

In this vein, Kirkland characterizes the Ashburns as the West's losers, using the ague as shorthand for their class' moral flaws: ignorance and indigence. Ashburn ignorantly builds his home in a swamp, where "agues... have nearly made skeletons of himself and his family" (1.66). Yet, he won't even admit his mistake: "his opinion is that it would not have a made a bit of difference if he had settled on the highest land in Michigan" (1.66). Thus, even when "there is perhaps no other case of disease in the neighbourhood," the Ashburns "are frequently prostrated with agues" (1.68). Kirkland uses the ague to signal the family's class and portend its demise; after all, the story ends with the family removing even further West. ${ }^{67}$ Yet she also, perhaps

66 "The Bee-Tree" was originally published in The Gift in 1840.

${ }^{67}$ As Timothy Sweet notes, genteel agrarians may not have actively murdered or removed poor whites as they did Native Americans, but they did imagine their demise - their habitual self- 
inadvertently, demonstrates the impossibility of a complete malarial seasoning. Despite being "among the earliest settlers" in the area, and, therefore, among those who should be fully seasoned, the Ashburns continually suffer by the ague (1.61). As complete immunity to malaria is medically impossible, a completely successful seasoning would have also been impossible. While Kirkland certainly employs the ague to stigmatize the Ashburns and their entire class, she also inadvertently highlights how inadequate the seasoning frame was for explaining lived experience of malaria.

Kirkland criticizes the gap between the seasoning paradigm and lived experience. On the one hand, she demonstrates how previous, repeated experiences of disease produce a particular culture. Longstanding locals did develop partial immunity and thus would have experienced less painful agues, generating the seasoning culture that considered the ague common, routine, and unimpressive. This culture, in turn, affected lived experience; the local lack of sympathy, warranted by seasoning, led to a less attentive and less feeling culture that exacerbated newcomers' illnesses. On the other hand, Kirkland demonstrates how the seasoning paradigm failed to account for a spectrum of material experiences, including those of the newcomers and the locals like the Ashburns. In short, she emphasizes how lived experiences of the ague undermined the static and inflexible paradigm of seasoning.

Of course, Kirkland did not understand immunity or acquired resistance. Nonetheless, she chronicles their effects in her descriptions of newcomers' experiences and the Ashburn family's unyielding agues. Malaria itself, its symptoms—cycling fevers, relapses, and impossible

removals ever further West - to be inevitable. American Georgics, 116-17. To this end, Kirkland may use the ague and its associations with swamplands to link poor whites to Native Americans. Susan Sleeper-Smith argues that indigenous Americans resisted removal by inhabiting Michigan's swamplands. Indian Women and French Men, 141-42. 
immunity—undermined the paradigm of seasoning. As malaria infected and transformed the human body, provoking fevers, chills, and eventually partial resistance, it also resisted and reshaped the seasoning paradigm and Kirkland's writing of it.

\section{A Fitful Regionalism: When the Region in Regionalism is Malarial}

Although Kirkland's Western works share affinities with many genres, regionalism seems to best capture her attention to the local environment and culture, as well as gender and class. Yet many critics frame Kirkland's regionalism as a failure. ${ }^{68}$ Fetterley and Pryse consider her to be a limited precursor to a more perfect regionalism. She "engages in complex internal negotiations around her own biases and prejudices," but "never relinquishes control over her narrative or its meaning," attempting to "reconstruct" the West in her own Eastern image. ${ }^{69}$ Similarly, Watts figures Kirkland as an imperial outsider, whose Eastern elitism discredits her from a truly Western identity and canon. ${ }^{70}$ Her writing is too prejudiced or too imperialist to actually be regional.

If we adopt Snyder's bioregional framework, however, Kirkland does not fail at regionalism nor at being Western; rather, her regionalism is deeply embedded in her region and is thus malarial. Whether Kirkland considers herself a Westerner or not, her record of malarial seasonings embed her writing in her region. Conjoining Snyder's bioregionalism with literary regionalism's emphasis on Eastern hierarchy, Kirkland's regionalism can be considered fitful.

\footnotetext{
68 Josephine Donovan is an exception, but she does not extensively analyze Kirkland, who was outside of her New England focus. See New England Local Color Literature, introduction.

${ }^{69}$ Fetterley and Pryse, Writing out of Place, 77.

${ }^{70}$ Watts, An American Colony, chap. 8
} 
She is not universally imperialist, as Watts diagnoses. Instead, her writing of the West is as mercurial as her region and its relapsing fevers and agues.

Kirkland struggles to represent herself and her personal relationship to Michigan and frontier life. She is both a seasoned insider and an unacclimated outsider, illustrated by the generic shifts between A New Home and Forest Life. While Kirkland's first book opts for "desultory sketches" from a semi-autobiographical narrator in a single village (ANH 3), her second collection travels throughout Michigan and employs fictional, plotted narratives through multiple perspectives. ${ }^{71}$ This shift, Brigitte Georgi-Findlay argues, signals how "the Eastern outsider had become the Western insider."72 Yet, rather than providing a more "sympathetic" depiction of Michiganders, Kolodny asserts that Kirkland's ambulatory perspective is detached, disengaging her from her "real-world neighbors."73 Smith argues that these generic discrepancies demonstrate how Kirkland "struggled to find a satisfactory form" to represent an agricultural rather than an heroic West, but, like her physical body, her shifting genres and perspectives are tied to her malarial environment. ${ }^{74}$

For example, Sibthorpe's letter reveals that Kirkland is neither fully outside nor fully inside of the culture she writes about. Although she should be seasoned by her second book, her writing is not so teleological, because the ague is not teleological. Kirkland does not overcome the ague but instead displaces its trauma onto Mr. Sibthorpe and his graphic letter. On the one hand, she highlights an outsider's experience of the ague, centering her compassion on the unseasoned Eastern transplant; she differentiates herself from the locals and their seasoning

\footnotetext{
${ }^{71}$ See Kolodny, The Land Before Her, 149 and Smith, Virgin Land, 225-27 on this difference.

72 Georgi-Findlay, The Frontiers of Women's Writing, 20

${ }^{73}$ Knott, Imagining the Forest, 47; Kolodny, The Land Before Her, 149.

${ }^{74}$ Smith, Virgin Land, 226.
} 
paradigm by depicting the disease's horror and by reifying her gentility through sympathy. On the other hand, she displaces this insight onto a fictional male persona through "the epistolary mode of the previous century," devices that distance her from the experience. ${ }^{75}$ There is no slippage between Mr. Sibthorpe and Kirkland as there is between Mrs. Clavers and Kirkland. She awkwardly severs herself from her classed ally, the genteel Sibthorpe, writing, "we could not but think his feelings very natural, although to us old settlers they appeared somewhat exaggerated" ( $F L$ 2.94). In this line, Kirkland wants it both ways: she wants to validate Mr. Sibthorpe's experience as "natural" and thus maintain her own status as an uncontaminated, genteel Easterner, but she also aligns herself with the "old settlers," acknowledging that she is more of a seasoned insider than both Sibthorpe and her reader.

Kirkland is neither a born-again Wolverine nor an unadulterated Eastern imperialist. Nor is she somehow neatly between these two extremes. Rather, she and her writing are sometimes outside of the culture they observe and sometimes within, sometimes offering unseasoned condemnation and at other times singing seasoned praise. This is not because she is a secret imperialist or an Eastern proselytizer, but because she is deeply embedded in her malarial region. If the ague itself —its material symptoms — both warranted and undermined the seasoning paradigm, then it also inflects Kirkland's material and literary West. Her regionalism is malarial; the ague ties her to a distinct bioregion, and its cycling fevers and relapses shape her inconsistent, fitful integration into her frontier community.

\section{Fitful Regionalism's Frontier Women}

${ }^{75}$ Ibid. 
Kirkland routinely exposes fantasies of the West, rejecting "the glowing pencil of fancy" that romantically colored the frontier $(A N H$ 6). In particular, she emphasizes how frontier life unsettled gendered roles and expectations. Mrs. Clavers tracks a snake, severs it in half, and displays the snake's tail end like a trophy, "exalt[ing] the coda to a high station on the logs at the corner of the house - for fear none of the scornful sex would credit our prowess" (ANH 59), while Mr. Clavers ineptly assumes the cooking, cleaning, and childrearing when his wife comes down with the ague, nearly falling into the fire.

Yet nowhere is Kirkland's inconsistent acclimation and acculturation to Michigan more evident than in her fitful relation to other Western women. Women were vital to settling the West, to creating a life, home, and community. As Mrs. Clavers claims, "In this newly-formed world... men look upon each one, newly arrived, merely as an additional business automaton," while women have "a feeling of hostess-ship toward the new comer" (ANH 64). Frontier women forged their new community by providing psychological and material support during illness. Kirkland's malarial regionalism extends to all aspects of her writing, but it is especially notable in her representation of this female network of care. As she awkwardly positions herself within and without the community in Sibthorpe's letter, her classed sensibility renders a similarly awkward integration into this community of women healers. Kirkland frequently aims to denigrate poor, Western women's medical knowledge, but her writing nonetheless renders their experience and knowledge visible and vital. Moreover, her consistent policing of appropriate medical authority, in addition to her advocacy for quinine, ironically styles herself as a "petticoated professor of the healing art" (FL 1.84). As the ague shapes her regionalism, it similarly re-envisions women doctors and healers not as backwoods last-resorts, nor as secondary supplements to male doctors, but as vital products of and participants in Michigan life. 
On the frontier, where doctors were scarce, costly, and distant, women fostered, maintained, and restored health. In A New Home, Mrs. Rivers and Mrs. Clavers assist the Titmouse family, all of whom were suffering from the ague. The women draw water, make tea, cook, and dispense quinine pills (114-18). Elsewhere, Mrs. Clavers rushes to help a boy bitten by a snake (17) and a former servant girl dying of a botched abortion (110-11). Mrs. Clavers herself is nursed by Mrs. Jennings and another unnamed woman during her first ague (60-62). Similarly, Mr. Keene's niece, Clarissa, helps the Ashburns recover from their stubborn agues (WC 1.7779), while Mrs. Lettson sets Mr. Sibthorpe's daughter's wrist with a poultice of local flora ( $F L$ 2.201-5). From cleaning and cooking to providing medicine and herbs, women knitted together a community by mending broken bodies and minds.

Yet Kirkland does not romanticize this community nor her relationship to it. Classism pervades her female network of care. In particular, she envisions care as unidirectional, flowing from genteel women like Mrs. Clavers, Mrs. Rivers and Clarissa, Mr. Keene's niece, to poor Westerners like the Titmouses and the Ashburns. The poor, ill locals allow Kirkland and other middle-class white women to enact what Rosemarie Garland-Thomson calls "benevolent maternalism": the process by which white bourgeois women shored up their own classed and able-bodied social position and momentarily stepped beyond gendered constraints by furnishing medical care to the diseased or disabled poor. That is, women like Mrs. Clavers could use care for poor and ill others to "launch themselves into a more prestigious, more influential public role that captured some elements of liberal selfhood" that their gender typically rendered inaccessible. ${ }^{76}$ Mrs. Clavers and her ilk, therefore, use their cultural position as caregivers to

\footnotetext{
${ }^{76}$ Garland-Thomson, Extraordinary Bodies, 82.
} 
reinforce their class status and to expand their gendered limits. Like "manifest domesticity," benevolent maternalism allowed white women to enact their own brand of imperialism.

To this end, Kirkland positions her genteel self as the bearer of medical enlightenment to a superstitious, backwoods populace. Significantly, she advocates for quinine, the "only true elixir against the ague" (FL 1.79). Locals, however, deploy "a violent prejudice" against it, preferring to let their agues "“run' ...the whole year round" than to imbibe the bitter nostrum ( $F L$ 1.78). Though she admits that quinine can be dangerous ( $A N H$ 62) and costly (FL 1.78), she nonetheless envisions local resistance as unadulterated, characteristically-Western superstition. In a passage in Forest Life, she devotes herself to debunking both romantic myths of the West and Western superstition as well. As her carriage pulls away from her village and onto her journey throughout Michigan, she pulls out a notebook to begin writing: "about the edges...played a prismatic halo—an edging of rainbow; such (only more brilliant) as will sometimes be the effect of that bewitched condition of the eyes which is the consequence of over-dosing with quinine" (1.14-15). She finds this display too "dazzling" and consequently covers her eyes with a "veil" before again "look[ing] abroad in the sunshine" (1.15). At the beginning of Forest Life, this passage undoubtedly speaks to the "veil" of Eastern romanticism, but, in the context of her repeated praise of quinine, it also challenges Western superstition. In this way, Kirkland figures herself as a benevolent mother, dispensing medical knowledge to the "backwoods" rubes, validating her class status and pushing the limits of her gender. She also, probably inadvertently, positions herself as a medical authority.

Of course, Western circumstances undermine benevolent maternalism, and illness frequently highlights the limits of genteel women's aid. Though Mrs. Clavers and Mrs. Rivers provide the poor Titmouse family with food, drink, and quinine, they cannot milk the cow when 
asked. When she laments their "defective education," Kirkland not only mocks what passes for "education" in the West but, more importantly, admits that they cannot fulfill their benevolent roles $(A N H 118)$. They fail to "render[] so simple yet so necessary a service to the sick poor" (ANH 118). Similarly, when Mrs. Clavers asks Mrs. Newland how long her daughter had been ill, "expressing my surprise that I had heard nothing of it," Mrs. Newland cries, “'What, you've heard their lies too, have ye!"”(110). While Mrs. Clavers does not know that the young Newland has died of an abortion, she manages both to arrive too late to help and to insult Miss Newland's memory and her mother, albeit unintentionally. She not only fails to provide succor but actually exacerbates the situation. Mrs. Clavers attempts to use care for the poor ill to reinforce her class privilege and expand her gendered limits, but her Western experiences erode her Eastern elitism, or, at least, her writing of it.

Western illness resists benevolent maternalism by reversing its direction; in the West, care does not only flow from the middle-class to the poor but vice versa. When Mrs. Clavers develops her first ague, it is Mrs. Jennings who diagnoses and cares for her. Mrs. Jennings, however, washes her clothes "al fresco by the side of the creek" (49), drinks tea directly from the teapot's spout, "saying 'it tasted better so,"” and plunges her personal cutlery into every communal dish (51). In short, Mrs. Jennings is a female Silas Ashburn, the quintessential local with no notion of or patience for classed and gendered notions of decorum. Yet, as a local, Mrs. Jennings recognizes the ague's symptoms even when Mrs. Clavers herself mistakes them for simple shock: “'Why you've got th' agur! Woman alive! Why I know the fever-agur as well as I know beans! It a'n't nothin' else!'” (60). Mrs. Jennings, the poor, uneducated, and crass Westerner, diagnoses Mrs. Clavers and nurses her. She only leaves when she is called away to provide for her own daughter. While Mrs. Clavers downplays Mrs. Jennings' role, calling her 
"Dame" and exoticizing and demeaning her dialect, Mrs. Clavers's sarcastic assertion that "Mrs. Jennings consoled me" by reasserting her diagnosis "every ten minutes" nonetheless demonstrates that the Western woman remained by the Eastern woman's side (60). Whereas providing care reifies class privilege, receiving care threatens it. That is, illness undermines benevolent maternalism's classism and imperialism. Mrs. Clavers's caustic humor only amplifies this unsettling point.

Having already dramatically pressured and changed the individual body, the local paradigm of seasoning, and Kirkland's regionalism, the ague here fractures benevolent maternalism. Its rhythmic fevers and relapses reverse the linear flow of care that benevolent maternalism requires It prevents Kirkland and other genteel white women from cementing their class status by preventing them from fully and uni-directionally furnishing aid. As the ague belies the seasoning's teleology, it similarly belies benevolent maternalism's inevitability. Middle-class women can and do fall ill themselves, while poor women assist, diagnose, and even heal them. In other words, those relapsing fevers and partial immunities upend the classed distinctions of gender that women like Mrs. Clavers strived to import to the West. When Kirkland and Mrs. Clavers advocate for quinine, they attempt to capture some of the authority that sexism withheld from them. Their benevolent maternalism aimed to bolster their class and vitality at the expense of their gender. It also aimed to enact a particularly domestic version of the imperialism men were deploying at a grander scale. The ague, however, proved not only that this logic was unsuitable and unsustainable in Michigan but also that medical authority was never uniquely male nor genteel.

The ague, therefore, affirms medical insight outside of an Eastern elitist mainstreamand, notably, outside of Kirkland's intentions. Unsettled by Mrs. Jennings's care, Mrs. Clavers 
attempts to their inverted relationship; she accords her restoration to a male physician with a "first-rate education, who had walked European hospitals, and who had mother-wit in abundance" rather than to Mrs. Jennings ( $A N H$ 60). Although this doctor only echoes Mrs. Jennings's diagnosis and attitude, asserting "an ague was as easily managed as a common cold" (62), it is the doctor who receives credit for mitigating "the severe attack of rheumatic fever...into a daily ague" (61). That is, when Mrs. Jennings upsets the classed hierarchy of benevolent maternalism, Mrs. Clavers corrects this reversal by deferring to conventional gendered hierarchies and professional medical authority. After all, what is the male doctor's salvific cure?- - finding a young, unnamed woman to nurse the Clavers family. As Kirkland attempted to use medical care and knowledge to cement a classed authority that circumvented her gender, in this scene she attempts to stabilize her class by forfeiting her gender and Western women's medical knowledge. As Mrs. Jennings and the second, unnamed nurse reveal, however, the ague renders such a straightforward correction impossible.

Even when Kirkland aims to denigrate medical women, the ague highlights their importance. On the one hand, Kirkland conflates the "petticoated professor of the healing art-a female physician" with backwoods superstition. She argues that Michiganders would rather a female doctor "prescribe the most deadly drugs" or "a dose of centipedes procured from beneath a fallen tree" than "employ an educated physician" (FL 1.84). If Kirkland's venom was not obvious, she concludes, "Happily this order of practitioners is not numerous, and...may be expected rather to diminish than to increase" (FL 1.84). Just as Kirkland posits the eventual disappearance of the lower class of settlers and of malaria itself, she banishes female physicians to an ever-regressing past. 
On the other hand, her fitful regionalism—-her malarial writing—belies this teleology just as it belied seasoning's teleology. Her texts are littered with female healers: Mrs. Jennings, the unnamed nurse, Mrs. Rivers, Mrs. Lettson, and Clarissa, among countless others. Most importantly, Kirkland's policing of medical authority, not to mention her advocacy of quinine, styles herself as an appropriate conduit of medical knowledge. Undeniably, Kirkland resists the figure of the "petticoated" doctor, especially when it did not conform to her vision of classed, benevolent maternalism. Yet the ague renders such women nurses, caretakers, healers, and doctors vital and visible in the West and in her Western writing. Thus, the ague disturbs Kirkland's paradigms for perceiving and ordering the West—seasoning, benevolent maternalism, manifest destiny and domesticity, and regionalism itself—by highlighting those alternative perspectives and agencies that contributed to the region's material and social culture, including poor women, ill people, and perhaps even nonhumans like malaria.

To Kirkland, being seasoned is being Western, and her representations and attitudes toward both are as inconsistent as the ague itself. Her writing is never fully Eastern, never fully Western; never only feminist, nor chauvinist; never completely elitist and imperialist, nor democratic. Ultimately, she produces a fitful regionalism, in which her perspectives and writings on the West oscillate like malaria itself, sometimes resisting a uniform, linear, and teleological seasoning and stereotypical representation, and sometimes bolstering Western expansion and Eastern imperialism. She critiques the myth of inexorable progress, mourning Michigan's deforestation, yet she also asserts, "the felling of the tree has something of the sublime in it," fetishizing the very same process ( $F L 51)$. Her fitful regionalism, therefore, revealed the seasoning's central paradox: malarial illnesses belied the closure that the seasoning guaranteed, just as such seasoning illnesses undermined the myth of inexorable Western colonization. 


\section{Conclusion}

Seasoning illnesses like malaria did not stop Western expansion and colonization. In part, white Westerners' faith in civilization had worked; the disease faded quickly in the Old Northwest where Flint and Kirkland settled, "where winters were hard, houses tight, cattle penned, and frontier conditions of shortest duration." ${ }^{" 77}$ Yet such illnesses undermined the very paradigm used to frame, explain, and contain them. In an extended meditation on the ague in Forest Life, Kirkland describes how the disease resists straightforward intelligibility:

Every body trusts this particular fit is to be positively the last visit of the foul fiend. If we can only get through to-day, if the shake does not dislocate the neck bone, or the fever set the house on fire, we feel sure that we have had it so long, or we have had it so hard, or we have been so little subject to it, that it is not likely to return. This is certainly the most violent shake, or the delirious fever; there is more perspiration or less head-ache, or in some respect this attack differs from all that preceded it, so that we feel confident there has been a change in the system, and any change must be for the better. And many times these prognostics at a venture prove true, as if by miracle. An ague will quite one as suddenly and as inexplicably as it came on, without the use of remedies, whether of diet or medicine, and one may feel nothing of it for a year, perhaps for a life. The consequences wear away, and we forget them. (81)

No one knows for how long the chills will recur; no one knows if this fever will be the last; no one knows what might set off a relapse; no one knows how or why it suddenly disappears. The seasoning promised that disease was surmountable and civilization inevitable, but the ague-

${ }^{77}$ Cowdrey, This Land, This South, 85. 
stricken incessantly searched for signs — the strength of a shake or the amount of sweat $—$ of a closure that never seemed to materialize. The paradigm of seasoning attempted to minimize malarial illness's intransigent materiality, but the disease resisted closure, intelligibility, and, thus, the rhetoric of Western imperialism, if not Western imperialism itself.

While Trist, Flint, and Kirkland mobilize the seasoning paradigm to ensure their physical and cultural persistence, the illnesses themselves revealed a reciprocal, ongoing, unfinished, and uncertain process. The paradigm aimed to use the physical experience of illness to underwrite colonization, but no experience of illness is linear or universal, just as no experience of region is linear or universal. Instead, their malarial illnesses inscribed a regionalism that resisted imperialism's scripts. 


\section{Conclusion: John Tanner's Seasonal Paradigm}

In 1790, John Tanner, a white, nine-year-old boy, was taken captive by a group of Native American men from his home at the mouth of the Miami River, below Cincinnati. Sold to an Odawa-Ojibwe woman, Net-no-kwa, Tanner would eventually become fully adopted and acculturated to Anishinaabe life. ${ }^{1}$ He lived and hunted in the Old Northwest, ranging from Minnesota through Manitoba. ${ }^{2}$ Five years after the opening of the Erie Canal, which enabled the mass immigration of genteel Anglo-Easterners like Caroline Kirkland to the Old Northwest, Tanner published his life story, A Narrative of the Captivity and Adventures of John Tanner (1830). While critics have debated the role of Tanner's editor, Edwin James, John T. Fierst and Theodore Catton have argued that James preserved Tanner's primary framework for remembering and understanding his life: seasons. ${ }^{3}$ As Fierst contends, Tanner organizes his

${ }^{1}$ There is some debate on which nation originally captured Tanner. Tanner himself claims the Shawnee; Gordon M. Sayre agrees ("Abridging Between Two Worlds" 486). Theodore Catton, however, argues it was the Shawnee-Ottawa, while John T. Fierst and June Namias suggest the Saginaw-Ojibwe. See Catton, Rainy Lake House, 9; Fierst, "A Succession," and Namias, White Captives, 78. I have chosen to leave the question of who first took Tanner captive unaddressed. What is more important is the culture he was adopted into and perceived the world throughAnishinaabe, the related Algonquian nations of the Ojibwe, Odawa, and Potawatomi.

Additionally, there is some debate on when Tanner was taken captive. Neil Loomis, the 1956 edition's editor, locates Tanner's capture in 1789, using Tanner's count of the seasons to locate him in Anglo-American time. Fierst and Catton, however, locate Tanner's capture in 1790 through a state deposition on his abduction. See Fierst, "A Succession," n. pg., and Catton, Rainy Lake House, 346.

${ }^{2}$ Tanner moved within and without the United States with his Anishinaabe family. Additionally, though he was first captured in Ohio, he briefly lived with his biological family in Kentucky and Missouri. Importantly, Tanner's sense of place did not align with the United States' official geography nor with the Eastern transplant's understanding of region. Mark Rifkin analyzes how indigenous Americans' hunting patterns resisted colonial geography in Manifesting America, chap. 2.

${ }^{3}$ Some critics like Edward Watts argue that James was anti-Indian. See An American Colony, 85-86. Others claim he was sympathetic and anti-removal: John T. Fierst, "A Succession"; Kyhl Lyndgaard, Captivity Literature and the Environment, chap. 3; Catton, Rainy Lake House, 34749. Importantly, James frames Tanner's story with an introduction that criticizes fur trading companies for Native Americans' unfixed, uncivilized life, but he also includes a linguistic 
narrative through "observable changes in natural phenomena," including winter weather, mature rice, and seasonal game. ${ }^{4}$

Tanner's seasons offer an alternative to seasoning - to the way the paradigm framed illness, region, and colonization. Whereas the seasoning guaranteed closure and colonizationeven when the illnesses themselves subverted this paradigm —-Tanner's seasons instead emphasized illness as an ongoing, unromantic intra-action of human and nonhuman. Seasons recognize that humans can never dominate the environment, because domination presumes a separation that illness itself belies.

In the middle of the narrative, Tanner contracts an illness that damages his hearing. Unable to hunt and provide for his family, he determines to kill himself. While he is unsuccessful, he claims, "this sickness I looked upon as the commencement of misfortune, which

apparatus, which Robert Lawrence Gunn has shown actively enabled racism and Western expansion. See Ethnology and Empire, chap. 1. James, however, was erased in the 1994 Penguin Books edition of the Narrative. For analysis, see Fierst, "A Succession," and Sayre, "Abridging Between the Worlds," 484-86. Finally, on Tanner's use of seasons, see Fierst, "A Succession," and Catton, Rainy Lake House, 345.

${ }^{4}$ Fierst, "A Succession," n. pg. To Fierst and Sayre, these narrative factors warrant a reading of the Narrative as an Indian autobiography rather than a white captivity narrative. In his introduction to Native American Autobiography, Arnold Krupat differentiates between Indian autobiographies and autobiographies by Indians; the former "have been produced under the sign of history and (social) science," while the latter "have been produced under the sign of religion, non-scientific cultural commentary, and art" (4). James's editorial framework includes both political and linguistic commentary and thus straddled these two paradigms. At the very least, Tanner's is not the traditional captivity narrative of Mary Rowlandson, more closely resembles Mary Jemison's famous acculturation. Lyndgaard argues that Edwin James, Tanner's editor, purposefully employed the captivity genre rather than "the restrictive mode of government compiler" to resist the federal government's removal policies (76). Fierst, however, argues that the genre "denies the depth of John Tanner's transculturation" ("A Succession" n.pg.). For more on the captivity narrative, see, for example, Kathryn Zabelle Derounian-Stodola and James Arthur Levernier, The Indian Captivity Narrative, and Namias, White Captives. I read Tanner's work as something between or adjacent to captivity narrative and Indian autobiography, which complicates central ideas about these genres. 
was to follow me through life." ${ }^{5}$ Yet his misfortune had an even earlier origin than this particular illness: a beaver epidemic. On the hunt for food and furs at the beginning of winter, he discovers empty lodges where he anticipates multitudes of animals:

At last I found that some kind of distemper was prevailing among these animals, which destroyed them in vast numbers. I found them dead and dying on the ice, and on the land; sometimes I found one that, having cut a tree half down, had died at its roots; sometimes one who had drawn a stick of timber halfway to his lodge, was lying dead by his burthen. Many of them which I opened were red and bloody about the heart...Since that year the beaver have never been so plentiful in the country of Red River and Hudson's Bay. (104) Jody F. Decker suggests that the beavers may have been dying of tularemia, a zoonotic disease that resembles bubonic plague. ${ }^{6}$ Tanner skins the beavers for fur, but he refuses to eat them-a particularly dangerous loss at the beginning of winter. The beaver population was never "so plentiful" again (104).

While this epidemic endangered his livelihood, it also endangered his life. He writes, "In the ensuing fall...I moved...to the Wild Rice. While we engaged in collecting and preparing the grain, many among us were seized with a violent sickness. It commenced with cough and hoarseness, and sometimes bleeding from the mouth or nose. In a short time many died, and none were able to hunt" (110). Decker argues that the group may have contracted tularemia from the decaying beavers, which could have infected the water that fed the rice fields (160). He soon develops "a dreadful pain" in his ears; "abscesses had formed and discharged," damaging his hearing (111). Even if Tanner did not contract tularemia directly from the beavers, the adjective

\footnotetext{
5 Tanner, Narrative, 111, hereafter cited parenthetically.

${ }^{6}$ Decker, "Country Distemper," 160, hereafter cited parenthetically.
} 
"ensuing" and his emphasis on the location of the illness, in the rice paddies, suggests that Tanner envisions his family's epidemic as directly related to the beaver epidemic.

Tanner's illness, including the beaver epidemic, emphasizes seasons, offering an alternative to the seasoning paradigm. He first locates the beaver epidemic in a particular moment of winter, when "the snow was no more than a foot deep" (104). Elk would not sink when they ran, making them harder to hunt; thus, beavers were a vital food source, which the epidemic endangered. In short, it was a starving time. Similarly, he locates his own illness in the “ensuing fall," a traditional time to harvest rice and prepare for the following winter. Most fundamentally, Tanner's emphasis on seasons acts as a calendar, following a particularly Anishinaabe concept of time. Yet, in the context of the intertwined epidemics, Tanner's seasons also reflect and refract the regnant paradigm of seasoning. Whereas the seasoning anticipated and guaranteed closure - that illness, the intra-action of self and environment, would end - seasons emphasize an ongoing, enmeshed, and unromantic intra-action of human and nonhuman. The Romantics believed that the seasons wrote an eternal, inexorable script, but Tanner's seasons, like Grainger's poetic putrefaction, suggest that such a script did not necessarily serve human ends. Closure, domination, and sovereignty were not givens. Only an ongoing, mutable, and multivalent intra-action was inevitable.

If seasons thus undermined the seasoning's implicit promise of environmental domination, they also subverted Western colonization. In particular, Tanner contracts a malarial illness that undermines the relationship between colonization, civilization, and health. When Tanner finally decides to find his birth family, he reverses his white ancestors' journey West, travelling East, away from the frontier and toward white settlement. On his way to the Ohio Valley, he is "seized with a fever and ague," which was "extremely painful and distressing" 
(242). When he finally encountered a biological nephew, they traveled to the Ohio. His "fever continued to return daily, and when the chill commenced, we were compelled to stop for some time, so that our progress was not rapid" (246-47). He remains sick at his relative's home for a month. That is, Tanner develops a malarial seasoning illness not as he penetrates the Western frontier like Trist, Flint, and Kirkland, but rather as he journeys east, toward the "civilization" that these other writers believed would eradicate disease entirely. Moreover, during his return to the West, he decides, "I had found that it made me sick to sleep in a house, and on this journey I constantly refused to do so" (248). Tanner metonymically links his illness to the house and to all that the house symbolizes - the East, whiteness, and civilization. In turn, the environmental exposure that the others believed beget disease accomplishes the inverse; it restores him. Tanner's illness, therefore, refuses to conflate disease with the frontier and health with civilization. In this way, he also refuses to let seasoning claim illness as a tool of colonization.

Ultimately, the seasonal paradigm—not an acclimation, acculturation, and colonization to the land but an ongoing intra-action-made Tanner's complete restoration to white civilization impossible. Though he would live with white relatives in Kentucky for two years, he eventually returned to Anishinaabe life and died in the West. Still ill with fevers and chills, Tanner meets his brother outside of Detroit, but his brother does not recognize him: "he gave me a hasty look, and passed on" (251). Like Flint, Tanner is rendered unrecognizable by his environment. Unlike Flint, however, Tanner is unrecognizable because he is a seasonal rather than a seasoned man-a human who has been unmade and remade by intra-action, including his Anishinaabe acculturation. Tanner's seasonality, therefore, more fully acknowledged the seasoning's malarial lessons - that the human was always in relation to an environment that was also always in relation to humans. 
Like Tanner and even Flint, physically transformed by the diseases they encountered, early American literature was transformed by the diseases that encountered it. Diseases wrote bodies, lives, cultures, history, and literature. Syphilis posited the limits of human knowledge and mastery in the genre most dedicated to such pursuits, the natural history, while smallpox revealed the artificial borders of the white body politic. In turn, yellow fever uncoupled agency from intentionality and efficacy and, thus, the novel from white humanity. Dysentery exposed sensibility's hypocritical and unethical reliance on a limited definition of humanity. Finally, malaria resisted the closure that seasoning mobilized to colonize the real and literary West. Each of these chapters argues that particular diseases transformed human bodies in particular ways, subsequently transforming ideas about illness, humanity, and literature.

By emphasizing disease's material and literary agency, by conjoining the study of illness and disability with the study of the environment, this argument shows how disease challenges fundamental ideas about humanity, including sovereignty, autonomy, rationality, and intentionality. Yet this challenge is not entirely negative. Instead, it opens up a critical space for reimagining how humans relate to other humans and nonhumans, to how we experience, treat, and write about one of our most fundamental intra-actions-illness. In the age of the Anthropocene, and the global reckoning of human supremacy, it is absolutely vital that we reimagine and remap the relationship between humans and nonhumans, especially disease. 


\section{Works Cited}

Abeel, David G. An Inaugural Dissertation on Dysentery. New York, 1794. Eighteenth Century Collections Online, find.galegroup.com.www.libproxy.wvu.edu/ecco/infomark.do? $\&$ source $=$ galeprodId $=$ ECCO\&userGroupName $=$ morg77564\&tabID $=$ T001\&docId $=\mathrm{CB} 13$ 0360470\&type $=$ multipage \&contentSet $=$ ECCOArticles\&version=1.0\&docLevel=FASCI MILE.

Adair, James. The History of the American Indians. Edited by Kathryn E. Holland Braund, U of Alabama P, 2005. ProQuest Ebook Central, ebookcentral-proquest-com.proxy.library. vcu.edu/lib/vcu/detail.action?docID=438128.

Adams, Abigail. Letters, edited by the Massachusetts Historical Society. Founders Online, National Archives, founders.archives.gov/?q=\%20Author\%3A\%22Adams\% 2C\%20Abigail\%22\&s $=1111211111 \& \mathrm{r}=1$.

Adams, Percy G. Travel Literature and the Evolution of the Novel. The UP of Kentucky, 1983. ProQuest Ebook Central, ebookcentral.proquest.com/lib/wvu/detail.action?docID= 1915713.

Alaimo, Stacey. Bodily Natures: Science, Environment, and the Material Self. Indiana UP, 2010. Allewaert, Monique. Ariel's Ecology: Plantations, Personhood, and Colonialism in the American Tropics. U of Minnesota P, 2013.

---. “Insect Poetics: James Grainger, Personification, and Enlightenments Not Taken.” Early American Literature, vol. 52, no. 2, 2017, pp. 299-332. Project MUSE, doi:10.1353/eal.2017.0027.

---. "Swamp Sublime: Ecologies of Resistance in the American Plantation Zone." PMLA, vol. 123, no. 2, 2008, pp. 340-57. JSTOR, www-jstor-org.proxy.library.vcu.edu/stable/ 
25501858.

Altschuler, Sari. The Medical Imagination: Literature and Health in the Early United States. U of Pennsylvania P, 2018.

--- and Cristobal Silva. "Early American Disability Studies." Early American Literature, vol. 52, no. 1, 2017, pp. 1-27. Project MUSE, doi:10.1353/eal.2017.0000.

Akenside, Mark. A Commentary on the Dysentery: or Bloody Flux, translated by John Ryan. London, 1767. Eighteenth Century Collections Online, find.galegroup.com.www. libproxy.wvu.edu/ecco/infomark.do?\&source=galeprodId=ECCO\&userGroupName=mor $\mathrm{g} 77564 \& \operatorname{tabID}=\mathrm{T} 001 \&$ docId $=\mathrm{CW} 106833328 \&$ type $=$ multipage $\&$ contentSet=ECCOArtic les\&version=1.0\&docLevel=FASCIMILE.

"Amebic Dysentery." The Cambridge Historical Dictionary of Disease, edited by Kenneth F. Kiple, Cambridge University Press, 1st edition, 2003. Credo Reference, www.libproxy. wvu.edu/login?url=https://search.credoreference.com/content/entry/cupdisease/amebic_d ysentery/0?institutionId $=735$.

Anderson, Fred. Crucible of War: The Seven Years' War and the Fate of the Empire in British North America, 1754-1766. Alfred A. Knopf, 2000.

“Anopheles Mosquitoes." Centers for Disease Control and Prevention, 21 Oct. 2015, www.cdc.gov/malaria/about/biology/mosquitoes/index.html.

Anstey, Peter. "The Creation of the English Hippocrates." Medical History, vol. 55, no. 4, 2011, pp. 457-78. PubMed Central, www-ncbi-nlm-nih-gov.proxy.library.vcu.edu/pmc/articles/ PMC3199640/.

Apel, Thomas A. Feverish Bodies, Enlightened Minds: Science and the Yellow Fever Controversy in the Early American Republic. Stanford UP, 2016. ProQuest Ebook 
Central, ebookcentral.proquest.com/lib/wvu/detail.action?docID=4455196.

Armstrong, Nancy and Leonard Tennenhouse. Novels in the Time of Democratic Writing: The American Experience. U of Pennsylvania P, 2018.

Atkinson, Dwight. "The Philosophical Transactions of the Royal Society of London, 1675-1975: A Sociohistorical Discourse Analysis." Language in Society, vol. 25, no. 3, 1996, pp. 333-71. JSTOR, www.jstor.org/stable/4168717.

Axtell, James. Natives and Newcomers: The Cultural Origins of North America. Oxford UP, 2001.

"Bacillary Dysentery." The Cambridge Historical Dictionary of Disease, edited by Kenneth F. Kiple, Cambridge University Press, 1st edition, 2003. Credo Reference, www.libproxy.wvu.edu/login?url=https://search.credoreference.com/content/entry/cupdis ease/bacillary_dysentery/0?institutionId=735.

Baker, Brenda J. and George J. Armelagos. "The Origin and Antiquity of Syphilis: Paleopathological Diagnosis and Interpretation." Current Anthropology, vol. 29, no. 5, 1988, pp. 703-37. JSTOR, www.jstor.org/stable/2743609.

Banks, Joseph. The Endeavour Journal of Sir Joseph Banks. Project Gutenberg Australia, http://gutenberg.net.au/ebooks05/0501141h.html.

Baptish, Edward E. "Hidden in Plain View." Echoes of the Haitian Revolution, 1804-2004, edited by Martin Munroe and Elizabeth Walcott-Hackshaw, U of the West Indies P, 2009, pp. 1-27. ProQuest Ebook Central, ebookcentral.proquest.com/lib/wvu/detail. action?docID $=4388442$.

Barad, Karen. Meeting the Universe Halfway: Quantum Physics and the Entanglement of Matter and Meaning. Duke UP, 2007. 
Barker-Benfield, G. J. Abigail and John Adams: The Americanization of Sensibility. U of Chicago P, 2010. ProQuest Ebook Central, ebookcentral-proquest-com.proxy. library.vcu.edu/lib/vcu/detail.action?docID=616027.

---. The Culture of Sensibility: Sex and Society in Eighteenth-Century Britain. U of Chicago P, 1992.

Barnes, Elizabeth. States of Sympathy: Seduction and Democracy in the American Novel. Columbia UP, 1997.

Barnes, Ethne. Diseases and Human Evolution. U of New Mexico P, 2007. ProQuest Ebook Central, ebookcentral.proquest.com/lib/wvu/detail.action?docID=1118948.

Barry, Alyssa, and Diana Hansen. "Naturally Acquired Immunity to Malaria." Parasitology, vol. 143, no. 2, 2016, pp. 125-28. ProQuest, doi:http://dx.doi.org.www.libproxy.wvu.edu/ 10.1017/S0031182015001778.

Baym, Nina. Novels, Readers, and Reviewers: Responses to Fiction in Antebellum America. Cornell UP, 1984.

Bell, Andrew McIlwaine. Mosquito Soldiers: Malaria, Yellow Fever, and the Course of the American Civil War. Louisiana State UP, 2010.

Bennet, Jane. Vibrant Matter: A Political Ecology of Things. Duke UP, 2010.

Berkeley, Edmund and Dorothy Smith Berkeley. Doctor Alexander Garden of Charles Town. U of North Carolina P, 1969.

Bérubé, Michael. The Secret Life of Stories: From Don Quixote to Harry Potter, How Understanding Intellectual Disability Transforms the Way We Read. New York UP, 2016.

Bogost, Ian. Alien Phenomenology, Or, What It's like to Be a Thing. U of Minnesota P, 2012. 
Boudreau, Kristin. Sympathy in American Literature: American Sentiments from Jefferson to the Jameses. UP of Florida, 2002.

Boulware, Tyler. Deconstructing the Cherokee Nation: Town, Region, and Nation Among Eighteenth-Century Cherokees. UP of Florida, 2011.

Boyle, Robert. Certain Physiological Essays and Other Tracts Written at Distant Times. London, 1669. Early English Books Online, name.umdl.umich.edu/A28944.0001.001.

---. General Heads for the Natural History of a Country Great or Small Drawn out for the Use of Travellers and Navigators. London, 1692. Early English Books Online, name.umdl.umich.edu/A28984.0001.001.

Brancaccio, Patrick. "Studied Ambiguities: Arthur Mervyn and the Problem of the Unreliable Narrator." American Literature, vol. 42, no. 1, 1970, pp. 18-27. JSTOR, www.jstor.org/stable/2924376.

Breen, Louise A. “Cotton Mather, the 'Angelical Ministry,' and Inoculation.” Journal of the History of Medicine and Allied Sciences, vol. 46, no. 3, 1991, pp. 333-57. JSTOR, wwwjstor-org.proxy.library.vcu.edu/stable/24622667.

Brodhead, Richard H. Cultures of Letters: Scenes of Reading and Writing in Nineteenth-Century America. U of Chicago P, 1993.

Brown, Charles Brockden. Arthur Mervyn, or Memoirs of the Year 1793. 1798. Edited by Sydney J. Krause and S.W. Reid. Kent State UP, 2002.

---Ormond; Or, The Secret Witness. 1799. Edited by Mary Chapman. Broadview Press, 1999.

Brown, Kathleen M. Foul Bodies: Cleanliness in Early America. Yale UP, 2009.

Brown, Norman O. Life Against Death: The Psychoanalytical Meaning of History. 1958. Edited by Christopher Lasch, Wesleyan UP, 1985. ProQuest Ebook Central, /proxy.library.vcu. 
edu/login?url=http://search.ebscohost.com/login.aspx?direct=true\&AuthType $=$ ip,url,cookie,uid $\& \mathrm{db}=$ nlebk\&AN=45139\&site=ehost-live \&scope=site.

Brown, Richard Maxwell. The South Carolina Regulators. The Belknap Press of Harvard UP, 1963.

Brown, William Wells. Clotel; or, The President's Daughter: A Narrative of Slave Life. London 1853. Documenting the American South, docsouth.unc.edu/southlit/brown/brown.html\# p203.

Buffon, Georges Louis Leclerc, comte de. Barr's Buffon: Buffon's Natural History. Vol. 9. London, 1797. Eighteenth Century Collections Online, find.galegroup.com/ecco/info mark.do?\&source=gale\&prodId=ECCO\&userGroupName=viva_vcu\&tabID=T001\&docI $\mathrm{d}=\mathrm{CB} 128089757 \&$ type $=$ multipage $\&$ contentSet $=$ ECCOArticles\&version=1.0\&docLevel $=$ FASCIMILE.

Burbick, Joan. Healing the Republic: The Language of Health and the Culture of Nationalism in Nineteenth-Century America. Cambridge UP, 1994.

Burke, Edmund. A Philosophical Enquiry into the Origin of Our Ideas of the Sublime and Beautiful. 1757. Eighteenth Century Collections Online, name.umdl.umich.edu/ 004807802.0001.000.

Cameron, Catherin M., Paul Kelton, and Alan C. Swedlund, editors. Beyond Germs: Native Depopulation in North America. U of Arizona P, 2015. ProQuest Ebook Central, ebookcentral.proquest.com.proxy.library.vcu.edu/lib/vcu/detail.action?docID=3440645.

Carey, Brycchan. British Abolitionism and the Rhetoric of Sensibility: Writing, Sentiment, and Slavery, 1760-1807. Palgrave Macmillan, 2005.

Carey, Matthew. A Short Account of the Malignant Fever, Lately Prevalent in Philadelphia. 
Philadelphia, 1793. Eighteenth Century Collections Online, find.galegroup.com.www. libproxy.wvu.edu/ecco/infomark.do?\&source=gale\&prodId=ECCO\&userGroupName=m org77564\&tabID=T001\&version=1.0\&docLevel=FACSIMILE.

Carrigan, Jo Ann. "Yellow Fever: The Scourge of the South." Disease and Distinctiveness in the American South, edited by Todd L. Savitt and James Harvey Young, U of Tennessee P, 1988, pp. 55-78.

Carter, Landon. The Diary of Colonel Landon Carter of Sabine Hall, 1752-1778, edited by Jack P. Greene. 1965. Virginia Historical Society, 1985.

Castro, Mario M., et al. "Thoracic Aortic Aneurysm in a Pre-Columbian (210 BC) Inhabitant of Northern Chile: Implications for the Origins of Syphilis." International Journal of Paleopathology, vol. 13, 2016, pp. 20-26. Science Direct, doi.org/10.1016/j.jpp.2016.01.002.

Cates, Gerald L. "The Seasoning: Disease and Death Among the First Colonists of Georgia." The Georgia Historical Quarterly, vol. 64, no. 2, 1980, pp. 146-58. JSTOR, www.jstor.org /stable/40580681.

Catton, Theodore. Rainy Lake House: Twilight of Empire of the Northern Frontier. The Johns Hopkins UP, 2017.

Chakrabarti, Pratik. Materials and Medicine: Trade, Conquest, and Therapeutics in the Eighteenth Century. Manchester UP, 2010.

Chaplin, Joyce E. An Anxious Pursuit: Agricultural Innovation and Modernity in the Lower South, 1730-1815. U of North Carolina P, 1993. ProQuest Ebook Central, ebookcentral. proquest.com/lib/wvu/detail.action?docID $=4321890$.

---. Subject Matter: Technology, the Body, and Science on the Anglo-American Frontier, 1560- 
1676. 2001. Harvard UP, 2003.

Charon, Rita. Narrative Medicine: Honoring the Stories of Illness. Oxford UP, 2006. ProQuest Ebook Central, ebookcentral.proquest.com/lib/wvu/detail.action?docID=3053606.

Chen, Mel Y. Animacies: Biopolitics, Racial Mattering, and Queer Affect. Duke UP, 2012.

Cheyne, George. The English Malady: or, a Treatise of Nervous Diseases of All Kinds. 3rd ed., London, 1734. Eighteenth Century Collections Online, find.galegroup.com/www. libproxy.wvu.edu/ecco/infomark.do?\&source=gale\&prodId=ECCO\&userGroupName=m org77564\&tabId=T001\&docID=CW109854839\&type=multipage \&contentSet=ECCOArt icles\&version-1.0\&docLevel=FACSIMILE.

Christopherson, Bill. Apparition in the Glass: Charles Brockden Brown's American Gothic. U of Georgia P, 1993.

Clayton, Daniel. "Captain Cook and the Spaces of Contact at 'Nootka Sound."” Reading Beyond Words: Contexts for Native History, edited by Jennifer S.H. Brown and Elizabeth Vibert, Broadview Press, 1996, pp. 95-123.

Cook, James. The Journals of Captain James Cook on His Voyages of Discovery, edited by J.C. Beaglehole, Published for the Hakluyt Society at the Cambridge UP, 1955-1974. Vols. $1-4$.

Coon, David L. "Eliza Lucas Pinckney and the Reintroduction of Indigo Culture in South Carolina." Journal of Southern History, vol. 42, no. 1, 1976, pp. 61-76. JSTOR, DOI: $10.2307 / 2205661$.

Corbin, Alain. The Foul and the Fragrant: Odor and the French Social Imagination. Harvard UP, 1986.

Corkran, David H. The Cherokee Frontier: Conflict and Survival, 1740-1762. U of Oklahoma P, 
1962.

Cowdrey, Albert E. This Land, This South: An Environmental History. 1983. The UP of Kentucky, 1996. ACLS Humanities E-Book, http://hdl.handle.net.www.libproxy. wvu.edu/2027/heb.00363.

Crawford, Dorothy H. Deadly Companions: How Microbes Shaped Our History. Oxford UP, 2007.

---. Invisible Enemy: A Natural History of Viruses. Oxford UP, 2000.

Cronon, William. Changes in the Land: Indians, Colonists, and the Ecology of New England. Hill and Wang, 1983.

Crosby, Jr., Alfred W. The Columbian Exchange: Biological and Cultural Consequences of 1492. 1973. Praeger, 2003.

---. "The Early History of Syphilis: A Reappraisal." American Anthropologist, vol. 71, no. 2, 1969, pp. 218-27. JSTOR, www.jstor.org/stable/669854.

Cullen, William. Lectures on Materia Medica. London, 1772. Eighteenth Century Collections Online, find.galegroup.com.proxy.library.vcu.edu/ecco/infomark.do?\&source=gale\& prodId=ECCO\&userGroupName=viva_vcu\&tabID=T001\&docId=CW109611998\&type $=$ multipage $\&$ contentSet=ECCOArticles\&version=1.0\&docLevel=FACSIMILE .

Curtin, Philip D. “Epidemiology and the Slave Trade.” Political Science Quarterly, vol. 83, no. 2, 1968, pp. 190-216. JSTOR, DOI: 10.2307/2147089.

Daston, Lorraine and Peter Galison. Objectivity. Zone Books, 2007.

Davidson, Cathy N. Revolution and the Word: The Rise of the Novel in America. 1986. Oxford UP, 2004.

Davis, Cynthia. Bodily and Narrative Forms: The Influence of Medicine on America Literature. 
Stanford UP, 2000.

Dayan, Joan. Haiti, History, and the Gods. 1995. U of California P, 1998. ACLS Humanities EBook, hdl.handle.net.www.libproxy.wvu.edu/2027/heb.04571.

Dear, Peter. "Totius in Verba: Rhetoric and Authority in the Early Royal Society." Rhetoric and the Early Royal Society: A Sourcebook, edited by Tina Skouen and Ryan Stark, Brill, 2015, pp. 53-76. ProQuest Ebook Central, ebookcentral.proquest.com.proxy.library.vcu. edu/lib/vcu/detail.action?docID=1877216.

Decker, Jody F. “Country Distempers: Deciphering Disease and Illness in Rupert's Land before 1870.” Reading Beyond Words: Contexts for Native History, edited by Jennifer S. H. Brown and Elizabeth Vibert, Broadview Press, 1996, pp. 156-81.

Derounian-Stodola, Kathryn Zabelle and James Arthur Levernier. The Indian Captivity Narrative, 1550-1900. Twayne Publishers, 1993.

Dessens, Nathalie. From Saint-Domingue to New Orleans: Migration and Influences. UP of Florida, 2007.

Dillon, Elizabeth Maddock. "The Secret History of the Early American Novel: Leonora Sansay and the Revolution in Saint Domingue." Novel: A Forum on Fiction, vol. 40, no. 1/2, 2006/2007, pp. 77-103. JSTOR, www.jstor.org/stable/40267685.

Donegan, Kathleen. Seasons of Misery: Catastrophe and Colonial Settlement in Early America. U of Pennsylvania P, 2013. ProQuest Ebook Central, ebookcentral.proquest.com/lib/wvu /detail.action?docID=3442282.

Donovan, Josephine. New England Local Color Literature. Frederick Ungar Publishing Company, 1983.

Douglas, Mary. Purity and Danger: An Analysis of Concepts of Pollution and Taboo. 1966. 
Routledge, 2003. ProQuest Ebook Central, ebookcentral.proquest.com/lib/wvu/detail. action?docID $=1223047$.

Drexler, Michael. "Brigands and Nuns: The Vernacular Sociology of Collectivity after the Haitian Revolution." Messy Beginnings: Postcoloniality and Early American Studies, edited by Malini Johar Schueller and Edward Watts, Rutgers UP, 2003, pp. 175-99.

---. Introduction. "Secret History; or, The Horrors of St. Domingo" and "Laura." 2007. Broadview, 2008, pp. 10-37.

Dubois, Laurent. Avengers of the New World: The Story of the Haitian Revolution. The Belknap Press of Harvard UP, 2004.

Duffy, John. Epidemics in Colonial America. Louisiana State UP, 1953.

---. Sword of Pestilence: The New Orleans Yellow Fever Epidemic of 1853. Louisiana State UP, 1966.

Duggan, Ana, et al. " $17^{\text {th }}$ Century Variola Virus Reveals the Recent History of Smallpox." Current Biology, vol. 26, no. 24, 2016, pp. 3407-3412. ScienceDirect, Doi.org/10.1016/j.cub.2016.10.061.

Dun, James Alexander. “(Mis)Reading the Revolution: Philadelphia and 'St. Domingo,' 17891792." The Haitian Revolution and the Early United States: Histories, Textualities, and Geographies, edited by Elizabeth Maddock Dillon and Michael Drexler, U of Pennsylvania P, 2016, pp. 42-57. JSTOR, www.jstor.org/stable/j.cttlbmzkn3.

Egan, Jim. Authorizing Experience: Refigurations of the Body Politic in Seventeenth-Century New England Writing. Princeton UP, 1994. ProQuest Ebook Central, ebookcentral. proquest.com/lib/wvu/detail.action?docID $=581581$.

---. 'The 'Long'd for Aera' of an 'Other Race': Climate, Identity, and James Grainger's 
The Sugar-Cane." Early American Literature, vol. 38, no. 2, 2003, pp. 189-212. JSTOR, www.jstor.org/stable/25057314.

Elias, Norbert. The Civilizing Process: The History of Manners. Urizen Books, 1978.

"Eliza House Trist to Thomas Jefferson, 13 April [1784]." The Papers of Thomas Jefferson, edited by Julian P. Boyd. Founders Online, National Archives, founders.archives.gov/ documents/Jefferson/01-07-02-0092.

Ellis, Markman. “'Incessant Labour': Georgic Poetry and the Problem of Slavery.” Discourses of Slavery and Abolition: Britain and Its Colonies, 1760-1838, edited by Brycchan Carey, Markman Ellis, and Sara Salih, Palgrave Macmillan, 2004, pp. 45-62.

---. The Politics of Sensibility: Race, Gender, and Commerce in the Sentimental Novel. Cambridge UP, 1996.

Ellis, Scott. “Charles Brockden Brown's Ormond, Property Exchange, and the Literary Marketplace in the Early American Republic." Studies in the Novel, vol. 37, no. 1, 2005, pp. 1-19. JSTOR, www-jstor-org.proxy.library.vcu.edu/stable/29533662.

Espinosa, Mariola. "The Question of Racial Immunity to Yellow Fever in History and Historiography." Social Science History, vol. 38, no. 3/4, 2014, pp. 437-53. Project MUSE, muse.jhu/edu/article/687637.

Ferguson, Robert A. "Yellow Fever and Charles Brockden Brown: The Context of the Emerging Novelist.” Early American Literature, vol. 14, no. 3, 1979/1980, pp. 293-305. JSTOR, www.jstor.org/stable/25070949.

Fetterley, Judith. Provisions: A Reader from Nineteenth-Century America. Indiana UP, 1985. --- and Marjorie Pryse. Writing Out of Place: Regionalism, Women, and American Literary Culture. U of Illinois P, 2003. 
Fett, Sharla M. Working Cures: Healing, Health, and Power on Southern Slave Plantations. The U of North Carolina P, 2002. ProQuest Ebook Central, ebookcentral.proquest.com.proxy. library.vcu.edu/lib/vcu/detail.action?docID $=475179$.

Fiedler, Leslie A. Love and Death in the American Novel. Criterion Books, 1960.

---. The Return of the Vanishing American. Stein and Day, 1968.

Fierst, John T. “A 'Succession of Little Occurrences': Scholarly Editing and the Organization of Time in Tanner's Narrative." Scholarly Editing, vol. 33, 2012, n. pg. http://scholarlyediting.org/2012/essays/essay.fierst.html.

---. "Strange Eloquence: Another Look at The Captivity and Adventures of John Tanner." Reading Beyond Words: Contexts for Native History, edited by Jennifer S. H. Brown and Elizabeth Vibert, Broadview Press, 1996, pp. 220-41.

Finger, Simon. The Contagious City: The Politics of Public Health in Early Philadelphia. Cornell UP, 2012. ProQuest Ebook Central, ebookcentral.proquest.com.proxy. library.vcu.edu/lib/vcu/detail.action?docID=3138341.

Fishel, Stefanie R. The Microbial State: Global Thriving and the Body Politic. U of Minnesota P, 2017.

Flint, Timothy. Recollections of the Last Ten Years. Boston, 1826. Archive.org, archive.org/details/recollectionsla00flingoog.

Floyd, Janet. Writing the Pioneer Woman. U of Missouri P, 2002. ProQuest Ebook Central, https://ebookcentral.proquest.com/lib/wvu/detail.action?docID=3570665.

Frank, Arthur W. The Wounded Storyteller: Body, Illness, and Ethics. U of Chicago P, 1995. Franklin, Wayne. Discoverers, Explorers, Settlers: The Diligent Writers of Early America, U of Chicago P, 1979. 
Foa, Anna. "The New and the Old: The Spread of Syphilis (1494-1530)." Sex and Gender in Historical Perspective, edited by Edward Muir and Guido Ruggiero, translated by Margaret A. Gallucci, Mary M. Gallucci, and Carole C. Gallucci. The Johns Hopkins UP, 1990, pp. 26-45.

Foucault, Michel. Security, Territory, and Population: Lecture at the Collège de France, 19771978. Edited by Michael Senellart. Translated by Graham Burchell, Palgrave Macmillan, 2004.

---. The Order of Things: An Archaeology of the Human Sciences. Vintage Books, 1994.

Foy, Anna M. "Grainger and the 'Sordid Master': Plantocratic Alliance in The Sugar-Cane and Its Manuscript.” The Review of English Studies, vol. 68, no. 286, 2017, pp. 708-33. Oxford Academic, doi-org.www.libproxy.wvu.edu/10.1093/res/hgx001.

Fracastoro, Girolamo. Syphilis. 1530. Translated by Geoffrey Eautough. Francis Cairns, 1984.

Frohock, Richard. Heroes of Empire: The British Imperial Protagonist in America, 1596-1764. U of Delaware P, 2005.

Garden, Alexander. "His Correspondence with Ellis." A Selection of the Correspondence of Linnaeus and Other Naturalists, from the Original Manuscripts, edited by James Edward Smith, vol. 1, London, 1821, pp. 342-605. Archive.org, Archive.org/details/aselection Corre00linngoog.

Garland- Thomson, Rosemarie. Extraordinary Bodies: Figuring Physical Disability in American Culture and Literature. Columbia UP, 1997.

Gebhard, Caroline. “Comic Displacement: Caroline M. Kirkland's Satire of Frontier Democracy in A New Home, Who'll Follow?" Women, American, and Movement: Narratives of Relocation, edited by Susan L. Roberson, U of Missouri P, 1998, pp. 157-75. 
Geggus, David. "The Louisiana Purchase and the Haitian Revolution.” The Haitian Revolution and the Early United States: Histories, Textualities, and Geographies, edited by Elizabeth Maddock Dillon and Michael Drexler, U of Pennsylvania P, 2016, pp. 117-29. JSTOR, www.jstor.org/stable/j.ctt1bmzkn3.

Gelles, Edith B. First Thoughts: Life and Letters of Abigail Adams. Twayne Publishers, 1998. Georgi-Findlay, Brigitte. The Frontiers of Women's Writing: Women's Narratives and the Rhetoric of Westward Expansion. U of Arizona P, 1996.

Gerbi, Antonello. Dispute of the New World: History of a Polemic, 1750-1900, translated by Jeremy Moyle. 1955. U of Pittsburgh P, 1973.

Ghosh, Amitav. The Great Derangement: Climate Change and the Unthinkable. U of Chicago P, 2016. ProQuest Ebook Central, ebookcentral.proquest.com/lib/wvu/detail.action?docID $=4532285$.

Gibson, Charles, editor. The Black Legend: Anti-Spanish Attitudes in the Old World and the New. Knopf, 1971.

Gilmore, John. Introduction and Biographical Sketch. The Poetics of Empire: A Study of James Grainger's The Sugar Cane (1764). The Athlone Press, 2000. ProQuest Ebook Central, ebookcentral.proquest.com/lib/wvu/detail.action?docID $=436058$.

Goddu, Teresa A. Gothic America: Narrative, History, Nation. Columbia UP, 1997.

Goudie, Sean X. Creole America: The West Indies and the Formation of Literature and Culture in the New Republic. U of Pennsylvania P, 2006.

---. "On the Origin of American Specie(s): The West Indies, Classification, and the Emergence 
of Supremacist Consciousness in Arthur Mervyn." Revising Charles Brockden Brown: Culture, Politics, and Sexuality in the Early Republic, edited by Philip Barnard, Mark L. Kamrath, and Stephen Shapiro, The U of Tennessee P, 2004, pp. 60-87.

Gould, Philip. "Race, Commerce, and the Literature of Yellow Fever in Early National Philadelphia." Early American Literature, vol. 35, no. 2, 200, pp. 157-86. JSTOR, www.jstor.org/stable/25057192.

Graham, S. Scott. "Dis-Ease or Disease? Ontological Rarefaction in the Medical-Industrial Complex." Journal of Medical Humanities, vol. 32, no. 3, 2011, pp. 167-86. Proquest, doi:10.1007/s10912-011-9137-5.

Grainger, James. An Essay on the More Common West-India Diseases. 1764. Edited by William Wright, 1802. On the Treatment and Management of the More Common West-India Diseases, 1750-1802, edited by J. Edward Hutson. 2005. U of the West Indies P, 2010. ---. The Sugar-Cane. 1764. Edited by John Gilmore. The Athlone Press, 2000, pp. 87-198. ProQuest Ebook Central, ebookcentral.proquest.com/lib/wvu/detail.action?docID $=436058$.

Greenberg, Amy S. Manifest Manhood and the Antebellum American Empire. Cambridge UP, 2005.

Greene, Jack P, editor. Introduction. The Diary of Colonel Landon Carter of Sabine Hall, 17521778. 1965. Virginia Historical Society, 1985.

Greer, Margaret R., Walter D. Mignolo, and Maureen Quilligan. Rereading the Black Legend: The Discourses of Religious and Racial Difference in the Renaissance Empires. $\mathrm{U}$ of Chicago P, 2008. ProQuest Ebook Central, ebookcentral.proquest.com/lib/wvu/detail. action?docID $=408440$. 
Grob, Gerald N. The Deadly Truth: A History of Disease in America. Harvard UP, 2002.

ProQuest Ebook Central, ebookcentral.proquest.com/lib/wvu/detail.action? $\operatorname{doc} \mathrm{ID}=3300358$.

Gunn, Robert Lawrence. Ethnology and Empire: Languages, Literature, and the Making of the North American Borderlands. New York UP, 2015.

Halverson, Cathryn. Playing House in the American West: Western Women's Life Narratives, 1839-1987. U of Alabama P, 2013. ProQuest Ebook Central, ebookcentral.proquest.com /lib/wvu/detail.action?docID=1481319.

Haraway, Donna. The Companion Species Manifesto: Dogs, People, and Significant Otherness. Prickly Pear Press, 2003.

Hare, E. H. "The Origin and Spread of Dementia Paralytica." The Journal of Mental Science, vol. 105, no. 440, 1959, pp. 594-626. Cambridge Core, doi-org.proxy.library.vcu.edu/ 10.1192/bjp.105.440.594.

Harkin, Michael E. and David Rich Lewis, editors. Native Americans and the Environment: Perspectives on the Ecological Indian. U of Nebraska P, 2007.

Harman, Graham. The Quadruple Object. Zero Books, 2011.

Harris, Jonathan Gil. Foreign Bodies and the Body Politic: Social Discourses of Pathology in Early Modern England. Cambridge UP, 1998.

Hatley, Tom. The Dividing Paths: Cherokees and South Carolinians through the Revolutionary Era. Oxford UP, 1995. ProQuest Ebook Central, ebookcentral.proquest.com/lib/ wvu/detail.action?docID $=716756$.

Hawkins, Anne Hunsaker. Reconstructing Illness: Studies in Pathography. Purdue UP, 1993. Herzogenrath, Bernd. An American Body | Politic: A Deleuzian Approach. Darmouth College 
Press, 2010. ProQuest Ebook Central, ebookcentral.proquest.com/lib/wvu/detail. action?docID $=1084921$.

Hobbes, Thomas. Leviathan or the Matter, Forme, \& Power of a Common-Wealth Ecclesiastical and Civil. 1651. Edited by Edward White and David Widger, 2009. Project Gutenberg, www.gutenberg.org/files/3207/3207-h/3207-h.htm.

Holcomb, Richard C. Who Gave the World Syphilis? The Haitian Myth. Froeben Press, 1937.

Holman, David. A Certain Slant of Light: Regionalism and the Form of Southern and Midwestern Fiction. Louisiana State UP, 1995.

Hopkins, Donald R. The Greatest Killer: Smallpox in History. 1983. U of Chicago P, 2002.

Humphreys, Margaret. Malaria: Poverty, Race, and Public Health in the United States. JohnsHopkins UP, 2001. ProQuest Ebook Central, ebookcentral.proquest.com/lib/wvu/ detail.action?docID $=3318134$.

---. 'Vindicating the Minister's Medical Role: Cotton Mather's 'Nishmath-Chajim' and the Spiritualization of Medicine." Journal of the History of Medicine and Allied Sciences, vol. 36, no. 3, 1981, pp. 278-95. JSTOR, www-jstor.org.proxy.library.vcu.edu/stable/ 24625833.

---. Yellow Fever and the South. 1992. The John Hopkins UP, 1999.

Hunt, Alfred N. Haiti's Influence on Antebellum America: Slumbering Volcano in the Caribbean. Louisiana State UP, 1988.

Hunter, Kathryn Montgomery. Doctor's Stories: The Narrative Structure of Medical Knowledge. Princeton UP, 1991.

Hutchinson, Jonathan. “An Address on Syphilis as an Imitator.” British Medical Journal, vol. 1, no. 953, 1879, pp. 541-542. PubMed Central, www-ncbi-nlm-nih-gov.www.libproxy. 
wvu.edu/pmc/?cmd=Search\&term=00071447\%5Bjour\%5D+AND+1\%5Bvolume $\% 5 \mathrm{D}+$ AND $+541 \% 5$ Bpage $\% 5 \mathrm{D}+\mathrm{AND}+1879 \% 5 \mathrm{Bpdat} \% 5 \mathrm{D}$.

Iannini, Christopher P. Fatal Revolutions: Natural History, West Indian Slavery, and the Routes of American Literature. Published for the Omohundro Institute of Early American History and Culture by the U of North Carolina P, 2012.

Inglis, David. A Sociological History of Excretory Experience: Defecatory Manners and Toiletry Technologies. The Edwin Mellen Press, 2000.

Imbarrato, Susan Clair. Declarations of Independency in Eighteenth-Century American Autobiography. U of Tennessee P, 1998.

---. "Ordinary Travel: Tavern Life and Female Accommodation in Early America and the New Republic.” Women's Studies, vol. 28, no. 1, 1998, pp. 29-57. Taylor \& Francis Online, doi-org.www.libproxy.wvu.edu/10.1080/00497878. 1998.9979243.

---. Traveling Women: Narrative Visions of Early America. Ohio UP, 2006.

Isaac, Rhys. Landon Carter's Uneasy Kingdom: Revolution and Rebellion on a Virginia Plantation. Oxford UP, 2004.

Jefferson, Thomas. Notes on the State of Virginia. Philadelphia, 1787. Documenting the American South, docsouth.unc.edu/southlit/jefferson/jefferson.html.

Jehlen, Myra. "History before the Fact; or, Captain John Smith’s Unfinished Symphony." Critical Inquiry, vol. 19, no. 4, 1993, 677-92. JSTOR, www.jstor.org/stable/1343902.

Jeremiah, Edward T. The Emergence of Reflexivity in Greek Language and Thought: From Homer to Plate and Beyond. Brill, 2012. ProQuest Ebook Central, ebookcentral.proquest.com/lib/vcu/detail.action?docID $=867719$. 
Jolly, Margaret. “Desire, Difference and Disease: Sexual and Venereal Exchanges on Cook’s Voyages in the Pacific." Exchanges: Cross-Cultural Encounters in Australia and the Pacific, edited by Ross Gibson. Museum of Sydney Press, 1997, pp. 187-217.

Jones, Absalom and Richard Allen. A Narrative of the Proceedings of the Black People, During the Late Awful Calamity in Philadelphia, in the year 1793: And a Refutation of Some Censures, Thrown Upon Them in Some Late Publications. Philadelphia, 1794. Eighteenth Century Collections Online, find.galegroup.com.www.libproxy.wvu.edu/ecco/infomark. do? \&source $=$ gale $\&$ prodId $=$ ECCO\&userGroupName $=$ morg $77564 \& \operatorname{tab} I D=T 001 \&$ docId $=$ CB127036940\&type=multipage\&contentSet=ECCOArticles\&version-1.0\&docLevelFASCIMILE.

Jones, David S. Rationalizing Epidemics: Meanings and Uses of American Indian Mortality since 1600. Harvard UP, 2004. ProQuest Ebook Central, ebookcentral-proquestcom.proxy.library.vcu.edu/lib/vcu/detail.action?docID=3300634.

Jones, Gordon W. Introduction. The Angel of Bethesda. American Antiquarian Society and Barre Publishers, 1972, pp. xi-xl.

Kafer, Alison. Feminist, Queer, Crip. Indiana UP, 2013.

Kantorowicz, Ernst H. The King's Two Bodies: A Study in Medieval Political Theology. 1957. Princeton UP, 2016.

Kaplan, Amy. "Manifest Domesticity.” American Literature, vol. 70, no. 3, 1998, pp. 581-606. JSTOR, www.jstor.org/stable/2902710.

---. "Nation, Region, and Empire." The Columbia History of the American Novel, edited by Emory Eliot, et al, Columbia UP, 1991, pp. 240-66.

Karlen, Arno. Man and Microbes: Disease and Plagues in History and Modern Times. Simon \& 
Schuster Paperbacks, 1995.

Keetley, Dawn E. "Unsettling the Frontier: Gender and Racial Identity in Caroline Kirkland's $A$ New Home, Who'll Follow? and Forest Life." Legacy, vol. 12, no. 1, 1995, pp. 17-37. JSTOR, www.jstor.org/stable/25679149.

Kelton, Paul. Cherokee Medicine, Colonial Germs: An Indigenous Nation's Fight against Smallpox, 1518-1824. U of Oklahoma P, 2015. ProQuest Ebook Central, ebookcentral. proquest.com/lib/wvu/detail.action?docID $=3441364$.

---. "The British and Indian War: Cherokee Power and the Fate of the Empire in North America." The William and Mary Quaterly, vol. 69, no. 4, 2012, pp. 763-92. JSTOR, www-jstor-org.proxy.library.vcu.edu/stable/10.5309/willmaryquar.69.4.0763.

Kiple, Kenneth F. and Virginia Himmelsteib King. Another Dimension to the Black Diaspora: Diet, Disease and Racism. Cambridge UP, 1981.

Kirkland, Caroline. A New Home, Who'll Follow? or, Glimpses of Western Life. 1839. Edited by Sandra A. Zagarell. Rutgers UP, 1990.

---. Forest Life. London, 1842. Internet Archive, archive.org/details/forestlife00kirkuoft.

---. Western Clearings. New York, 1845. Internet Archive, archive.org/stream/westernclearing 02kirkgoog\#page/n8/mode/2up

Knott, John. Imagining the Forest: Narratives of Michigan and the Upper Midwest. U of Michigan P, 2012.

Knott, Sarah. Sensibility and the American Revolution. Omohundro Institute of Early American History and Culture, U of North Carolina P, 2009. ProQuest Ebook Central, ebookcentral.proquest.com/lib/wvu/detail.action?docID=4321908.

Kolodny, Annette. Introduction. The Travel Diary of Elizabeth House Trist: Philadelphia to 
Natchez, 1783-84. Journeys in New Worlds, edited by William L. Andrews, et. al. The U of Wisconsin P, 1990, pp. 181-200.

---. "Letting Go Our Grand Obsessions: Notes Toward a New Literary History of American Frontiers.” American Literature, vol. 64, no. 1, 1992, pp. 1-18. JSTOR, www.jstor.org/stable/2927486.

---. The Land Before Her: Fantasy and Experience of the American Frontiers, 1630-1860. U of North Carolina P, 1984.

---. The Lay of the Land: Metaphor as Experience and History in American Life and Letters. U of North Carolina P, 1975.

Krebsbach, Suzanne. "The Great Charlestown Smallpox Epidemic of 1760." The South Carolina Historical Magazine, vol. 97, no. 1, 1996, pp. 30-37. JSTOR, jstor.org/stable/27570134.

Krech III, Shepherd. The Ecological Indian: Myth and History. WW Norton and Company, 2000.

Krupat, Arnold, editor. Introduction. Native American Autobiography: An Anthology. U of Wisconsin P, 1994.

Lachance, Paul. "Repercussions of the Haitian Revolution in Louisiana." The Impact of the Haitian Revolution in the Atlantic World, edited by David P. Geggus, U of South Carolina P, 2002, pp. 209-30.

Lakoff, George. "Metaphor and War: The Metaphor System Used to Justify War in the Gulf." Viet Nam Generation Journal and Newsletter, vol. 3., no. 3, 1991. The Sixties Project, www2.iath.virginia.edu/sixties/HTML_docs/Texts/Scholarly/Lakoff_Gulf_Metaphor_1.h tml.

Lakoff, George and Mark Johnson. Metaphors We Live By. U of Chicago P, 1980. 
Lamb, Jonathan. Scurvy: The Disease of Discovery. Princeton UP, 2017.

Lapansky, Phillip. ““Abigail, a Negress': The Role and Legacy of African Americans in the Yellow Fever Epidemic." A Melancholy Scene of Devastation: The Public Response to the 1793 Philadelphia Yellow Fever Epidemic, edited by Billy G. Smith and J. Worth Estes, Science History Publications, 1997, pp. 61-78.

Laporte, Dominique. History of Shit. 1978. Translated by Nadia Benabid and Rodolphe elKhoury. MIT Press, 2000.

Latour, Bruno. “An Attempt at a Compositionist Manifesto.” New Literary History, vol. 41, no. 3, 2010, pp. 471-90. JSTOR, www-jstor-org.proxy.library.vcu.edu/stable/40983881.

---. Reassembling the Social: An Introduction to Actor-Network Theory. Oxford UP, 2005. ACLS Humanities E-Book, hdl.handle.net.proxy.library.vcu.edu/2027/heb.32135.

---. "Why Has Critique Run Out of Steam? From Matters of Fact to Matters of Concern." Critical Inquiry, vol. 30, no. 2, 2004, pp. 225-48. JSTOR, DOI: 10.1086/421123. Lawson, John. A New Voyage to North Carolina, edited by Hugh Talmage Lefler. The U of North Carolina P, 1967.

Levecq, Christine. Slavery and Sentiment: The Politics of Feeling in Black Atlantic Antislavery Writing, 1770-1850. U of New Hampshire P, 2008.

Leverenz, David. Manhood and the American Renaissance. Cornell UP, 1989.

Ligon, Richard. A True and Exact History of the Island of Barbados, edited by Karen Ordahl Kupperman. Hackett Publishing Company, Inc., 2011.

Locke, John. An Essay Concerning Human Understanding. 1690. Batoche Books, 2001. ProQuest Ebook Central, https://ebookcentral.proquest.com/lib/wvu/detail.action?doc $\underline{\mathrm{ID}=3117747 .}$. 
Loomis, Neil, editor. A Narrative of the Captivity and Adventures of John Tanner (U.S. Interpreter at the Saut de Ste. Marie,) During Thirty Years Residence Among the Indians in the Interior of North America. 1830. Minneapolis, 1956. Hathi Trust Digital Library, hdl.handle.net/2027/inu.30000007707148.

Loshe, Lillie Deming. The Early American Novel. The New Era Printing Company, 1907.

Lyndgaard, Kyhl D. Captivity Literature and the Environment: Nineteenth-Century American Cross-Cultural Collaborations. Routledge, 2017. ProQuest Ebook Central, ebookcentral.proquest.com/lib/wvu/detail.action?docID=4644364.

“Malaria--Disease.” Centers for Disease Control and Prevention, 4 Jan. 2019, www.cdc.gov/malaria/about/disease.html

Manning, Charles and Merrill Moore. "Sassafras and Syphilis." The New England Quarterly, vol. 9, no. 3, 1936, pp. 473-75. JSTOR, www.jstor.org/stable/360282.

"manure, n.1" Oxford English Dictionary Online, www.oed.com/view/Entry/113791.

Margolis, Stacey. "Network Theory circa 1800: Charles Brockden Brown's Arthur Mervyn." Novel: A Forum on Fiction, vol. 45, no. 3, 2012, pp. 343-67. JSTOR, www-jstororg.proxy.library.vcu.edu/stable/41810120.

Martin, Emily. Flexible Bodies: Tracking Immunity in American Culture-From the Days of Polio to the Age of AIDS. Beacon Press, 1994.

Mather, Cotton. The Angel of Bethesda, edited by Gordon W. Jones. American Antiquarian Society and Barre Publishers, 1972.

---. Selections from Cotton Mather, edited by Kenneth Ballard Murdock. Hafner Press, 1960. Mazel, David. American Literary Environmentalism. U of Georgia P, 2000.

McAllister, Marie E. "Stories of the Origin of Syphilis in Eighteenth-Century England: Science, 
Myth, and Prejudice." Eighteenth-Century Life, vol. 24, no. 1, 2000, pp. 22-44. Project MUSE, muse.jhu.edu/article/10508.

McAuley, Louis Kirk. “'Periodical Visitations': Yellow Fever as Yellow Journalism in Charles Brockden Brown's Arthur Mervyn.” Eighteenth Century Fiction, vol. 19, no. 3, 2007, pp. 307-40. Project MUSE, doi:10.1353/ecf.2007.0008.

McCandless, Peter. Slavery, Disease, and Suffering in the Southern Lowcountry. Cambridge UP, 2011.

McKeon, Michael. The Origins of the English Novel, 1600-1740. 1987. The Johns Hopkins UP, 2002.

McKinstry, Brian. "Paternalism and the Doctor-Patient Relationship in General Practice." British Journal of General Practice, vol. 42, no. 361, 1992, pp. 340-42. PubMed Central, wwwncbi-nlm-nih-gov.proxy.library.vcu.edu/pmc/articles/PMC1372178/.

McNeill, J.R. Mosquito Empires: Ecology and War in the Greater Caribbean, 1620-1913. Cambridge UP, 2010. ACLS Humanities E-Book, hdl.handle.net.www.libproxy.wvu. edu/2027/heb.30497.

McNeill, William H. Plagues and Peoples. Anchor Press/Doubleday, 1976.

Merrell, James H. "Second Thoughts on Colonial Historians and American Indians.” The William and Mary Quarterly, vol. 69, no. 3, 2012, pp. 451-512. JSTOR, www-jstororg.proxy.library.vcu.edu/stable/10.5309/willmaryquar.69.3.0451.

Mitchell, David T. and Sharon L. Snyder. Narrative Prosthesis: Disability and the Dependencies of Discourse. The U of Michigan P, 2000.

Monath, Thomas P. and Alan D.T Barrett. "Pathogenesis and Pathophysiology of Yellow Fever." Advances in Virus Research, vol. 60, 2003, pp. 343-95. Science Direct, 
doi.org/10.1016/S0065-3527(03)60009-6.

--- and Pedro F. C. Vasconcelos. "Yellow Fever." Journal of Clinical Virology, vol. 64, 2015, pp. 160-73. Elsevier, doi.org/10.1016/j.jcv.2014.08.030.

Morrison, Susan Signe. Excrement in the Late Middle Ages: Sacred Filth and Chaucer's Fecopoetics. Palgrave Macmillan, 2008.

"mortification, n.3" Oxford English Dictionary Online, www.oed.com/view/Entry/122481.

Morton, Timothy. Dark Ecology: For a Logic of Future Coexistence. Columbia UP, 2016.

---. Ecology without Nature: Rethinking Environmental Aesthetics. Harvard UP, 2007.

---. Hyperobjects: Philosophy and Ecology After the End of the World. U of Minnesota P, 2013. Proquest Ebook Central, ebookcentral-proquest-com.proxy.library.vcu.edu/lib/vcu/ detail.action?docID $=1477347$.

---. The Ecological Thought. Harvard UP, 2010.

Morton, Thomas. New English Canaan. Amsterdam, 1637. Archive.org, https://archive.org/details/Newenglishcanaa00mort_0_0.

Motulsky, Arno G. "Metabolic Polymorphisms and the Role of Infectious Diseases in Human Evolution.” Human Biology, vol. 61, no. 5/6, 1989, pp. 835-69. JSTOR, jstor.org/stable/41478728.

Moore, Peter N. "Archibald Simpson and the Care of Souls in Lowcountry South Carolina: Sustaining Communities between Awakenings." Presbyterian Historical Society, vol. 90, no. 2, 2012, pp. 60-71. JSTOR, www.jstor.org/stable/23338229.

Mullan, John. Sentiment and Sociability: The Language of Feeling in the Eighteenth Century 1988. Clarenon Press and Oxford UP, 2000.

Namias, June. White Captives: Gender and Ethnicity on the American Frontier. U of North 
Carolina P, 1993.

Obeyesekere, Gananath. The Apotheosis of Captain Cook: European Mythmaking in the Pacific. 1992. Princeton UP, 1997.

Oliphant, John. Peace and War on the Anglo-Cherokee Frontier, 1756-1763. Louisiana State UP, 2001.

Opperman, Serpil. “Compost.” Veer Ecology: A Companion for Ecological Thinking, edited by Jeffrey Jerome Cohen and Lowell Duckert, U of Minnesota P, 2017, pp. 136-50.

Oviedo, Gonzalo Fernández de. Natural History of the West Indies. 1526. Translated by Sterling A. Stoudemire. U of North Carolina P, 1959. JSTOR, www.jstor.org/stable/10.5149/ 9781469645636_deoviedo.

Packard, Randall M. The Making of a Tropical Disease: A Short History of Malaria. The Johns Hopkins UP, 2007.

Parrish, Susan Scott. American Curiosity: Cultures of Natural History in the Colonial British Atlantic World. U of North Carolina P, 2006.

---. "William Byrd II and the Crossed Languages of Science, Satire, and Empire in British North America." Creole Subjects in the Colonial Americas: Empires, Texts, Identities, edited by Ralph Bauer and José Antonio Mazzotti. U of North Carolina P, 2009, pp. 355-72.

Paster, Gail Kern. The Body Embarrassed: Drama and the Disciplines of Shame in Early Modern England. Cornell UP, 1993.

Pauw, Cornelius de. Recherces Philosophiques sur les Américains. London, 1770. Eighteenth Century Collections Online, find.galegroup.com/ecco/infomark.do?\&source=gale\& prodId=ECCO\&userGroupName=viva_vcu\&tabID=T001\&docId=CW102110814\&type $=$ multipage $\&$ contentSet=ECCOArticles\&version=1.0\&docLevel=FASCIMILE. 
Pearce, Roy Harvey. Savagism and Civilization: A Study of the Indian and the American Mind. 1953. U of California P, 1988. ProQuest Ebook Central, ebookcentral.proquest.com/lib/ wvu/detail.action?docID=223603.

Pernick, Martin S. "Politics, Parties, and Pestilence: Epidemic Yellow Fever in Philadelphia and the Rise of the First Party System." The William and Mary Quarterly, vol. 29, no. 4, 1972, pp. 559-86. JSTOR, DOI: 10.2307/1917393.

Persels, Jeff and Russell Ganim, editors. Fecal Maters in Early Modern Literature and Art: Studies in Scatology. 2004. Routledge, 2016. ProQuest Ebook Central, ebookcentral. proquest.com/lib/wvu/detail.action?docID $=4817190$.

Petter, Henri. The Early American Novel. Ohio State UP, 1971.

Pinckney, Eliza Lucas. The Letterbook of Eliza Lucas Pinckney, 1739-1762. U North Carolina P, 1972.

Popkin, Jeremy D. A Concise History of the Haitian Revolution. Wiley-Blackwell, 2012.

Pratt, Mary Louise. “Arts of the Contact Zone.” Profession, 1991, pp. 33-40. JSTOR, www.jstor.org/stable/25595469.

---. Imperial Eyes: Travel Writing and Transculturation. Routledge, 1992. EBSCOhost, proxy.library.vcu.edu/login?url=http://search.ebscohost.com/login. aspx?direct=true \&AuthType $=$ ip, url,cookie,uid\&db=nlebk\&AN=40460\&site=ehostlive $\&$ scope $=$ site.

Quintana, Ryan A. Making a Slave State: Political Development in Early South Carolina. U of North Carolina P, 2018.

Ramsay, David. The History of South-Carolina, from its First Settlement in 1670, to the Year 1808, vol. 1. Charleston, SC, 1809. America's Historical Imprints, docs-newsbank- 
com.proxy.library.vcu.edu/openurl?ctx_ver=z39.88-2004\&rft_id=info:sid/iw.

newsbank.com:EAIX\&rft_val_format=info:ofi/fmt:kev:mtx:ctx\&rft_dat=1044

04FCB1540D40\&svc_dat=Evans:eaidoc\&req_dat=E25D26F9985744EDB7C4A61154F

7F782.

Randhawa, Beccie Puneet. “The Inhospitable Muse: Locating Creole Identity in James

Grainger's The Sugar-Cane." The Eighteenth Century, vol. 49, no. 1, 2008, pp. 67-86. Project MUSE, doi:10.1353/ecy.0.0001.

Ravenel, Harriot Horry. Women of Colonial and Revolutionary Times: Eliza Pinckney. New

York, 1896. Hathi Trust Digital Library, catalog.hathitrust.org/Record/000363865.

Regis, Pamela. Describing Early America: Bartram, Jefferson, Crèvecoeur, and the Influence of Natural History. 1992. U of Pennsylvania P, 1999.

Reid, John Phillip. A Law of Blood: The Primitive Law of the Cherokee Nation. New York UP, 1970.

Reiss, Oscar. Medicine in Colonial America. University Press of America, 2000.

Reizenstein, Baron Ludwig von. The Mysteries of New Orleans, edited and translated by Steven Rowan. The Johns Hopkins UP, 2002.

Reno, Joshua Ozias. “Toward a New Theory of Waste: From 'Matter Out of Place' to Signs of Life." Theory, Culture \& Society, vol. 31, no. 6, 2014, pp. 3-27. Sage Journals, doiorg.proxy.library.vcu.edu/10.1177/0263276413500999.

Rifkin, Mark. Manifesting America: The Imperial Construction of U.S. National Space. Oxford UP, 2009.

Rinehart, Nicholas T. "The Man that Was a Thing: Reconsidering Human Commodification in Slavery." Journal of Social History, vol. 50, no. 1, 2016, pp. 28-50. Project MUSE, 
muse.jhu.edu/article/631853.

Roberts, Sîn Silyn. Gothic Subjects: The Transformation of Individualism in American Fiction, 1790-1861. U of Pennsylvania P, 2014. ProQuest Ebook Central, ebookcentral.proquest. com/lib/wvu/detail.action?docID $=3442378$.

Rosenberg, Charles E. Explaining Epidemics and Other Studies in the History of Medicine. Cambridge UP, 1992.

Rubin-Dorsky, Jeffrey. "The Early American Novel." The Columbia History of the American Novel, edited by Emory Eliot, et al, Columbia UP, 1991, pp. 6-25.

Rusert, Britt. Fugitive Science: Empiricism and Freedom in Early African American Culture. New York UP, 2017. New York University Scholarship Online, doi:10.18574/nyu/ 9781479885688.003.0001.

--- "Plantation Ecologies: The Experimental Plantation in James Grainger's The Sugar-Cane." Early American Studies, vol. 13, no. 2, 2015, pp. 341-73. Project MUSE, www.libproxy. wvu.edu/login?url=https://search-proquest-com.www.libproxy.wvu.edu/docview/167 5171557 accountid $=2837$.

Rush, Benjamin. Medical Inquiries and Observations. $2^{\text {nd }}$ ed. Philadelphia, 1789. Eighteenth Century Collections Online, find.galegroup.com.www.libproxy.wvu.edu/ecco/infomark. do?\&source= gale\&prodId=ECCO\&userGroupName $=$ morg77564\&tabID $=$ T001\&docId $=$ CW 107067876\&type $=$ multipage $\&$ contentSet $=$ ECCOArticles\&version $=1.0 \&$ docLevel $=F$ ASCIMILE.

---. Observations Upon the Origin of the Malignant Bilious, or Yellow Fever in Philadelphia, and Upon the Means of Preventing It. Philadelphia, 1799. Eighteenth Century Collections Online, find.galegroup.com.www.libproxy.wvu.edu/ecco/infomark.do?\&source=gale\& 
prodId $=$ ECCO\&userGroupName $=$ morg77564\&tabID $=$ T001\&docId $=$ CB130359890\&typ $\mathrm{e}=$ multipage \&contentSet=ECCOArticles\&version=1.0\&docLevel=FASCIMILE.

Russo, James R. "The Chameleon of Convenient Vice: A Study of the Narrative of Arthur Mervyn.” Studies in the Novel, vol. 11, no. 4, 1979, pp. 381-405. JSTOR, www.jstor.org/stable/29531999.

Rutman, Darrett B. and Anita H. Rutman. "Of Agues and Fevers: Malaria in the Early Chesapeake." William and Mary Quarterly, vol. 33, no. 1, 1976, pp. 31-60. JSTOR, www.jstor.org/stable/1921692.

Sahlins, Marshall. How "Natives" Think: About Captain Cook, For Example. U of Chicago P, 1995.

---. Islands of History. U of Chicago P, 1985.

Sansay, Leonora. Laura. 1809. Edited by Michael J. Drexler, Broadview Press, 2008.

---. Secret History; or, The Horrors of St. Domingo. 1808. Edited by Michael J. Drexler, Broadview Press, 2008.

Savitt, Todd L. Medicine and Slavery: The Diseases and Healthcare of Blacks in Antebellum Virginia. U of Illinois P, 1978.

Sayre, Gordon M. “Abridging Between Two Worlds: John Tanner as American Indian Autobiographer." American Literary History, vol. 11, no. 3, 1999, pp. 480-99. JSTOR, www.jstor.org/stable/490129.

---. "If Thomas Jefferson had Visited Niagara Falls: The Sublime Spectacle in America 1775-1825." Interdisciplinary Studies in Literature and the Environment, vol. 8, no. 2, 2001, pp. 141-62. Oxford Academic, doi-org.www.libproxy.wvu.edu/10.1093/ isle/8.2.141. 
Shapin, Steven. "Pump and Circumstance: Robert Boyle's Literary Technology." Social Studies of Science, vol. 14, no. 4, 1985, pp. 481-520. JSTOR, www.jstor.org/stable/284940.

--- and Simon Schaffer. Leviathan and the Air-Pump: Hobbes, Boyle, and the Experimental Life. 1989. Princeton UP, 1989. ACLS Humanities E-Book, hdl.handle. net.www.libproxy.wvu.edu/2027/heb.05328.

Schell, Heather. "The Sexist Gene: Science Fiction and the Germ Theory of History." American Literary History, vol. 14, no. 4, 2002, pp. 805-27. JSTOR, www-jstor-org.proxy.library. vcu.edu/stable/3568025.

Schiebinger, Londa L. Plants and Empire: Colonial Bioprospecting in the Atlantic World. Harvard UP, 2004. http://hdl.handle.net.www.libproxy.wvu.edu/2027/heb.06217.

Schillmeier, Michael. Rethinking Disability: Bodies, Senses, and Things. Routledge, 2010.

Schoenfeldt, Michael C. Bodies and Selves in Early Modern England: Physiology and Inwardness in Spenser, Shakespeare, Herbert, and Milton. Cambridge UP, 1999.

Schweiger, Tristan J. “Grainger's West Indian Planter: Property and Authority in The SugarCane." Eighteenth-Century Studies, vol. 50, no. 4, 2017, pp. 401-16. Project MUSE, doi:10.1353/ecs.2017.0031.

Shah, Sonia. The Fever: How Malaria has Ruled Humankind for 500,000 Years. Sarah Crichton Books, 2010.

Shapiro, Stephen. The Culture and Commerce of the Early American Novel: Reading the Atlantic-World Systems. Penn State UP, 2008.

Sheridan, Richard B. Doctors and Slaves: A Medical and Demographic History of Slavery in the British West Indies, 1680-1834. Cambridge UP, 1984.

---. Oracles of Empire: Poetry, Politics, and Commerce in British America, 1690-1750. U of 
Chicago P, 1990. ACLS Humanities Ebook, https://hdl-handle-net.www.libproxy.wvu. edu/2027/fulcrum.qf85nb50p.

Shryock, Richard Harrison. Medicine in America: Historical Essays. The Johns Hopkins UP, 1966.

Siebers, Tobin. Disability Theory. U of Michigan P, 2008.

Silva, Cristobal. "Georgic Fantasies: James Grainger and the Poetry of Colonial Dislocation." ELH, vol. 83, no. 1, 2016, pp. 127-56. Project MUSE, doi:10.1353/elh.2016.0000.

---. Miraculous Plagues: An Epidemiology of Early New England Narrative. Oxford UP, 2011.

--- "Republic of Medicine: Immunology and National Identity in the Age of Revolution." The Haitian Revolution and the Early United States: Histories, Textualities, and Geographies, edited by Elizabeth Maddock Dillon and Michael Drexler, U of Pennsylvania P, 2016, pp. 130-44. JSTOR, www.jstor.org/stable/j.ctt1bmzkn3.

Simpson, Archibald. The South Carolina Diary of Reverend Archibald Simpson: Part 1, May 1754-April 1770, edited by Peter N. Moore. U of South Carolina P, 2012.

Sleeper-Smith, Susan. Indian Women and French Men: Rethinking Cultural Encounters in the Western Great Lakes. U of Massachusetts P, 2001.

Sloane, Hans. A Voyage to the Islands Madera, Barbados, Nieves, S. Christopher and Jamaica. London, 1707. Archive.org, archive.org/details/mobot31753000820123/page/n5.

Slotkin, Richard. Regeneration through Violence: The Mythology of the American Frontier, 1600-1860. Wesleyan UP, 1973.

---. The Fatal Environment: The Myth of the Frontier in the Age of Industrialization, 1800-1890. Atheneum Press, 1985.

Smith, Adam. The Theory of Moral Sentiments. 1759. London, 1761. Eighteenth Century 
Collections Online, find.galegroup.com.www.libproxy.wvu.edu/ecco/infomark.do? $\&$ source $=$ galeprodId $=$ ECCO\&userGroupName $=$ morg77564\&tabID $=$ T001\&docId $=$ CW 1 $22356493 \&$ type $=$ multipage $\&$ contentSet=ECCOArticles \&version=1.0\&docLevel=FASCI MILE.

Smith, Henry Nash. Virgin Land: The American West as Symbol and Myth. 1950. Harvard UP, 1970. ACLS Humanities E-Book, hdl-handle net.www.libproxy.wvu.edu/2027/ fulcrum.t148fh16n.

Smith-Rosenberg, Carroll. "Black Gothic: The Shadowy Origins of the American Bourgeoisie." Possible Pasts: Becoming Colonial in Early America, edited by Robert Blair St. George, Cornell UP, 2000, pp. 243-69.

Smith, Peter J. Between Two Stools: Scatology and its Representations in English Literature, Chaucer to Swift. Manchester UP, 2012. JSTOR, www.jstor.org/stable/j.ctt18mvm78.

Snyder, Gary. The Practice of the Wild. Shoemaker and Hoard, 1990. Proquest Ebook Central, ebookcentral.proquest.com/lib/wvu/detail.action?docID=478862.

Sontag, Susan. AIDS and its Metaphors. 1989. Picador, 2002.

---. Illness as Metaphor. 1978. Picador, 2002.

Sprat, Thomas. The History of the Royal-Society of London, for the Improving of Natural Knowledge. 2nd ed., London, 1702. Eighteenth Century Collections Online, find.galegroup.com.www.libproxy.wvu.edu/ecco/infomark.do?\&source=gale\&prodId=E CCO\&userGroupName $=$ morg $77564 \&$ tabId $=$ T001\&docId $=$ CW108403230\&type=multipa ge\&contentSet=ECCOArticles\&version=1.0\&docLevel=FACSIMILE.

Stamm, Lola V. "Global Challenge of Antibiotic-Resistant Treponema pallidum." Antimicrobial Agents and Chemotherapy, vol. 54, no. 2, 2010, 583-89. PubMedCentral, 
doi: 10.1128/AAC.01095-09.

Stange, Marion. Vital Negotiations: Protecting Settlers' Health in Colonial Louisiana and South Carolina, 1720-1763. V\&R Unipress, 2012.

"Statutes of the Royal Society Enacted in 1663." A History of the Royal Society with Memoirs of the Presidents, Compiled from Authentic Documents. Charles Richard Weld. London, 1848, pp. 524-40. Archive.org, https://archive.org/details/ahistoryroyalso00weldgoog/ page/n11.

Stern, Julia A. The Plight of Feeling: Sympathy and Dissent in the Early American Novel. U of Chicago P, 1996. ProQuest Ebook Central, ebookcentral.proquest.com/lib/wvu/ detail.action?docID=408567.

Stevens, Laura M. The Poor Indians: British Missionaries, Native Americans, and Colonial Sensibility. U of Pennsylvania P, 2004. ProQuest Ebook Central, ebookcentral. proquest.com/lib/wvu/detail.action?docID=3441516.

Stone, Andrea. Black Well-Being: Health and Selfhood in Antebellum Black Literature. UP of Florida, 2016. ProQuest Ebook Central, ebookcentral.proquest.com/lib/wvu/detail. action? $\operatorname{doc} I D=4458127$.

"sudorific, adj. and n." Oxford English Dictionary Online, www.oed.com/view/Entry/193489.

Sweet, Timothy. American Georgics: Economy and Environment in Early American Literature, 1580-1864. U of Pennsylvania P, 2002. ProQuest Ebook Central, ebookcentral.proquest. com/lib/wvu/detail.action?docID=3442154.

Sydenham, Thomas. The Entire Works of Dr Thomas Sydenham, edited by John Swan. London, 1742. Eighteenth Century Collections Online, find.galegroup.com.www.libproxy.wvu. edu/ecco/infomark.do?\&source=gale\&prodId=ECCO\&userGroupName=morg77564 
$\&$ tabID=T001\&docId=CW108327691\&type=multipage \&contentSet=ECCOArticles\&ver sion=1.0\&docLevel=FACSIMILE.

Tampa, M. "Brief History of Syphilis." Journal of Medicine and Life, vol. 7, no. 1, 2014, pp. 410. PubMed Central, www-ncbi-nlm-nih-gov.proxy.library.vcu.edu/pmc/articles/ PMC3956094.

Tanner, John. A Narrative of the Captivity and Adventures of John Tanner (U.S. Interpreter at the Saut de Ste. Marie,) During Thirty Years Residence Among the Indians in the Interior of North America, edited by Edwin James. New York, 1830. Archive.org, https://archive.org/details/cihm_42507/page/n5.

The Statues at Large of South Carolina, edited by Thomas Cooper. 5 vols., Columbia, S.C., 1838. Archive.org, archive.org/details/statutesatlargeo03edit.

Thèves, C., P. Biagini, and E. Crubézy. “The Rediscovery of Smallpox.” Clinical Microbiology and Infection, vol. 20, no. 3, 2014. Wiley Online Library, doi: 10.1111/1469-0691.12536.

Thomas, Steven W. “Doctoring Ideology: James Grainger's The Sugar Cane and the Bodies of Empire.” Early American Studies, vol. 4, no. 1, 2006, pp. 78-111. Project MUSE, doi:10.1353/eam.2006.0008.

Thornton, John. Africa and Africans in the Making of the Atlantic World, 1400-1800. Cambridge UP, 1992.

Tindol, Robert. "Getting the Pox Off All Their Houses: Cotton Mather and the Rhetoric of Puritan Science.” Early American Literature, vol. 46, no. 1, 2011, pp. 1-23. Project MUSE, doi:10.1353/eal.2011.0002.

Tobin, Beth Fowkes. Colonizing Nature: The Tropics in British Arts and Letters, 1760-1820. U of Pennsylvania P, 2004. ProQuest Ebook Central, ebookcentral.proquest.com/lib/wvu/ 
detail.action?docID $=3441453$.

---. "Tropical Bounty, Local Knowledge, and the Imperial Georgic."

Monstrous Dreams of Reason: Body, Self, and Other in the Enlightenment, edited by

Laura J. Rosenthal and Mita Choudhury, Bucknell UP, 2002, pp. 211-30.

Tompkins, Jane. Sensational Designs: The Cultural Work of American Fiction, 1790-1860. Oxford UP, 1985.

Tortora, Daniel J. Carolina in Crisis: Cherokees, Colonists, and Slaves in the American Southeast, 1756-1763. U of North Carolina P, 2015. ProQuest Ebook Central, ebookcentral.proquest.com/lib/wvu/detail.action?docID=3039552.

Trist, Elizabeth House. The Travel Diary of Elizabeth House Trist: Philadelphia to Natchez, 1783-84, edited by Annette Kolodny. Journeys in New Worlds, edited by William L. Andrews, et. al. The U of Wisconsin P, 1990, pp. 201-32.

Turner, Frederick Jackson. Rereading Frederick Jackson Turner: "The Significance of the Frontier in American History" and Other Essays, edited by John Mack Faragher. Yale UP, 1994. JSTOR, www.jstor.org/stable/j.ctt32bv5g.

Tuthill, Maureen. Health and Sickness in the Early American Novel: Social Affection and Eighteenth-Century Medicine. Palgrave Macmillan, 2016.

Valenčius, Conevery Bolton. The Health of the Country: How American Settlers Understood Themselves and their Land. Basic Books, 2002. ACLS Humanities E-Book, https://hdlhandle-net.www.libproxy.wvu.edu/2027/fulcrum.12579s52q.

Van Sant, Ann Jessie. Eighteenth-Century Sensibility and the Novel: The Senses in Social Context. Cambridge UP, 1993.

Wain, John, et al. “Typhoid Fever.” The Lancet, vol. 385, no. 9973, 2015, pp. 1136-45. 
ScienceDirect, doi.org/10.1016/S0140-6736(13)62708-7.

Wald, Priscilla. Contagious: Cultures, Carriers, and the Outbreak Narrative. Duke UP, 2008.

Waterman, Bryan. “Arthur Mervyn's Medical Repository and the Early Republic's Knowledge Industries." American Literary History, vol. 15, no. 2, 2003, pp. 213-47. Project MUSE, muse.jhu.edu/article/42121.

---. Republic of Intellect: The Friendly Club of New York City and the Making of American Literature. The Johns Hopkins UP, 2007.

Watt, Ian. The Rise of the Novel: Studies in Defoe, Richardson and Fielding. 1957. U of California P, 2001.

Watt, James. "Medical Aspects and Consequences of Cook's Voyages." Captain James Cook and His Times, edited by Robin Fisher and Hugh Johnston, Australian National UP, 1979, pp. 129-57.

Watts, Edward. An American Colony: Regionalism and the Roots of Midwestern Culture. Ohio UP, 2002.

Wendell, Susan. "Unhealthy Disabled: Treating Chronic Illnesses as Disabilities." Hypatia, vol. 16, no. 4, 2001, pp. 17-33. JSTOR, www-jstor-org.proxy.library.vcu.edu/stable/3810781. Wertheim, Joel O. "Viral Evolution: Mummy Virus Challenges History of Smallpox." Current Biology, vol. 27, no. 3, 2017, pp. R119-R120. Science Direct, Doi.org/10.1016/j.cub.2016.12.008.

White, Ashli. Encountering Revolution: Haiti and the Making of the Early Republic. The Johns Hopkins UP, 2010.

White, Ed. "Invisible Tagkanysough.” PMLA, vol. 120, no. 3, 2005, pp. 751-67. MLA Journals, doi-org.www.libproxy.wvu.edu/10.1632/003081205X63840. 
Wilkins, John. “An Essay Towards a Real Character, and a Philosophical Language.” London, 1668. Early English Books Online, name. umdl.umich.edu/A66045.0001.001.

Wilson, Catherine. Invisible World: Early Modern Philosophy and the Invention of the Microscope. Princeton UP, 1997.

Winthrop, John. “A Modell of Christian Charitie.” 1630. Hanover Historical Texts Collection, history.hanover.edu/texts/winthmod.html.

Wisecup, Kelly. Medical Encounters: Knowledge and Identity in Early American Literature. U of Massachusetts P, 2013.

Woertendyke, Gretchen. "Haiti and the New-World Novel." The Haitian Revolution and the Early United States: Histories, Textualities, and Geographies, edited by Elizabeth Maddock Dillon and Michael Drexler, U of Pennsylvania P, 2016, pp. 130-44. JSTOR, www.jstor.org/stable/j.cttlbmzkn3.

---. "Romance to Novel: A Secret History.” Narrative, vol. 17, no. 3, 2009, pp. 255-73. Project MUSE, doi:10.1353/nar.0.0028.

Wood, Peter H. Black Majority: Negroes in Colonial South Carolina from 1670 through the Stono Rebellion. Alfred A. Knopf, 1975. ACLS Humanities E-Book, http://hdl.handle. net.www.libproxy.wvu.edu/2027/heb.00338.

Wright, William. Advertisement. An Essay on the More Common West-India Diseases. 1802. On the Treatment and Management of the More Common West-India Diseases, 1750-1802, edited by J. Edward Hutson. 2005. U of the West Indies P, 2010.

Wrobel, David M. Global West, American Frontier: Travel, Empire, and Exceptionalism from Manifest Destiny to the Great Depression. U of New Mexico P, 2013. ProQuest Ebook Central, ebookcentral.proquest.com/lib/wvu/detail.action?docID=1376974. 
Yates, Julian. "Represent." Veer Ecology: A Companion for Ecological Thinking, edited by Jeffrey Jerome Cohen and Lowell Duckert, U of Minnesota P, 2017, pp. 122-35.

Ziff, Larzer. Writing in the New Nation: Prose, Print, and Politics in the Early United States. Yale UP, 1991. JSTOR, www.jstor.org/stable/j.ctt1xp3v48.

Zagarell, Sandra A. Introduction. A New Home, Who'll Follow? Or Glimpses of Western Life. Rutgers UP, 1990, pp. xi-xlvi.

Ziser, Michael. Environmental Practice and Early American Literature. Cambridge UP, 2013. 